\title{
Caracterização dos sistemas de criação de bovinos com atividade reprodutiva e estimativa da prevalência da Brucelose bovina na Região Centro-Sul do Brasil
}

Dissertação apresentada ao Programa de PósGraduação em Epidemiologia Experimental Aplicada às Zoonoses da Faculdade de Medicina Veterinária e Zootecnia da Universidade de São Paulo para obtenção do título de Mestre em Ciências

Departamento:

Medicina Veterinária Preventiva e Saúde Animal

Área de Concentração:

Epidemiologia Experimental Aplicada às Zoonoses

Orientador:

Prof. Dr. Ricardo Augusto Dias

São Paulo

2010 
Autorizo a reprodução parcial ou total desta obra, para fins acadêmicos, desde que citada a fonte.

DADOS INTERNACIONAIS DE CATALOGAÇÃO-NA-PUBLICAÇÃO

(Biblioteca Virginie Buff D’Ápice da Faculdade de Medicina Veterinária e Zootecnia da Universidade de São Paulo)

Braga, Guilherme Basseto

Caracterização dos sistemas de criação de bovinos com atividade reprodutiva e estimativa da prevalência de Brucelose bovina na Região Centro-Sul do Brasil / Guilherme Basseto Braga. -- 2010.

206 p. : il.

Dissertação (Mestrado) - Universidade de São Paulo. Faculdade de Medicina Veterinária e Zootecnia. Departamento de Medicina Veterinária Preventiva e Saúde Animal, São Paulo, 2010.

Programa de Pós-Graduação: Epidemiologia Experimental e Aplicada às Zoonoses.

Área de concentração: Epidemiologia Experimental e Aplicada às Zoonoses.

Orientador: Prof. Dr. Ricardo Augusto Dias.

1. Caracterização. 2. Bovinos. 3. Pecuária 4. Prevalência. 5. Brucelose. I. Título. 


\section{CERTIFICADO}

Certificamos que o Projeto intitulado "Caracterização dos sistemas de criação de bovinos com atividade reprodutiva e estimativa da prevalência da brucelose bovina na região centro-sul do Brasil", não utilizando animais, protocolado sob o n⿳1631/2009, sob a responsabilidade do Prof. Dr. Ricardo Augusto Dias, está de acordo com os princípios éticos de experimentação animal da Comissão de Bioética da Faculdade de Medicina Veterinária e Zootecnia da Universidade de São Paulo e foi aprovado em reunião de 22/04/09.

We certify that the Research "Characterization of cattle herds with productive activity and estimation of the prevalence of bovine brucellosis in south-central region of Brazil", protocol number 1631/2009, under the responsibility Prof. Dr. Ricardo Augusto Dias, agree with Ethical Principles in Animal Research adopted by Bioethic Commission of the School of Veterinary Medicine and Animal Science of University of São Paulo and was approved in the meeting of day 04/22/09.

São Paulo, 23 de abril de 2009

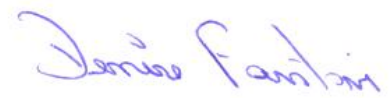

Profa Dra Denise Tabacchi Fantoni

Vice-Presidente da Comissão de Bioética

FMVZ/USP 
Nome: BRAGA, Guilherme Basseto

Título: Caracterização dos sistemas de criação de bovinos com atividade reprodutiva e estimativa da prevalência da Brucelose bovina na Região Centro-Sul do Brasil.

Dissertação apresentada ao Programa de PósGraduação em Epidemiologia Experimental Aplicada às Zoonoses da Faculdade de Medicina Veterinária e Zootecnia da Universidade de São Paulo para obtenção do título de Mestre em Ciências

Data: I I

\section{Banca Examinadora}

Prof. Dr. Instituição:

Assinatura: Julgamento:

Prof. Dr. Instituição:

Assinatura: Julgamento:

Prof. Dr. Instituição:

Assinatura: Julgamento: 
À minha família, por todo o amor e esforço realizado para nos proporcionar a melhor educação possível. Sem eles este trabalho não seria possível. 


\section{AGRADECIMENTOS}

Ao Prof. Dr. Ricardo Augusto Dias, meu orientador e amigo, pelo apoio e pelas ajudas prestadas desde o primeiro dia em que bati na sua porta.

Aos docentes do LEB, Prof. Dr. Fernando Ferreira, Prof. Dr. José Soares Ferreira Neto e Prof. Dr. Marcos Amaku, pela amizade e disponibilidade em ajudar sempre.

A todos os companheiros do LEB, Zé Grisi, Rísia, João, Raul, Ana Julia, Carol, Fernanda, Maria Fernanda, Marcello, Mônica, Rita, Bibs, Bianca, Mauro, Aline, Vanessinha, Jucélia por todos os momentos e risadas que demos juntos.

Aos amigos, funcionários e docentes do VPS, pele apoio oferecido, sempre que necessário.

Ao MAPA, pela parceria que proporcionou a realização deste trabalho.

À CAPES pelo apoio financeiro imprescindível.

A Júlia, pela companhia maravilhosa e por todo o apoio que me é oferecido todos os dias. 
"... and in the end, the love you take is equal to the love you made."

The end - Lennon/McCartney 
BRAGA, G.B. Caracterização dos sistemas de criação de bovinos com atividade reprodutiva e estimativa da prevalência da Brucelose bovina na Região CentroSul do Brasil. [Characterization of cattle herds with reproductive activity and estimation of the prevalence of bovine brucellosis in Central-Southern region of Brazil]. 2010. 206 p. Dissertação (Mestrado em Ciências) - Faculdade de Medicina Veterinária e Zootecnia, Universidade de São Paulo. São Paulo, 2010.

A pecuária é um setor do agronegócio que vêm se destacando na economia nacional. Com a intenção de amparar esta importante cadeia produtiva, a atuação dos serviços de fomento e defesa sanitária animal tornam-se cada vez mais necessárias. A compreensão integral do espaço sobre o qual estes serviços exercem sua influência, tornaria mais efetiva as estratégias de atuação frente aos problemas enfrentados. Em 2001, o Ministério da Agricultura Pecuária e Abastecimento realizou um estudo soroepidemiológico visando conhecer a situação epidemiológica da brucelose bovina em 14 Unidades Federativas. O trabalho incluiu um questionário epidemiológico aplicado na intenção de avaliar os possíveis fatores de risco para a doença nos rebanhos. O mesmo possibilitou a realização de uma análise descritiva da pecuária em diversas regiões. Os resultados demonstraram que a cadeia produtiva no país é altamente heterogênea, revelando diferenças significativas mesmo dentro dos Estados. De maneira geral, as frequências encontradas a respeito de investimento em tecnologia, intensificação dos manejos, utilização da inseminação artificial, utilização de raças especializadas, e participação de assistência veterinária, demonstrou-se crescente à medida que se avança em direção às Unidades Federativas da região Sul. A comercialização de reprodutores demonstrou-se intensa e realizada diretamente entre as propriedades. O comércio informal do leite e da carne bovina ainda corresponde por uma parcela significativa do mercado. Tendo em vista a escassez de projetos com este foco, reflete-se a respeito da necessidade de outros projetos deste tipo, considerando que os cenários em que as criações estão inseridas, deveriam ser tomados como ponto de partida na elaboração de estratégias de atuação frente aos problemas encontrados no setor.

Palavras-chave: Caracterização. Bovinos. Pecuária. Prevalência. Brucelose. 
BRAGA, G.B. Characterization of cattle herds with reproductive activity and estimation of the prevalence of bovine brucellosis in Central-Southern region of Brazil. [Caracterização dos sistemas de criação de bovinos com atividade reprodutiva e estimativa da prevalência da Brucelose bovina na Região Centro-Sul do Brasil.]. 2010. 206 p. Dissertação (Mestrado em Ciências) - Faculdade de Medicina Veterinária e Zootecnia, Universidade de São Paulo. São Paulo, 2010.

Livestock is an agribusiness sector highlighted in the current national economy. With the intention of supporting this important activity, the performance of animal health promotion and defense services become increasingly necessary. With a full understanding of the environment on which these services exert its influence, strategies actions to minimize the problems faced become more effective. In 2001, the Ministry of Livestock Agriculture conducted a seroepidemiological study aiming to explore the epidemiological situation of bovine brucellosis in 14 Federal Units. The study included an epidemiological questionnaire which objective was to assess the possible risk factors for disease in livestock. It also allowed the development of a descriptive analysis of livestock breeding and raising in various regions. The results showed that the productive chain in Brazil is highly heterogeneous, revealing significant differences even within the same state. In general, frequencies of investment in technology, management practices, use of artificial insemination, use of specialized breeds, and veterinary care, increases as one moves toward the Federal Units located in the South of Brazil. The sale of breeding proved to be intense and conducted directly between the properties. The informal trade of milk and beef still accounts for a significant portion of the market. Given the lack of projects with this focus, the need for other projects of this type appears to be relevant when one considers that the scenarios in which the creations are found should be the starting point to develop strategies to act face the problems found in the industry.

Keywords: Characterization. Cattle. Livestock. Prevalence. Brucellosis. 


\section{LISTA DE MAPAS}

Mapa 1- Estados integrantes dos estudos de situação da brucelose bovina no Brasil

Mapa 2-Divisão das Unidades Federativas em circuitos pecuários. 36

Mapa 3- Distribuição dos tipos de exploração de bovinos predominantes nos circuitos pecuários- Brasil - out 2001-dez 2004... 50

Mapa 4- Distribuição das frequências estimadas de exploração de corte nos Estados- Brasil - out 2001-dez 2004 51

Mapa 5- Distribuição das frequências estimadas de exploração de corte nos circuitos- Brasil - out 2001-dez 2004

Mapa 6 - Distribuição das frequências estimadas de exploração de leite nos Estados- Brasil - out 2001-dez 2004

Mapa 7- Distribuição das frequências estimadas de exploração de leite nos circuitos- Brasil - out 2001-dez 2004

Mapa 8- Distribuição das frequências estimadas de exploração mista (corte e leite) nos Estados- Brasil - out 2001-dez 2004....

Mapa 9- Distribuição das frequências estimadas de exploração mista (corte e leite) nos circuitos- Brasil - out 2001-dez 2004

Mapa 10- Distribuição das medianas de tamanho dos rebanhos nos circuitos produtores- Brasil - out 2001-dez 2004

Mapa 11- Distribuição das medianas de tamanho dos rebanhos de corte nos circuitos- Brasil - out 2001-dez 2004

Mapa 12- Distribuição das medianas de tamanho dos rebanhos leiteiros nos circuitos- Brasil - out 2001-dez 2004

Mapa 13- Distribuição das medianas de tamanho dos rebanhos mistos nos circuitosBrasil - out 2001-dez 2004 66

Mapa 14- Distribuição dos sistemas de criação predominantes nos circuitos pecuários- Brasil - out 2001-dez 2004.

Mapa 15- Distribuição das frequências estimadas de sistemas extensivos de criação nos Estados- Brasil - out 2001-dez 2004......

Mapa 16- Distribuição das frequências estimadas de sistemas extensivos de criação nos circuitos pecuários- Brasil - out 2001-dez 2004 
Mapa 17- Distribuição das frequências estimadas de sistemas de criação em semiconfinamentos nos Estados- Brasil - out 2001-dez 2004.

Mapa 18- Distribuição das frequências estimadas de sistemas de criação em semiconfinamentos nos circuitos pecuários- Brasil - out 2001-dez 2004.

Mapa 19- Distribuição das frequências estimadas de sistemas de criação em confinamentos nos Estados- Brasil - out 2001-dez 2004

Mapa 20- Distribuição das frequências estimadas de sistemas de criação em confinamentos nos circuitos pecuários- Brasil - out 2001-dez 2004

Mapa 21- Distribuição das frequências estaduais estimadas de propriedades que utilizam predominantemente o gado zebuíno- Brasil - out 2001-dez 2004 ..81

Mapa 22- Distribuição das frequências estimadas por circuito de propriedades que utilizam predominantemente raças zebuínas- Brasil - out 2001-dez 2004...82

Mapa 23- Distribuição das frequências estaduais estimadas de propriedades que utilizam predominantemente raças européias especializadas em leite- Brasil

- out 2001-dez 2004

Mapa 24- Distribuição das frequências estimadas por circuito de propriedades que utilizam predominantemente raças européias especializadas em leite- Brasil

- out 2001-dez 2004

Mapa 25- Distribuição das frequências estaduais estimadas de propriedades que utilizam predominantemente o gado europeu de corte- Brasil - out 2001-dez 2004

Mapa 26- Distribuição das frequências estimadas por circuito de propriedades que utilizam predominantemente o gado europeu de corte- Brasil - out 2001-dez 2004.

Mapa 27- Distribuição das frequências estaduais estimadas de propriedades que utilizam predominantemente o gado mestiço- Brasil - out 2001-dez 2004...86

Mapa 28- Distribuição das frequências estimadas por circuito de propriedades que utilizam predominantemente o gado mestiço- Brasil - out 2001-dez 2004...86

Mapa 29- Distribuição das frequências estaduais estimadas de propriedades que utilizam predominantemente outras raças- Brasil - out 2001-dez 2004 .......87

Mapa 30- Distribuição das frequências estaduais estimadas de propriedades que utilizam predominantemente outras raças- Brasil - out 2001-dez 2004

Mapa 31- Distribuição das frequências estimadas por circuito de propriedades que realizam o manejo da ordenha apenas uma vez por dia- Brasil - out 2001dez 2004 
Mapa 32- Distribuição das frequências estimadas por circuito de propriedades que realizam o manejo da ordenha duas ou mais vezes por dia- Brasil - out 2001-dez 2004

Mapa 33- Distribuição das frequências estimadas por circuito de propriedades que realizam a ordenha manual- Brasil - out 2001-dez 2004

Mapa 34- Distribuição das frequências estimadas por circuito de propriedades que realizam a ordenha mecânica com balde ao pé- Brasil - out 2001-dez 2004

Mapa 35- Distribuição das frequências estimadas por circuito de propriedades que realizam a ordenha mecânica em sala de ordenha- Brasil - out 2001-dez 2004 95

Mapa 36- Distribuição das frequências estimadas de propriedades que realizam o resfriamento do leite após a ordenha nos Estados- Brasil - out 2001-dez 2004 97

Mapa 37- Distribuição das frequências estimadas de propriedades que realizam o resfriamento do leite após a ordenha nos Estados- Brasil - out 2001-dez 2004 98

Mapa 38- Distribuição das frequências estimadas de propriedades que possuem assistência técnica veterinária nos Estados- Brasil - out 2001-dez 2004.. 109

Mapa 39- Distribuição das frequências estimadas de propriedades que possuem assistência técnica veterinária nos circuitos pecuários- Brasil - out 2001-dez 2004 109

Mapa 40- Distribuição estadual das frequências estimadas de propriedades onde a assistência técnica é realizada por Veterinários particulares- Brasil - out 2001-dez 2004 110

Mapa 41- Distribuição por circuito pecuário das frequências estimadas de propriedades onde a assistência técnica é realizada por veterinários particulares- Brasil - out 2001-dez 2004. 111

Mapa 42- Distribuição estadual das frequências estimadas de propriedades onde a assistência técnica é realizada por Veterinários de cooperativa- Brasil - out 2001-dez 2004

Mapa 43- Distribuição por circuito pecuário das frequências estimadas de propriedades onde a assistência técnica é realizada por Veterinários de cooperativa- Brasil - out 2001-dez 2004.

Mapa 44- Distribuição estadual das frequências estimadas de propriedades que compram reprodutores diretamente de outras propriedades- Brasil - out 2001-dez 2004 116 
Mapa 45- Distribuição por circuito pecuário das frequências estimadas de propriedades que compram reprodutores diretamente de outras propriedades- Brasil - out 2001-dez 2004.

Mapa 46- Distribuição estadual das frequências estimadas de propriedades que compram reprodutores diretamente de comerciantes- Brasil - out 2001-dez 2004

Mapa 47- Distribuição das frequências estimadas de propriedades que compram reprodutores diretamente de comerciantes nos circuitos pecuários- Brasil out 2001-dez 2004

Mapa 48- Distribuição estadual das frequências estimadas de propriedades que compram reprodutores em leilões- Brasil - out 2001-dez 2004..................118

Mapa 49- Distribuição das frequências estimadas de propriedades que compram reprodutores em leilões- Brasil - out 2001-dez 2004 ...............................118

Mapa 50- Distribuição estadual das frequências estimadas de propriedades que compram reprodutores em exposições- Brasil - out 2001-dez 2004.

Mapa 51- Distribuição das frequências estimadas de propriedades que compram reprodutores em exposições nos circuitos pecuários- Brasil - out 2001-dez 2004.

Mapa 52- Distribuição estadual das frequências estimadas de propriedades que vendem reprodutores diretamente para outros rebanhos- Brasil - out 2001dez 2004

Mapa 53- Distribuição por circuito das frequências estimadas de propriedades que vendem reprodutores diretamente para outros rebanhos- Brasil - out 2001dez 2004

Mapa 54- Distribuição estadual das frequências estimadas de propriedades que vendem reprodutores diretamente para comerciantes- Brasil - out 2001-dez 2004 123

Mapa 55- Distribuição por circuito das frequências estimadas de propriedades que vendem reprodutores diretamente para comerciantes- Brasil - out 2001-dez 2004 .

Mapa 56- Distribuição estadual das frequências estimadas de propriedades que vendem reprodutores em leilões- Brasil - out 2001-dez 2004....................124

Mapa 57- Distribuição por circuito das frequências estimadas de propriedades que vendem reprodutores em leilões- Brasil - out 2001-dez 2004...................124

Mapa 58- Distribuição estadual das frequências estimadas de propriedades que vendem reprodutores em exposições- Brasil - out 2001-dez 2004. 
Mapa 59- Distribuição por circuito das frequências estimadas de propriedades que vendem reprodutores em exposições- Brasil - out 2001-dez 2004 125

Mapa 60- Distribuição estadual das frequências estimadas de propriedades que alugam pastos em alguma época do ano- Brasil - out 2001-dez 2004...... 128

Mapa 61- Distribuição por circuito das frequências estimadas de propriedades que alugam pastos em alguma época do ano- Brasil - out 2001-dez 2004...... 128

Mapa 62- Distribuição estadual das frequências estimadas de criações que possuem pastos em comum com outras propriedades- Brasil - out 2001-dez 2004 130

Mapa 63- Distribuição por circuito das frequências estimadas de criações que possuem pastos em comum com outras propriedades- Brasil - out 2001-dez 2004 130

Mapa 64- Distribuição estadual das frequências estimadas de propriedades que possuem áreas alagadiças às quais o gado tem acesso- Brasil - out 2001dez 2004 . 131

Mapa 65- Distribuição por circuito das frequências estimadas de propriedades que possuem áreas alagadiças às quais o gado tem acesso- Brasil - out 2001dez 2004. 132

Mapa 66- Distribuição estadual das frequências estimadas de propriedades que possuem piquete separado para fêmeas na fase de parto e/ou pós-partoBrasil - out 2001-dez 2004 134

Mapa 67- Distribuição por circuito das frequências estimadas de propriedades que possuem piquete separado para fêmeas na fase de parto e/ou pós-partoBrasil - out 2001-dez 2004 134

Mapa 68- Distribuição estadual das frequências estimadas de propriedades onde foram avistados casos de aborto nos doze meses que antecederam a entrevista- Brasil - out 2001-dez 2004 136

Mapa 69- Distribuição estadual das frequências estimadas de propriedades onde foram avistados casos de aborto nos doze meses que antecederam a entrevista- Brasil - out 2001-dez 2004 136

Mapa 70- Distribuição estadual das frequências estimadas de propriedades onde nada é feito com o material abortado- Brasil - out 2001-dez 2004. 138

Mapa 71- Distribuição por circuito das frequências estimadas de propriedades onde nada é feito com o material abortado- Brasil - out 2001-dez 2004 139

Mapa 72- Distribuição estadual das frequências estimadas de propriedades onde se permite que outras espécies de animais se alimentem do material abortadoBrasil - out 2001-dez 2004 
Mapa 73- Distribuição por circuito das frequências estimadas de propriedades onde se permite que outras espécies de animais se alimentem do material abortado- Brasil - out 2001-dez 2004...

Mapa 74- Distribuição estadual das frequências estimadas de propriedades onde o material abortado recebe um destino adequado (enterra, joga fora, queima)Brasil - out 2001-dez 2004.

Mapa 75- Distribuição por circuito das frequências estimadas de propriedades onde o material abortado recebe um destino adequado (enterra, joga fora, queima)- Brasil - out 2001-dez 2004 141

Mapa 76- Distribuição estadual das frequências estimadas de propriedades que não utilizam a inseminação artificial- Brasil - out 2001-dez 2004 143

Mapa 77- Distribuição estadual das frequências estimadas de propriedades que não utilizam a inseminação artificial- Brasil - out 2001-dez 2004 143

Mapa 78- Distribuição estadual das frequências estimadas de propriedades onde a inseminação artificial é utilizada juntamente com a monta natural- Brasil out 2001-dez 2004

Mapa 79- Distribuição por circuito das frequências estimadas de propriedades onde a inseminação artificial é utilizada juntamente com a monta natural- Brasil out 2001-dez 2004 .

Mapa 80- Distribuição estadual das frequências estimadas de propriedades onde se utiliza somente a inseminação artificial- Brasil - out 2001-dez 2004.

Mapa 81- Distribuição por circuito das frequências estimadas de propriedades onde se utiliza somente a inseminação artificial- Brasil - out 2001-dez 2004 .....146

Mapa 82- Distribuição estadual das frequências estimadas de propriedades onde o consumo de leite cru foi constatado- Brasil - out 2001-dez 2004...

Mapa 83- Distribuição estadual das frequências estimadas de propriedades onde o consumo de leite cru foi constatado- Brasil - out 2001-dez 2004.

Mapa 84- Distribuição estadual das frequências estimadas de propriedades que abatem os reprodutores no fim da vida reprodutiva em estabelecimentos inspecionados- Brasil - out 2001-dez 2004 152

Mapa 85- Distribuição por circuito das frequências estimadas de propriedades que abatem os reprodutores no fim da vida reprodutiva em estabelecimentos inspecionados- Brasil - out 2001-dez 2004. 153

Mapa 86- Distribuição estadual das frequências estimadas de propriedades que abatem os reprodutores no fim da vida reprodutiva em estabelecimentos sem inspeção- Brasil - out 2001-dez 2004. 
Mapa 87- Distribuição por circuito das frequências estimadas de propriedades que abatem os reprodutores no fim da vida reprodutiva em estabelecimentos sem inspeção- Brasil - out 2001-dez 2004

Mapa 88- Distribuição estadual das frequências estimadas de propriedades que abatem os reprodutores no fim da vida reprodutiva na própria fazendaBrasil - out 2001-dez 2004

Mapa 89- Distribuição estadual das frequências estimadas de propriedades que abatem os reprodutores no fim da vida reprodutiva na própria fazendaBrasil - out 2001-dez 2004 156

Mapa 90- Distribuição estadual das frequências estimadas de propriedades que produzem queijo e/ou manteiga na propriedade- Brasil - out 2001-dez 2004

Mapa 91- Distribuição por circuito das frequências estimadas de propriedades que produzem queijo e/ou manteiga na propriedade- Brasil - out 2001-dez 2004

Mapa 92- Distribuição estadual das frequências estimadas de propriedades que comercializa o queijo e/ou manteiga produzido- Brasil - out 2001-dez 2004

Mapa 93- Distribuição estadual das frequências estimadas de propriedades que comercializa o queijo e/ou manteiga produzido- Brasil - out 2001-dez 2004

Mapa 94- Distribuição estadual das frequências estimadas de propriedades foco de brucelose bovina- Brasil - out 2001-dez 2004 163

Mapa 95- Distribuição estadual das frequências estimadas de propriedades foco de brucelose bovina- Brasil - out 2001-dez 2004

Mapa 96- Distribuição das medianas do número de fêmeas maiores do que 24 meses nos circuitos produtores- Brasil - out 2001-dez 2004. 


\section{LISTA DE GRÁFICOS}

Gráfico 1- Distribuição decrescente das frequências pontuais de explorações de corte e dos seus respectivos intervalos de confiança de $95 \%$, segundo o circuito produtor- Brasil - out 2001-dez 2004

Gráfico 2- Distribuição decrescente das frequências pontuais de explorações de leite e dos seus respectivos intervalos de confiança de $95 \%$, segundo o circuito produtor- Brasil - out 2001-dez 2004 55

Gráfico 3- Distribuição decrescente das frequências pontuais de explorações mistas e dos seus respectivos intervalos de confiança de $95 \%$, segundo o circuito

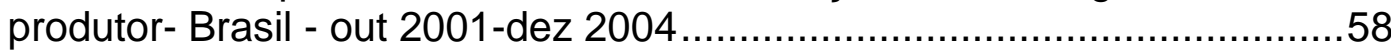

Gráfico 4- Diagrama de caixas do tamanho dos rebanhos segundo Unidade Federativa- Brasil - out 2001-dez 2004

Gráfico 5- Diagrama de caixas do tamanho dos rebanhos de exploração de corte segundo a Unidade Federativa- Brasil - out 2001-dez 2004

Gráfico 6- Diagrama de caixas do tamanho dos rebanhos de exploração de leite segundo a Unidade Federativa- Brasil - out 2001-dez 2004

Gráfico 7 - Diagrama de caixas do tamanho dos rebanhos de exploração mista segundo a Unidade Federativa- Brasil - out 2001-dez 2004

Gráfico 8- Distribuição decrescente das frequências pontuais e intervalos de confiança de $95 \%$ de propriedades que utilizam sistemas extensivos na criação de bovinos nos circuitos produtores- Brasil - out 2001-dez 2004

Gráfico 9- Distribuição decrescente das frequências pontuais e intervalos de confiança de $95 \%$ de propriedades que utilizam o sistema semi-intensivo de criação de bovinos nos circuitos- Brasil - out 2001-dez 2004.

Gráfico 10- Distribuição decrescente das frequências pontuais e intervalos de confiança de $95 \%$ de propriedades que utilizam confinamentos na criação de bovinos nos circuitos- Brasil - out 2001-dez 2004

Gráfico 11- Diagrama de caixas do número de vacas em lactação nas explorações de leite por Unidade Federativa- Brasil - out 2001-dez 2004.

Gráfico 12- Diagrama de caixas da produção diária média de leite (litros) nos estabelecimentos de exploração leiteira por Unidade Federativa- Brasil out 2001-dez 2004.

Gráfico 13- Diagrama de caixas da produção diária média de leite (litros) por vaca em lactação nas explorações leiteiras por Unidade Federativa- Brasil out 2001-dez 2004. 
Gráfico 14- Diagrama de caixas do número de vacas em lactação nas explorações mistas por Unidade Federativa- Brasil - out 2001-dez 2004

Gráfico 15- Diagrama de caixas da produção diária média de leite (litros) nos estabelecimentos de exploração mista por Unidade Federativa- Brasil out 2001-dez 2004

Gráfico 16- Diagrama de caixas da produção diária média de leite (litros) por vaca em lactação nas explorações mistas por Unidade Federativa- Brasil - out 2001-dez 2004

Gráfico 17- Proporções de estabelecimentos agropecuários que possuem assistência técnica segundo o sexo e nível de escolaridade. Brasil, 2006. Fonte: IBGE (2007) 


\section{LISTA DE TABELAS}

Tabela 1 - Resumo dos estudos sorológicos estaduais para diagnóstico da brucelose bovina realizados no Brasil a partir de 1975

Tabela 2- Nomenclatura adotada para os circuitos pecuários das Unidades Federativas

Tabela 3- Detalhamento amostral por Unidade Federativa e seus respectivos circuitos pecuários

Tabela 4 - Estimativa da distribuição dos rebanhos segundo o tipo de exploração dos rebanhos- Brasil - out 2001-dez 2004.

Tabela 5 - Tamanho e composição dos rebanhos segundo o tipo de exploração pecuária. Brasil - out 2001-dez 2004.

Tabela 6- Distribuição das frequências estimadas de sistemas de criação de bovinos segundo os tipos de exploração- Brasil - out 2001-dez 2004

Tabela 7- Valores da média e mediana dos tamanhos de rebanho segundo o tipo de exploração pecuária- Brasil - out 2001-dez 2004 ..................................79

Tabela 8- Distribuição das frequências de utilização de raças de bovinos segundo o tipo de exploração pecuária- Brasil - out 2001-dez 2004

Tabela 9- Distribuição das frequências estimadas do número de ordenhas diárias realizadas nas propriedades segundo o tipo de exploração pecuáriaBrasil - out 2001-dez 2004

Tabela 10 - Valores de média e mediana de produção diária de leite por animal e por rebanho segundo o número de ordenhas diárias- Brasil - out 2001-dez 2004

Tabela 11 - Distribuição das frequências estimadas de tipo de ordenha utilizado nas propriedades segundo o tipo de exploração pecuária- Brasil - out 2001dez 2004

Tabela 12- Distribuição das frequências estimadas do número de ordenhas realizadas nas segundo o tipo de ordenha adotada- Brasil - out 2001-dez 2004

Tabela 13- Distribuição das frequências estimadas de propriedades que realizam o resfriamento do leite após a ordenha segundo os tipos de exploração pecuária- Brasil - out 2001-dez 2004

Tabela 14- Distribuição das frequências estimadas de locais onde o leite é resfriado segundo o tipo de exploração- Brasil - out 2001-dez 2004 
Tabela 15- Distribuição das frequências estimadas do destino de entrega do leite segundo o tipo de exploração pecuária- Brasil - out 2001-dez 2004 ... 100

Tabela 16- Valores de produção diária de leite por estabelecimento e por vaca em lactação e do número de vacas em lactação segundo os tipos de exploração pecuária - Brasil - out 2001-dez 2004

Tabela 17- Distribuição das proporções estimadas de propriedades que possuem assistência técnica veterinária segundo o tipo de exploração pecuáriaBrasil - out 2001-dez 2004 108

Tabela 18- Distribuição do tipo de assistência veterinária segundo o tipo de exploração pecuária- Brasil - out 2001-dez 2004. 108

Tabela 19- Proporção estimada de propriedades que compram de animais para reprodução segundo o tipo de exploração- Brasil - out 2001-dez 2004114

Tabela 20- Locais de origem dos animais adquiridos para a reprodução- Brasil - out 2001-dez 2004

Tabela 21- Proporção estimada de propriedades que vendem reprodutores segundo o tipo de exploração- Brasil - out 2001-dez 2004 120

Tabela 22- Locais de destino dos reprodutores comercializados- Brasil - out 2001dez 2004 120

Tabela 23- Proporção de propriedades que realizam o aluguem de pastos segundo o tipo de exploração pecuária- Brasil - out 2001-dez 2004

Tabela 24- Proporção estimada de estabelecimentos que possuem áreas de pastagem em comum com outras propriedades segundo o tipo de exploração- Brasil - out 2001-dez 2004

Tabela 25- Distribuição das proporções de propriedades que utilizam os piquetes maternidade segundo o tipo de exploração- Brasil - out 2001-dez 2004

Tabela 26- Distribuição das proporções de casos de aborto nos últimos 12 meses segundo o tipo de exploração pecuária- Brasil - out 2001-dez 2004 ... 135

Tabela 27- Distribuição das proporções de destino dado aos restos de aborto encontrados nas propriedade segundo o tipo de exploração - Brasil - out 2001-dez 2004

Tabela 28- Distribuição das proporções de utilização da inseminação artificial segundo os tipos de exploração pecuária. Brasil - out 2001-dez 2004142

Tabela 29- Distribuição das estimativas de frequência de propriedades que alegaram consumir leite cru, segundo os tipos de exploração- Brasil - out 2001-dez 2004 
Tabela 30- Distribuição das estimativas de frequência de abate de reprodutores segundo os tipos de exploração pecuária- Brasil - out 2001-dez 2004151

Tabela 31- Distribuição das proporções de propriedades que produzem derivados do leite dentro do próprio estabelecimento segundo os tipos de exploração-

Brasil - out 2001-dez 2004.

Tabela 32- Finalidades da produção de derivados do leite segundo os tipos de exploração- Brasil - out 2001-dez 2004

Tabela 33- Distribuição da estimativa da prevalência de focos de brucelose segundo os tipos de exploração pecuária- Brasil - out 2001-dez 2004 163 


\section{LISTA DE ABREVIATURAS E SIGLAS}

2-ME 2- mercaptoetanol

AAT Antígeno Acidificado Tamponado

d Precisão

FC Fixação do Complemento

FMVZ Faculdade de Medicina Veterinária e Zootecnia de São Paulo

IC 95\% Intervalo de Confiança de 95\%

MAPA Ministério da Agricultura, Pecuária e Abastecimento

p Probabilidade de ocorrência ao acaso

PNCEBT Programa Nacional de Controle e Erradicação da Brucelose e Tuberculose Bovina

UnB Universidade de Brasília

USP Universidade de São Paulo

UF $\quad$ Unidade Federativa

VPS Departamento de Medicina Veterinária Preventiva e Saúde Animal

$\mathrm{Z}_{\mathrm{a}} \quad$ Valor da distribuição normal para o grau de confiança de $95 \%$ 
1 INTRODUÇÃO

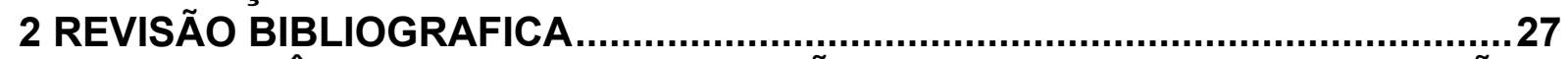

2.1 A IMPORTÂNCIA DA CARACTERIZAÇÃO DAS FORMAS DE ORGANIZAÇÃO

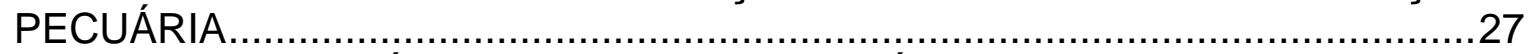

2.2 O RECENTE INQUÉRITO SORO-EPIDEMIOLÓGICO DA BRUCELOSE

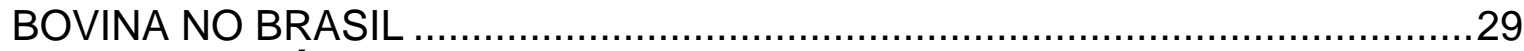

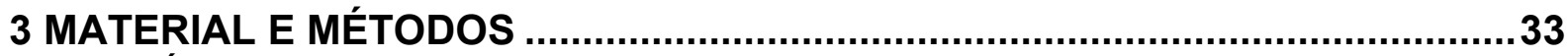

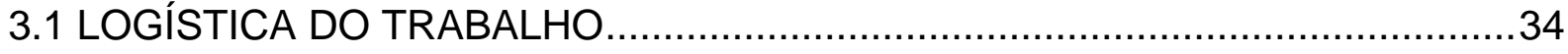

3.1.1 População de estudo e delineamento amostral .......................................35

3.1.2 Detalhamento da amostragem por Unidade Federativa............................40

3.1.3 Aplicação dos questionários epidemiológicos .........................................42

3.1.4 Criação de novas variáveis ........................................................................44

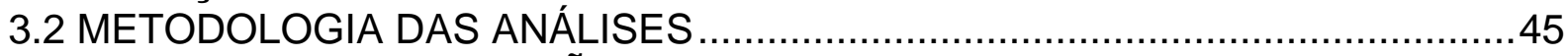

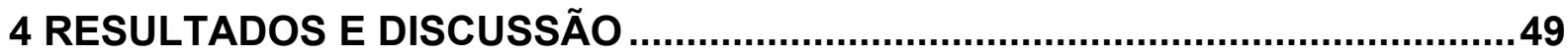

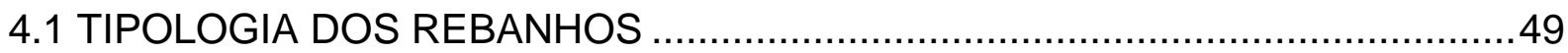

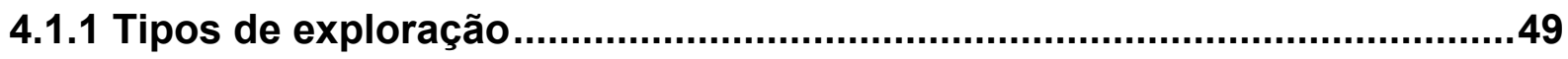

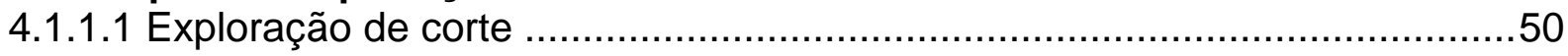

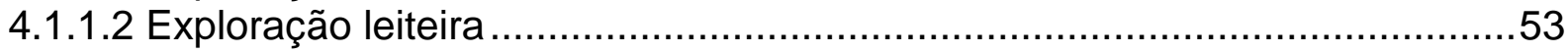

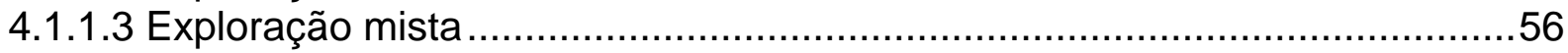

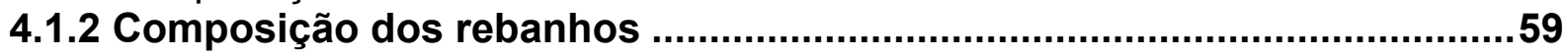

4.1.2.1 Composição dos rebanhos de corte .....................................................62

4.1.2.1 Composição dos rebanhos de leite ........................................................63

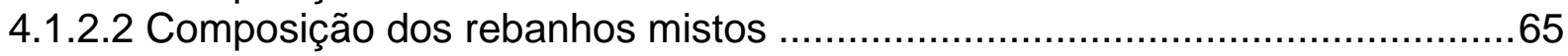

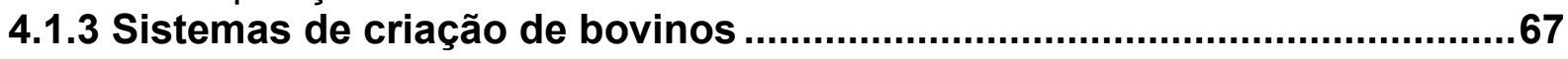

4.1.3.1 Sistemas de criação e tipos de exploração ..................................................68

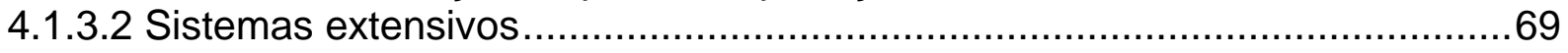

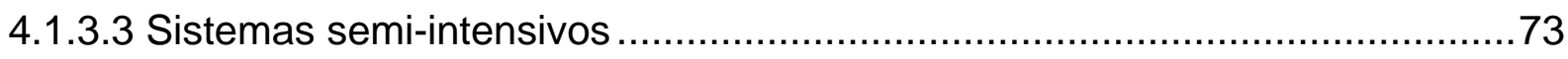

4.1.3.4 Sistemas intensivos (confinamentos) ……...............................................

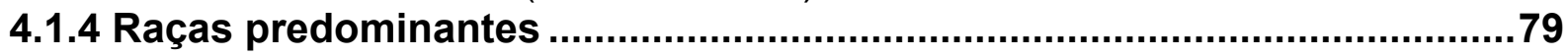

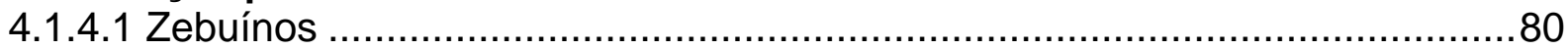

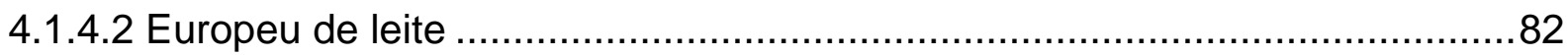

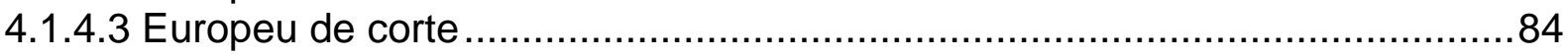

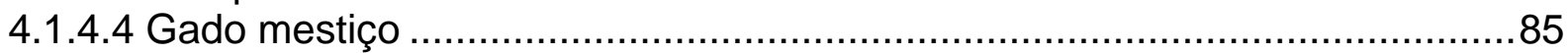

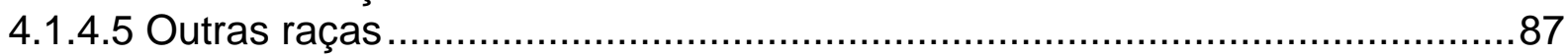

4.1.5 Variáveis relacionadas à atividade leiteira ..............................................89

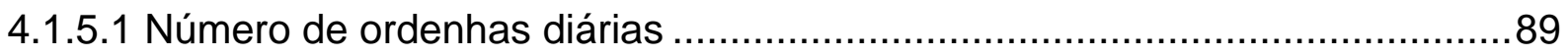

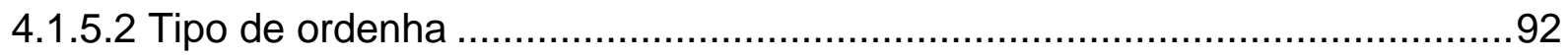

4.1.5.3 Tipo de ordenha e número de ordenhas diárias .......................................95

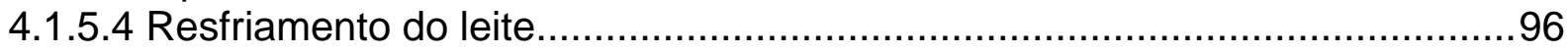

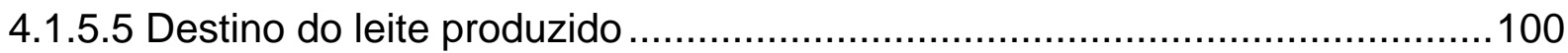

4.1.5.6 Produtividade leiteira ....................................................................... 102

4.2 CARACTERÍSTICAS DE IMPORTÂNCIA SANITÁRIA NOS REBANHOS .......107

4.2.1 Presença de assistência veterinária ...................................................107

4.2.2 Movimentação de reprodutores ............................................................113

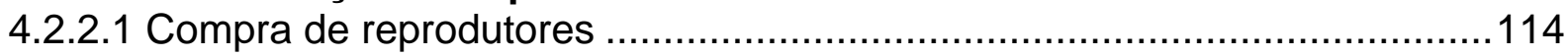

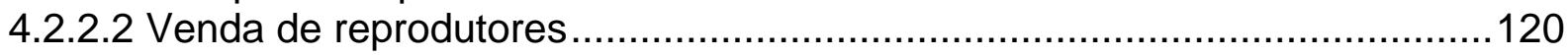

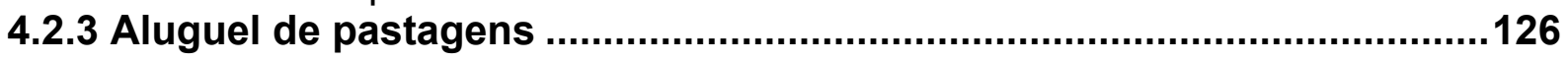




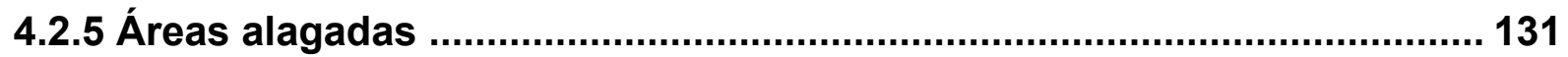

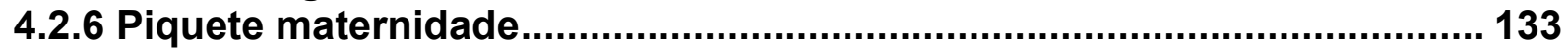

4.2.7 Relato de aborto nos últimos 12 meses ............................................ 135

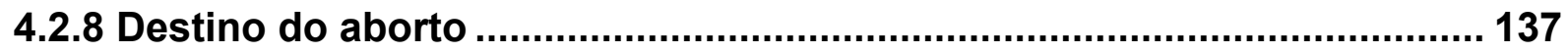

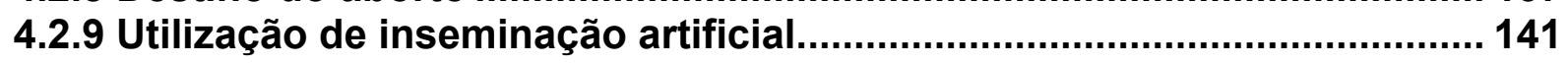

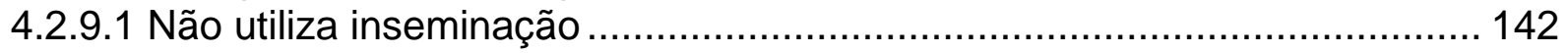

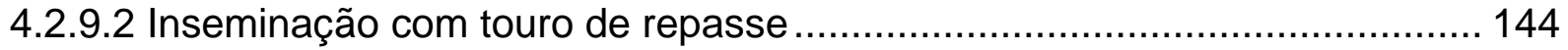

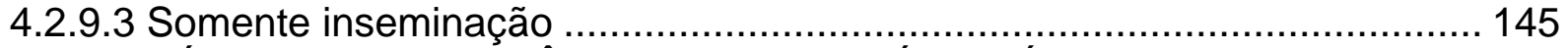

4.3 VARIÁVEIS DE IMPORTÂNCIA PARA A SAÚDE PÚBLICA …..................... 148

4.3.1 Consumo de leite cru ..................................................................... 148

4.3.2 Local de abate de reprodutores........................................................... 151

4.3.3 Fabricação de derivados do leite na propriedade.................................... 157

4.4 PREVALÊNCIA DE FOCOS DE BRUCELOSE ........................................... 162

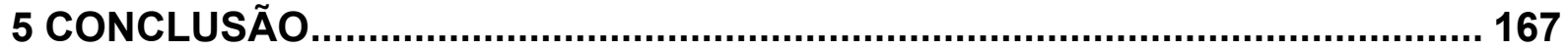

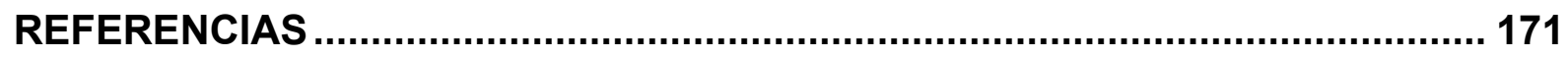

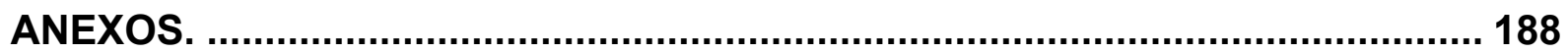




\section{INTRODUÇÃO}

O agronegócio possui um reconhecido papel no desenvolvimento social e econômico do Brasil, considerando que as riquezas geradas por este setor oferecem condições para a melhoria da qualidade de vida dos diferentes atores envolvidos no seu processo e contribuem com a economia do país como um todo. De acordo com Gasques et al. (2004), um fator que corrobora com a sua importância social é o emprego direto de cerca de 17,4 milhões de pessoas, o que corresponde a $24,2 \%$ da População Economicamente Ativa (PEA) no país. É dentro deste cenário que está inserida a cadeia produtiva de bovinos, através do fornecimento de carne, leite e derivados.

A bovinocultura é um setor que têm se destacado na economia nacional e a cada ano vem assumindo posições de liderança no mercado internacional, tanto no mercado da carne quanto no mercado leiteiro. O Brasil possui o maior rebanho comercial de bovinos do mundo, é o segundo país em volume de abates e ocupa o primeiro lugar em volume de exportações, tendo comercializado para outros países em 2009, mais de 1,2 milhões de toneladas de carne bovina, o que gerou uma receita de aproximadamente 4,1 bilhões de dólares para o país (ABIEC, 2009). A pecuária leiteira também exerce um papel de destaque na economia brasileira, considerando que em 2008, havia cerca de 21,6 milhões vacas ordenhadas e mais de 27,6 bilhões de litros de leite foram produzidos. Este valor coloca o país como o quarto maior produtor de leite do mundo (atrás da Índia, China e Rússia) e o segundo em número de vacas ordenhadas, ficando atrás apenas da Índia (IBGE, 2008). Apesar de tudo, estes valores indicam o potencial de crescimento da produtividade do rebanho leiteiro nacional.

Apesar dos resultados garantirem ao Brasil uma posição privilegiada entre os maiores produtores dentro desta cadeia produtiva, o país demonstra um enorme potencial de expansão da produção em razão da combinação entre diversos fatores de produção que incluem: o extenso território, o clima propício, o solo, a água, baixos custos de produção das criações essencialmente extensivas e os recursos humanos. Estes fatores, somados às ações governamentais de controle e erradicação de enfermidades do rebanho, investimento em tecnologia e melhoramento do potencial genético dos animais, constituem-se como uma 
vantagem competitiva ao país, permitindo oferecer aos mercados carne bovina e leite de qualidade, em volumes cada vez maiores e a preços bastante competitivos.

Os sistemas de exploração agropecuária no país são caracterizados como sistemas de alta heterogeneidade, especialmente no tocante aos sistemas de produção rural, com especificidades regionais acentuadas. Esta complexa distribuição de formas de criar bovinos desencadeia a existência de problemas de diferentes ordens, em especial àqueles relativos às questões sanitárias e a informalidade entre muitos dos agentes que atuam na cadeia produtiva. Nestes casos, considera-se necessário o desenvolvimento de políticas públicas para o setor na intenção de aumentar a sua estabilidade, uma vez que diversos problemas podem interferir nos aspectos de comercialização dos excedentes, na imagem da cadeia e na perda de mercados importantes.

Em relação ao mercado externo, ressalta-se a importância que as exigências técnico-sanitárias e as políticas muitas vezes de caráter protecionista, podem representar entraves ao crescimento das exportações e à conquista de novos mercados. Estes agentes, em substituição aos mecanismos tradicionais envolvendo barreiras tarifárias, têm criado um complexo sistema de transações através da instituição de novas formas de proteção, uma vez que ao passo que desejam ampliar o comércio, também almejam a estabilidade da economia interna. Um exemplo recente da atuação destes mercados na pecuária brasileira, foram os focos de febre aftosa detectados em Mato Grosso do Sul e no Paraná em outubro de 2005, que causaram um grande impacto econômico na competitividade e lucratividade da cadeia produtiva por conta do embargo imposto pelos países que importavam carne bovina brasileira.

Neste cenário, com a intenção de proteger este importante nicho de exploração animal, a atuação dos serviços de fomento e defesa sanitária animal torna-se cada vez mais presentes. Sendo assim, faz-se necessário realizar uma compreensão integral do espaço sobre o qual estes serviços exercem sua influência, descrevendo os sistemas produtivos, de maneira que é possível afirmar que quanto maior este conhecimento, mais efetiva será a preparação frente aos problemas. Este trabalho teve como objetivo, caracterizar os sistemas produtivos de bovinos onde ocorre atividade reprodutiva nas 14 unidades federativas (UFs) participantes de um estudo da situação epidemiológica da brucelose animal e realizar o cálculo da prevalência geral da brucelose bovina para estes Estados. 


\section{REVISÃO BIBLIOGRAFICA}

\subsection{A IMPORTÂNCIA DA CARACTERIZAÇÃO DAS FORMAS DE ORGANIZAÇÃO PECUÁRIA}

Astudillo et al. (1990), descrevem a tradição no meio veterinário de conceber a saúde animal a partir do paradigma biomédico, fazendo abstrações ao ambiente social, econômico e cultural em que a pecuária está inserida regionalmente. Os mesmos descrevem ainda que o enfoque microbiológico sobre a Medicina Veterinária Preventiva, associada especialmente às técnicas diagnósticas, sem sombra de dúvidas produziu um enorme avanço tecnológico. Em contrapartida, gerou uma tendência ao reducionismo na análise diagnóstica, estimulando a fragmentação das atividades sanitárias não como um fim, mas como um meio e simultaneamente levaram a uma visão parcial do conceito de saúde animal ao desconsiderar os determinantes sócio-econômicos do processo.

As formas como as enfermidades animais atuam, estão relacionadas com a maneira como os sistemas de produção se organizam. Isto proporcionaria, portanto, regiões que apresentariam um alto risco de ocorrência de determinadas doenças, enquanto que em outros locais este risco seria menor. Portanto, o conhecimento das diferentes formas de organização pecuária e do espaço geográfico e social nos quais os rebanhos estão inseridos, ajudaria a estabelecer estratégias específicas de atuação frente às doenças de acordo com estas variações regionais (ZOTELLE et al., 1993).

O processo humano de ocupação do ambiente, a partir do esforço para adaptar e utilizar os recursos naturais para satisfazer necessidades, envolve necessariamente a modificação do local em onde esteja. Considerando que a maneira como o homem se insere no ambiente está ligada a fatores históricos, culturais, sociais, econômicos e políticos, uma vasta série de relações organizacionais foram e continuam sendo originadas ao longo do tempo (ASTUDILLO; DORA; SILVA, 1986). Da mesma forma, cada sistema de exploração pecuária é resultante da maneira como o homem historicamente se utilizou dos recursos disponíveis para satisfazer as suas necessidades, desenvolvendo em alguns espaços geográficos, regiões homogêneas onde predominam formas 
específicas de produção para a obtenção de determinado fim (criações de corte, cria, produção leiteira, rebanhos de ciclo completo, consumo próprio, etc.) (OBIAGA, 1979).

Alves (2009) observa que a estrutura do sistema de defesa sanitária animal existente no país, é decorrente da luta contra a febre aftosa iniciada na década de 60. Naquele período, os resultados pouco efetivos obtidos através de uma visão antiquada dos aspectos epidemiológicos da doença e da adoção da vacinação em massa, fizeram com que a estratégia de atuação frente à febre aftosa fosse alterada, baseando-se em uma visão epidemiológica ampla, considerando os aspectos geográficos, produtivos, econômicos e o contexto onde as atividades pecuárias ocorriam, sendo adotados diversos enfoques de atuação de acordo com as características epidemiológicas regionais. Os programas atuais de prevenção, controle e erradicação de doenças existentes no país seguem ainda boa parte dos princípios criados àquela época.

A estratégia de regionalização e a criação do conceito de "ecossistemas de febre aftosa", contaram com a colaboração de Rosenberg e Goic (1973) e foram sugeridos durante os trabalhos de reformulação das estratégias de atuação frente à febre aftosa no início da década de 70. Apoiando-se em sistemas de informação que permitiram a elaboração de indicadores sobre o comportamento da enfermidade, a demografia animal e a estrutura de produção preponderante em determinadas regiões, a definição destes ecossistemas proporcionou aos agentes sanitários a possibilidade de intervir sobre o meio através de ações diferenciadas de acordo com as particularidades e os objetivos previstos em cada caso.

Mais tarde, o conceito de "ecossistemas" e esta visão sistêmica do processo foram estendidos para outras doenças de importância dos rebanhos (OBIAGA et al., 1979). Baseando-se nesta metodologia, vários países desenvolveram sistemas de prevenção de introdução de enfermidades exóticas, sendo estendido em alguns casos para cobrir as encefalites equinas e a Peste Suína Clássica. Alguns países, realizaram a adaptação desta estratégia para o monitoramento de indicadores produtivos dos rebanhos, a comercialização e distribuição de materiais biológicos, controle da higiene de alimentos (particularmente os matadouros) e a vigilância de zoonoses (OLASCOAGA; ROSENBERG; ASTUDILLO, 1991).

Fernandes; Bressan e Verneque (2004), descrevem o reconhecimento da comunidade científica quanto a importância dos trabalhos de caracterização de 
propriedades agropecuárias e sugerem que devido ao intenso dinamismo do setor, a necessidade de investimento em tecnologias integradas de coleta de dados e de atualização constante se faz necessária. Os mesmos também definem que a estratégia de regionalização é de extrema importância nestes trabalhos, já que permite que diferenças sejam reveladas entre os diversos locais de produção.

Até então, poucos trabalhos a respeito da caracterização da cadeia produtiva de bovinos têm sido realizados. O que geralmente se encontra são trabalhos pontuais, realizados em regiões delimitadas, com metodologias, enfoques e objetivos variados (FROIS, 1995; VIANA; CRUZ; LAENDER, 1987; PRADO, 1989; TEIXEIRA, 1989; FERRÃO, 2000; MADALENA, 2001a; DUARTE, 2002; ANDRADE, 2003; COTRIM, 2003; FERNANDES; BRESSAN; VERNEQUE, 2004; CARVALHO et al., 2006; MICHELS; SPROESSER; MENDONÇA, 2001; BONJOUR; FIGUEIREDO; MARTA, 2008; OLIVEIRA NETO et al., 2008; ALVES, 2009).

Estes fatores chamam atenção para a inovação deste trabalho, considerando a amplitude geográfica estudada e o enfoque utilizado ao considerar as características produtivas, de manejo e sanitárias das criações onde ocorre atividade reprodutiva.

\subsection{O RECENTE INQUÉRITO SORO-EPIDEMIOLÓGICO DA BRUCELOSE BOVINA NO BRASIL}

A brucelose é uma infecto-contagiosa bacteriana causada por bactérias do gênero Brucella levando às explorações pecuárias diversas perdas econômicas diretas e indiretas. A Brucella abortus têm como hospedeiros preferenciais os bovinos e bubalinos, podendo inclusive infectar o homem. As manifestações clínicas nos animais estão ligadas, principalmente, a problemas de caráter reprodutivo como (abortos, nascimentos prematuros, esterilidade, baixos índices reprodutivos), redução na produção de leite e também contribuindo para uma considerável redução do potencial de produção de leite e carne pelas propriedades infectadas. A manifestação clínica no homem é bastante variável e é responsável por incapacidade total ou parcial para o trabalho (BRASIL, 2006).

Os prejuízos relacionados à presença da brucelose nos rebanhos estão ligados à diminuição da produção carne e leite nos rebanho acometido, além da 
diminuição do valor comercial dos animais e dos subprodutos provenientes de zonas endêmicas, da perda de mercados potenciais e dos custos provenientes dos serviços médicos e do afastamento de humanos da função produtiva (GARCIACARRILO, 1987). Os custos de prevenção e controle da doença são sempre inferiores aos gastos quando a doença já está disseminada pelo rebanho (DIAS, 2004).

Alguns trabalhos estimam que a infecção pode ocasionar perdas de 20 a $25 \%$ na produção de leite, quando da interrupção da lactação pelo abortamento e no caso de vacas inseminadas com sêmen infectado, os prejuízos econômicos podem decorrer da repetição de cio (ACHA; SZYFRES, 2001). Faria (1984) descreve perdas de 10 a 15\% na produção de carne, 15\% de perdas decorrentes da necessidade de reposição dos bezerros abortados, necessidade de aumento de $30 \%$ nas taxas de reposição de animais, intervalo entre partos entendidos de 11,5 para 20 meses e perda de uma em cada cinco vacas reprodutoras por esterilidade permanente.

Os trabalhos de combate à brucelose no Brasil na década de 70 eram regulamentados através da Portaria 23 de 1976. Todavia, a ausência de um programa nacional bem estruturado não proporcionou que uma boa eficácia das ações de combate fosse atingida na época. Apesar deste cenário de desarticulação nacional no combate à doença, algumas UFs como o Rio Grande do Sul (em 1965) e Minas Gerais (em 1994), demonstraram iniciativas individuais de vacinação em massa dos seus rebanhos (POESTER; GONÇALVES; LAGE, 2002).

O primeiro estudo nacional de prevalência da brucelose bovina foi realizado pelo Ministério da Agricultura Pecuária e Abastecimento (MAPA) no ano de 1975 e envolveu 18 Estados da federação. A técnica sorológica adotada na época foi a 'Soro aglutinação rápida em placa' (BRASIL, 1977). Mais tarde, alguns Estados realizaram estudos sorológicos isoladamente, os quais não evidenciaram grandes alterações em relação aos índices nacionais verificados em 1975 (BRASIL, 2006) (Tabela 1).

O Ministério da Agricultura, Pecuária e Abastecimento (MAPA), verificando a ineficácia das medidas até recentemente adotadas, elaborou e lançou no início de 2001, o Programa Nacional de Controle Erradicação da Brucelose e Tuberculose Animal (PNCEBT), elaborado através de condutas preconizadas por organismos internacionais e representando flexibilidade suficiente para ser implementada nos diferentes Estados do país (DIAS et al., 2009a). Os objetivos específicos do 
programa envolvem a diminuição da prevalência e a da incidência da brucelose (e da tuberculose) e criar um número significativo de propriedades certificadas que oferecem produtos com baixo risco sanitário. Além da certificação de propriedades livres e monitoradas, de adesão voluntária, também foram aplicadas medidas compulsórias, como a vacinação de bezerras de três a oito meses de idade com a vacina B19 e controle de trânsito de reprodutores (BRASIL, 2006).

Tabela 1 - Resumo dos estudos sorológicos estaduais para diagnóstico da brucelose bovina realizados no Brasil a partir de 1975

\begin{tabular}{|c|c|c|c|c|c|c|}
\hline \multirow{2}{*}{$\begin{array}{c}\text { Unidade } \\
\text { Federativa } \\
\text { Data }\end{array}$} & \multicolumn{6}{|c|}{ Freqüência de animais sororeatores (\%) } \\
\hline & 1975 & 1980 & 1986 & 1989 & 1996 & 1998 \\
\hline NORTE & 4,1 & & & & & \\
\hline \multicolumn{7}{|l|}{ Rondônia } \\
\hline \multicolumn{7}{|l|}{ Acre } \\
\hline \multicolumn{7}{|l|}{ Amazonas } \\
\hline \multicolumn{7}{|l|}{ Roraima } \\
\hline Pará & 11,6 & & & & & \\
\hline \multicolumn{7}{|l|}{ Amapá } \\
\hline \multicolumn{7}{|l|}{ Tocantins } \\
\hline NORDESTE & 2,5 & & & & & \\
\hline Maranhão & 1,3 & & & & & \\
\hline Piauí & 0,2 & & & & & \\
\hline Ceará & 0,6 & & & & & \\
\hline Rio Grande Norte & 0,8 & & & & & \\
\hline Paraíba & 0,8 & & & & & \\
\hline Pernambuco & 1,5 & & & & & \\
\hline Alagoas & 0,9 & & & & & \\
\hline Sergipe & 10,5 & & & & & \\
\hline Bahia & 6,2 & & & & & \\
\hline SUDESTE & 7,5 & & & & & \\
\hline Minas Gerais & 7,6 & 6,7 & & & & \\
\hline Espírito Santo & 9,6 & & & & & \\
\hline Rio de Janeiro & 4,6 & & & & & \\
\hline São Paulo & 6,8 & & & & & \\
\hline SUL & 4,0 & & & & & \\
\hline Paraná & 9,9 & & & 4,6 & & \\
\hline Santa Catarina & 0,2 & & & & 0,6 & \\
\hline Rio Grande Sul & 2,0 & & 0,3 & & & \\
\hline CENTRO OESTE & 6,8 & & & & & \\
\hline Mato Grosso & 6,25 & & & & & \\
\hline $\begin{array}{c}\text { Mato Grosso do } \\
\text { Sul }\end{array}$ & & & & & & 6,3 \\
\hline Goiás & & & & & & \\
\hline Distrito Federal & & & & & & \\
\hline
\end{tabular}

Considerando que os custos de implantação de um programa deste porte são elevados, o conhecimento da situação epidemiológica da doença nas diversas regiões do país demonstrou ser uma informação de extrema importância para adoção das medidas de controle e erradicação, tendo permitido escolher as melhores estratégias de atuação dependendo da prevalência, distribuição e características regionais, como também, possibilitaria acompanhar o andamento do 
programa e julgar a necessidade de ajustes, evitando o desperdício de tempo e recursos (SILVA, 2008).

Para realizar o suporte à planificação e execução do PNCEBT e futuras avaliações sobre as medidas adotadas nas diferentes Unidades Federativas (UFs), formalizou-se uma parceria entre o MAPA, o Departamento de Medicina Veterinária Preventiva e Saúde Animal (VPS) da Faculdade de Medicina Veterinária e Zootecnia (FMVZ) da Universidade de São Paulo (USP), a Universidade de Brasília (UnB) e os serviços de defesa sanitária dos Estados, com a finalidade de realizar inquéritos epidemiológicos a respeito da brucelose bovina nas propriedades rurais de 14 UFs (ALVES, 2009).

Esta iniciativa deu origem a diversos trabalhos a respeito da situação epidemiológico da doença nas UFs e através do envolvimento de alunos de pósgraduação no tratamento dos dados, cálculos de prevalências e estudos de fatores de risco, originando diversas publicações sobre a posição de cada Estado em relação à brucelose bovina (ALVEZ et al., 2009; AZEVEDO et al., 2009; DIAS et al., 2009a,b; GONÇALVES et al., 2009a,b; ROCHA et al., 2009; NEGREIROS et al., 2009; KLEIN-GUNNEWIEK et al., 2009; MARVULO et al., 2009; OGATA et al., 2009; SIKUZAWA et al., 2009; SILVA et al., 2009; VILLAR et al., 2009). Além disso, esta iniciativa proporcionou a realização de um resgate da caracterização do perfil produtivo da pecuária bovina nos 14 Estados participantes, através da aplicação de um questionário epidemiológico padronizado para todos eles.

O objetivo do questionário epidemiológico foi obter informações a respeito dos sistemas de produção e de manejo adotados nas propriedades, assim como características intrínsecas a cada uma como composição do rebanho, raças predominantes, trocas comerciais, volumes de produção, etc. (ALVES, 2009). O estudo da tipologia dos rebanhos onde ocorre a atividade reprodutiva, não será útil somente para o conhecimento e atuação frente aos rebanhos infectados pela brucelose, mas também como subsídio para qualquer outra doença de caráter reprodutivo. 


\section{MATERIAL E MÉTODOS}

Uma das atividades integrantes do Programa Nacional de Controle e Erradicação de Brucelose e Tuberculose Animal (PNCEBT), foi a realização de um estudo amostral de propriedades rurais com atividade reprodutiva, dirigido a detectar a prevalência da brucelose bovina e identificar tipos de criação, práticas de manejo e fatores de risco que poderiam estar associados à presença da enfermidade em 14 UFs do Brasil. Até o presente momento, participaram deste estudo os Estados do Rio Grande do Sul, Santa Catarina, Paraná, São Paulo, Minas Gerais, Rio de Janeiro, Espírito Santo, Bahia, Sergipe, Goiás, Tocantins, Rondônia, Mato Grosso e o Distrito Federal (Mapa 1).

Durante as atividades de campo, um questionário epidemiológico (Anexo A) foi aplicado em cada uma das propriedades participantes do projeto. Este questionário foi elaborado com o objetivo primário de estudar possíveis fatores de risco associados com a presença da infecção nos animais.

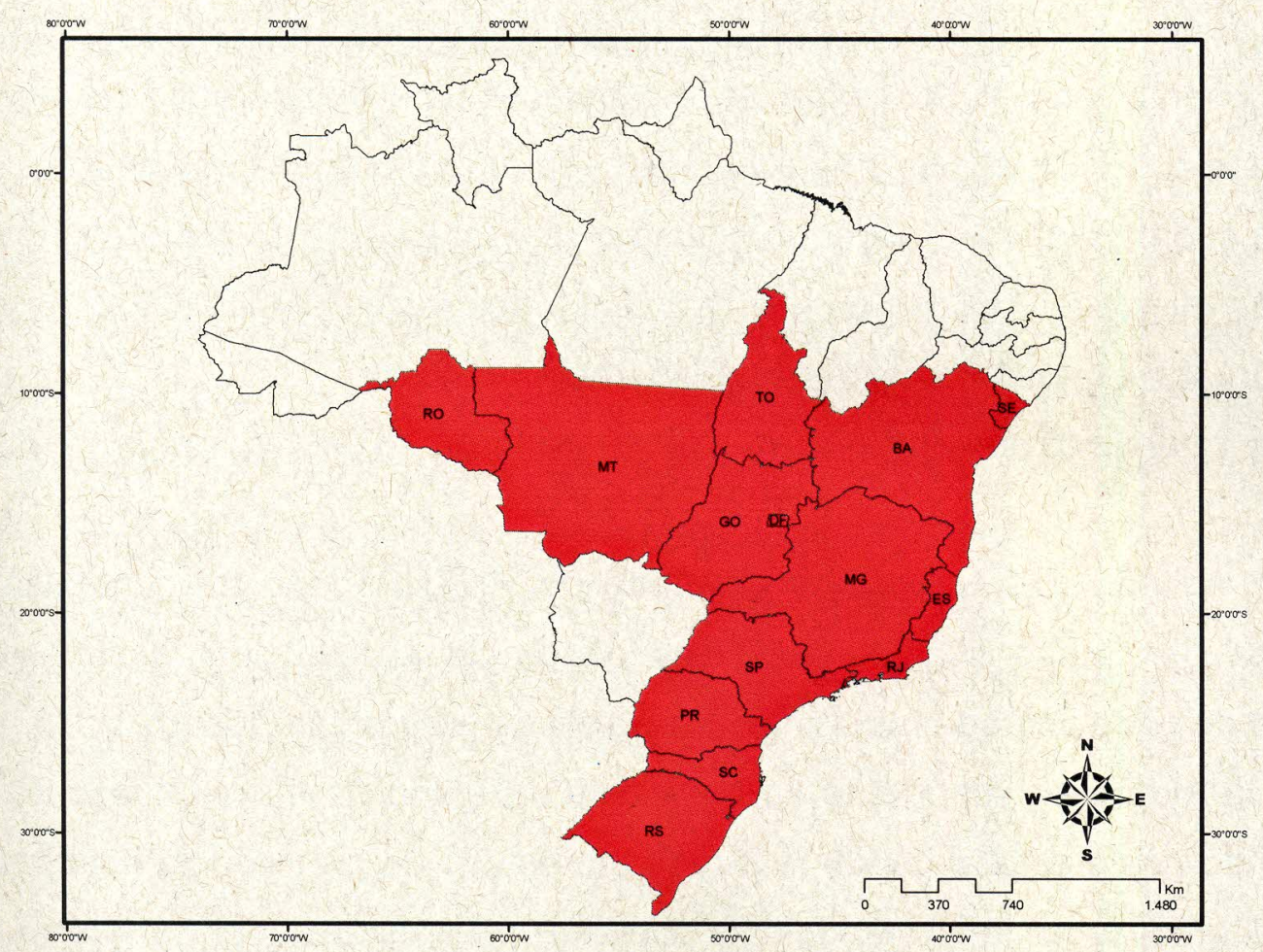

Mapa 1- Estados integrantes dos estudos de situação da brucelose bovina no Brasil 
propriedades avaliadas. Cada propriedade foi interrogada a respeito das características de produção de bovinos empregadas e também sobre condições sanitárias de manejo (principalmente aquelas possivelmente associadas à presença da brucelose bovina). A coleta dos dados, sua reorganização e posterior análise, possibilitaram avaliar e visualizar diversas diferenças regionais de produção de bovinos em propriedades onde ocorre atividade reprodutiva.

Tendo em vista que estes questionários foram originados a partir dos estudos epidemiológicos da brucelose realizados nas UFs participantes, julgou-se necessário citar aqui a metodologia da definição de amostras e a forma de aplicação das entrevistas nas propriedades durante as atividades do PNCEBT, para um melhor entendimento da logística do processo.

\subsection{LOGÍSTICA DO TRABALHO}

No ano de 2001, estabeleceu-se uma cooperação entre o Departamento de Medicina Veterinária Preventiva e Saúde Animal (VPS) da Faculdade de Medicina Veterinária e Zootecnia (FMVZ) da Universidade de São Paulo (USP), a Universidade de Brasília (UnB) e o Ministério da Agricultura, Pecuária e Abastecimento, com a finalidade de estabelecer uma colaboração na análise dos resultados do PNCEBT. As atribuições de cada órgão foram as seguintes:

a. a coordenação e o desenho amostral ficaram a cargo do MAPA, VPS e UnB;

b. as atividades de campo e a realização dos testes diagnósticos, a cargo dos órgãos executores estaduais e laboratórios oficiais;

c. o tratamento dos dados ficou a cargo do VPS.

A adesão das UFs nesta atividade do PNCEBT não foi compulsória e os trabalhos de campo tiveram seu ritmo ditado de acordo com a capacidade de trabalho de cada unidade federativa integrante do programa (Quadro 1).

Considera-se importante salientar que o Estado do Mato Grosso do Sul não foi incluído neste estudo, tendo realizado um estudo de prevalência estadual no ano de 1998 e utilizado uma metodologia diferente para estabelecer os fatores de risco para a brucelose, portanto, os resultados não seriam convenientemente comparáveis (CHATE et al., 2009). 
Quadro 1- Período de realização dos trabalhos de campo por Unidade da Federação

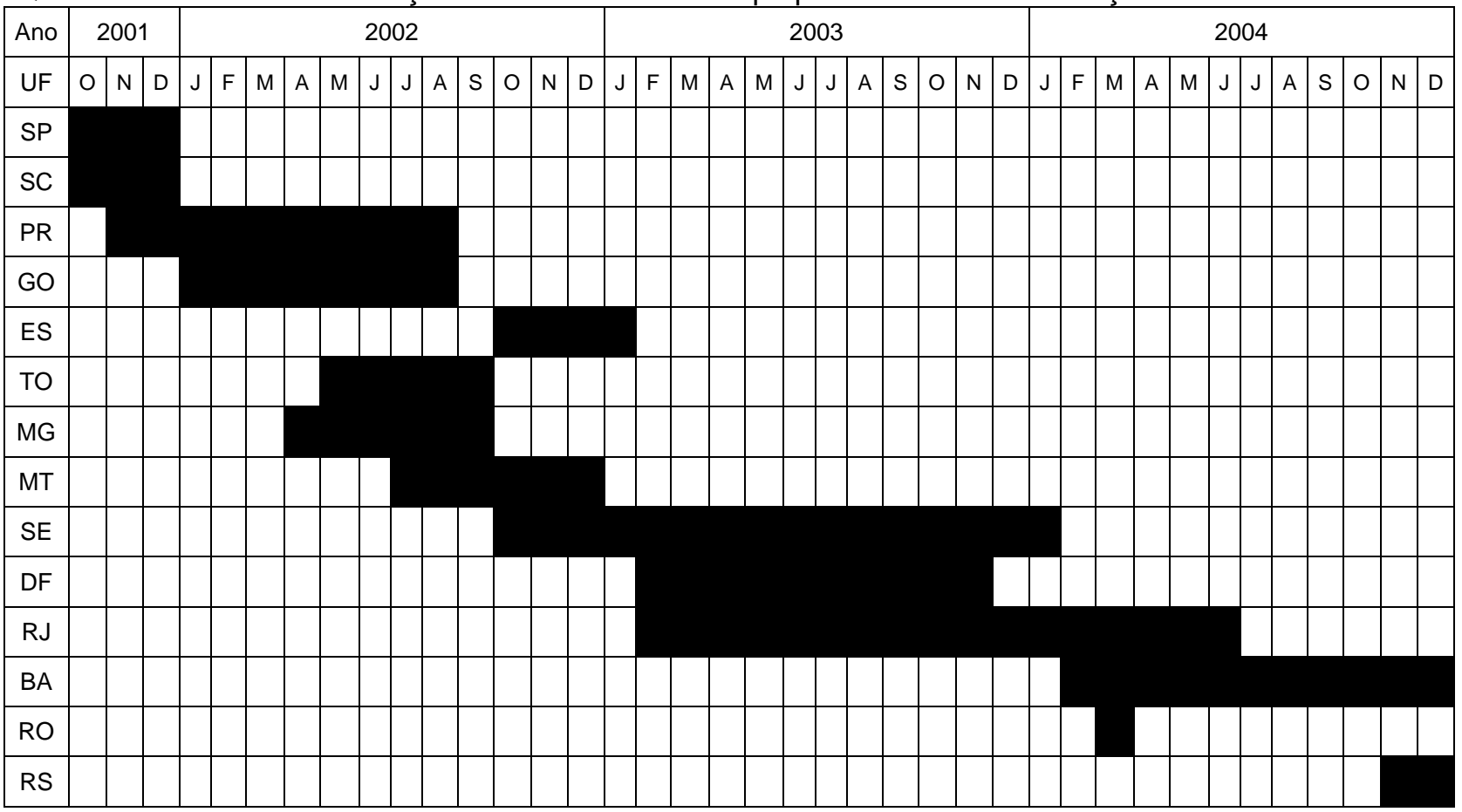

Fonte: FERREIRA-NETO, 2009.

\subsubsection{População de estudo e delineamento amostral}

Das 14 UFs integrantes do inquérito soro-epidemiológico, 13 foram estratificadas em 60 circuitos produtores de bovinos (Mapa 2). Esta divisão foi feita levando-se em conta os diferentes sistemas de produção, práticas de manejo, finalidades de exploração, tamanho médio de rebanhos e sistemas de comercialização. O Distrito Federal, excepcionalmente, não foi dividido em circuitos. A divisão do Estado em circuitos produtores também levou em consideração a capacidade logística e operacional dos órgãos executores estaduais de saúde animal para a realização das atividades de campo, baseando-se nas áreas de atuação das suas unidades regionais (DIAS, 2004). 


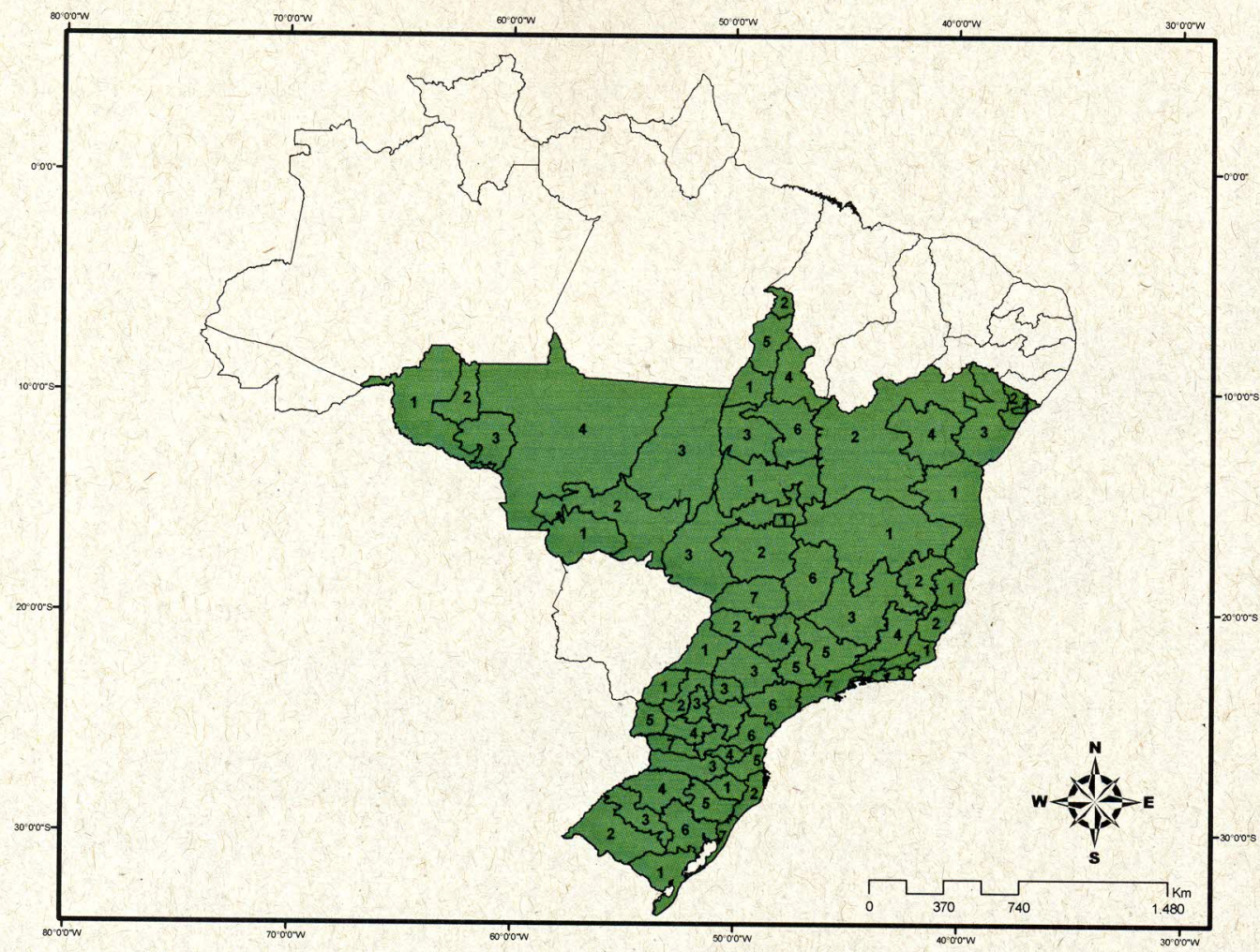

Mapa 2-Divisão das Unidades Federativas em circuitos pecuários

$\mathrm{Na}$ intenção de auxiliar na localização, descrição e discussão dos dados encontrados, considerou-se pertinente nomear cada circuito produtor baseando-se na sua equivalência com as mesorregiões brasileiras definidas pelo IBGE (2010) (tabela 2).

Tabela 2- Nomenclatura adotada para os circuitos pecuários das Unidades Federativas

\begin{tabular}{|c|c|c|}
\hline $\begin{array}{c}\text { Unidade } \\
\text { Federativa }\end{array}$ & Circuito & Nomenclatura adotada \\
\hline Bahia & $\begin{array}{l}\mathrm{BA} 01 \\
\mathrm{BA} 02 \\
\mathrm{BA} 03 \\
\mathrm{BA} 04 \\
\end{array}$ & $\begin{array}{c}\text { Centro-sul baiano } \\
\text { Oeste e Vale do São Francisco baiano } \\
\text { Nordeste baiano } \\
\text { Centro-norte baiano }\end{array}$ \\
\hline $\begin{array}{l}\text { Distrito } \\
\text { Federal }\end{array}$ & DF 01 & Distrito Federal \\
\hline $\begin{array}{l}\text { Espírito } \\
\text { Santo }\end{array}$ & $\begin{array}{l}\text { ES } 01 \\
\text { ES } 02\end{array}$ & $\begin{array}{l}\text { Centro-norte do Espírito-Santo } \\
\text { Centro-sul do Espírito Santo }\end{array}$ \\
\hline Goiás & $\begin{array}{lll}\text { GO } & 01 \\
\text { GO } & 02 \\
\text { GO } & 03\end{array}$ & $\begin{array}{c}\text { Norte goiano } \\
\text { Sudeste goiano } \\
\text { Centro-sudoeste goiano }\end{array}$ \\
\hline $\begin{array}{c}\text { Mato } \\
\text { Grosso }\end{array}$ & $\begin{array}{l}\text { MT } 01 \\
\text { MT } 02 \\
\text { MT } 03 \\
\text { MT } 04\end{array}$ & $\begin{array}{c}\text { Pantanal mato-grossense } \\
\text { Centro e sudeste mato-grossense } \\
\text { Nordeste mato-grossense } \\
\text { Noroeste mato-grossense } \\
\end{array}$ \\
\hline $\begin{array}{l}\text { Minas } \\
\text { Gerais }\end{array}$ & $\begin{array}{l}\text { MG } 01 \\
\text { MG } 02 \\
\text { MG } 03\end{array}$ & $\begin{array}{c}\text { Norte mineiro } \\
\text { Vale do Mucuri } \\
\text { Centro-sul mineiro }\end{array}$ \\
\hline
\end{tabular}




\begin{tabular}{|c|c|c|}
\hline $\begin{array}{c}\text { Unidade } \\
\text { Federativa }\end{array}$ & Circuito & Nomenclatura adotada \\
\hline & MG 04 & Zona da Mata mineira \\
\hline & MG 05 & Sudoeste mineiro \\
\hline & MG 06 & Centro-oeste mineiro \\
\hline & MG 07 & Triângulo Mineiro \\
\hline \multirow{7}{*}{ Paraná } & PR 01 & Noroeste paranaense \\
\hline & PR 02 & Norte central e centro-ocidental paranaenses \\
\hline & PR 03 & Norte pioneiro e região central paranaenses \\
\hline & PR 04 & Centro-sul e Centro-leste paranaense \\
\hline & PR 05 & Oeste paranaense \\
\hline & PR 06 & Curitiba e sudeste paranaense \\
\hline & PR 07 & Sudoeste paranaense \\
\hline \multirow{3}{*}{$\begin{array}{l}\text { Rio de } \\
\text { Janeiro }\end{array}$} & RJ 01 & Norte fluminense \\
\hline & RJ 02 & Centro-sul fluminense \\
\hline & RJ 03 & Rio de Janeiro e Baixadas \\
\hline \multirow{7}{*}{$\begin{array}{l}\text { Rio Grande } \\
\text { do Sul }\end{array}$} & RS 01 & Sudeste rio-grandense \\
\hline & RS 02 & Sudoeste rio-grandense \\
\hline & RS 03 & Centro ocidental rio-grandense \\
\hline & RS 04 & Noroeste rio-grandense \\
\hline & RS 05 & Nordeste rio-grandense \\
\hline & RS 06 & Centro-oriental rio-grandense \\
\hline & RS 07 & Litoral rio-grandense \\
\hline \multirow{3}{*}{ Rondônia } & RO 01 & Madeira-Guaporé \\
\hline & RO 02 & Centro-norte rondoniense \\
\hline & RO 03 & Sudeste rondoniense \\
\hline \multirow{5}{*}{$\begin{array}{c}\text { Santa } \\
\text { Catarina }\end{array}$} & SC 01 & Serrana \\
\hline & SC 02 & Grande Florianópolis e Sul catarinense \\
\hline & SC 03 & Oeste catarinense \\
\hline & SC 04 & Norte catarinense \\
\hline & SC 05 & Vale do Itajaí \\
\hline \multirow{7}{*}{ São Paulo } & SP 01 & Presidente Prudente \\
\hline & SP 02 & São José do Rio Preto/ Araçatuba \\
\hline & SP 03 & Bauru/Marília/Assis \\
\hline & SP 04 & Ribeirão Preto/Araraquara \\
\hline & SP 05 & Campinas/Piracicaba \\
\hline & SP 06 & Litoral sul paulista \\
\hline & SP 07 & Vale do Paraíba paulista \\
\hline \multirow{2}{*}{ Sergipe } & SE 01 & Nordeste sergipano \\
\hline & SE 02 & Oeste sergipano \\
\hline \multirow{6}{*}{ Tocantins } & TO 01 & Centro-oeste \\
\hline & TO 02 & Extremo norte \\
\hline & TO 03 & Sudoeste \\
\hline & TO 04 & Nordeste \\
\hline & TO 05 & Noroeste \\
\hline & TO 06 & Sudeste \\
\hline
\end{tabular}

Em cada circuito produtor, estimou-se a prevalência de propriedades com infecção pela brucelose bovina e de animais positivos nos testes sorológicos através de um estudo amostral realizado em dois estágios, dirigido com o intuito de detectar focos da doença: 
1. Primeiro estágio: sorteou-se de forma aleatória um número pré-estabelecido de propriedades com atividade reprodutiva (unidades primárias de amostragem). A escolha das unidades primárias de amostragem foi feita aleatoriamente, baseada nos cadastros estaduais de propriedades rurais com atividade reprodutiva de bovinos.

2. Segundo estágio: dentro de cada estabelecimento sorteou-se um número préestabelecido de fêmeas bovinas com idade igual ou superior a 24 meses (unidades secundárias de amostragem). Exclusivamente no Estado de Santa Catarina, foram amostradas fêmeas com idade igual ou superior a 12 meses já que nesta UF a vacina B19 nunca foi adotada.

Nos casos particulares onde as propriedades rurais possuíam mais de um rebanho, foi escolhido como alvo do estudo o rebanho de maior importância econômica (corte, leite ou misto), no qual os animais estavam submetidos ao mesmo tipo de manejo, ou seja, sob as mesmas condições de risco. Quando, por algum motivo, foi necessário substituir alguma propriedade sorteada inicialmente (por exemplo, por recusa do proprietário), os agentes de campo foram instruídos a escolher outra propriedade nas proximidades, com características de produção semelhantes.

O tamanho da amostra por circuito produtor, foi determinado pelo grau de confiança do resultado, pelo nível de precisão desejado e pelo valor da prevalência esperada, sendo influenciada também pela capacidade operacional e financeira dos órgãos executores estaduais. O objetivo da amostragem das unidades primárias, foi estimar um número mínimo de propriedades que fosse suficiente para estimar a realidade do circuito produtivo amostrado. Para isto, utilizou-se a fórmula para amostras simples aleatórias, segundo Thrusfied (1995) e Noordhuizen (1997):

$$
n=\frac{Z_{\alpha}^{2} \cdot \sqrt{P(1-P)}}{d^{2}}
$$


Onde:

- $\quad n=$ número de propriedades amostradas por circuito produtor;

- $Z_{\alpha}=$ valor da distribuição normal para o grau de confiança de 95\%;

- $\quad P=$ prevalência esperada, fixada em $20 \%$;

- $d=$ precisão, fixada em 5\% (6\% para São Paulo) .

O objetivo do planejamento amostral para as unidades secundárias (fêmeas com idade igual ou superior a 24 meses nos Estados e igual ou superior a 12 meses em Santa Catarina) visou estimar um número mínimo de animais a serem examinados dentro de cada propriedade de forma a permitir a sua classificação como foco ou não foco de brucelose. Para tanto, utilizou-se o conceito de sensibilidade e especificidade de rebanho. Para efeito dos cálculos adotou-se 95\% e 99,5\%, respectivamente, para os valores de sensibilidade e especificidade do protocolo de testes utilizado (FLETCHER, 1988) e 20\% para a prevalência estimada. Nesse processo foi utilizado o programa Herdacc version 3 (UNIVERSITY OF GUELPH, 1995) e o tamanho da amostra escolhido foi aquele que permitiu valores de sensibilidade e especificidade de rebanho, superiores a 90\%.

A escolha das fêmeas dentro das propriedades foi realizada de maneira casual sistemática. O número de amostras secundárias escolhidas em cada propriedade selecionada funcionou da seguinte maneira: nos estabelecimentos onde havia até 10 fêmeas maiores do que 24 (ou 12 para Santa Catarina) meses, todas foram amostradas; nas propriedades com até 99 fêmeas nesta faixa etária, foram amostrados 10 animais e naquelas com 100 ou mais fêmeas nesta faixa etária, foram selecionados 15 animais. As fêmeas no peri-parto (aproximadamente 15 dias antes ou após) foram excluídas da amostragem.

O protocolo de testes foi realizado de acordo com as diretrizes recomendadas no PNCEBT (BRASIL, 2001) e foi realizado em dois estágios. Inicialmente os soros dos animais selecionados foram submetidos a uma triagem onde empregou-se 0 teste do antígeno acidificado tamponado ou teste Rosa Bengala (TRB). Em seguida, os animais positivos na triagem foram retestados com o teste do 2-mercaptoetanol (2-ME) (em São Paulo o teste empregado foi a Fixação de complemento [FC]). Os testes foram realizados em laboratórios oficiais da rede do MAPA, laboratórios dos 
órgãos estaduais de defesa sanitária animal ou em faculdades de Medicina Veterinária.

Quando na propriedade detectou-se ao menos um animal soropositivo para brucelose bovina, a propriedade foi considerada foco. Quando os testes de determinada propriedade resultaram, exclusivamente, em resultados inconclusivos ou inconclusivos e negativos, estas propriedades foram excluídas das análises por não tornar possível a sua classificação.

O planejamento amostral permitiu determinar as frequências das diferentes tipologias de criação, assim como, a prevalência estimada de focos de brucelose bovina por Estado e por circuito produtor. O peso estatístico de cada propriedade foi determinado através da seguinte fórmula (DEAN, 1994):

$$
\text { Peso }=\frac{\text { propriedades no circuito produtor }}{\text { propriedades amostradas no circuito produtor }}
$$

A estrutura operacional do projeto está descrita no manual de procedimentos do inquérito soroepidemiológico da brucelose (Anexo B).

\subsubsection{Detalhamento da amostragem por Unidade Federativa}

No momento dos trabalhos, os cadastros estaduais de propriedades com bovinos em atividade reprodutiva nas 14 UFs totalizavam 1.852 .872 estabelecimentos com um número total 56.016.237 de fêmeas bovinas com idade igual ou superior a 24 meses. O tamanho final da amostra foi constituído por 17.534 propriedades distribuídas por 14 UFs e 61 circuitos produtores, sendo que o número de propriedades analisadas por circuito variou entre 144 a 396 propriedades e 0 número total de soros coletados para análise foi de 143.259. Na tabela 3, estão listados: o detalhamento amostral, o número de propriedades com atividade reprodutiva, o número total de fêmeas bovinas com idade igual ou superior a 24 (ou 12) meses e o número de soros coletados por UF e circuitos pecuários participante. 
Tabela 3- Detalhamento amostral por Unidade Federativa e seus respectivos circuitos pecuários

\begin{tabular}{|c|c|c|c|c|c|}
\hline Unidade Federativa & Circuito & $\begin{array}{l}\text { Propriedades } \\
\text { com atividade } \\
\text { reprodutiva de } \\
\text { bovinos }\end{array}$ & $\begin{array}{l}\text { Número de } \\
\text { propriedades } \\
\text { analisadas }\end{array}$ & $\begin{array}{c}\text { Total de } \\
\text { fêmeas } \\
\text { bovinas com } \\
\text { idade } \geq 24 \\
\text { meses } \\
\end{array}$ & $\begin{array}{l}\text { Número de } \\
\text { soros } \\
\text { coletados }\end{array}$ \\
\hline \multirow{5}{*}{ Bahia } & BA 01 & 51.613 & 382 & 1.813 .278 & 3565 \\
\hline & BA 02 & 80.782 & 336 & 1.293 .665 & 2621 \\
\hline & BA 03 & 63.918 & 364 & 720.057 & 2140 \\
\hline & BA 04 & 32.530 & 331 & 430.329 & 2490 \\
\hline & Total & 228.843 & 1413 & 4.257.329 & 10.816 \\
\hline Distrito Federal & DF 01 & 3.176 & 278 & 42.272 & 2.019 \\
\hline \multirow{3}{*}{ Espírito Santo } & ES 01 & 10.670 & 309 & 468.563 & 2.644 \\
\hline & ES 02 & 12.585 & 313 & 297.117 & 2.707 \\
\hline & Total & 23.255 & 622 & 765.680 & 5.351 \\
\hline \multirow{4}{*}{ Goiás } & GO 01 & 26.141 & 299 & 1.360 .348 & 3.723 \\
\hline & GO 02 & 54.560 & 297 & 3.059 .157 & 3.500 \\
\hline & GO 03 & 40.544 & 299 & 3.917 .127 & 3.515 \\
\hline & Total & 121.245 & 895 & 8.336 .632 & 10.738 \\
\hline \multirow{5}{*}{ Mato Grosso } & MT 01 & 5.479 & 144 & 815.946 & 1.883 \\
\hline & MT 02 & 23.438 & 375 & 2.296 .126 & 4.453 \\
\hline & MT 03 & 14.004 & 298 & 1.744 .381 & 3.710 \\
\hline & MT 04 & 39.553 & 298 & 3.520 .980 & 3.490 \\
\hline & Total & 82.474 & 1115 & 8.377 .433 & 13.536 \\
\hline \multirow{8}{*}{ Minas Gerais } & MG 01 & 60.547 & 318 & 1.977 .439 & 3.178 \\
\hline & MG 02 & 20.472 & 307 & 824.916 & 2.898 \\
\hline & MG 03 & 73.932 & 326 & 1.577 .485 & 2.972 \\
\hline & MG 04 & 43.688 & 323 & 597.115 & 2.619 \\
\hline & MG 05 & 55.602 & 316 & 988.230 & 2.744 \\
\hline & MG 06 & 25.568 & 305 & 1.039 .756 & 2.909 \\
\hline & MG 07 & 20.921 & 309 & 1.599 .449 & 3.323 \\
\hline & Total & 300.730 & 2.204 & 8.604 .390 & 20.643 \\
\hline \multirow{8}{*}{ Paraná } & PR 01 & 23.104 & 299 & 1.140 .410 & 2.764 \\
\hline & PR 02 & 20.835 & 306 & 750.002 & 2.715 \\
\hline & PR 03 & 27.403 & 297 & 972.554 & 2.264 \\
\hline & PR 04 & 42.738 & 300 & 878.916 & 1.970 \\
\hline & PR 05 & 33.451 & 301 & 616.012 & 1.969 \\
\hline & PR 06 & 18.616 & 292 & 173.396 & 1.889 \\
\hline & PR 07 & 44.126 & 299 & 517.315 & 1.237 \\
\hline & Total & 210.273 & 2094 & 5.048 .605 & 14.808 \\
\hline \multirow{4}{*}{ Rio de Janeiro } & RJ 01 & 18.566 & 311 & 514.731 & 2.712 \\
\hline & RJ 02 & 9.181 & 318 & 232.761 & 2.863 \\
\hline & RJ 03 & 6.377 & 316 & 184.043 & 2.667 \\
\hline & Total & 34.124 & 945 & 931.535 & 8.242 \\
\hline \multirow{6}{*}{ Rio Grande do Sul } & RS 01 & 34.908 & 294 & 1.046 .003 & 2.396 \\
\hline & RS 02 & 30.318 & 298 & 2.219 .933 & 3.610 \\
\hline & RS 03 & 51.729 & 318 & 957.908 & 3.698 \\
\hline & RS 04 & 139.501 & 302 & 697.219 & 1.993 \\
\hline & RS 05 & 39.295 & 300 & 486.090 & 1.918 \\
\hline & RS 06 & 86.074 & 280 & 692.043 & 1.422 \\
\hline
\end{tabular}




\begin{tabular}{|c|c|c|c|c|c|}
\hline Unidade Federativa & Circuito & $\begin{array}{l}\text { Propriedades } \\
\text { com atividade } \\
\text { reprodutiva de } \\
\text { bovinos }\end{array}$ & $\begin{array}{l}\text { Número de } \\
\text { propriedades } \\
\text { analisadas }\end{array}$ & $\begin{array}{c}\text { Total de } \\
\text { fêmeas } \\
\text { bovinas com } \\
\text { idade } \geq 24 \\
\text { meses } \\
\end{array}$ & $\begin{array}{l}\text { Número de } \\
\text { soros } \\
\text { coletados }\end{array}$ \\
\hline & RS 07 & 11.162 & 165 & 214.213 & 936 \\
\hline & Total & 392.987 & 1957 & 6.314 .228 & 15.973 \\
\hline \multirow{4}{*}{ Rondônia } & RO 01 & 13.653 & 308 & 1.162 .413 & 3.300 \\
\hline & RO 02 & 18.143 & 306 & 1.159 .407 & 3.150 \\
\hline & RO 03 & 17.852 & 307 & 1.329 .597 & 3.267 \\
\hline & Total & 49.648 & 921 & 3.651 .417 & 9.717 \\
\hline \multirow{6}{*}{ Santa Catarina } & SC 01 & 13.024 & 299 & 225.823 & 1.920 \\
\hline & SC 02 & 30.635 & 298 & 163.609 & 1.253 \\
\hline & SC 03 & 80.754 & 396 & 693.752 & 2.171 \\
\hline & SC 04 & 11.113 & 299 & 86.319 & 1.181 \\
\hline & SC 05 & 33.383 & 296 & 197.896 & 1.276 \\
\hline & Total & 168.909 & 1.588 & 1.367 .399 & 7.801 \\
\hline \multirow{8}{*}{ São Paulo } & SP 01 & 29.091 & 145 & 1.333 .508 & 1.428 \\
\hline & SP 02 & 35.052 & 151 & 1.071 .847 & 1.230 \\
\hline & SP 03 & 29.875 & 148 & 1.220 .983 & 1.321 \\
\hline & SP 04 & 14.970 & 153 & 378.485 & 1.200 \\
\hline & SP 05 & 22.551 & 179 & 351.553 & 1.161 \\
\hline & SP 06 & 18.247 & 146 & 351.612 & 1.107 \\
\hline & SP 07 & 10.213 & 151 & 224.226 & 1.314 \\
\hline & Total & 159.999 & 1.073 & 4.932 .214 & 8.761 \\
\hline \multirow{3}{*}{ Sergipe } & SE 01 & 3.582 & 325 & 262.442 & 2.620 \\
\hline & SE 02 & 17.022 & 263 & 70.473 & 2.137 \\
\hline & Total & 20.604 & 588 & 322.915 & 4.757 \\
\hline \multirow{7}{*}{ Tocantins } & TO 01 & 6.837 & 305 & 505.357 & 3.370 \\
\hline & TO 02 & 7.696 & 295 & 239.997 & 3.022 \\
\hline & TO 03 & 9.706 & 307 & 751.619 & 3.902 \\
\hline & TO 04 & 6.771 & 308 & 190.203 & 3.167 \\
\hline & TO 05 & 13.856 & 311 & 803.594 & 3.764 \\
\hline & TO 06 & 11.739 & 315 & 573.418 & 3.688 \\
\hline & Total & 56.605 & 1841 & 3.064 .188 & 20.913 \\
\hline TOTAL & & 1.852 .872 & 17.534 & 56.016 .237 & 154.075 \\
\hline
\end{tabular}

\subsubsection{Aplicação dos questionários epidemiológicos}

Os questionários epidemiológicos foram preenchidos pelos agentes de campo juntamente com os trabalhos de coleta de soro dos animais selecionados pela amostragem. As perguntas incluídas no questionário, como previamente citado, buscaram englobar diversas características existentes nas criações de bovinos que posteriormente pudessem ser utilizadas para caracterizar os sistemas de produção e tipos de manejo sanitário com a presença ou ausência da doença nas criações.

Foram avaliadas as seguintes variáveis de rebanho: 
a) Variáveis qualitativas

- tipo de exploração;

- tipo de criação;

- número de ordenhas diárias;

- tipo de ordenha realizada;

- utilização de inseminação artificial;

- raça bovina predominante;

- compra fêmeas ou machos com finalidade reprodutiva;

- venda fêmeas ou machos com finalidade reprodutiva;

- abate de reprodutores no fim da vida;

- aluguel de pastagens;

- existência de áreas alagadiças;

- presença de piquetes exclusivos para parto;

- destino do leite produzido;

- resfriamento do leite;

- produção de queijo e manteiga na propriedade;

- consumo de leite cru;

- assistência veterinária;

- tipo de assistência veterinária.

b) Variáveis quantitativas

- número de machos castrados;

- número de machos entre 0 e 6 meses;

- número de machos entre 6 e 12 meses;

- número de machos entre 12 e 24 meses;

- número de machos acima de 24 meses;

- número de fêmeas entre 0 e 6 meses;

- número de fêmeas entre 6 e 12 meses;

- número de fêmeas entre 12 e 24 meses;

- número de fêmeas acima de 24 meses; 
- número de vacas em lactação;

- produção diária de leite (em litros).

Algumas perguntas presentes no questionário epidemiológico não foram utilizadas no trabalho. As razões principais da exclusão, foram a possibilidade de algumas perguntas darem origem a respostas enviesadas, não fazer parte do foco principal do trabalho de caracterização dos sistemas de produção de bovinos ou que poderiam sofrer influência da data de início dos trabalhos de campo em relação à data de início do PNCEBT e não possibilitariam comparações entre as UFs .

\subsubsection{Criação de novas variáveis}

Durante a organização do banco de dados, novas variáveis puderam ser criadas através das variáveis supracitadas. As seguintes estão listadas abaixo:

a) Tamanho total do rebanho

Esta variável foi obtida através da soma de todas as faixas etárias de animais em cada propriedade amostrada (número de machos castrados; machos entre 0 e 6 meses; machos entre 6 e 12 meses; machos entre 12 e 24 meses; machos acima de 24 meses; fêmeas entre 0 e 6 meses; fêmeas entre 6 e 12 meses;fêmeas entre 12 e 24 meses; fêmeas acima de 24 meses).

b) Produção diária de leite por vaca em lactação

Calculou-se a produção média (em litros) de leite por vaca em lactação através da divisão entre as variáveis de produção diária de leite (em litros) na propriedade pelo número de vacas em lactação. 


\subsection{METODOLOGIA DAS ANÁLISES}

A caracterização do perfil produtivo dos rebanhos foi realizada através da consolidação das informações geradas durante o processo do inquérito soroepidemiológico nas UFs integrantes do projeto. Estes bancos de dados foram cedidos gentilmente por todos os envolvidos nos estudos de situação epidemiológica da brucelose nos Estados. Os arquivos foram enviados em formato de planilha eletrônica. Logo após, procedeu-se a junção e reorganização dos dados de todos os Estados em uma planilha nacional. O formulário foi verificado em busca de erros de digitação que poderiam interferir nas análises futuras.

Muitos dos bancos de dados, vieram com as propriedades que apresentaram resultados inconclusivos nos exames para brucelose bovina. Estas foram descartadas do formulário, de maneira que restassem no banco apenas as propriedades foco e não foco durante os cálculos de prevalência da doença nos Estados. Ao todo foram excluídas 77 propriedades classificadas como inconclusivas nos testes de brucelose.

Alguns erros de preenchimento do formulário eletrônico fizeram com que algumas propriedades fossem excluídas de algumas análises específicas, mas não do banco de dados. Por exemplo, alguns estabelecimentos afirmaram que o seu "tipo de exploração principal" era o leite, no entanto, quando questionados quanto ao "número de ordenhas diárias" e o "tipo de ordenha empregada", algumas destas propriedades apresentaram a resposta "não ordenha" em uma das duas variáveis. Segundo o treinamento e o manual de procedimentos fornecidos às equipes (Anexo B), estas respostas só poderiam ser admitidas nos rebanhos amostrados onde não era realizada a ordenha, como por exemplo nos rebanhos de corte. A solução encontrada foi excluir, dentro dos rebanhos classificados como leiteiros, todas as respostas a respeito do número de ordenha e tipo de ordenha empregada que apresentassem a resposta "não ordenha" em um ou em ambos os casos, para que em análises posteriores (criação de tabelas cruzadas entre estas variáveis) estas inconsistências não interferissem nos resultados.

Para os cálculos das frequências gerais e por UF, foram necessários cálculos para amostras complexas, sendo necessário calcular os pesos amostrais das 
propriedades dentro de cada circuito produtor. Os cálculos foram realizados com 0 auxílio dos programas Epi Info 6.04 e SPSS 9.0.

a) Análise das variáveis qualitativas

Para as variáveis qualitativas de rebanho, realizaram-se cálculos visando estimar a sua frequência em cada circuito produtor. Posteriormente, calculou-se a estimativa destas frequências por Estado e para o Centro-sul do país (14 UFs analisadas). Além das análises de estimativa das freqüências das variáveis, calculou-se também o intervalo de confiança de 95\% (IC 95\%) para todos os resultados de prevalência obtidos, o que possibilitou uma melhor compreensão e comparação entre eles.

b) Análise das variáveis quantitativas

Todas as variáveis quantitativas de rebanho foram testadas previamente quanto a sua normalidade através do teste de Kolmogorov-Smirnov e demonstraram não apresentar uma distribuição normal $(p<0,05)$ (ZAR, 1999). Esta característica levou à escolha de testes não-paramétricos para a realização das comparações entre os dados quantitativos encontrados entre os diferentes tipos de exploração pecuária.

Para as demonstrações gráficas e interpretações dos dados, optou-se preferencialmente pela utilização da mediana (como medida de tendência central) e dos quartis (como medidas de posição de frequências). Esta escolha foi feita por duas razões básicas: primeiro pelo fato de que nenhuma das variáveis quantitativas estudadas apresentou distribuição normal e em segundo, como os dados analisados apresentaram muitos valores aberrantes, a mediana sofre menos influência destes valores se comparada à média aritmética. No entanto, como a média de diversas variáveis é habitualmente utilizada na literatura, esta também foi calculada por medida de comparação.

Para verificar se haviam diferenças significantes nos resultados quantitativos encontrados entres os tipos de exploração (corte, leite ou misto), aplicou-se o teste de Kruskal-Wallis para $k$ amostras independentes. Nos casos em que se observou que havia diferença estatística entre os grupos de circuitos avaliados, os valores 
para cada tipo de exploração foram comparados entre si através do teste de MannWhitney $U$ para 2 amostras independentes.

c) Representação gráfica dos resultados

Gráficos foram elaborados com o auxílio do programa Origin 8.0 para a representação de alguns resultados.

d) Representação espacial dos resultados

Os resultados das frequências estimadas das variáveis qualitativas e das medianas das variáveis quantitativas por UF e seus respectivos circuitos de produção, foram representadas em mapas elaborados com o auxílio do programa ArcGis 9.2. 


\section{RESULTADOS E DISCUSSÃO}

Foram calculadas estimativas de frequência dos diferentes tipos de criação encontrados, as particularidades que poderiam influenciar na disseminação de doenças entre os animais, comportamentos que poderiam representar riscos à saúde pública. Também foi calculado a prevalência geral de focos de brucelose bovina para as 14 UFs que integraram os trabalhos.

\subsection{TIPOLOGIA DOS REBANHOS}

Os rebanhos foram caracterizados segundo o tipo de exploração, a composição de animais por sexo e faixa etária, os sistemas de criação utilizados, as raças predominantes e quanto as suas particularidades de exploração de leite.

\subsubsection{Tipos de exploração}

$\mathrm{Na}$ análise geral, as explorações mistas e de leite foram as mais frequentes com 38,78\% [37,90\%; 39,67\%] e 38,62\% [37,78\%; 39,47\%], respectivamente, não havendo diferença significativa entre elas. Os estabelecimentos de exploração prioritária de gado de corte, representaram 22,6\% (21,9\%; 23,3\%) na estimativa total (Tabela 4).

Tabela 4 - Estimativa da distribuição dos rebanhos segundo o tipo de exploração dos rebanhos- Brasil - out 2001-dez 2004

\begin{tabular}{ccc}
\hline Tipo de exploração & Valor estimado (\%) & IC 95\% \\
\hline Corte & 22,60 & 21,$95 ; 23,26$ \\
Leite & 38,62 & 37,$78 ; 39,47$ \\
Mista & 38,78 & 37,$90 ; 39,67$ \\
\hline Total & 100,0 & \\
\hline
\end{tabular}

Na intenção de designar as áreas com predominância (ou não) entre um ou outro tipo de exploração pecuária por circuito produtor, foi utilizado além das comparações entre os intervalos de confiança de 95\% das frequências, o "diagrama ternário" para localizar e classificar as regiões onde havia preponderância. Este diagrama é utilizado para representar sistemas constituídos por três variáveis no 
qual a soma é uma constante (100\%). No mapa 3 estão representadas, além do diagrama, as regiões onde cada tipo de exploração representou ser o principal.

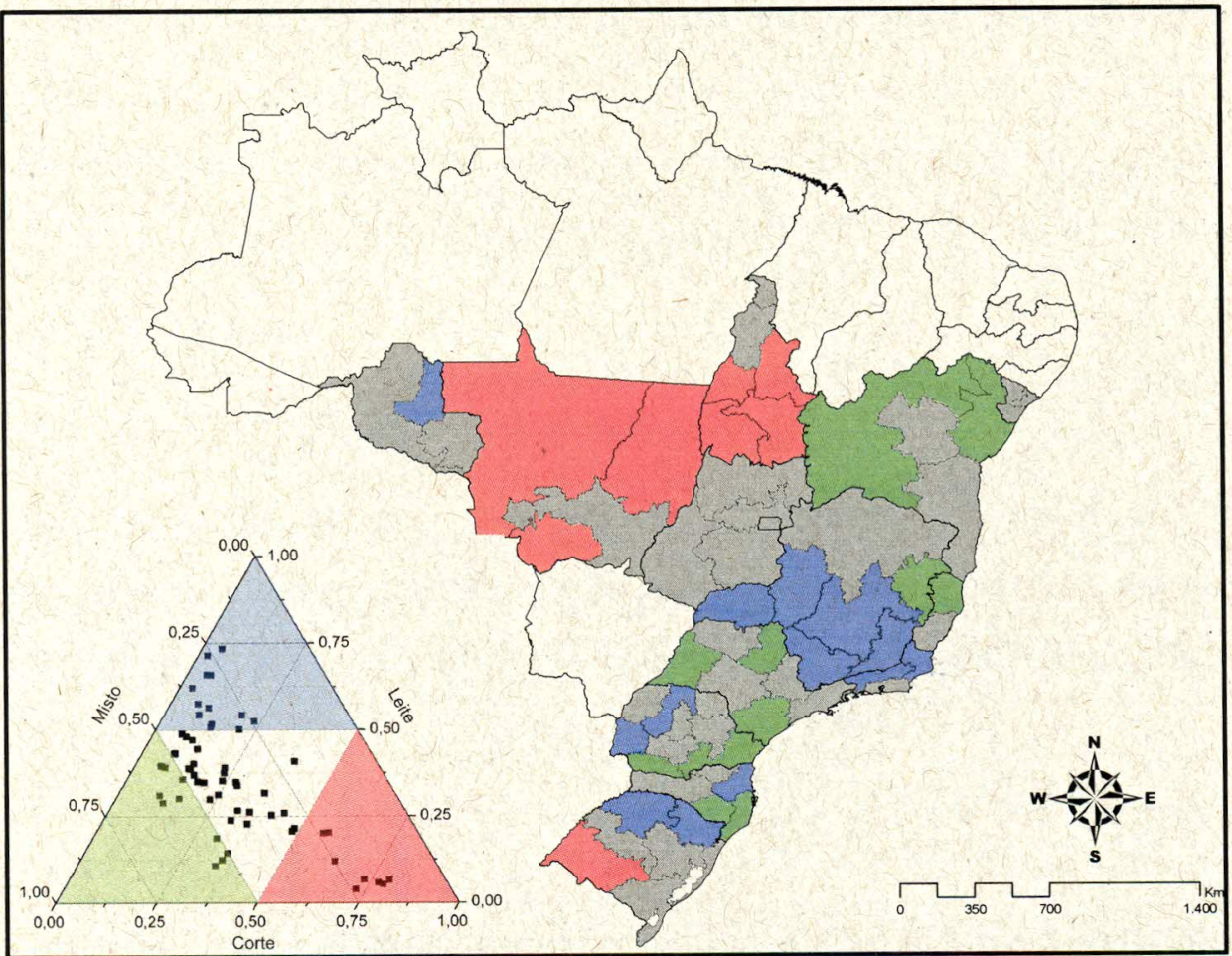

Mapa 3- Distribuição dos tipos de exploração de bovinos predominantes nos circuitos pecuários- Brasil - out 2001-dez 2004

Os tipos de exploração pecuária, suas frequências, distribuição e discussão dos resultados encontrados foram avaliados individualmente.

\subsubsection{Exploração de corte}

As estimativas estaduais das frequências de propriedades onde são explorados animais exclusivamente para corte, apresentaram valores variando entre $7,47 \%$ [5,63\%; 7,84\%] no Espírito Santo a $59,28 \%$ [57,07\%; $61,45 \%]$ no Tocantins. A UF onde a proporção de propriedades de corte superou significativamente as outras explorações, além do Tocantins, foi o Estado de Mato Grosso com 55,43\% [52,13\%; $58,68]$ dos estabelecimentos criando bovinos exclusivamente para corte (Mapa 4). As frequências por circuito pecuário, demonstram que os locais onde a pecuária de corte destaca-se diante dos demais tipos de exploração, localizam-se de maneira 
geral nos circuitos do Mato Grosso, Tocantins e do sudoeste do Rio Grande do Sul (Mapa 5).

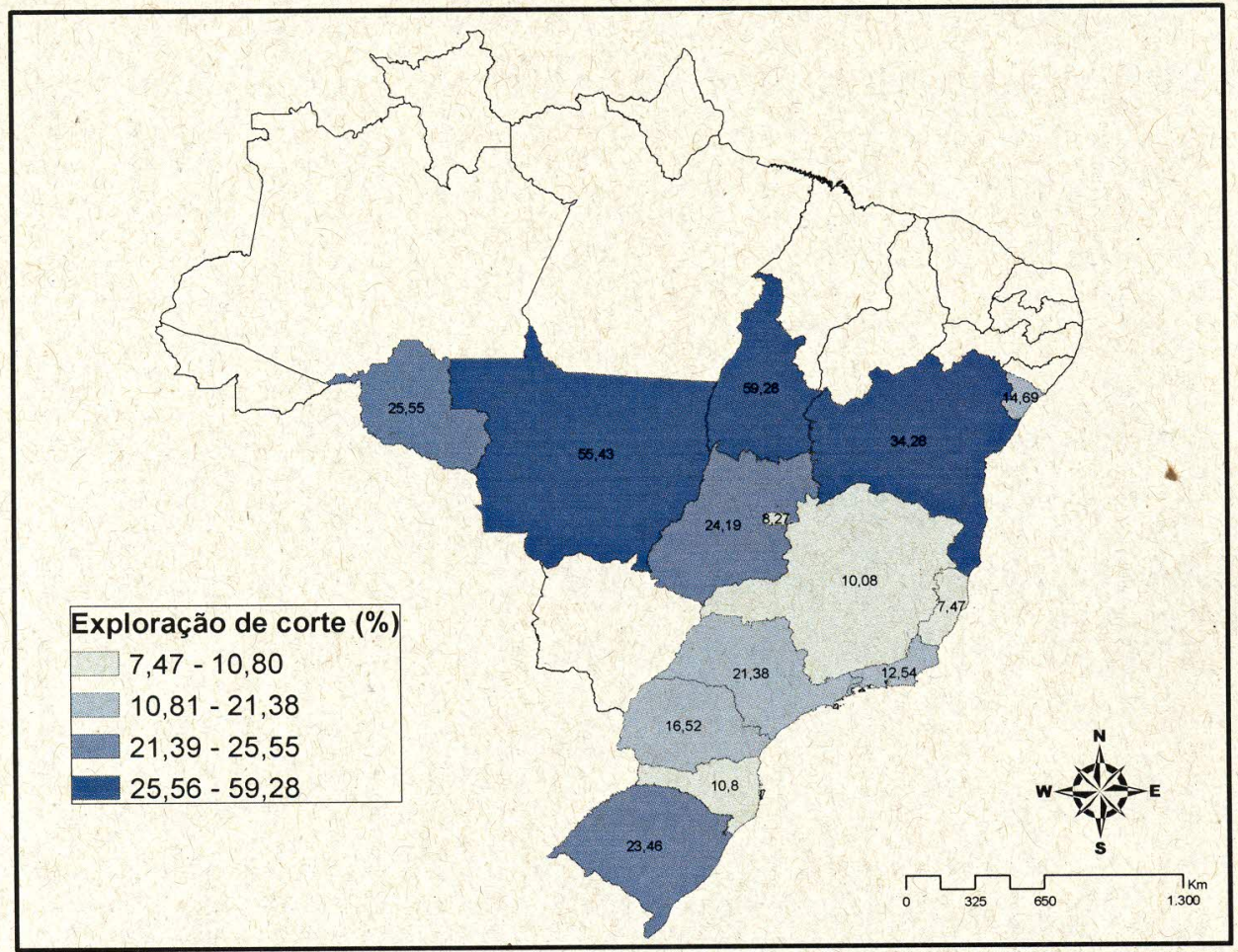

Mapa 4- Distribuição das frequências estimadas de exploração de corte nos Estados- Brasil - out 2001-dez 2004

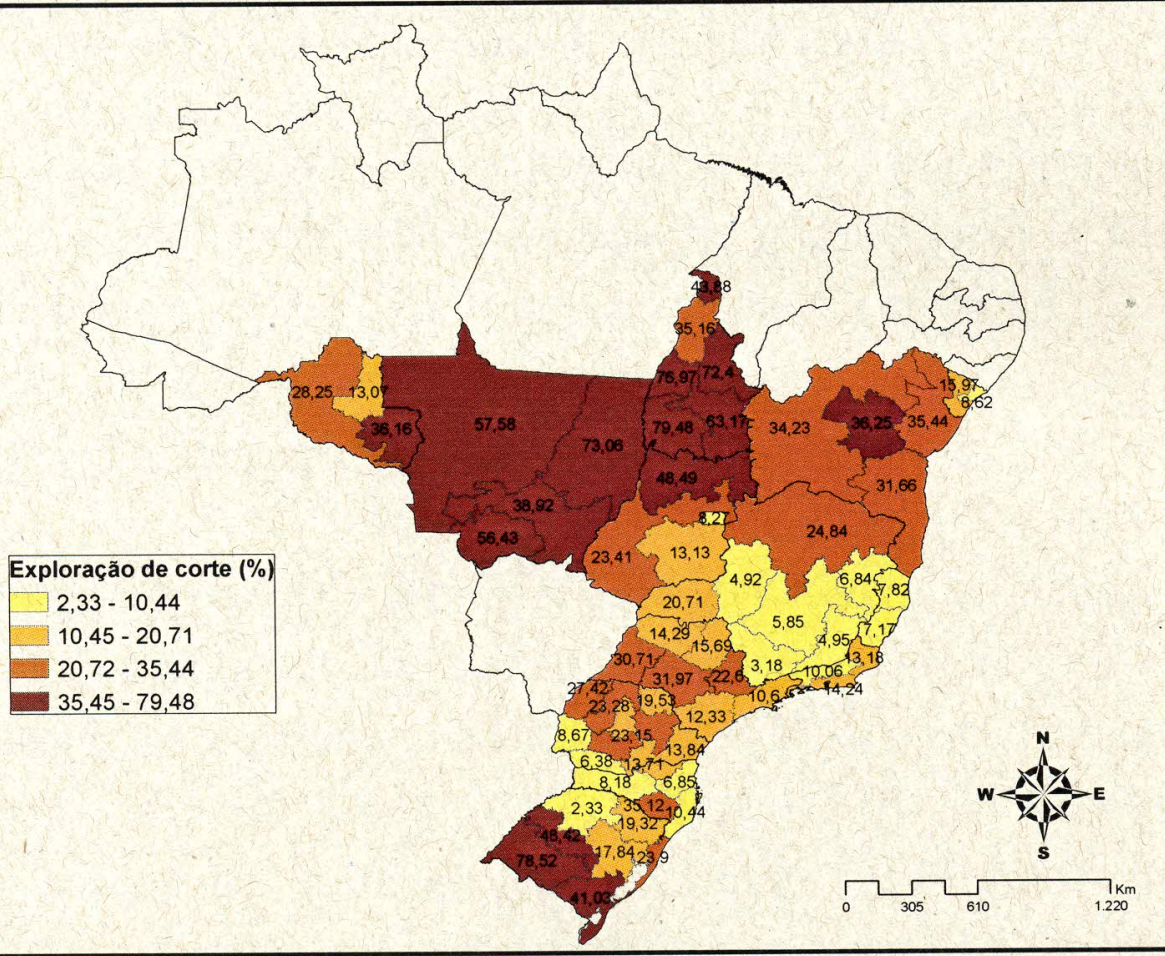

Mapa 5- Distribuição das frequências estimadas de exploração de corte nos circuitos- Brasil - out 2001-dez 2004 
No gráfico 1, estão dispostos em ordem decrescente, os valores pontuais das proporções de estabelecimentos de corte e seus respectivos intervalos de confiança de $95 \%$ encontrados em cada circuito produtor.

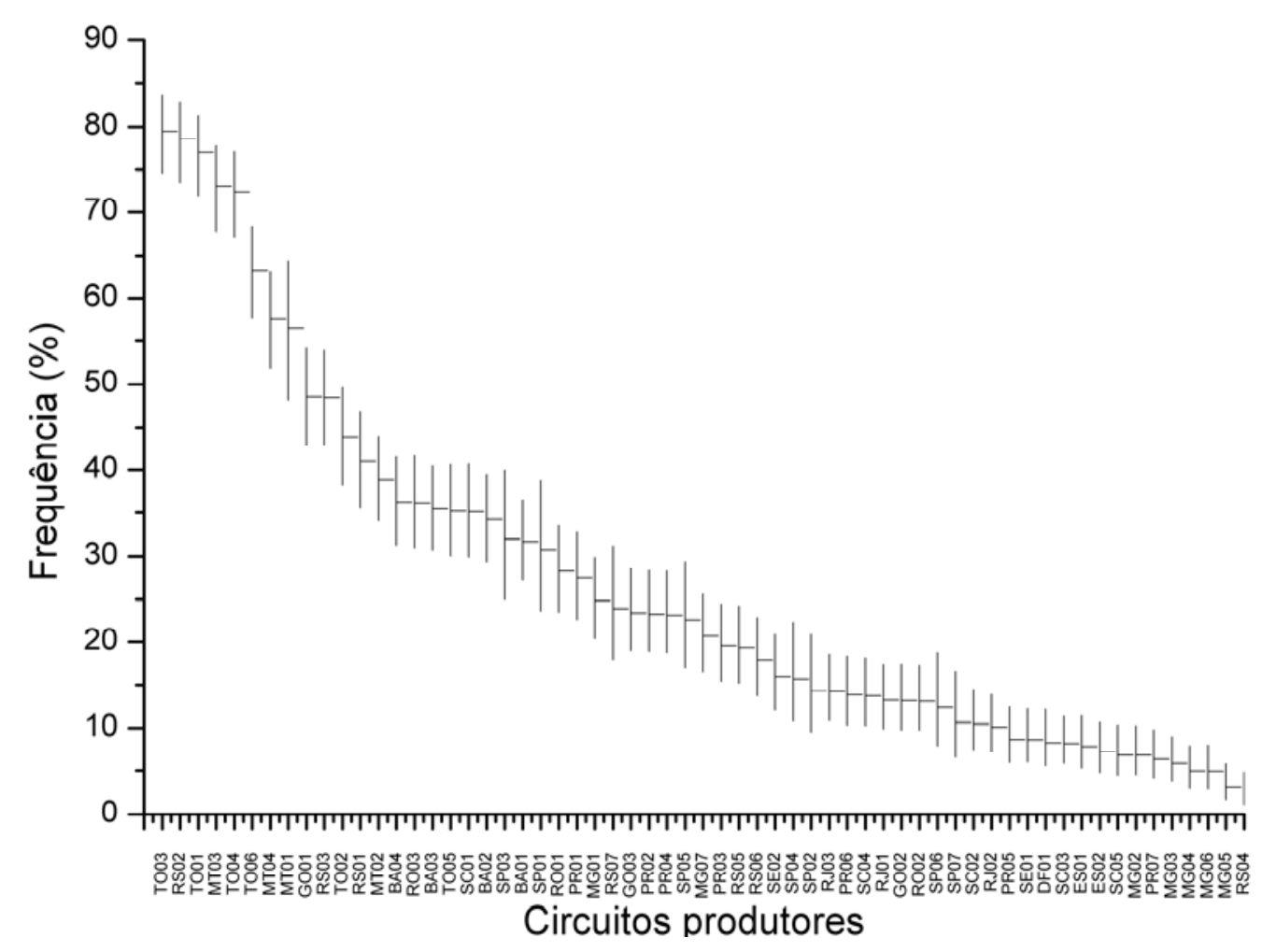

Gráfico 1- Distribuição decrescente das frequências pontuais de explorações de corte e dos seus respectivos intervalos de confiança de $95 \%$, segundo o circuito produtor- Brasil - out 2001-dez 2004

Este conjunto de valores demonstra a concentração de locais especializados em criações de gado de corte em algumas regiões específicas, principalmente em Mato Grosso, Tocantins e sudoeste do Rio Grande do Sul. No ano de 2006, estes três Estados juntos corresponderam por cerca de $24,35 \%$ do total de animais abatidos no país, gerando uma receita de aproximadamente 425 milhões de reais (IBGE, 2006a).

A importância da pecuária de corte em Mato Grosso e no sudoeste do Rio Grande do Sul (Campanha Gaúcha ou Pampa) são historicamente reconhecidas e geralmente identificadas pela pecuária extensiva praticada em grandes latifúndios (FONTOURA, 2000; RODRIGUES; BEZZI, 2005; SEVERO; MIGUEL, 2006; BONJOUR; FIGUEIREDO; MARTA, 2008), já a UF de Tocantins, apesar ter demonstrado altas frequências de especialização em produção de gado de corte, possuía o $12^{\circ}$ rebanho de bovinos do país no ano de 2004 (IBGE, 2004). Neste 
mesmo ano, o rebanho bovino brasileiro foi estimado em 204 milhões de cabeças (IBGE, 2004), atingindo nesta mesma época uma produção de cerca de 8,5 milhões de toneladas em equivalente carcaça de carne bovina (IBGE, 2005). Estes dados exprimem a importância do mercado da carne bovina para a economia brasileira destas UFs e demonstram o potencial de produtividade da pecuária de corte no país.

\subsubsection{Exploração leiteira}

As propriedades pecuárias em que a principal atividade econômica reside na exploração do leite, apresentaram-se com freqüências estaduais estimadas que variaram entre $14,70 \%$ [13,09\%; 16,47\%] no Tocantins e 56,36\% [54,20\%; 58,50\%] em Minas Gerais, sendo que em algumas UFs, como Minas Gerais $(56,36 \%$ [54,20\%; 58,50\%]), Rio de Janeiro (50,00\% [46,49\%; 53,51]) e Rio Grande do Sul (44,88\% [42,49\%; 47,31\%]), as proporções estimadas de propriedades leiteiras foram significativamente maiores do que os outros tipos de exploração (Mapa 6).

$\mathrm{Na}$ observação dos circuitos, as regiões que apresentaram freqüências de rebanhos leiteiros que superaram de maneira significativa as frequências médias em relação aos outros tipos de exploração estão localizadas nas regiões centro-sul, sudoeste, centro-oeste, Zona da Mata e Triângulo mineiros; norte e centro-sul fluminenses; região do norte central, centro ocidental e oeste paranaenses, Vale do Itajaí catarinense; nordeste e noroeste do Rio Grande do Sul e no centro-norte de Rondônia (Mapa 7).

No gráfico 2, estão dispostos em ordem decrescente, os valores pontuais das proporções de estabelecimentos leiteiros e seus respectivos intervalos de confiança de $95 \%$ encontrados em cada circuito produtor. 


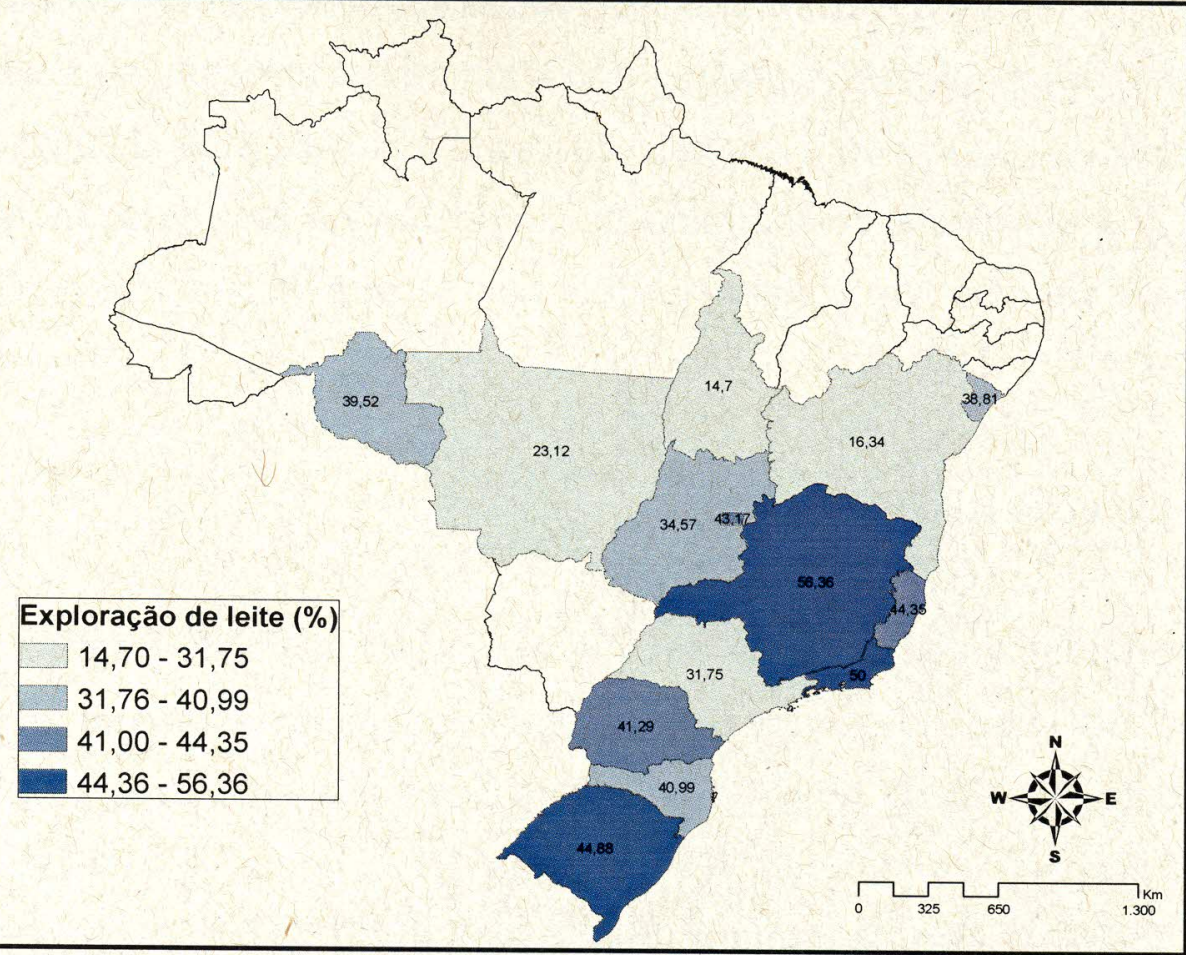

Mapa 6 - Distribuição das frequências estimadas de exploração de leite nos Estados- Brasil - out 2001-dez 2004

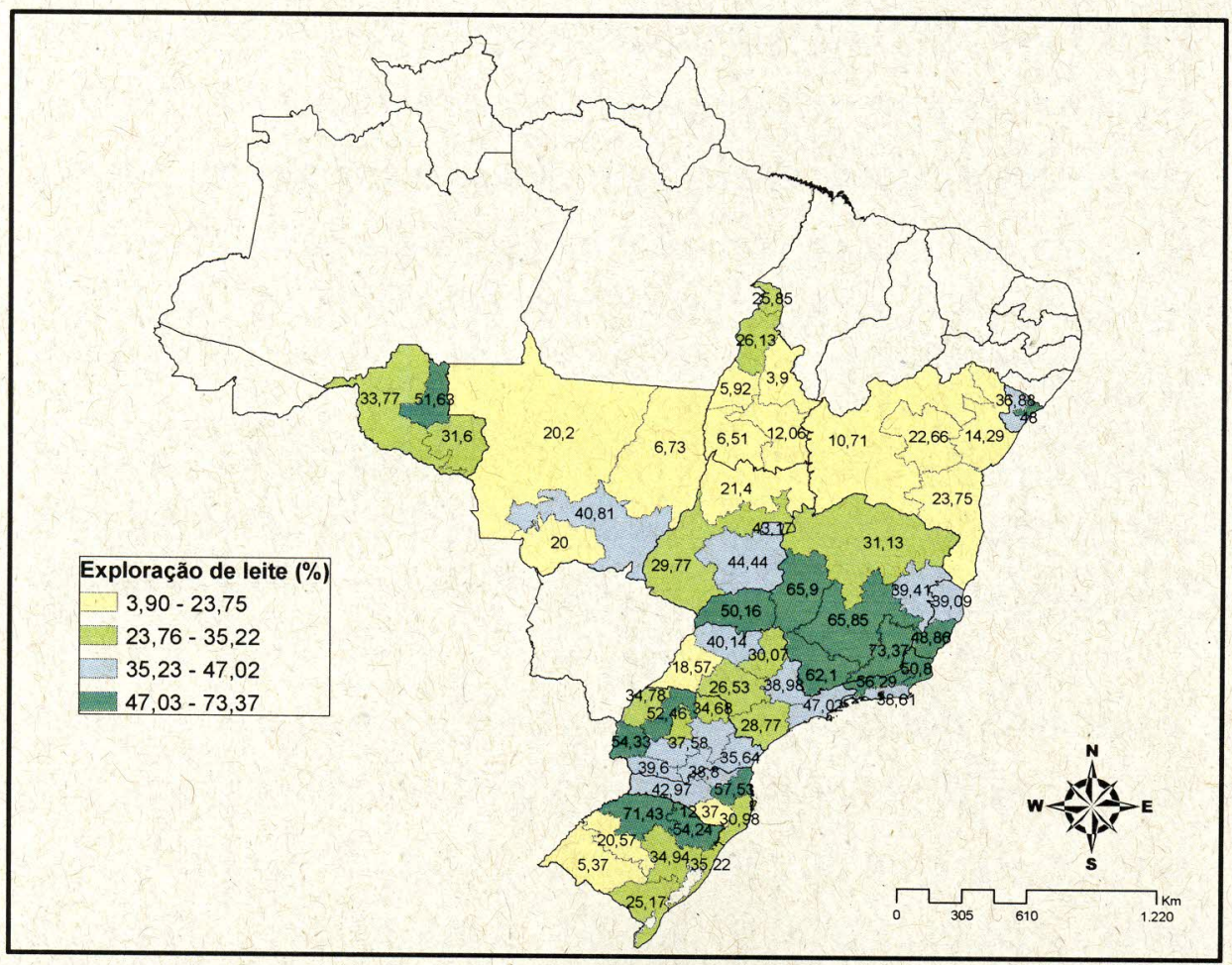

Mapa 7- Distribuição das frequências estimadas de exploração de leite nos circuitos- Brasil - out 2001-dez 2004 


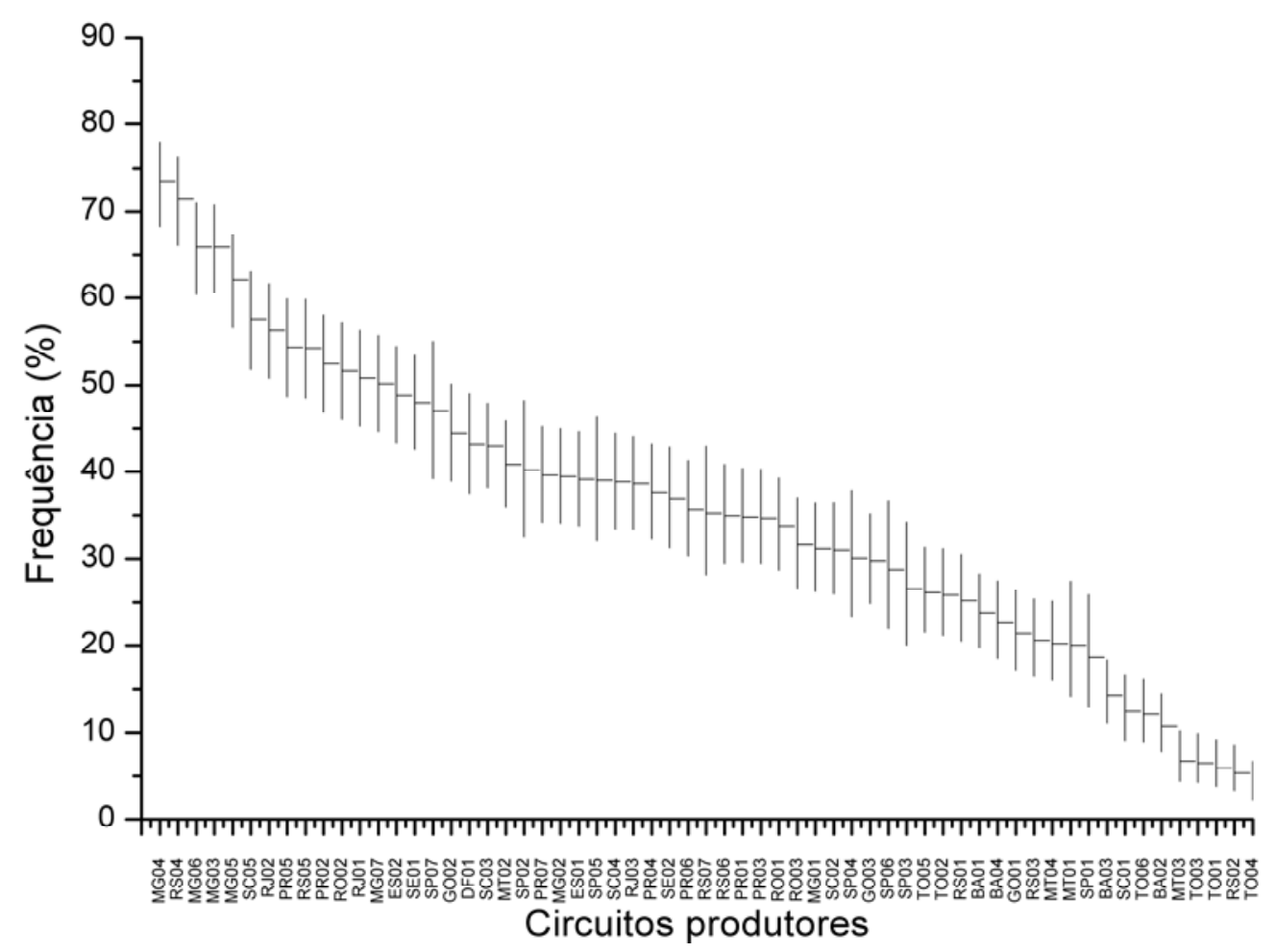

Gráfico 2- Distribuição decrescente das frequências pontuais de explorações de leite e dos seus respectivos intervalos de confiança de 95\%, segundo o circuito produtor- Brasil - out 2001-dez 2004

A pecuária leiteira demonstra a cada ano a sua importância no desenvolvimento econômico e social do país. A produção total de leite no país em 2004, foi estimada em 23,5 bilhões de litros, gerando uma receita em torno de $R \$ 11$ bilhões (IBGE, 2004). Em 2008, estimou-se que a produção total de leite foi de aproximadamente 27,6 bilhões de litros gerando uma receita de próxima de $R \$ 17$ bilhões (IBGE, 2008). O Brasil segue como sendo o $6^{\circ}$ maior produtor de leite do mundo (FAO, 2007), respondendo por mais de 60\% do volume total de leite produzido pelos países que compõem o Mercosul e crescendo a uma taxa média anual de $4 \%$, sendo esta superior a de todos os outros países que ocupam os primeiros lugares de produtividade (ALENCAR; POTT, 2003).

Ferreira e Lopes (2002) descrevem importância histórica da cadeia leiteira em Minas Gerais, estando ela presente por todo o seu território, gerando empregos e excedentes comercializáveis e representando uma importante fonte de renda para boa parte da população. A tradição da exploração leiteira em Minas é claramente reconhecida, principalmente nas regiões do centro-sul do Estado. A aptidão mineira em produzir leite pode ser observada nas estimativas do ano de 2004 , onde dos 23,5 milhões de litros de leite produzidos pelo país no ano, Minas Gerais contribuiu 
isoladamente com aproximadamente $28 \%$ desta produção (REIS; MEDEIROS; MONTEIRO, 2001; IBGE, 2004).

Todavia, Minas Gerais não se apresenta como o único pólo de exploração leiteira no país. Os resultados encontrados neste trabalho se assemelham às descrições feitas por Zoccal et al. (2006) ao caracterizar a pecuária leiteira nas diversas microrregiões do país. Os autores observaram que boa parte das concentrações de vacas ordenhadas e de densidade de produção leiteira no Brasil, localiza-se na faixa que se estende do noroeste do Rio Grande do Sul, passam pelo oeste de Santa Catarina e chega ao Oeste do Paraná; nas regiões centrais e do sul de Minas Gerais; região de São José do Rio Preto em São Paulo; centro-sul goiano; centro-sul fluminense e norte do Rio; leste rondoniense e algumas regiões espíritosantenses.

\subsubsection{Exploração mista}

As estimativas das proporções estaduais de rebanhos mistos variaram entre $21,46 \%$ [18,82\%; 24,36] no Mato Grosso e 49,38\% [46,66\%; 52,11\%] na Bahia, sendo que as UFs onde os este tipo de exploração foram significativamente superiores em relação às outras formas foram, além da Bahia (49,38\% [46,66\%; 52,11\%]), o Estado de Santa Catarina (48,22\% [45,37\%; 51,07\%]) (Mapa 8).

Os circuitos produtores onde as explorações mistas demonstraram predominância em relação às outras, foram observados na região centro-sudoeste de Goiás; Vale do Mucuri e norte de Minas Gerais; centro-sul, região oeste e do Vale do Rio São Francisco e nordeste da Bahia; região centro-norte do Espírito Santo; nas mesorregiões paulistas de Presidente Prudente, Ribeirão Preto/Araraquara e do litoral sul; no sudoeste, sudeste e região de Curitiba no Paraná; região Serrana e sul de Santa Catarina e na porção centro-oriental do Rio Grande do Sul (Mapa 9).

No gráfico 3, estão dispostos em ordem decrescente, os valores pontuais das proporções de estabelecimentos de exploração mista e seus respectivos intervalos de confiança de $95 \%$ encontrados em cada circuito produtor. 


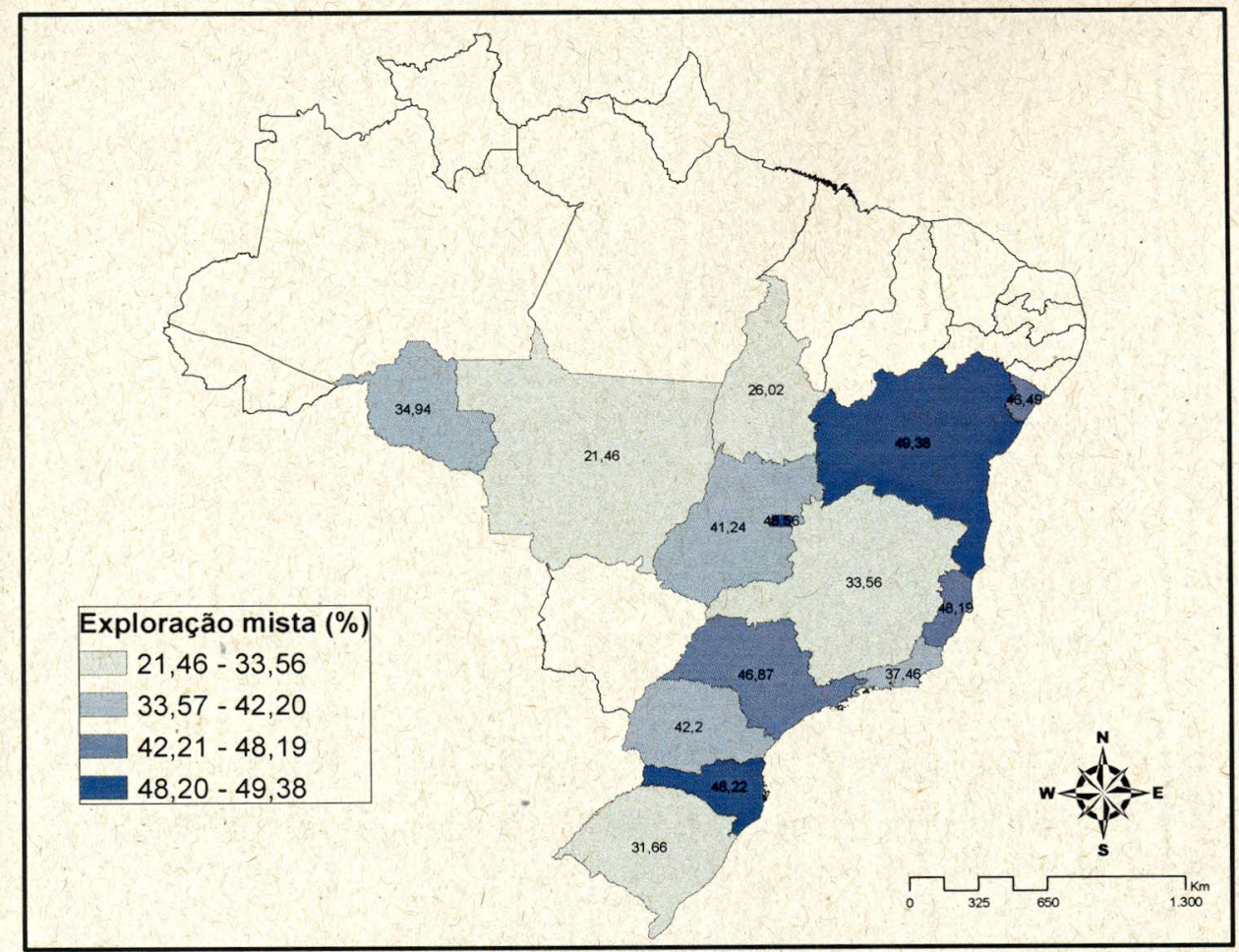

Mapa 8- Distribuição das frequências estimadas de exploração mista (corte e leite) nos Estados- Brasil - out 2001-dez 2004

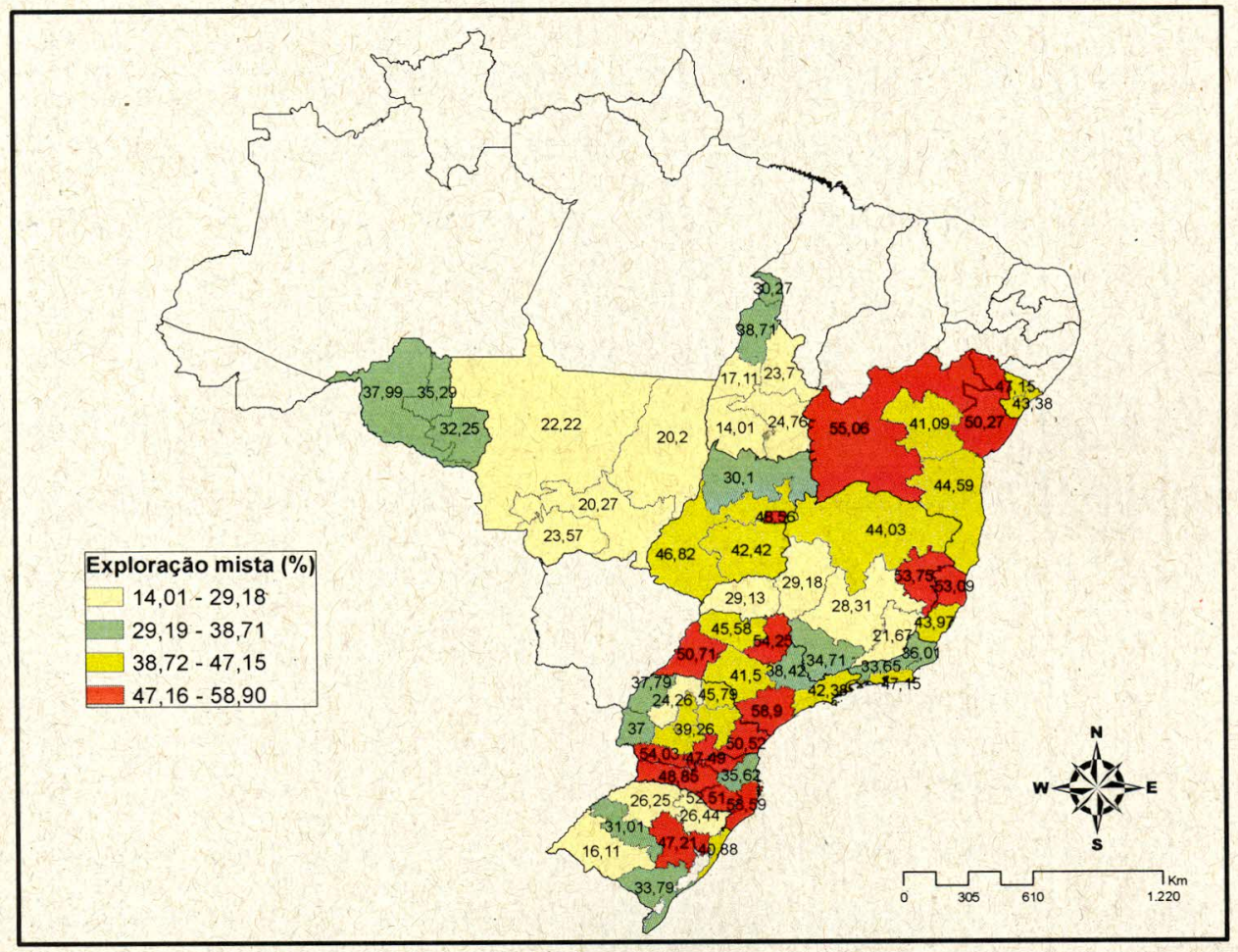

Mapa 9- Distribuição das frequências estimadas de exploração mista (corte e leite) nos circuitos- Brasil - out 2001-dez 2004 


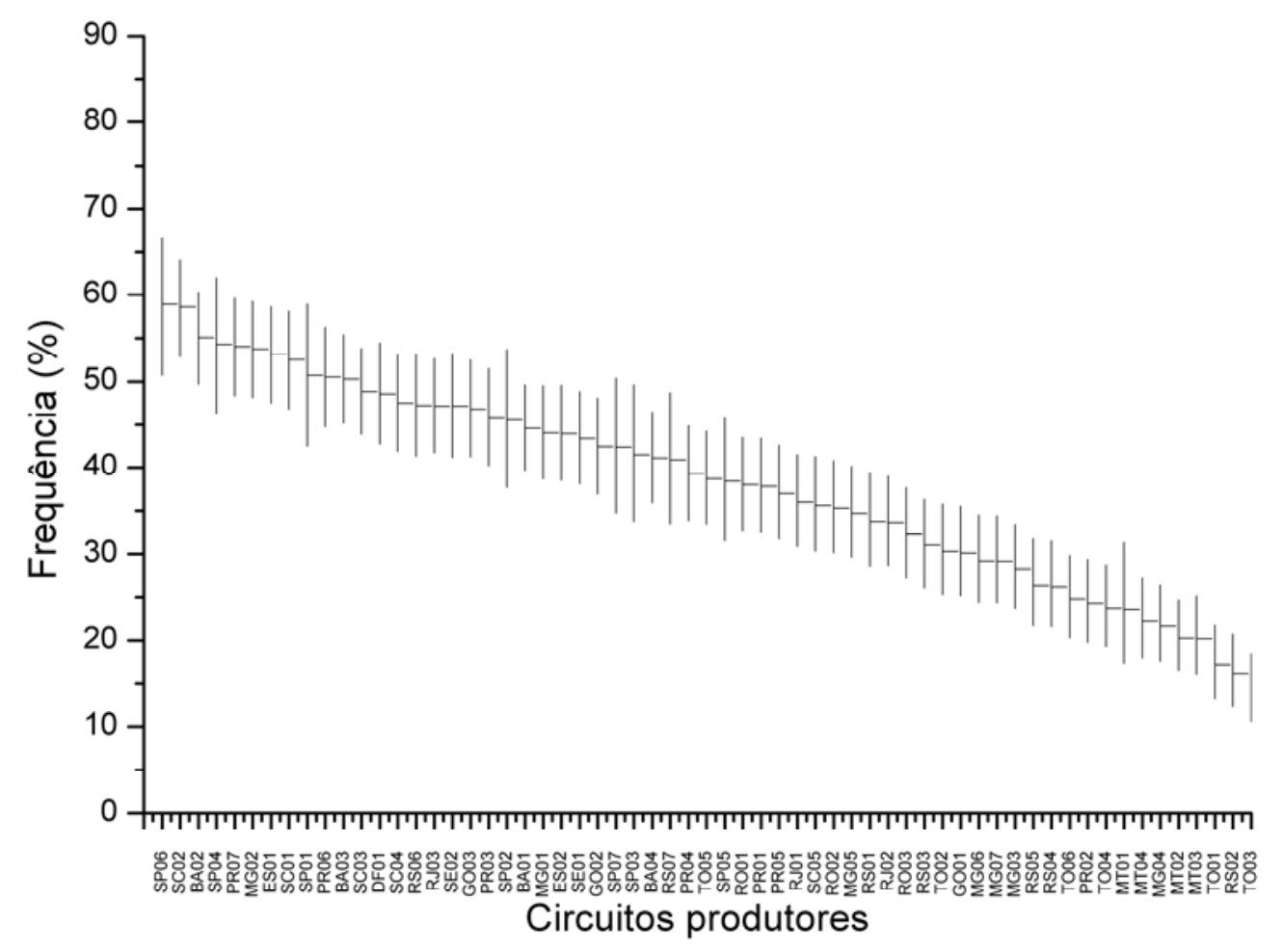

Gráfico 3- Distribuição decrescente das frequências pontuais de explorações mistas e dos seus respectivos intervalos de confiança de 95\%, segundo o circuito produtor- Brasil - out 2001-dez 2004

Conforme observado, as frequências estaduais e por circuito produtor de criações de duplo propósito algumas vezes superaram as proporções de rebanhos especializados em corte ou leite. Madalena (1986) considera que as explorações mistas são as predominantes na América Latina tropical. Uma das vantagens destes sistemas segundo Barbosa e Bueno (2000), seria a flexibilidade para regular a produção tanto de leite quanto de carne e derivados segundo as flutuações dos preços relativos de ambos os produtos. Os mesmos autores estimam que $25 \%$ de todo o leite produzido no Brasil provêm de propriedades mistas, proporção esta que é crescente quanto mais se avança para os Estados do Norte e Centro-Oeste do país.

Apesar dos sistemas de duplo propósito e a diversificação da produção muitas das vezes serem considerados indicativos de atraso em relação à pecuária especializada, alguns trabalhos como os de Holman (1998), Holanda Jr. e Gomes (1999) e Madalena (2001b), demonstram que estes sistemas podem ser rentáveis economicamente, e em alguns casos até mais vantajosos do que criações especializadas, onde os investimentos muitas das vezes superam os lucros obtidos. 


\subsubsection{Composição dos rebanhos}

O conjunto de dados forneceu informações relevantes a respeito do tamanho e composição dos rebanhos por sexo e idade dos animais. Os resultados das análises dos tamanhos de rebanho e das suas composições por sexo e faixa etária estão presentes na tabela 5. Os dados também foram estratificados por tipo de exploração para possibilitar uma melhor compreensão sobre elas.

Tabela 5 - Tamanho e composição dos rebanhos segundo o tipo de exploração pecuária. Brasil

\begin{tabular}{|c|c|c|c|c|c|c|c|c|c|c|c|c|c|c|}
\hline & & & $\begin{array}{c}\text { Tamanho do } \\
\text { rebanho }\end{array}$ & $\begin{array}{l}\text { Total de } \\
\text { machos }\end{array}$ & $\begin{array}{l}\text { Total de } \\
\text { fêmeas }\end{array}$ & $\begin{array}{l}\text { Machos } \\
\text { castrados }\end{array}$ & $\begin{array}{c}\text { Machos } \\
0-6 \mathrm{~m}\end{array}$ & $\begin{array}{l}\text { Machos } \\
6-12 m\end{array}$ & $\begin{array}{c}\text { Machos } \\
12-24 m\end{array}$ & $\begin{array}{c}\text { Machos } \\
\text { acima } \\
24 \mathrm{~m}\end{array}$ & $\begin{array}{l}\text { Fêmeas } \\
0-6 \mathrm{~m}\end{array}$ & $\begin{array}{l}\text { Fêmeas } \\
6-12 \mathrm{~m}\end{array}$ & $\begin{array}{l}\text { Fêmeas } \\
12-24\end{array}$ & $\begin{array}{c}\text { Fêmeas } \\
\text { acima } \\
24 \mathrm{~m}\end{array}$ \\
\hline \multirow{7}{*}{$\begin{array}{l}\text { 峁 } \\
\text { 岀 } \\
\text { J }\end{array}$} & \multicolumn{2}{|c|}{ Média } & 155,73 & 51,23 & 103,67 & 18,13 & 9,45 & 14,14 & 16,81 & 11,92 & 9,88 & 15,32 & 19,25 & 68,13 \\
\hline & \multicolumn{2}{|c|}{ Mediana } & 42,00 & 9,00 & 30,00 & 0,00 & 3,00 & 3,00 & 1,00 & 1,00 & 3,00 & 4,00 & 5,00 & 19,00 \\
\hline & \multicolumn{2}{|c|}{ Mínimo } & 1,00 & 0,00 & 0,00 & 0,00 & 0,00 & 0,00 & 0,00 & 0,00 & 0,00 & 0,00 & 0,00 & 0,00 \\
\hline & \multicolumn{2}{|c|}{ Máximo } & 16669,00 & 9602,00 & 14890,00 & 4537,00 & 2000,00 & 3000,00 & 6035,00 & 3000,00 & 2000,00 & 3081,00 & 2910,00 & 14710,00 \\
\hline & \multirow{3}{*}{ 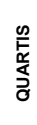 } & 25 & 15,00 & 3,00 & 10,00 & 0,00 & 1,00 & 0,00 & 0,00 & 1,00 & 1,00 & 1,00 & 1,00 & 6,00 \\
\hline & & 50 & 42,00 & 9,00 & 30,00 & 0,00 & 3,00 & 3,00 & 1,00 & 1,00 & 3,00 & 4,00 & 5,00 & 19,00 \\
\hline & & 75 & 116,00 & 26,00 & 84,00 & 2,00 & 7,00 & 10,00 & 5,00 & 3,25 & 8,00 & 12,00 & 15,00 & 52,00 \\
\hline \multirow{7}{*}{$\begin{array}{l}\text { w } \\
\text { 品 } \\
\text { o }\end{array}$} & \multirow{4}{*}{\multicolumn{2}{|c|}{$\begin{array}{c}\text { Média } \\
\text { Mediana } \\
\text { Mínimo } \\
\text { Máximo }\end{array}$}} & 363,77 & 122,43 & 238,22 & 44,65 & 18,98 & 31,16 & 36,37 & 25,53 & 19,48 & 32,72 & 40,04 & 159,69 \\
\hline & & & 103,00 & 20,00 & 73,00 & 0,00 & 4,00 & 5,00 & 1,00 & 2,00 & 4,00 & 8,00 & 10,00 & 47,00 \\
\hline & & & 1,00 & 0,00 & 0,00 & 0,00 & 0,00 & 0,00 & 0,00 & 0,00 & 0,00 & 0,00 & 0,00 & 0,00 \\
\hline & & & 16669,00 & 9602,00 & 14890,00 & 4537,00 & 2000,00 & 3000,00 & 6035,00 & 3000,00 & 2000,00 & 3081,00 & 2910,00 & 14710,00 \\
\hline & \multirow{3}{*}{$\begin{array}{l}\frac{n}{1} \\
\frac{\alpha}{4} \\
\text { ơ }\end{array}$} & 25 & 35,00 & 6,00 & 22,00 & 0,00 & 0,00 & 0,00 & 0,00 & 1,00 & 0,00 & 2,00 & 2,00 & 14,00 \\
\hline & & 50 & 103,00 & 20,00 & 73,00 & 0,00 & 4,00 & 5,00 & 1,00 & 2,00 & 4,00 & 8,00 & 10,00 & 47,00 \\
\hline & & 75 & 323,50 & 77,00 & 215,00 & 10,00 & 15,00 & 20,00 & 10,00 & 8,00 & 15,00 & 27,00 & 32,50 & 145,00 \\
\hline \multirow{7}{*}{ 唇 } & \multirow{4}{*}{\multicolumn{2}{|c|}{$\begin{array}{c}\text { Média } \\
\text { Mediana } \\
\text { Mínimo } \\
\text { Máximo }\end{array}$}} & 62,41 & 16,92 & 45,20 & 5,68 & 4,65 & 5,57 & 4,45 & 3,48 & 5,27 & 6,67 & 8,37 & 29,07 \\
\hline & & & 33,00 & 6,00 & 24,00 & 0,00 & 2,00 & 2,00 & 0,00 & 1,00 & 3,00 & 4,00 & 3,00 & 15,00 \\
\hline & & & 1,00 & 0,00 & 0,00 & 0,00 & 0,00 & 0,00 & 0,00 & 0,00 & 0,00 & 0,00 & 0,00 & 0,00 \\
\hline & & & 2675,00 & 2518,00 & 1715,00 & 2240,00 & 293,00 & 196,00 & 894,00 & 1655,00 & 199,00 & 196,00 & 288,00 & 1206,00 \\
\hline & \multirow{3}{*}{ 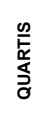 } & 25 & 13,00 & 2,00 & 10,00 & 0,00 & 1,00 & 0,00 & 0,00 & 1,00 & 1,00 & 1,00 & 1,00 & 6,00 \\
\hline & & 50 & 33,00 & 6,00 & 24,00 & 0,00 & 2,00 & 2,00 & 0,00 & 1,00 & 3,00 & 4,00 & 3,00 & 15,00 \\
\hline & & 75 & 75,00 & 15,00 & 57,00 & 2,00 & 6,00 & 7,00 & 3,00 & 2,00 & 7,00 & 8,00 & 10,00 & 35,00 \\
\hline \multirow{7}{*}{$\frac{O}{\frac{0}{2}}$} & \multicolumn{2}{|c|}{ Média } & 98,04 & 33,58 & 64,19 & 9,94 & 6,72 & 8,77 & 13,19 & 8,51 & 7,14 & 9,90 & 13,21 & 40,79 \\
\hline & \multicolumn{2}{|c|}{ Mediana } & 32,00 & 8,00 & 22,00 & 0,00 & 2,00 & 3,00 & 1,00 & 1,00 & 2,00 & 4,00 & 4,00 & 13,00 \\
\hline & \multicolumn{2}{|c|}{ Mínimo } & 1,00 & 0,00 & 0,00 & 0,00 & 0,00 & 0,00 & 0,00 & 0,00 & 0,00 & 0,00 & 0,00 & 0,00 \\
\hline & \multicolumn{2}{|c|}{ Máximo } & 7025,00 & 4314,00 & 2816,00 & 1263,00 & 500,00 & 1901,00 & 3700,00 & 1571,00 & 500,00 & 600,00 & 720,00 & 1903,00 \\
\hline & \multirow{3}{*}{$\begin{array}{l}\frac{n}{E} \\
\frac{\alpha}{4} \\
\text { ơ }\end{array}$} & 25 & 11,00 & 3,00 & 7,00 & 0,00 & 1,00 & 1,00 & 0,00 & 1,00 & 1,00 & 1,00 & 1,00 & 4,00 \\
\hline & & 50 & 32,00 & 8,00 & 22,00 & 0,00 & 2,00 & 3,00 & 1,00 & 1,00 & 2,00 & 4,00 & 4,00 & 13,00 \\
\hline & & 75 & 91,00 & 22,00 & 65,00 & 2,00 & 6,00 & 8,00 & 5,00 & 3,00 & 7,00 & 10,00 & 12,00 & 40,00 \\
\hline
\end{tabular}

No total geral de propriedades amostradas a mediana do tamanho do rebanho por propriedade foi de 42 , significando que $50 \%$ de todos os rebanhos amostrados, possuíam até 42 animais. O terceiro quartil demonstra que $75 \%$ dos estabelecimentos apresentavam até 116 bovinos. A média geral foi de 155,73 animais por propriedade, sendo que o menor rebanho amostrado possuía apenas 
um animal e o maior 16.669. O diagrama de caixas (boxplot) demonstra estes contrastes entre os tamanhos de rebanhos dentro de cada UF. Nota-se que os maiores rebanhos do país encontram-se nos Estados do centro-oeste e norte do país (Mato Grosso, Goiás e Tocantins) (Gráfico 4).

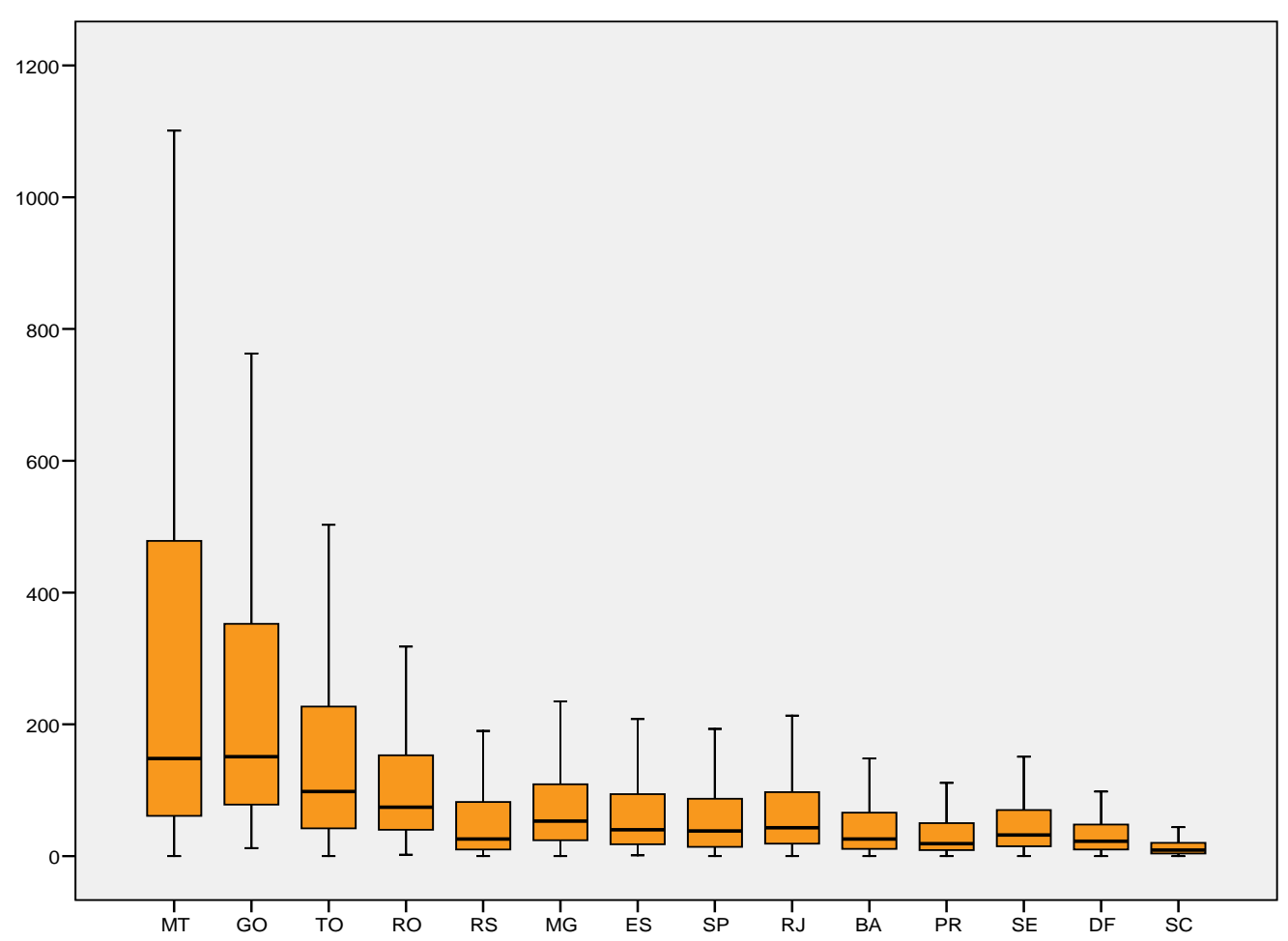

Gráfico 4- Diagrama de caixas do tamanho dos rebanhos segundo Unidade Federativa- Brasil - out 2001-dez 2004

No mapa 10, observam-se as medianas dos tamanhos de rebanhos distribuídas por circuito pecuário. Observa-se que o quartil de circuitos com os maiores valores de mediana estão presentes, na regiões Centro-oeste e Norte do país e no Rio Grande do Sul nas regiões do sudoeste e porção centro-ocidental do Estado. 


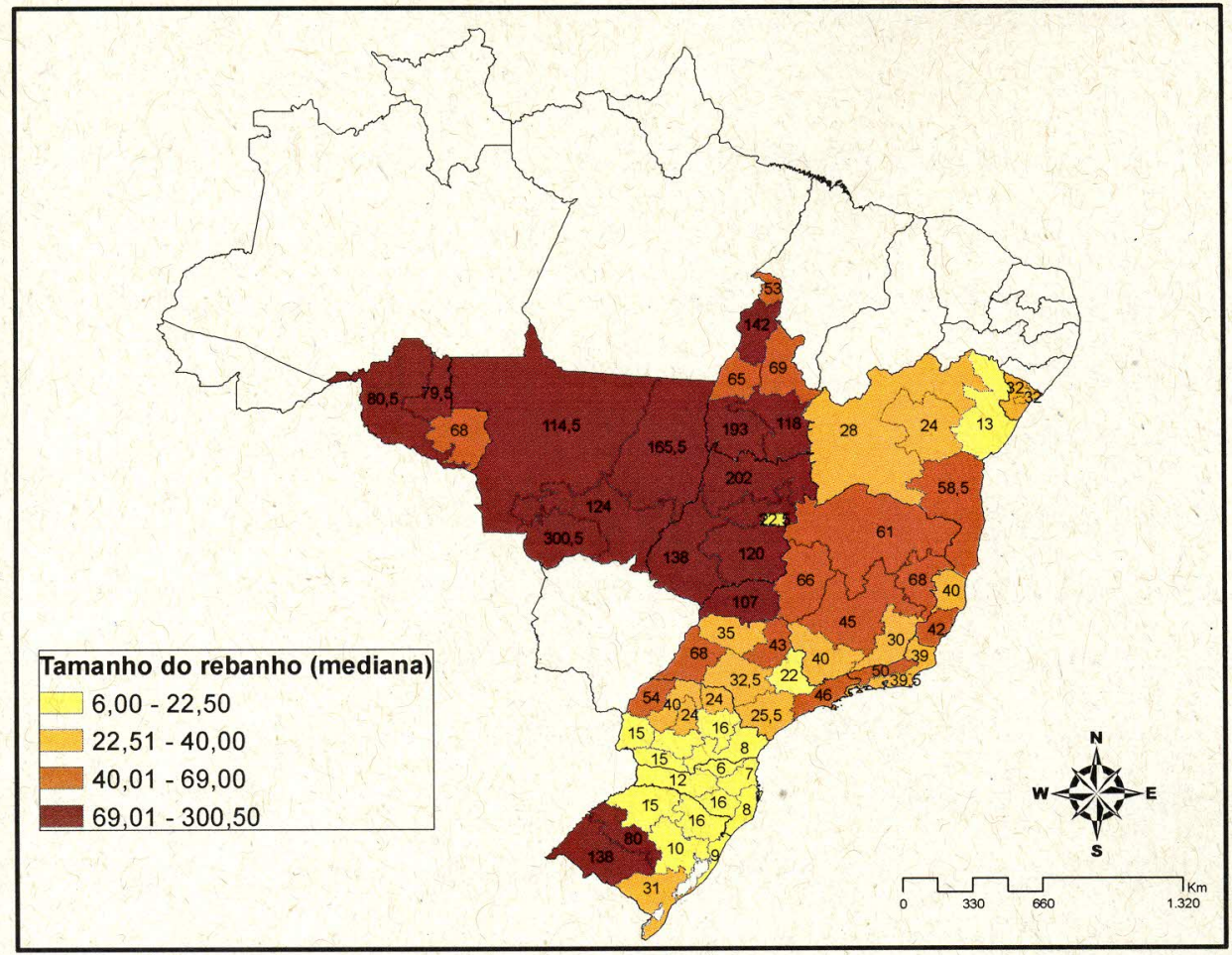

Mapa 10- Distribuição das medianas de tamanho dos rebanhos nos circuitos produtores- Brasil - out 2001-dez 2004

Os Estados de Mato Grosso e Goiás, apesar de terem demonstrado os maiores rebanhos, não figuram entre as UFs com maiores números de propriedades de exploração pecuária, sendo classificadas em 2006 como a $11^{\circ}$ e $9^{\circ}$ UFs em número de estabelecimentos, respectivamente. Isto sugere que a maior parte dos animais concentra-se em uma pequena parcela de propriedades. Estimativas do mesmo ano demonstraram que aproximadamente $20 \%$ das criações de bovinos no (àquelas com mais de 50 cabeças), eram responsáveis por $80,7 \%$ do rebanho total do país (IBGE, 2006a).

O coeficiente de Gini, utilizado pelo IBGE em 2006 para calcular desigualdades no uso das terras, corrobora com estas hipóteses ao demonstrar que as maiores desigualdades nas Distribuição de terras são encontradas nas regiões geográficas do Centro-Oeste e Nordeste do país, sendo que na primeira este processo vem acompanhando o processo de modernização produtiva e inserção no competitivo mercado mundial de commodities agrícolas e na segunda, ocorre devido a processos históricos de colonização. Em contrapartida, a região Sul do país constitui-se como o local com as menores desigualdades (IBGE, 2006a). 
4.1.2.1 Composição dos rebanhos de corte

Os rebanhos de exploração prioritária de corte demonstraram um tamanho de rebanho médio de 363,77 bovinos e uma mediana de 103 animais por estabelecimento. Estes rebanhos demonstraram ser significativamente maiores do que os rebanhos de leite e mistos pelo teste de Mann-Whitney $U(p=0,000)$, sendo que cerca de $75 \%$ das propriedades possuíam até 323,50 animais. Os maiores rebanhos foram observados nos Estados de Mato Grosso e Goiás (Gráfico 5).

A distribuição dos maiores tamanhos de rebanhos de corte demonstrou que 0 os Estados com os maiores valores foram o Mato Grosso e Goiás. Os quartil de circuito produtores com os maiores valores de medianas de tamanho de rebanho foram encontradas no extremo sul do país, em boa parte dos Estados do Centrooeste e Norte participantes, na mesorregião de Presidente Prudente em São Paulo e nas messoregiões fluminenses das baixadas e do Rio de Janeiro. O circuito que apresentou a maior mediana de tamanho de rebanho foi localizado na região centrosudoeste de Goiás, onde a mediana foi de 494,5 animais (Mapa 11).

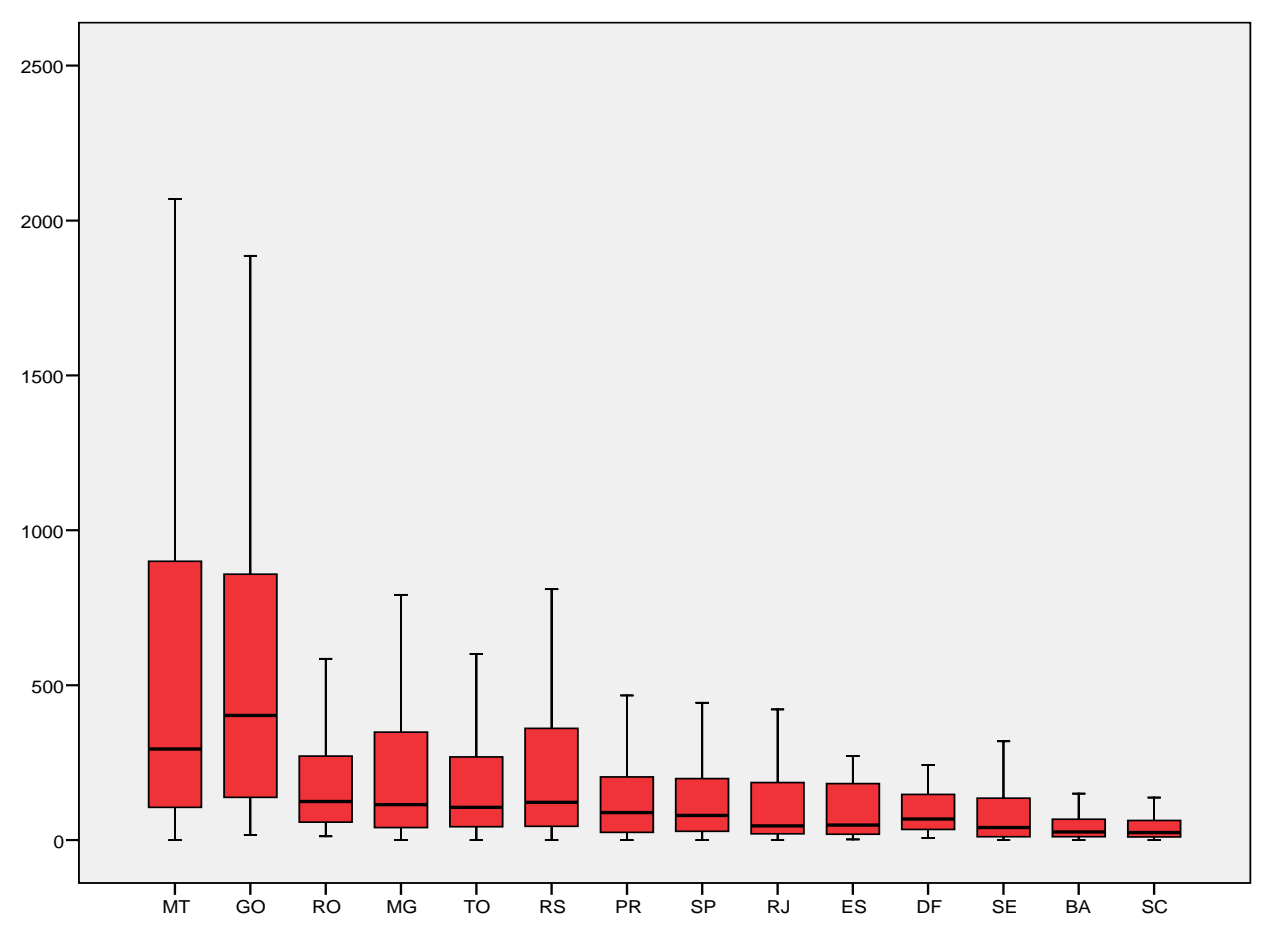

Gráfico 5- Diagrama de caixas do tamanho dos rebanhos de exploração de corte segundo a Unidade Federativa- Brasil - out 2001-dez 2004 


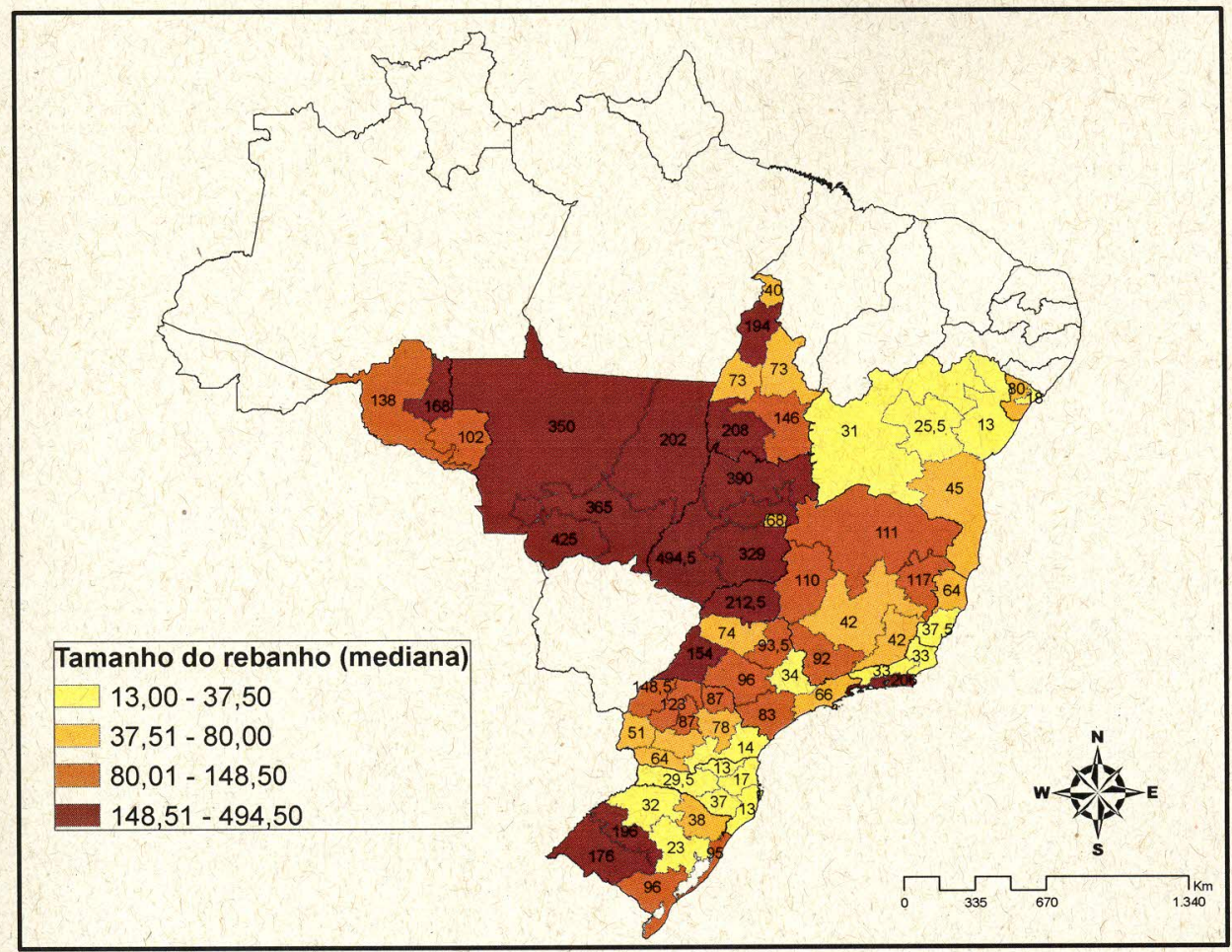

Mapa 11- Distribuição das medianas de tamanho dos rebanhos de corte nos circuitos- Brasil - out 2001-dez 2004

\subsubsection{Composição dos rebanhos de leite}

Os rebanhos exclusivamente leiteiros apresentaram uma média de 62,41 animais por estabelecimento e uma mediana de 32 animais. O maior rebanho encontrado dentre os estabelecimentos amostrados possuía 2.675 animais enquanto que o menor possuía apenas um. Este tipo de exploração apresentou valores significativamente menores de tamanho de rebanho em comparação com os outros tipos de exploração (corte e mistas) no teste estatístico de Mann-Whitney $U$ $(p=0,000)$.

Observa-se que os Estados de Goiás e Tocantins (Gráfico 6) apresentaram os maiores rebanhos leiteiros e o quartil superior circuitos pecuários com as maiores medianas de tamanho de rebanho foram encontrados em uma faixa que desce do extremo-norte Tocantinense até os circuitos do Triângulo Mineiro e centro-oeste de Minas Gerais; no sudeste e Pantanal matogrossenses; centro-sul da Bahia e nas regiões de Madeira-Guaporé e centro-norte rondonienses (Mapa 12). Isto demonstra um possível deslocamento destes rebanhos para as regiões centro-oeste e norte do pais. 


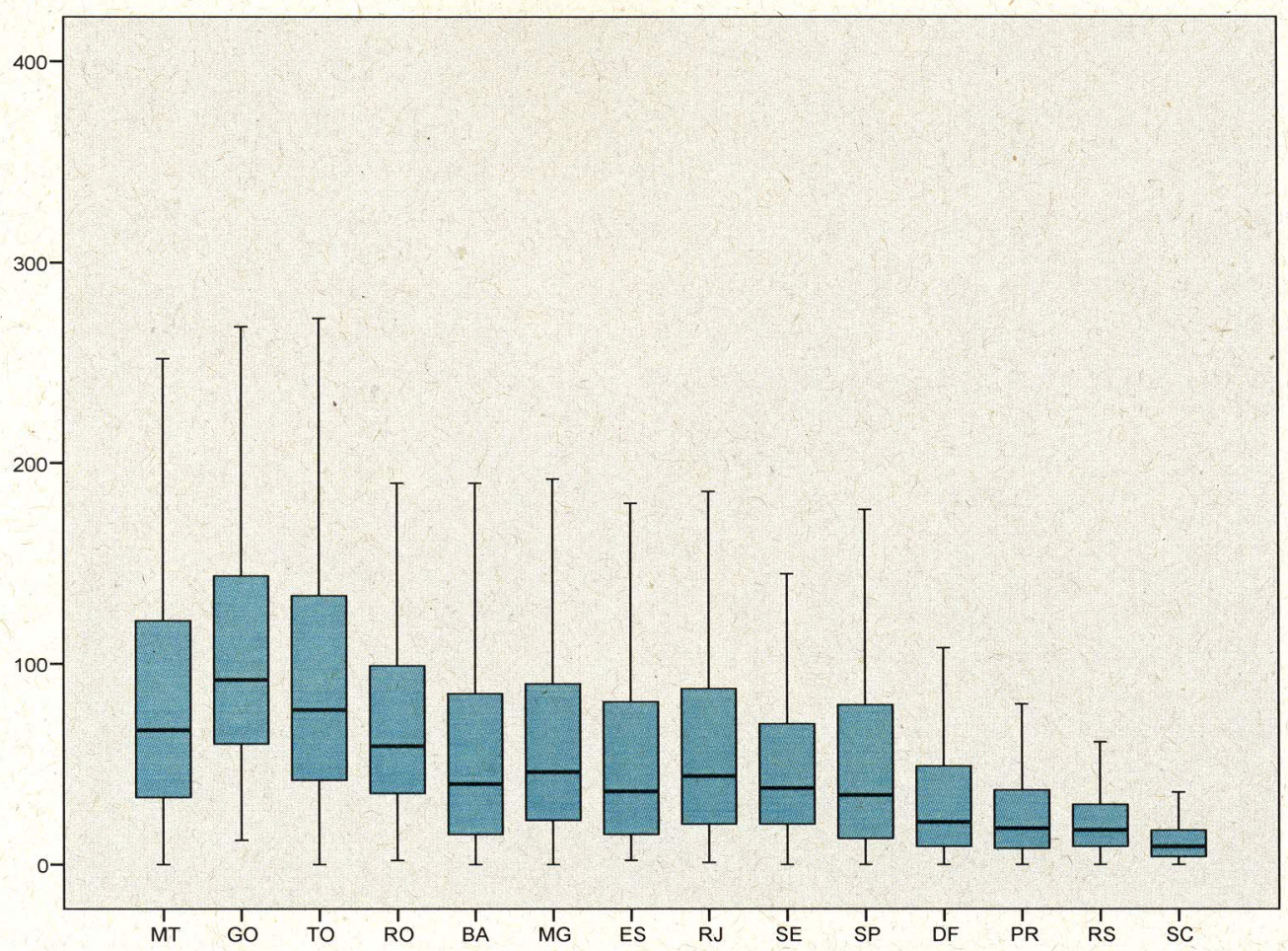

Gráfico 6- Diagrama de caixas do tamanho dos rebanhos de exploração de leite segundo a Unidade Federativa- Brasil - out 2001-dez 2004

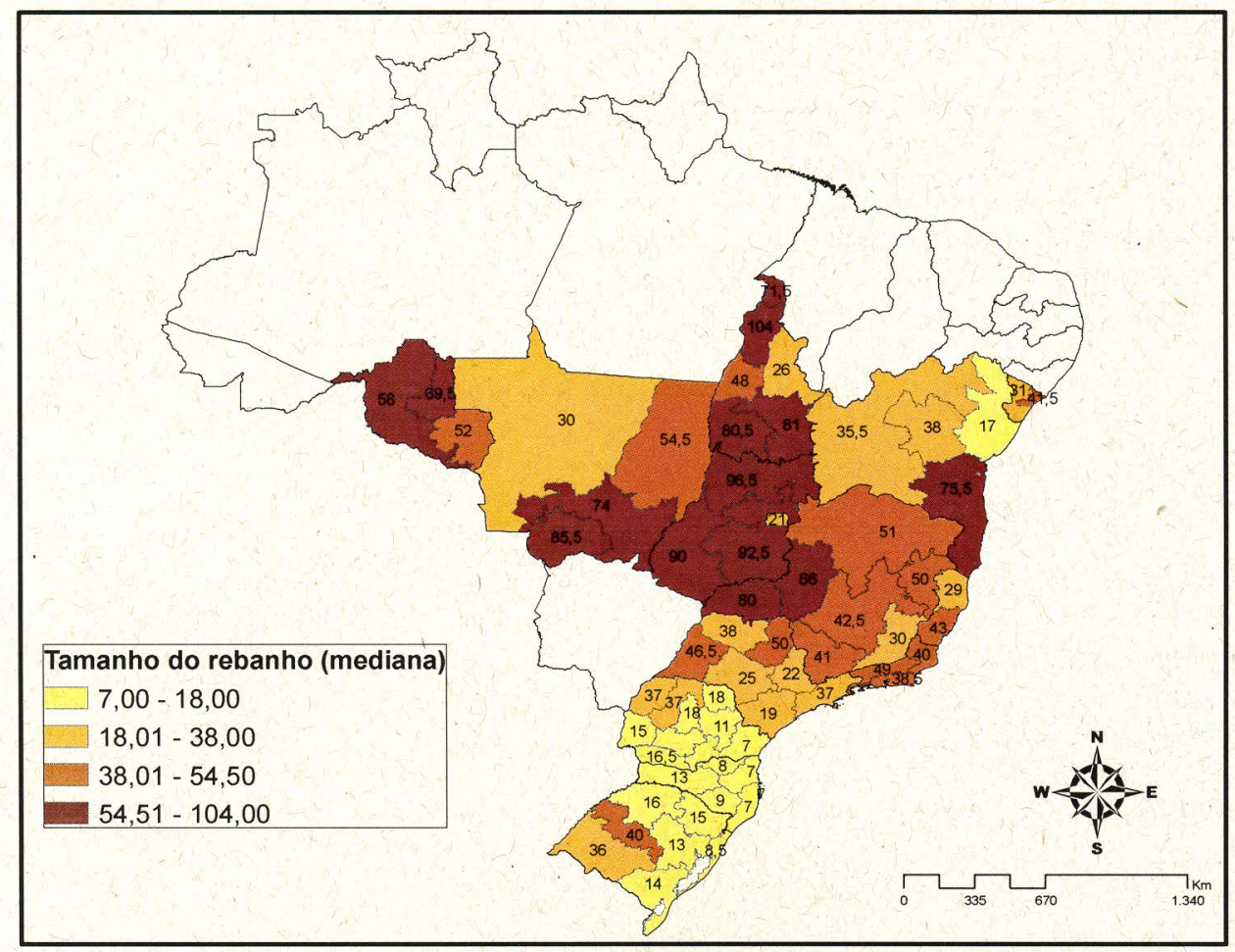

Mapa 12- Distribuição das medianas de tamanho dos rebanhos leiteiros nos circuitos- Brasil - out 2001-dez 2004

Estes dados sugerem que nas regiões do Centro-oeste os rebanhos leiteiros são explorados de maneira extensiva e em propriedades de grande porte, ao passo 
que nas tradicionais bacias leiteiras do país, presentes no centro-sul de Minas Gerais, oeste do Paraná e norte do Rio Grande do Sul, o leite é produzido, geralmente, em um grande número de propriedades de menor porte. Estimativas que corroboram com esta hipótese foram obtidas no ano de 2006, onde Minas Gerais e Goiás figuram como os dois Estados onde estão presentes os maiores números de vacas ordenhadas. Em contrapartida, os maiores números de propriedades que exploram o leite foram encontrados em Minas Gerais, Rio Grande do Sul e Paraná, sendo que o Estado de Goiás aparece no ranking como o $8^{\circ}$ colocado (IBGE, 2006a).

\subsubsection{Composição dos rebanhos mistos}

As propriedades de exploração mista, revelaram uma média de 98,04 animais por propriedade e uma mediana de 32 animais por estabelecimento pecuário. 0 rebanho misto que demonstrou o maior número de animais possuía 7.025 cabeças e o menor possuía apenas uma. Neste tipo de exploração os números de animais por rebanho demonstraram ser significativamente maiores que os rebanhos de leite e menores que os exclusivamente de corte no teste de Mann-Whitney $U(p=0,000)$.

O diagrama de caixas dos tamanhos de rebanhos mistos demonstra que as UFs de Goiás e Mato Grosso, concentraram os maiores números de animais por estabelecimento (Gráfico 7). Os circuitos pecuários que integraram o quartil superior de circuitos que apresentaram as maiores medianas de tamanho de rebanho foram encontrados em todas as regiões de Rondônia; no Pantanal, sudeste, centro e nordeste de Mato Grosso; todos os circuitos de Goiás, circuitos do sul e noroeste de Tocantins e região do Vale do Mucuri em Minas Gerais (Mapa 13). 


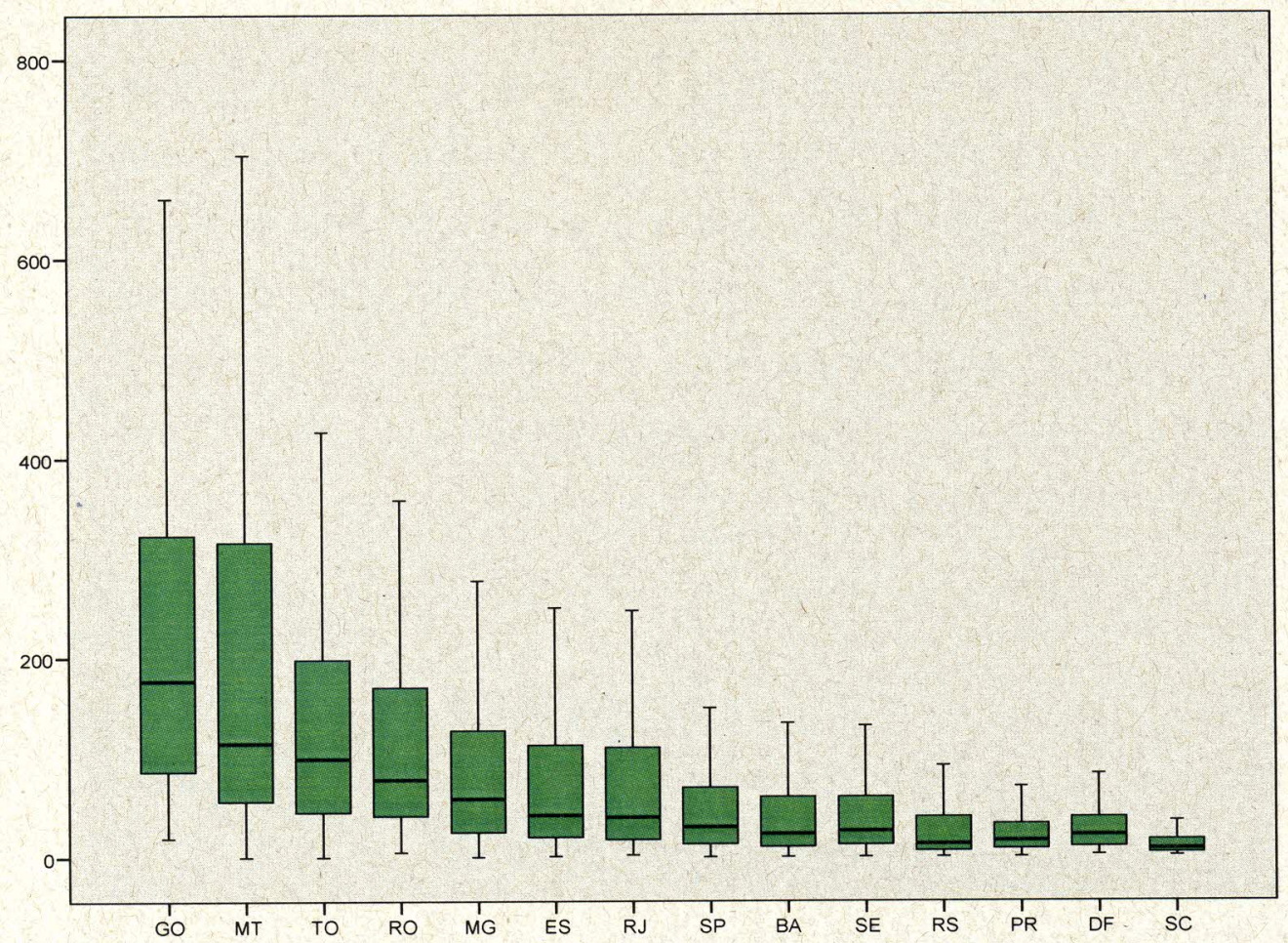

Gráfico 7 - Diagrama de caixas do tamanho dos rebanhos de exploração mista segundo a Unidade Federativa- Brasil - out 2001-dez 2004

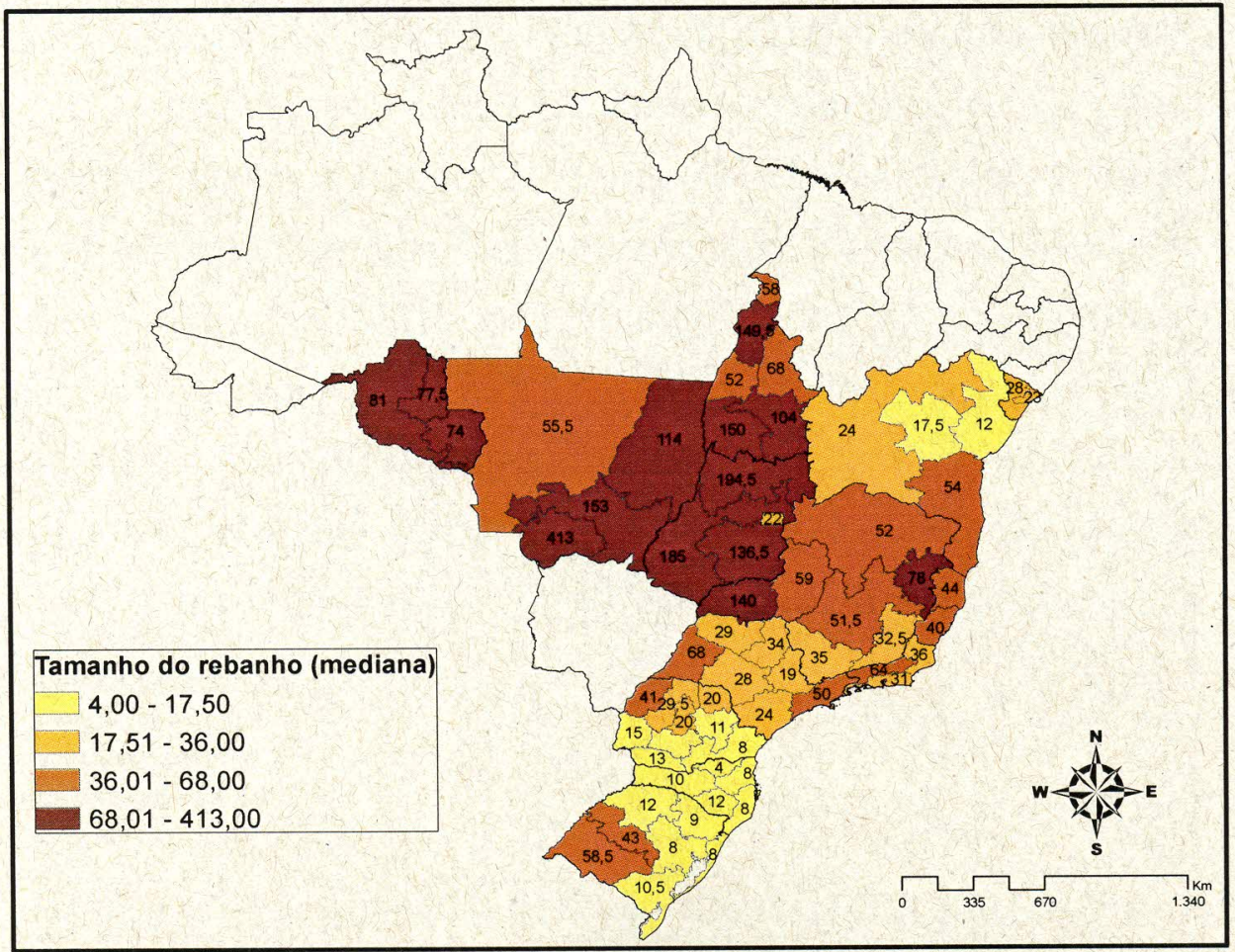

Mapa 13- Distribuição das medianas de tamanho dos rebanhos mistos nos circuitos- Brasil - out 2001-dez 2004 


\subsubsection{Sistemas de criação de bovinos}

$\mathrm{Na}$ intenção de realizar uma descrição dos sistemas de produção segundo o "regime alimentar" empregado nos rebanhos, optou-se por agrupar e classificar as proporções de utilização destes sistemas nos diversos circuitos. Para isto, foram considerados os sistemas: extensivos, semi-intensivos e em confinamento.

Um valor estimado de $75,51 \%$ [74,72\%; 76,28\%] das propriedades criam os animais extensivamente. Os sistemas de criação semi-intensivos, apresentaram-se em $23,87 \%$ [23,11\%; $24,65 \%]$ dos locais, enquanto que os sistemas intensivos (confinamentos), representaram uma pequena proporção do total de propriedades, com 0,62\% [0,49\%; 0,77\%] (Tabela 6).

Para avaliar os circuitos pecuários onde cada tipo de exploração é mais adotado, elaborou-se o diagrama ternário para fazer as comparações entre as proporções por região. No mapa 14 estão representados o diagrama e a predominância de tipo de criação por circuito pecuário. Observando o digrama e respeitando os respectivos intervalos de confiança de $95 \%$ das variáveis, foi possível verificar os circuitos onde ocorre a predominância de entre os tipos de criação.

Os resultados demonstraram que na maior parte das regiões os sistemas extensivos de criação são os mais adotados. Os locais onde os semi-confinamentos demonstraram ser utilizados com frequência significativamente maior do que os outros sistemas foram o Distrito Federal, Triângulo Mineiro e noroeste do Rio Grande do Sul. Nos circuitos do oeste paranaense, Vale do Ribeira paulista, centro-sul fluminense e no centro-sul mineiro não foram encontradas predominâncias entre um ou outro sistema, sendo que nestes locais as criações extensivas e em semiconfinamentos apresentaram proporções parecidas. Os confinamentos não demonstraram ser predominantes em nenhum dos circuitos produtores. 


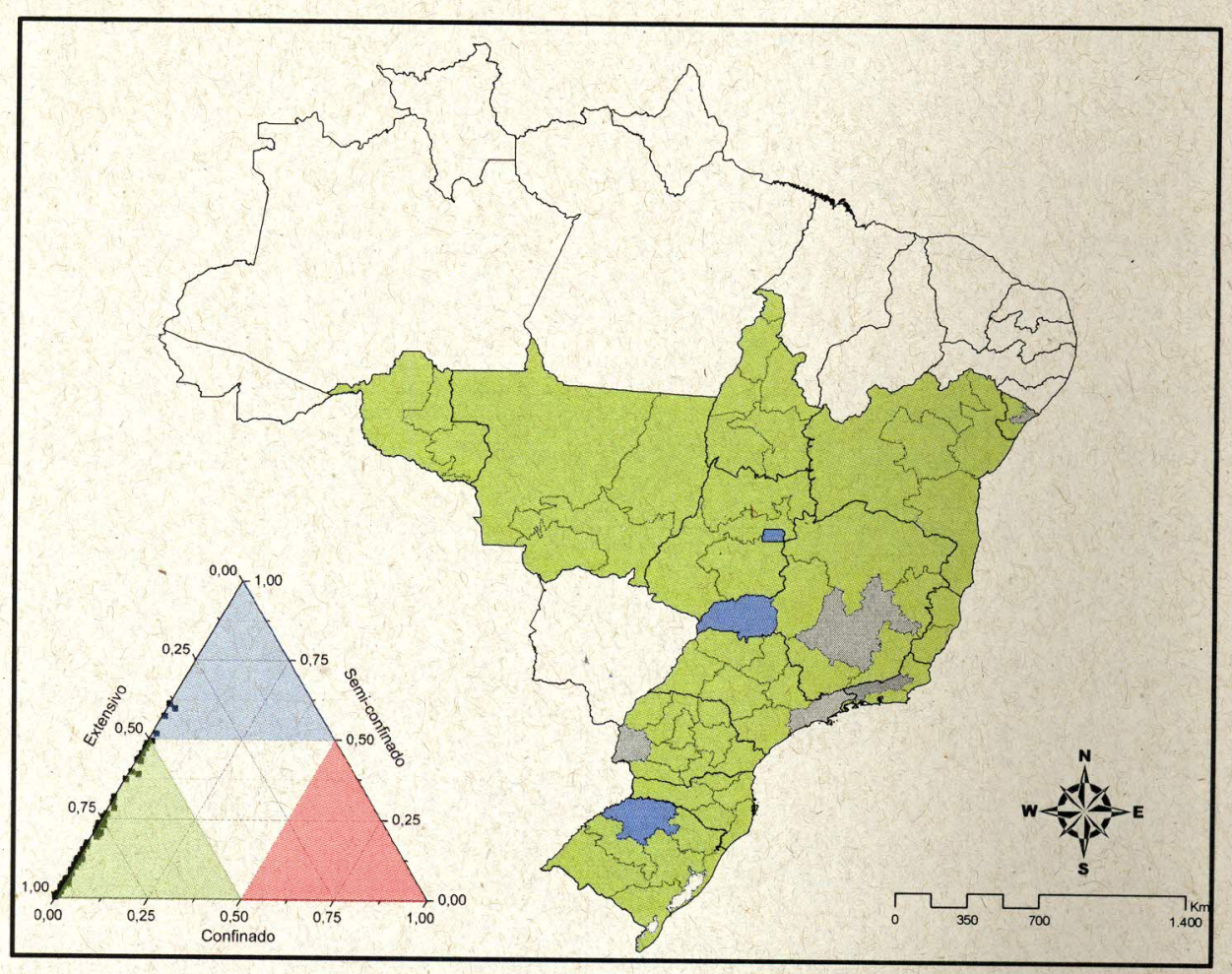

Mapa 14- Distribuição dos sistemas de criação predominantes nos circuitos pecuários- Brasil - out 2001-dez 2004

\subsubsection{Sistemas de criação e tipos de exploração}

Realizando uma análise comparativa entre os dados de sistemas de criação e os tipos de exploração, observou-se que a maior parte das propriedades de exploração de corte e mista, criam animais de maneira extensiva com 94,33\% [93,40\%-95,13\%] e $80,14 \%$ [74,72; 76,28] das criações, respectivamente. Em contrapartida, nos estabelecimentos especializados em produção de leite, este valor foi menor, sendo estimado em $58,61 \%$ [57,05\%; $60,15 \%]$ das propriedades. Os rebanhos exclusivamente leiteiros apresentaram as maiores proporções de criações semi-intensivas, sendo adotadas em 40,42\% [38,88\%; 41,98\%] das criações. Quanto ao confinamento de bovinos, todos os tipos de exploração demonstraram valores próximos ou inferiores a $1 \%$ (Tabela 6 ). 
Tabela 6- Distribuição das frequências estimadas de sistemas de criação de bovinos segundo os tipos de exploração- Brasil - out 2001-dez 2004

\begin{tabular}{ccccccccc}
\hline & \multicolumn{5}{c}{ Tipo de exploração } \\
\hline $\begin{array}{c}\text { Sistema de } \\
\text { criação }\end{array}$ & $\begin{array}{c}\text { Corte } \\
(\%)\end{array}$ & IC $95 \%$ & $\begin{array}{c}\text { Leite } \\
(\%)\end{array}$ & IC 95\% & Mista (\%) & IC 95\% & Total (\%) & IC 95\% \\
\hline $\begin{array}{c}\text { Intensivo } \\
\text { Semi- } \\
\text { intensivo }\end{array}$ & 0,55 & 0,$32 ; 0,92$ & 0,97 & 0,$73 ; 1,30$ & 0,30 & 0,$18 ; 0,52$ & 0,62 & 0,$49 ; 0,77$ \\
Extensivo & 94,33 & 93,$40 ; 95,13$ & 58,61 & 57,$05 ; 60,15$ & 81,41 & 80,$14 ; 82,61$ & 75,51 & 74,$72 ; 76,28$ \\
\hline Total (\%) & 100,00 & & 100,00 & & 100,00 & 17,$10 ; 19,55$ & 23,87 & 23,$11 ; 24,65$ \\
\hline
\end{tabular}

\subsubsection{Sistemas extensivos}

Estes sistemas são identificados através utilização exclusiva de pastagens (nativas e/ou cultivadas) como única fonte de alimentos energéticos e protéicos. Todavia, pelas deficiências inerentes às pastagens em determinados nutrientes, muitas vezes são fornecidos aos animais suplementação mineral (CEZAR et al., 2005).

As frequências estaduais de rebanhos criados de maneira extensiva, variaram de $38,13 \%$ [32,60\%; 43,99\%] no Distrito Federal chegando a 94,44\% [95,17\%; 97,38\%] no Estado de Rondônia (Mapa 15). Conforme observado anteriormente, as criações de gado extensivas apresentaram-se como o tipo de criação mais utilizado nos Estados, dentre os quais apenas na UF do Distrito Federal, este sistema não foi o predominante. As estimativas por circuito, apresentaram frequências entre 38,13\% [32,60\%; 43,99\%] no Distrito Federal e 99,67\% [97,71\%; 99,95\%] no centro-norte rondoniense, sendo que em boa parte dos circuitos o sistema extensivo de criação demonstrou ser adotado com altas frequências (mediana = 84,89\%) (Mapa 16).

No gráfico 8, estão dispostos em ordem decrescente, os valores pontuais das frequências de criações extensivas e seus respectivos intervalos de confiança de 95\% encontrados em cada circuito produtor. 


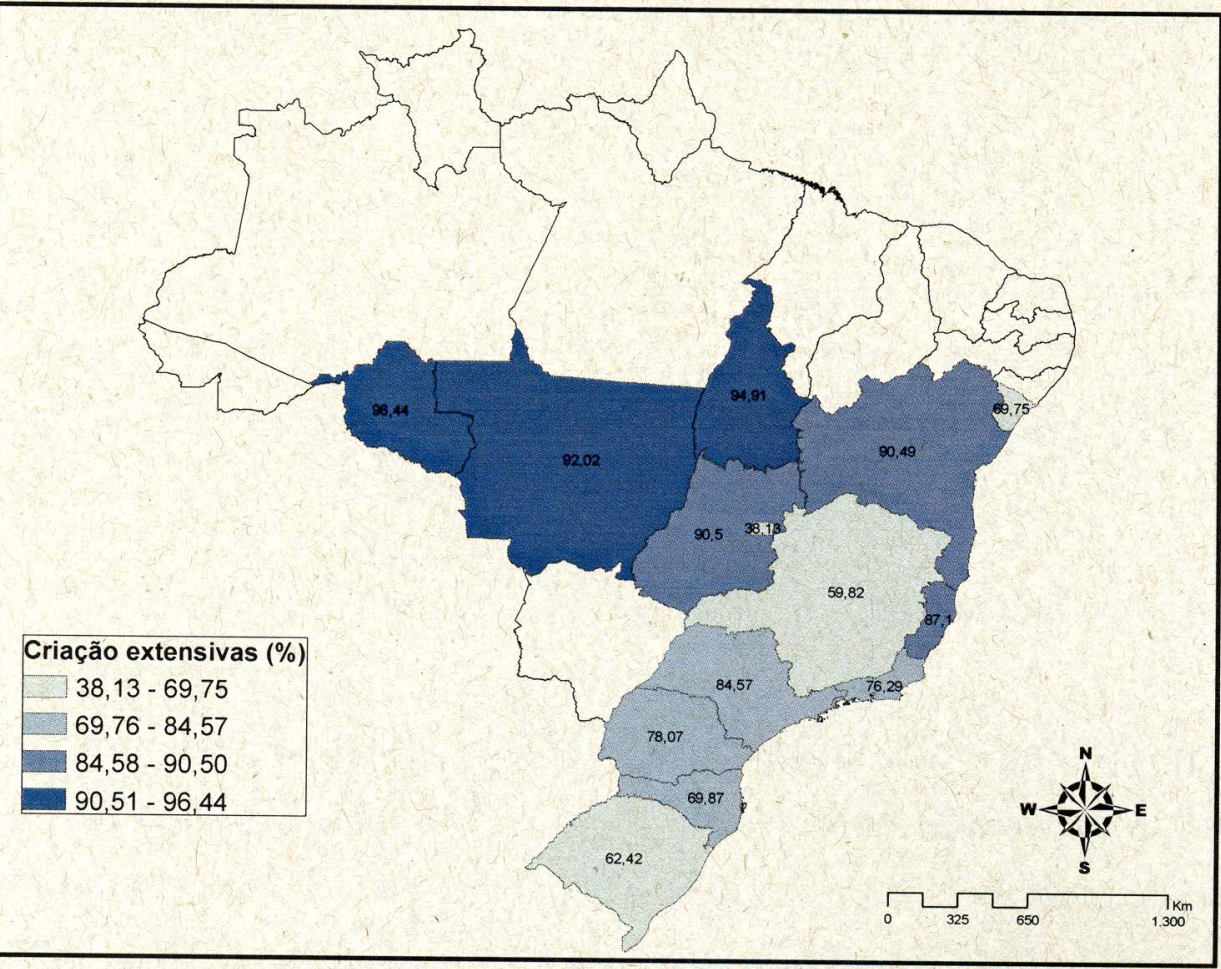

Mapa 15- Distribuição das frequências estimadas de sistemas extensivos de criação nos Estados- Brasil - out 2001-dez 2004

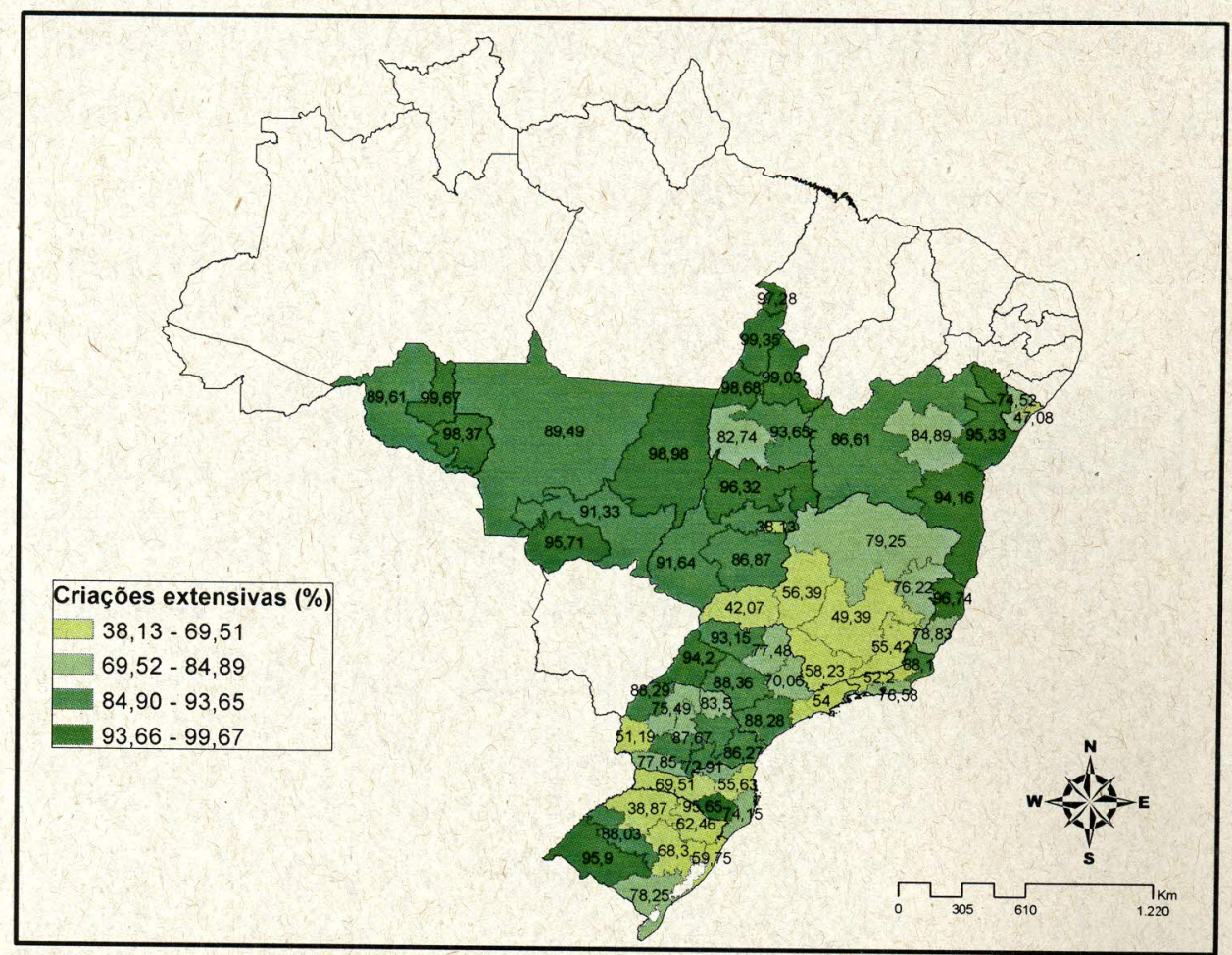

Mapa 16- Distribuição das frequências estimadas de sistemas extensivos de criação nos circuitos pecuários- Brasil - out 2001-dez 2004 


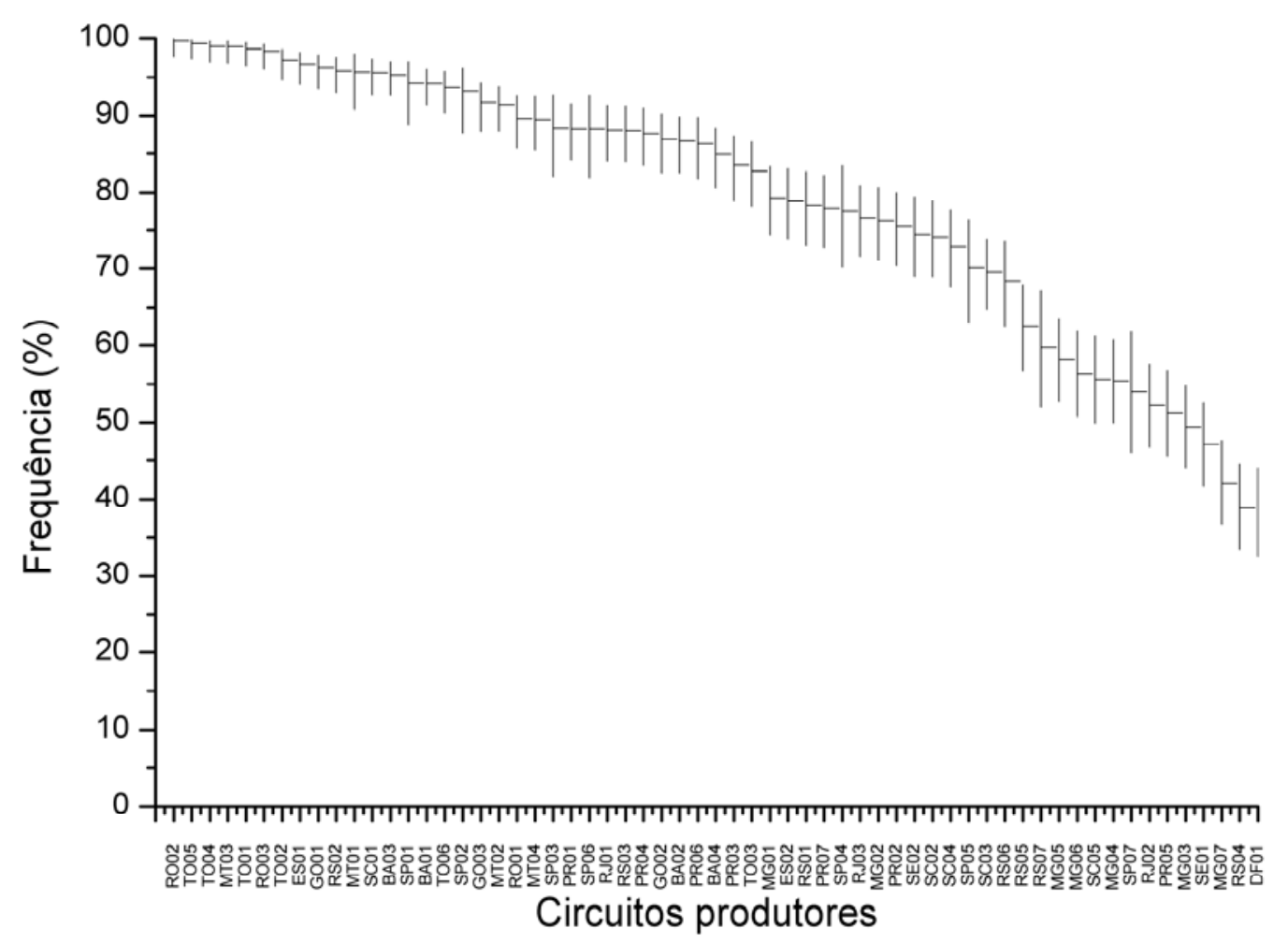

Gráfico 8- Distribuição decrescente das frequências pontuais e intervalos de confiança de 95\% de propriedades que utilizam sistemas extensivos na criação de bovinos nos circuitos produtores- Brasil - out 2001-dez 2004

O regime de criação de animais em pastagens se constitui na forma mais prática e econômica de alimentação de bovinos, sendo que o Brasil, pela extensão territorial e pelas condições climáticas favoráveis, apresenta enorme potencial de produção de carne em pastagens (ALENCAR; POTT, 2003).

Historicamente, a pecuária brasileira desenvolveu-se como uma atividade pioneira, ligada às ocupações fronteiriças. Os modelos de ocupação territorial adotados, em geral, apoiaram-se na intensa utilização da terra e dos recursos naturais prontamente disponíveis, desta forma constituindo-se em um modelo extrativista de produção. Ao longo do tempo, o desempenho da terra em função de preservar ativos fixos de reserva de valor terminou por elevar os seus preços, sendo assim, o modelo pecuário "boi-terra" acabou sendo encarado como uma forma de reserva de capital ao invés de uma atividade cuja remuneração econômica obtida através da produção, pudesse estimular o seu desenvolvimento e investimento em novas tecnologias (HELFAND; REZENDE 2003; BARIONI et al., 2006; BARCELLOS et al., 2008). Barioni et. al. (2006) comenta que desde a década de 70 a pecuária nacional avançou perante diversos conflitos de ordem política e econômica e sugere 
que a sociedade agropecuária, diante destas incertezas, a atividade pecuária encontrou nos sistemas de criação extensivos um ambiente seguro de produção em função do seu baixo risco e sua liquidez.

As pastagens do país se apresentam basicamente de duas maneiras: na forma nativa ou cultivada. As formas nativas, ainda possuem um significado econômico expressivo para a produção pecuária, sendo estimadas em algumas estatísticas do ano de 2006 em aproximadamente 57.316.457 de hectares (IBGE, 2006b). Estas pastagens apresentam, em geral, valores nutritivos baixos, alta variabilidade e proporcionam uma baixa capacidade de suporte aos animais comparativamente às pastagens cultivadas de boa qualidade. Por este motivo, ao longo dos anos estas pastagens vêm sendo substituídas por áreas cultivadas, as quais apresentam características superiores em produtividade e qualidade quando manejadas adequadamente. Estas forrageiras apresentaram um incremento de área em torno a $300 \%$ nos último 30 anos. A quantidade estimada destas pastagens no ano de 2006 foi de 101,4 milhões de hectares (63,9\% da área total de pastagens) (O'DONOVAN, 1979; CEZAR et al., 2005, ZIMMER; BARBOSA, 2005).

Uma possível vantagem competitiva da pecuária extensiva sob o aspecto da sustentabilidade, seria a capacidade de fixação de carbono pelas pastagens. Considerando que as atividades de produção animal convivem com ônus dos impactos ambientais e sua inter-relação com a emissão de gases causadores do efeito estufa (GEE), diversos trabalhos têm surgido na intenção de estudar a capacidade de seqüestro de GEE em pastagens bem manejadas (SOUZA et al., 1997; HUMPHREYS, 1994; MONTENEGRO; ABARCA, 2000; LIMA, 2002; BODDEY; ALVES; URQUIAGA; 2004; ZIMMER; BARBOSA, 2005; CERRI; EASTER; PAUSTIAN; 2007; PAIVA; FARIA, 2007; FORNARA; TILMAN, 2008; SALTON; MIELNICZUK; BAYER, 2008; BARCELLOS et al., 2008; NICOLOSO et al., 2008). Tendo em vista a área de pastagens e a proporção dos sistemas de criação extensivos no país, se explorada de maneira coerente, esta característica poderia ser utilizada como uma maneira de agregar tanto valor quanto uma melhor imagem ao excedente produzido. 


\subsubsection{Sistemas semi-intensivos}

Assim como nos sistemas extensivos, nos sistemas semi-intensivos as pastagens continuam representando a base da alimentação dos animais, contudo, neste caso são utilizadas fontes adicionais para a suplementação protéica e energética do rebanho, podendo ser citados aqui alguns alimentos concentrados como o milho, sorgo, aveia, milheto, farelo de soja, farelo de algodão, uréia, farelos de glúten de milho e grãos de soja. Em certos locais, dependendo da disponibilidade, alguns criadores optam pela utilização de subprodutos agroindustriais (farelo de arroz, farelo de trigo, casquinha de soja, polpa cítrica) ou resíduos (de cervejaria, fábricas de fécula, secagem de grãos). O objetivo primordial da utilização deste sistema é o alcance de uma pecuária de ciclo mais curto através da suplementação dos animais em suas diversas fases de crescimento, dependo das metas produtivas pretendidas (CEZAR et al., 2005).

O Distrito Federal foi a UF onde o sistema semi-intensivo de criação superou significativamente os demais, estando presente em $(59,71 \%[53,83 \% ; 65,33])$ das criações. Minas Gerais e Rio Grande do Sul apresentaram este tipo de criação em 38,80\% [36,67\%; 40,98] e 37,35\% [34,90\%; 39,87], respectivamente (Mapa 17), sendo que nestes Estados é provável que os resultados tenham sido influenciados pelas características de produção leiteira de alguns de seus circuitos, considerando que do total de semi-confinamentos encontrados, 65,42\% [63,38\%; 67,40\%] demonstraram ser estabelecimentos de exploração exclusivamente leiteira.

O quartil de circuitos com os maiores proporções de utilização do sistema semi-intensivo (>29,97\%), foi observado na região do Triângulo Mineiro, Zona da Mata, sudoeste e centro-sul de Minas Gerais, no oeste paranaense, norte e região centro oriental do Rio Grande do Sul, Vale do Itajaí, em uma parcela que se estende do Vale do Paraíba paulista ao centro-sul fluminense e também no leste do Estado de Sergipe (Mapa 18).

No gráfico 9, estão dispostos em ordem decrescente, os valores pontuais das frequências de criações de bovinos em semi-confinamento e seus respectivos intervalos de confiança de 95\% encontrados em cada circuito produtor. 


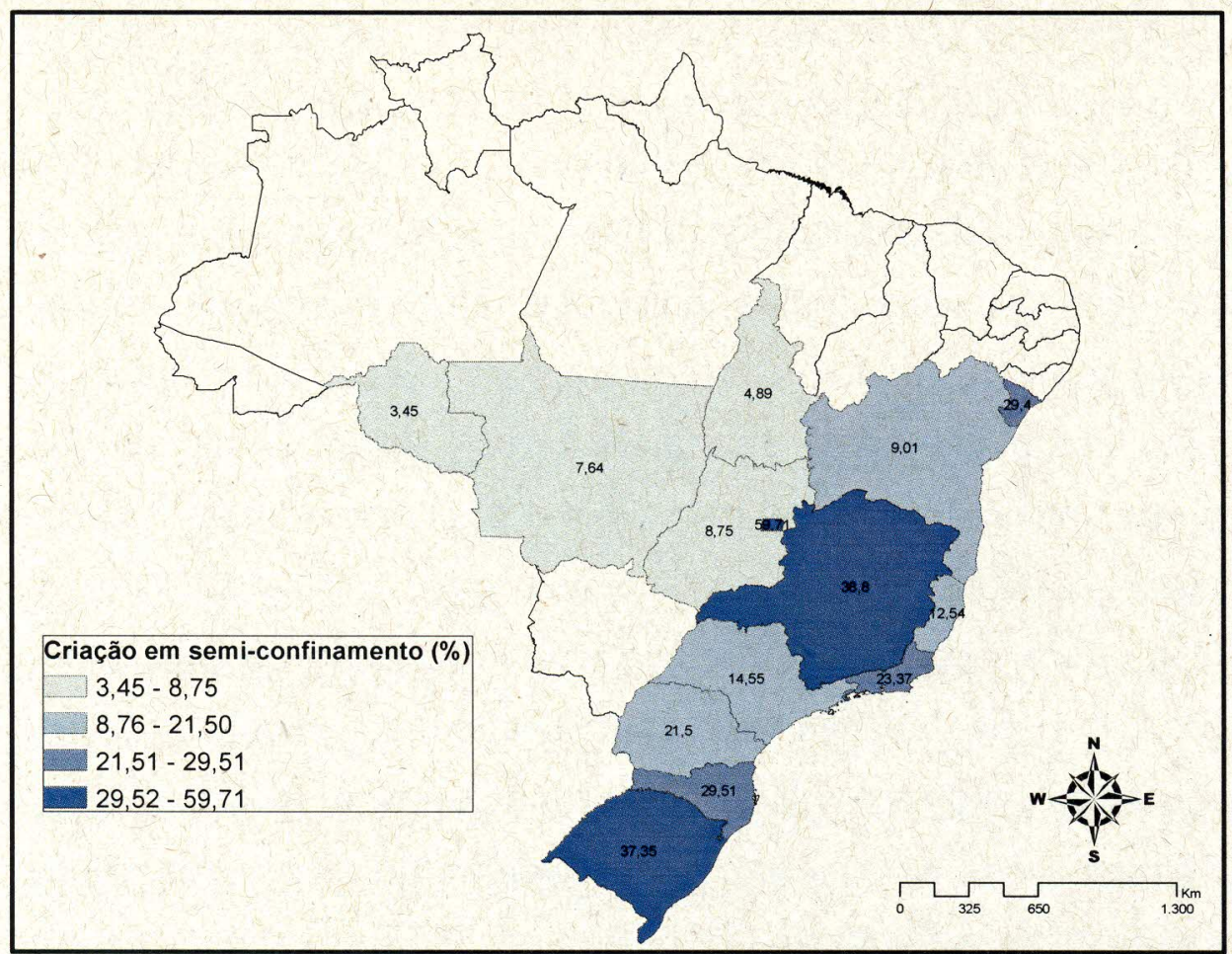

Mapa 17- Distribuição das frequências estimadas de sistemas de criação em semi-confinamentos nos Estados- Brasil - out 2001-dez 2004

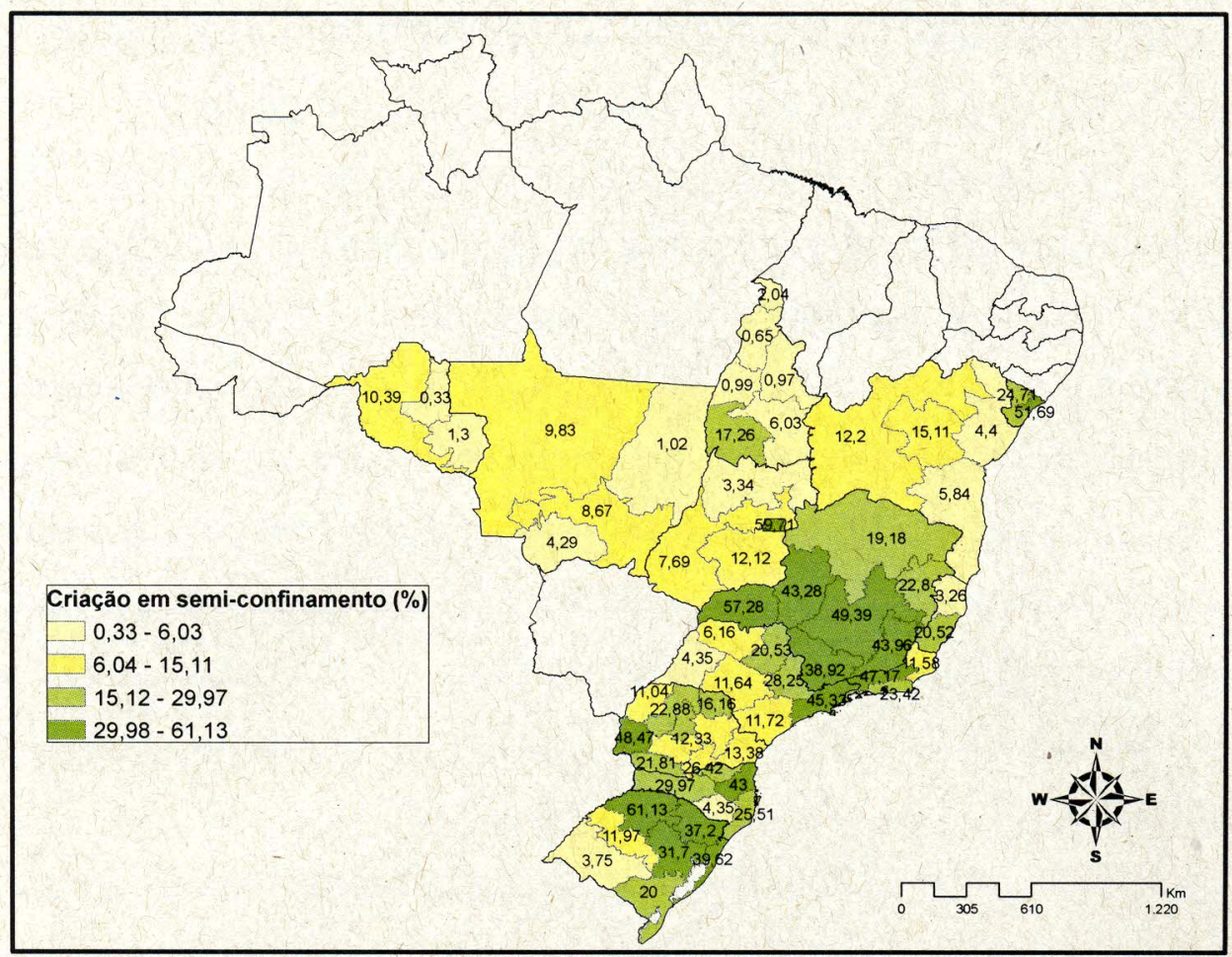

Mapa 18- Distribuição das frequências estimadas de sistemas de criação em semi-confinamentos nos circuitos pecuários- Brasil - out 2001dez 2004 


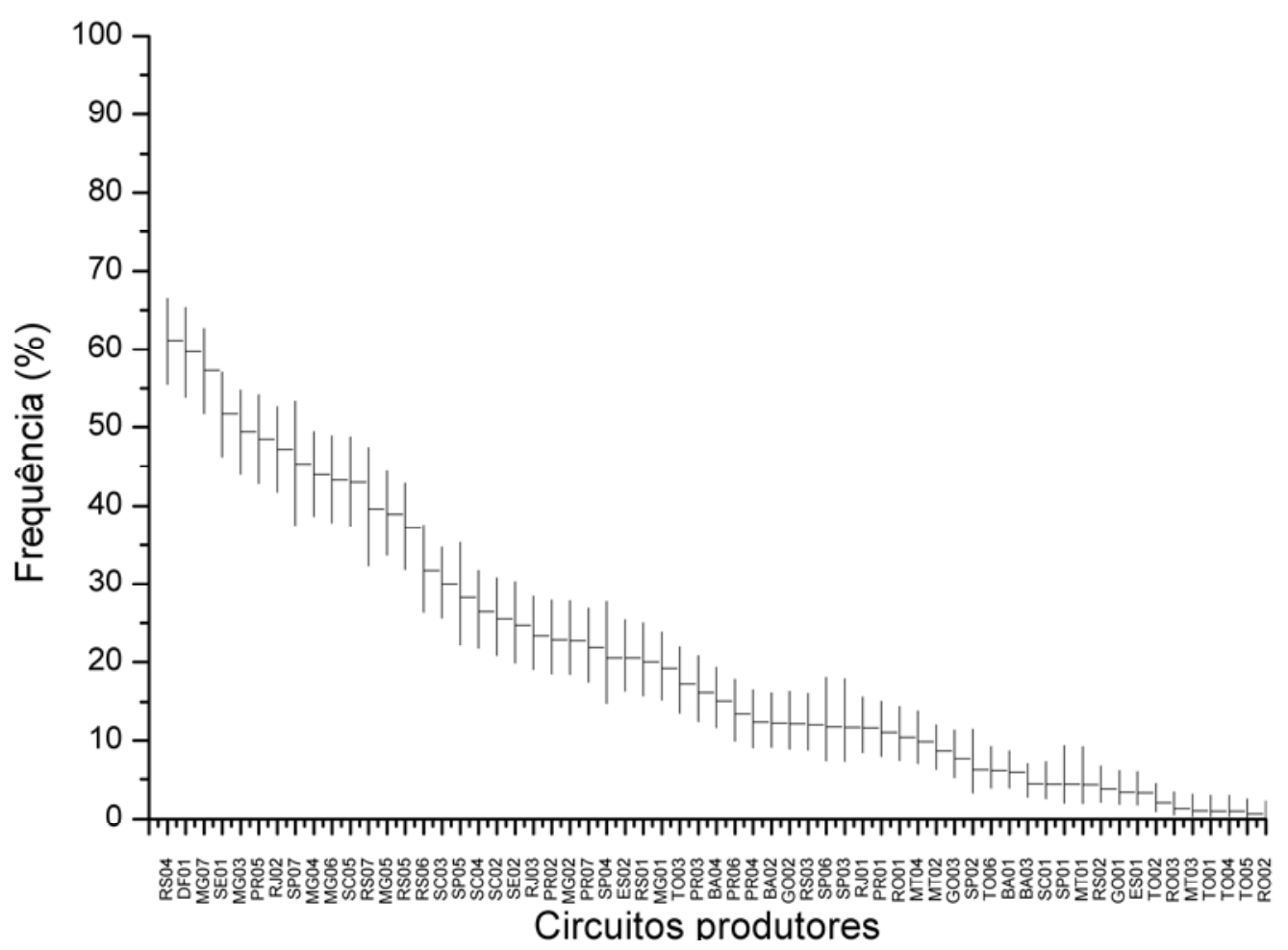

Gráfico 9- Distribuição decrescente das frequências pontuais e intervalos de confiança de $95 \%$ de propriedades que utilizam o sistema semiintensivo de criação de bovinos nos circuitos- Brasil - out 2001-dez 2004

Os sistemas de criação extensivos em regime de pastagens, sujeitam os animais à escassez periódica de forragem, comprometendo seu desenvolvimento e sua eficiência reprodutiva, e concentrando a oferta de carne em determinada época do ano (ALENCAR; POTT, 2003). Nestes casos, alguns sistemas de semiconfinamento podem satisfazer os requerimentos nutricionais necessários pelos animais, principalmente nos períodos de seca.

Correa et. al (2000) descrevem a obtenção de índices zootécnicos apreciáveis e a viabilidade econômica do sistema. Contudo, os mesmos discorrem a respeito das vantagens da implantação destes sistemas, descrevendo o grau de complexidade das decisões envolvidas quando da opção pela intensificação da produção e citam que o sucesso deste investimento depende da interação entre componentes genéticos (potencial genético dos animais), ambientais (manejo adotado e gerência do rebanho) e mercadológicos (preços de insumos e produtos). Descreveram ainda, que apesar da rentabilidade econômica demonstrada, este sistema é altamente sensível às variações do preço da arroba de carne e ao preço 
dos insumos (milho), tornando o investimento em intensificação da produção um fator complexo e que não se adapta a qualquer situação.

\subsubsection{Sistemas intensivos (confinamentos)}

Este sistema envolve os rebanhos em que os animais são encerrados em piquetes ou currais de área restrita e onde água e alimentos são fornecidos em cochos. Este manejo é mais propriamente utilizado nos casos de terminação de bovinos, a fase da produção que antecede o abate dos animais e envolve o acabamento da carcaça que será comercializada (CARDOSO, 2000). Segundo Cezar et al. (2005), existem três tipos predominantes de confinadores, o criador que confina os animais provenientes da própria fazenda, o criador de recria e engorda que confina os animais adquiridos através de terceiros e os confinadores que praticam o chamado "boitel", onde animais de diferentes propriedades são engordados, cabendo a este confinador fornecer as instalações e alimentação, o qual cobra em troca o tempo de permanência dos animais da terminação até o abate.

As freqüências de confinamentos demonstraram ser significantemente menores em comparação aos outros sistemas. A UF onde foi encontrada a maior proporção de propriedades que confinam animais foi o Distrito Federal, sendo que a participação deste sistema de criação nos rebanhos da capital foi estimada em apenas 2,16\% [0,97\%; 4,74\%] das propriedades (Mapa 19). Na análise dos circuitos, a estimativa da prevalência de confinamentos também se revelou baixa em comparação às criações extensivas e semi-intensivas, tendo em vista que a região sul/sudoeste de Minas Gerais que apresentou as maiores frequências destes sistemas de criação, apresentou um valor estimado de confinamentos de apenas 2,85\% [1,49\%; 5,39\%] (Mapa 20).

No gráfico 10, estão dispostos em ordem decrescente, os valores pontuais das proporções de criações de bovinos em confinamento e seus respectivos intervalos de confiança de $95 \%$ encontrados em cada circuito produtor. 


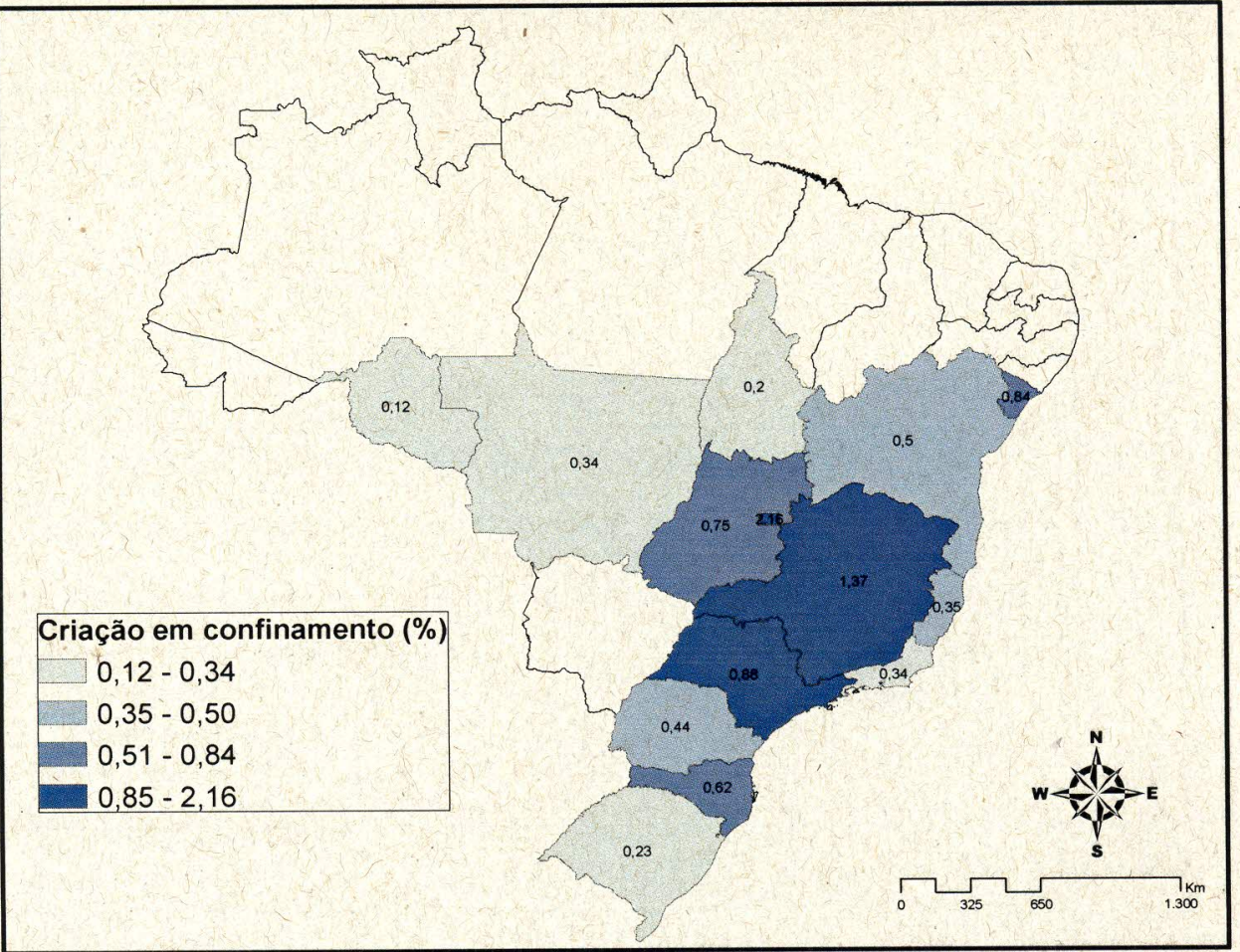

Mapa 19- Distribuição das frequências estimadas de sistemas de criação em confinamentos nos Estados- Brasil - out 2001-dez 2004

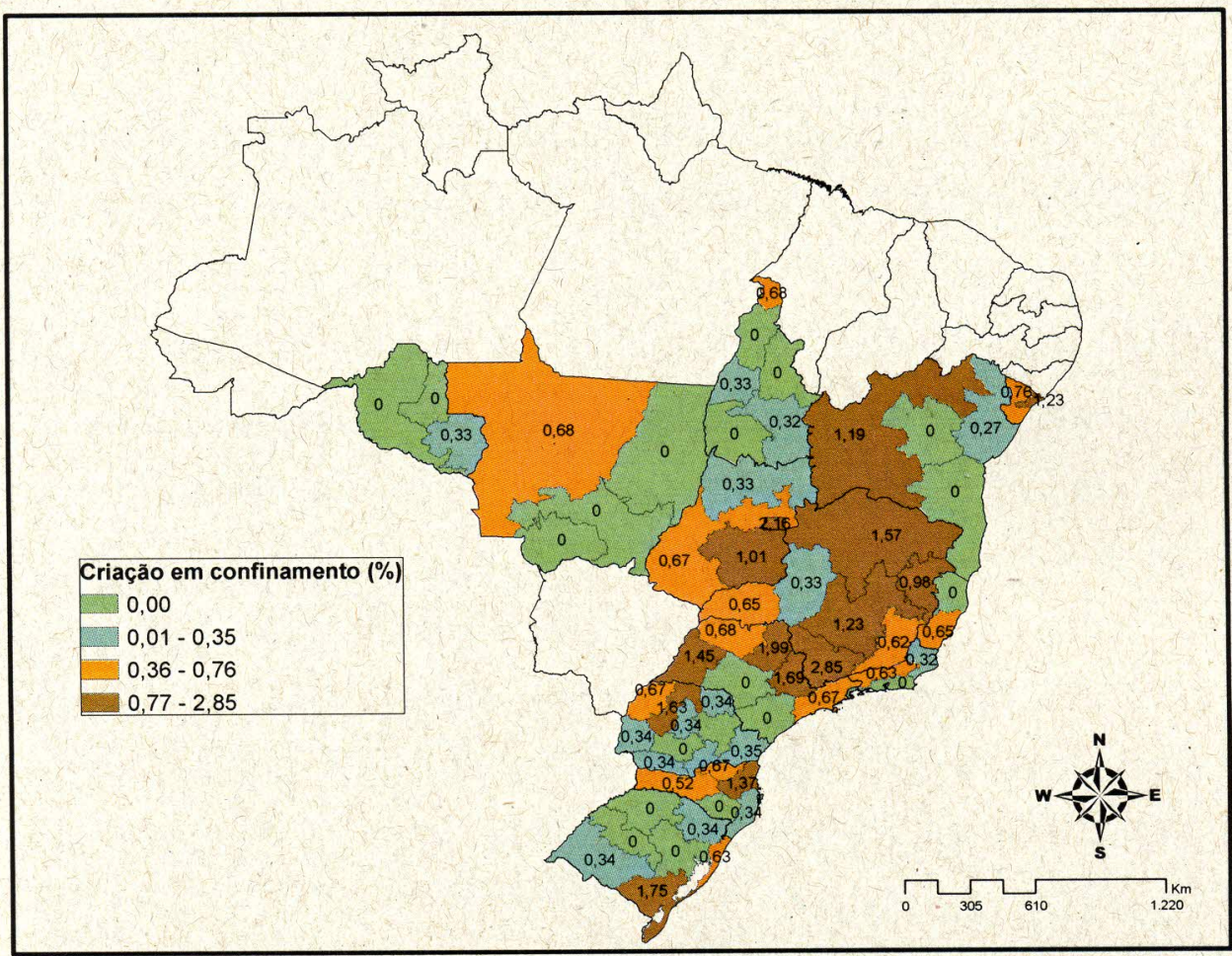

Mapa 20- Distribuição das frequências estimadas de sistemas de criação em confinamentos nos circuitos pecuários- Brasil - out 2001-dez 2004 


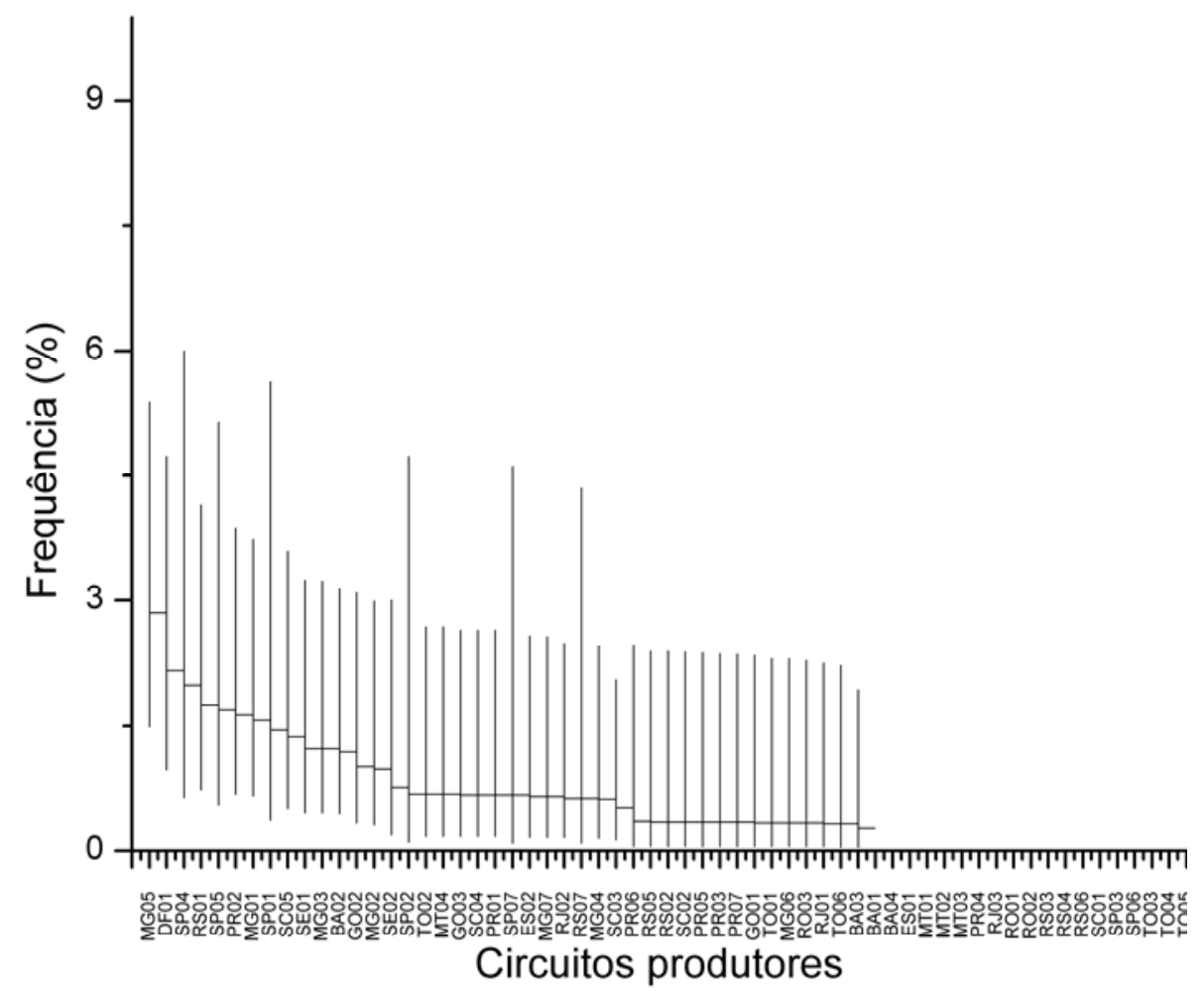

Gráfico 10- Distribuição decrescente das frequências pontuais e intervalos de confiança de $95 \%$ de propriedades que utilizam confinamentos na criação de bovinos nos circuitos- Brasil out 2001-dez 2004

Apesar das baixas frequências de confinamentos encontradas (0,62\% [0,49\%; 0,77\%]), estima-se o número de animais confinados entre 1995 e 2003 cresceu cerca de $61,8 \%$, sendo que o número de bovinos terminados em confinamentos abatidos em 2004 foi de aproximadamente 2,4 milhões de cabeças. Este número representou cerca de $5,17 \%$ do total de animais abatidos neste mesmo ano (ANUALPEC, 2005; CEZAR et al., 2005). Isto indica que apesar das criações em sistemas intensivos não serem tão comumente encontradas quanto os sistemas extensivos e semi-intensivos, estes rebanhos geralmente possuem um grande número de animais. O tamanho médio e a mediana do número total de animais nos rebanhos confinados, foram significativamente maiores $(p<0,05)$ em relação aos animais criados em semi-confinamento, mas não em relação aos sistemas extensivos $(p=0,663)$ (Tabela 7$)$. 
Tabela 7- Valores da média e mediana dos tamanhos de rebanho segundo o tipo de exploração pecuária- Brasil - out 2001-dez 2004

\begin{tabular}{cccc}
\hline $\begin{array}{c}\text { Tamanho dos } \\
\text { rebanhos }\end{array}$ & Sistema extensivo & Sistema semi-intensivo & Sistema intensivo \\
\hline Média & 172,08 & 89,59 & 238,83 \\
Mediana & 44,00 & 35,00 & 53,00 \\
\hline
\end{tabular}

Trabalhos a respeito da viabilidade da implantação dos sistemas intensivos de criação vêm sendo publicados por diversos autores sob diversos aspectos, alguns dos quais podemos citar: a utilização de insumos, idade dos animais; raças e cruzamentos empregados, rentabilidade econômica, utilização de animais castrados e custos de produção (TOWNSEND, 1988; LEME, 2000; RESTLE et al., 2004; LOPES et al., 2005; LOPES \& MAGALHÃES, 2005).

\subsubsection{Raças predominantes}

Os estabelecimentos foram questionados a respeito da raça predominante na propriedade, devendo considerar:

1. Zebu, qualquer raça da espécie Bos indicus (ex: nelore, guzerá).

2. Europeu de leite, raças de origem européia (Bos taurus) especializadas em produção leiteira (ex:holandês, Jersey).

3. Europeu de corte, raças de origem européia (Bos taurus) especializadas em produção de carne.

4. Mestiço, animais resultantes de cruzamentos entre raças, não sendo caracterizado dentro de uma ou mais raças específicas, considerados portanto, bovinos sem raça definida.

5. Outras raças: são incluídos aqui os animais que não se enquadram nas categorias acima, como por exemplo raças que não se encaixam nas categorias supracitadas ou ainda os chamados "cruzamentos industriais", provenientes da cruza entre Bos indicus e Bos taurus, independente do grau de sangue (Girolanda).

Para as 14 UFs, o gado encontrado com maior frequência foi o mestiço, estimado em 56,40\% [55,50\%; 57,30\%] dos locais. As propriedades onde o gado 
principal possui raça especializada (gado zebu e europeu), totalizaram 39,30\% [38,43\%; 40,18\%] e os locais onde o gado predominante era proveniente de cruzamentos industriais ou de raças que não cumpriam os requisitos de classificação em nenhuma destas variáveis, foram representativos em 4,30\% [3,96\%; 4,67\%] das criações. Estratificando por tipo de exploração, observa-se que nas criações exclusivamente de corte o gado encontrado com mais frequência foi o zebuíno, estimado em 59,69\% [57,97; 61,38] das criações. Nas propriedades leiteiras e mistas o gado mais frequente foi o mestiço, sendo observado em $54,90 \%$ $[53,35 ; 56,45 \%]$ e $74,27 \%$ [72,91\%; 75,57\%] destes locais, respectivamente (Tabela 8).

Tabela 8- Distribuição das frequências de utilização de raças de bovinos segundo o tipo de

\begin{tabular}{|c|c|c|c|c|c|c|c|c|}
\hline $\begin{array}{c}\text { Raça } \\
\text { Predominante }\end{array}$ & Corte (\%) & IC $95 \%$ & Leite (\%) & IC $95 \%$ & Mista (\%) & IC $95 \%$ & Total (\%) & IC $95 \%$ \\
\hline Zebu & 59,69 & $\begin{array}{c}57,97 \\
61,38\end{array}$ & 2,65 & $\begin{array}{c}2,21 \\
3,17\end{array}$ & 13,96 & $\begin{array}{c}12,98 \\
14,99\end{array}$ & 19,84 & $\begin{array}{c}19,23 \\
20,47\end{array}$ \\
\hline $\begin{array}{l}\text { Europeu de } \\
\text { Leite }\end{array}$ & 1,55 & $\begin{array}{c}1,13 \\
2,13\end{array}$ & 36,49 & $\begin{array}{c}34,99 \\
38,01\end{array}$ & 6,51 & $\begin{array}{c}5,70 \\
7,42\end{array}$ & 17,03 & $\begin{array}{c}16,33 \\
17,77\end{array}$ \\
\hline $\begin{array}{l}\text { Europeu de } \\
\text { Corte }\end{array}$ & 8,68 & $\begin{array}{c}7,68 \\
9,79\end{array}$ & 0,48 & $\begin{array}{c}0,28 \\
0,82\end{array}$ & 0,72 & $\begin{array}{l}0,51 \\
1,01\end{array}$ & 2,41 & $\begin{array}{c}2,15 \\
2,71\end{array}$ \\
\hline Mestiço & 28,26 & $\begin{array}{c}26,68 \\
29,89\end{array}$ & 54,90 & $\begin{array}{c}53,35 \\
56,45\end{array}$ & 74,27 & $\begin{array}{c}72,91 \\
75,57\end{array}$ & 56,41 & $\begin{array}{c}55,50 \\
57,31\end{array}$ \\
\hline Outras raças & 1,82 & $\begin{array}{c}1,43 \\
2,33\end{array}$ & 5,49 & $\begin{array}{c}4,86 ; \\
6,19\end{array}$ & 4,55 & $\begin{array}{c}3,99 ; \\
5,19\end{array}$ & 4,30 & $\begin{array}{c}3,96 ; \\
4,67 \\
\end{array}$ \\
\hline Total & 100,00 & & 100,00 & & 100,00 & & 100,00 & \\
\hline
\end{tabular}

\subsubsection{Zebuínos}

Nos Estados de Mato Grosso e Tocantins foram encontradas as maiores proporções de propriedades que possuem o gado zebu como a raça principal do rebanho, sendo estimado em 70,98\% [68,06\%; 73,73\%] e 62,80\% [60,62\%; 64,94\%] das propriedades destas UFs, respectivamente (Mapa 21). O quartil superior de circuitos com as maiores frequências de gado zebuíno (>35,88\%), foi encontrado em uma faixa que se estende do sudeste de Rondônia, Mato Grosso, Tocantins, norte goiano até a região do Vale do São Francisco e oeste da Bahia e região norte de Minas Gerais (Mapa 22). 


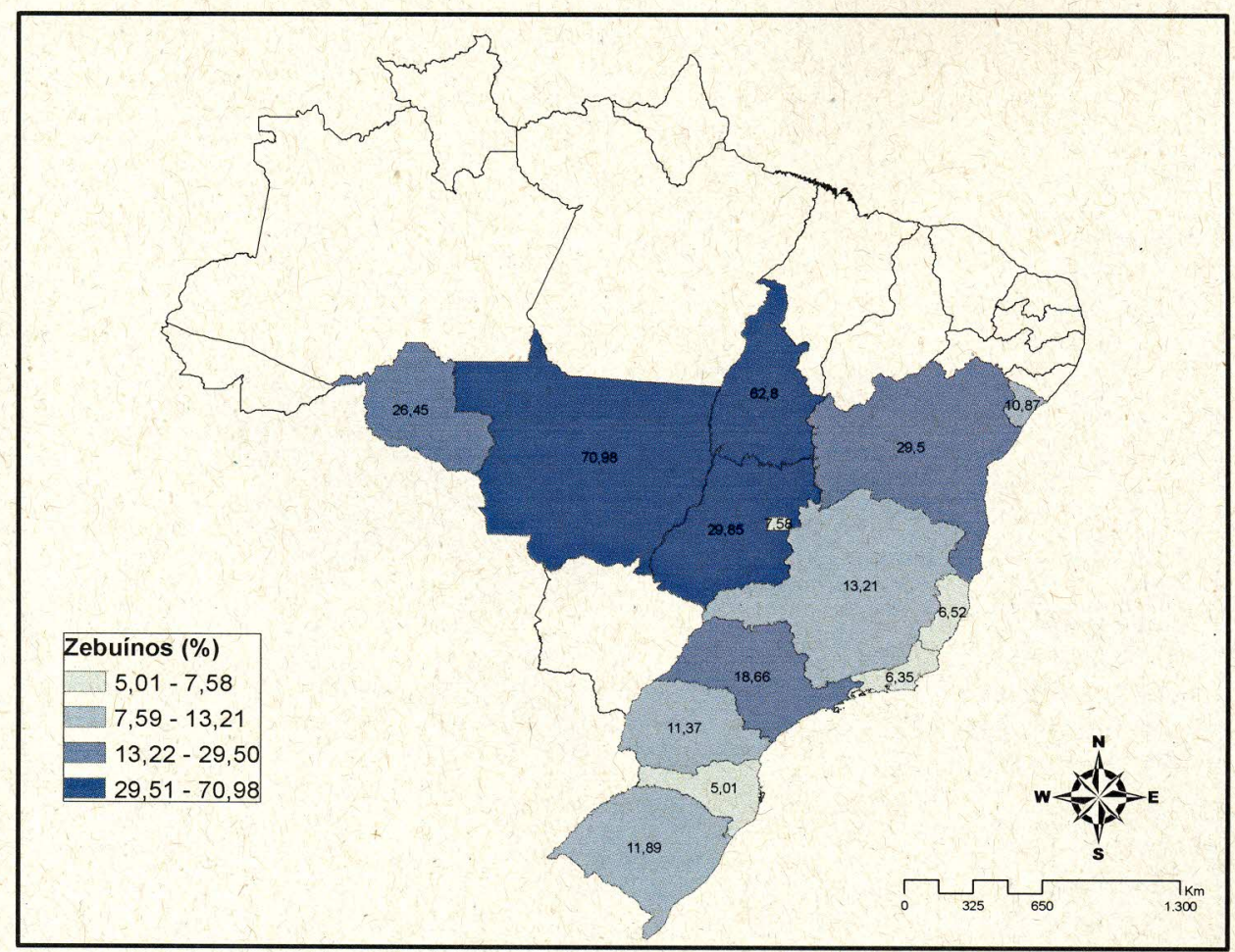

Mapa 21- Distribuição das frequências estaduais estimadas de propriedades que utilizam predominantemente o gado zebuíno- Brasil - out 2001-dez 2004

Todavia, em alguns circuitos pecuários como no noroeste e nordeste do Rio Grande do Sul; Vale do Itajaí, norte e oeste de Santa Catarina; sudeste, sudoeste e oeste paranaenses; norte do Espírito Santo; norte e centro-sul fluminenses e na região de São José do Rio Preto/Araçatuba em São Paulo as frequências de utilização destas raças situaram-se no $1^{\circ}$ quartil $(<7,20 \%)$ sendo que em algumas destas regiões, como no sudeste paranaense e no norte catarinense, as frequências estimadas foram quase nulas. Uma justificativa para as baixas proporções de propriedades que exploram zebuínos em algumas destes locais, pode ser explicada pelo fato de que em algumas delas estão localizadas boa parte das propriedades de caráter leiteiro e, consequentemente, este é o tipo de exploração que demonstrou as menores proporções de utilização destas raças, com apenas 2,65\% [2,21\%;3,17\%] delas utilizando este gado (Tabela 8). 


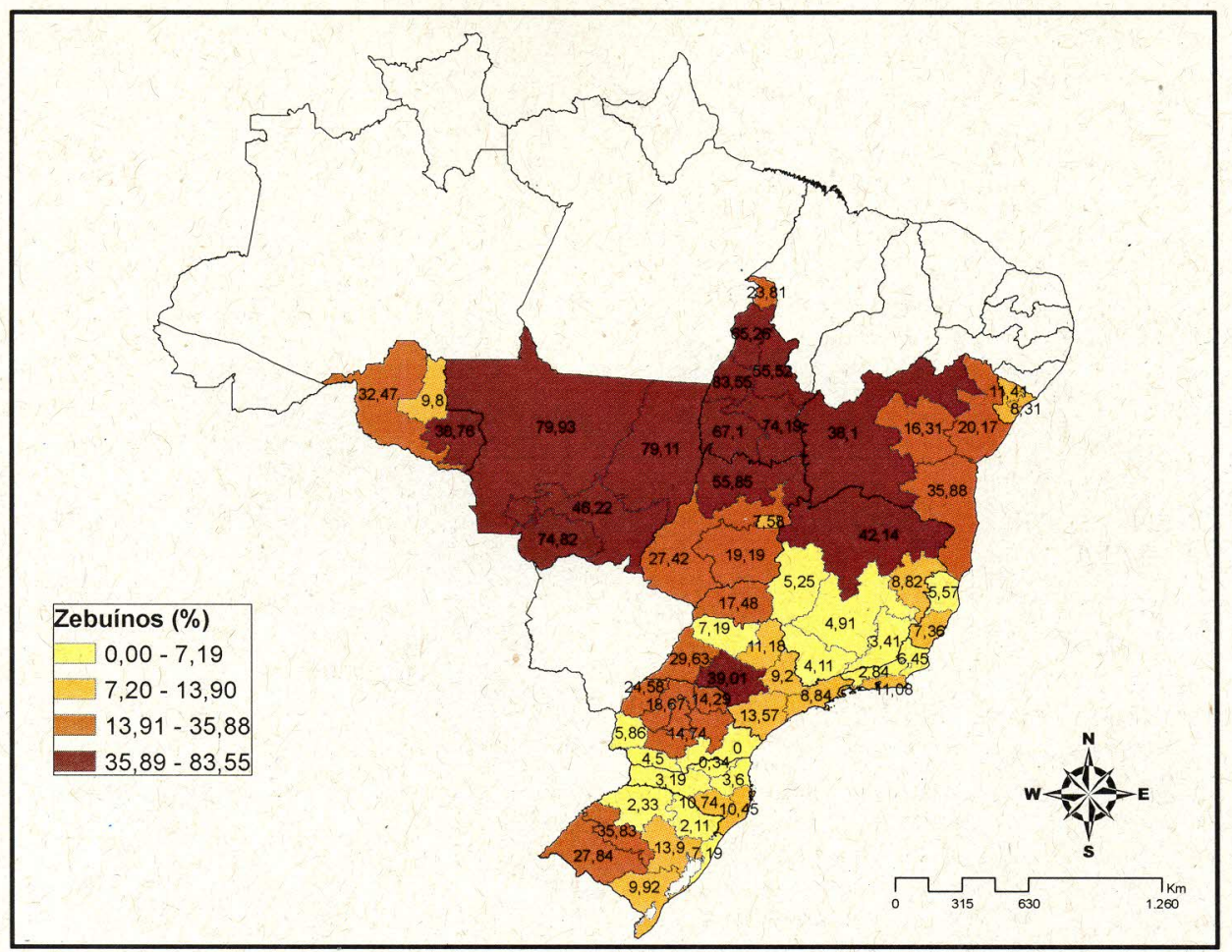

Mapa 22- Distribuição das frequências estimadas por circuito de propriedades que utilizam predominantemente raças zebuínas- Brasil - out 2001-dez 2004

\subsubsection{Europeu de leite}

Os bovinos de raça européia com aptidão para a produção de leite, demonstraram as maiores proporções de utilização nos Estados do sul do país, sendo que a maior parte dos circuitos que integraram o quartil superior $(>15,80 \%)$ foi encontrada nesta região (Mapa 23). Fora dos circuitos do sul, a região centro-oeste de Minas Gerais foi a única que fez parte deste grupo de circuitos. Estes locais apresentaram estimativas que variaram de $19,85 \%[15,53 \% ; 25,03 \%]$ no sudeste paranaense a $52,67 \%[47,00 \% ; 58,27 \%]$ no noroeste do Rio Grande do Sul (Mapa 24). 
Europeu de leite (\%)

$\square 1,89-3,00$

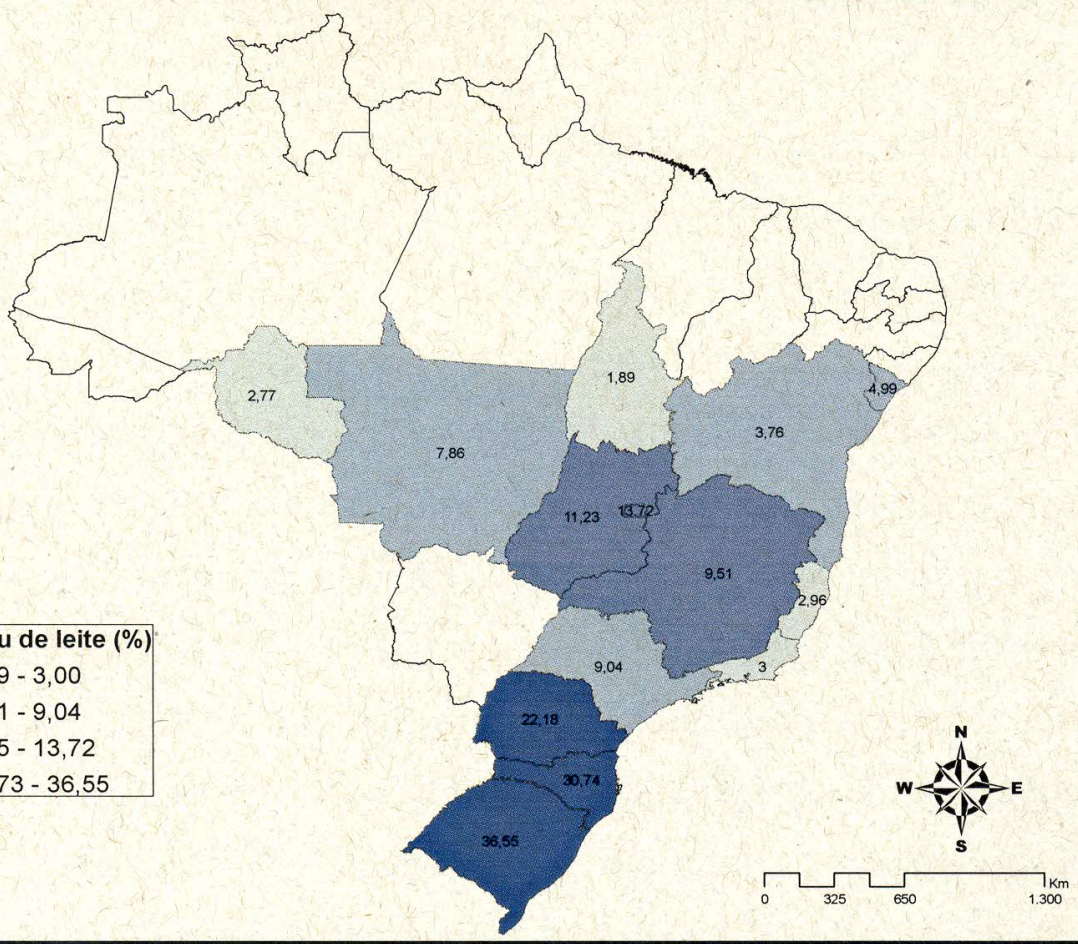

Mapa 23- Distribuição das frequências estaduais estimadas de propriedades que utilizam predominantemente raças européias especializadas em leite- Brasil - out 2001-dez 2004

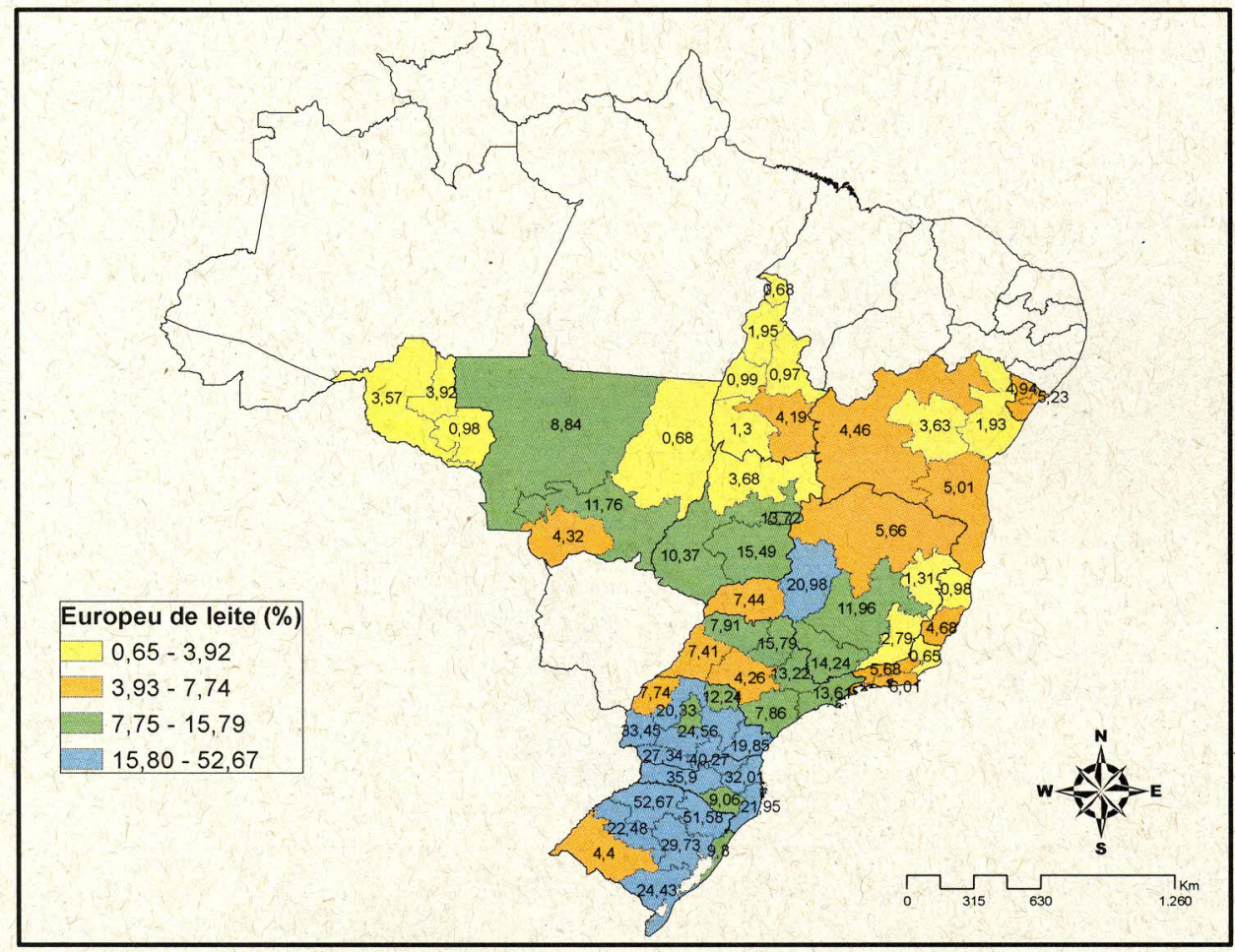

Mapa 24- Distribuição das frequências estimadas por circuito de propriedades que utilizam predominantemente raças européias especializadas em leite- Brasil - out 2001-dez 2004 


\subsubsection{Europeu de corte}

As estimativas estaduais de propriedades que utilizam predominantemente raças européias de corte variaram de $0 \%$ no Tocantins a $7,77 \%[6,70 \% ; 8,99 \%]$ no Rio Grande do Sul. Em boa parte das UFs analisadas, a prevalência de estabelecimentos que adotam estas raças foi baixa em relação às outras, sendo praticamente nulas em algumas delas (Mapa 25). No Estado do Tocantins por exemplo, nenhuma das propriedades amostradas apresentou animais europeus de corte como sendo a raça principal do rebanho. O quartil superior de circuitos pecuários com as maiores frequências de rebanhos de raça européia de corte $(>2,00 \%)$, localizou-se principalmente no sul e sudeste do país, sendo que em algumas regiões como no sudoeste, sudeste e parte centro-ocidental do Rio Grande do Sul, as frequências chegaram a 24,54\% [19,79\%; 30,01], 15,65\% [11,73\%; $20,58 \%]$ e $15,31 \%[11,69 \% ; 19,79]$, respectivamente (Mapa 26 ).

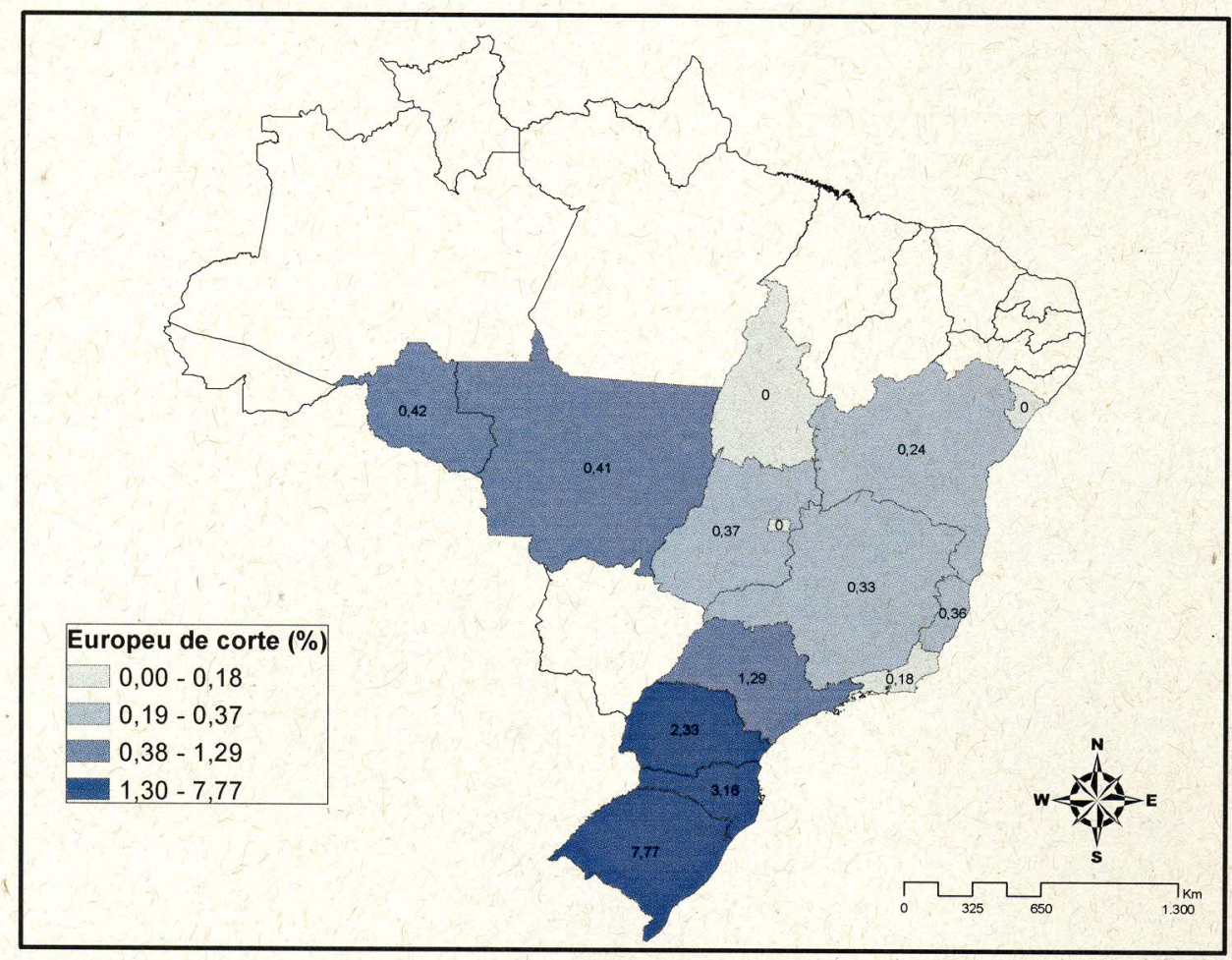

Mapa 25- Distribuição das frequências estaduais estimadas de propriedades que utilizam predominantemente o gado europeu de corte- Brasil out 2001-dez 2004 


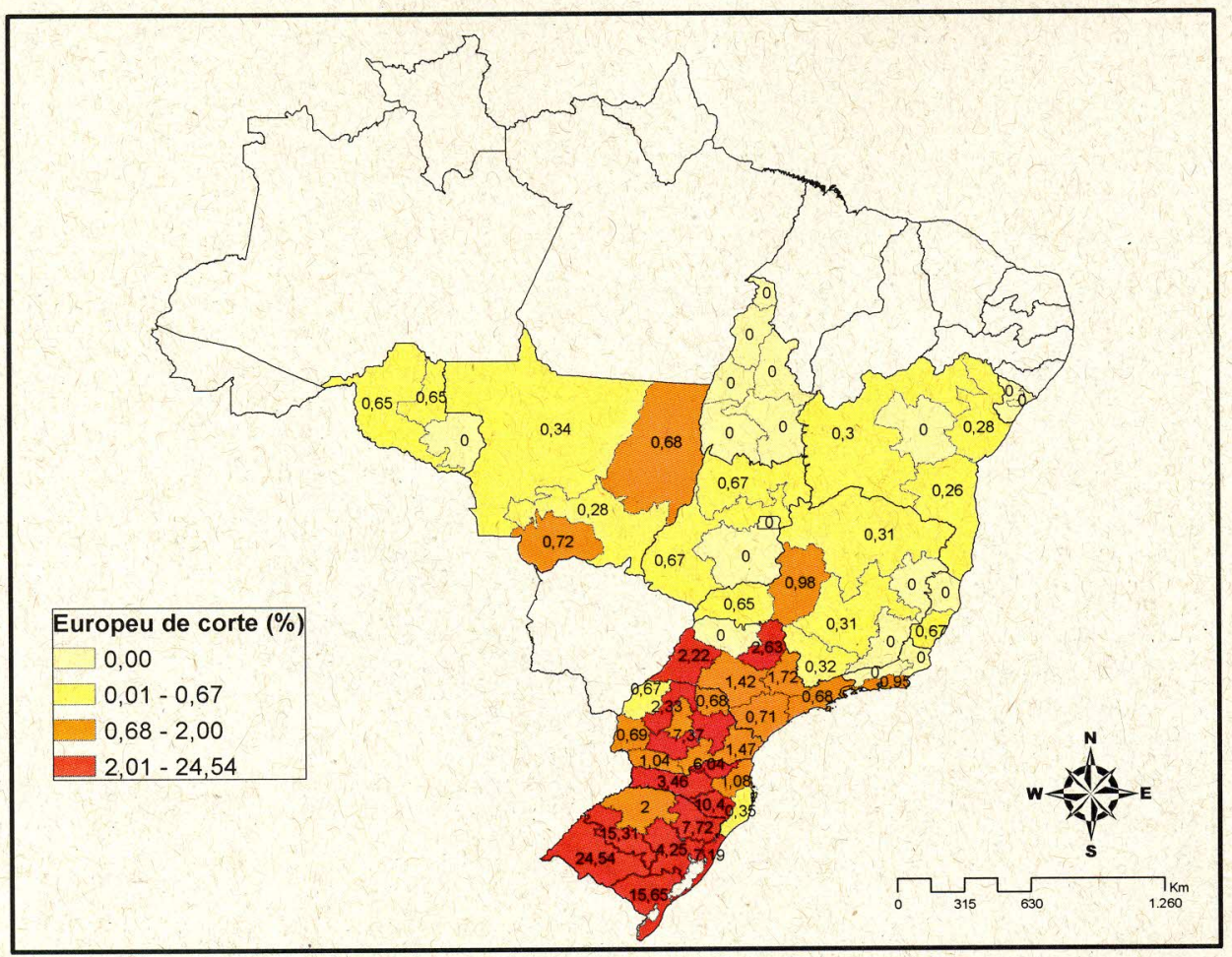

Mapa 26- Distribuição das frequências estimadas por circuito de propriedades que utilizam predominantemente o gado europeu de corte- Brasil out 2001-dez 2004

\subsubsection{Gado mestiço}

Bovinos sem raça definida demonstraram ser o gado mais freqüente em -11 das 14 UFs, com exceção de Mato Grosso, Tocantins e Rio Grande do Sul (Mapa 27). Uma faixa de circuitos pecuários que se estende do sudeste paranaense e segue percorrendo todos os circuitos litorâneos até o norte do Espírito Santo, compreenderam o quartil superior $(>71,20 \%)$ de proporções de rebanhos compostos predominantemente por animais mestiços $(>71,20 \%)$. Além destas regiões, fizeram parte deste quartil a região centro-norte de Rondônia, o nordeste sergipano e no centro-norte da Bahia (Mapa 28). 


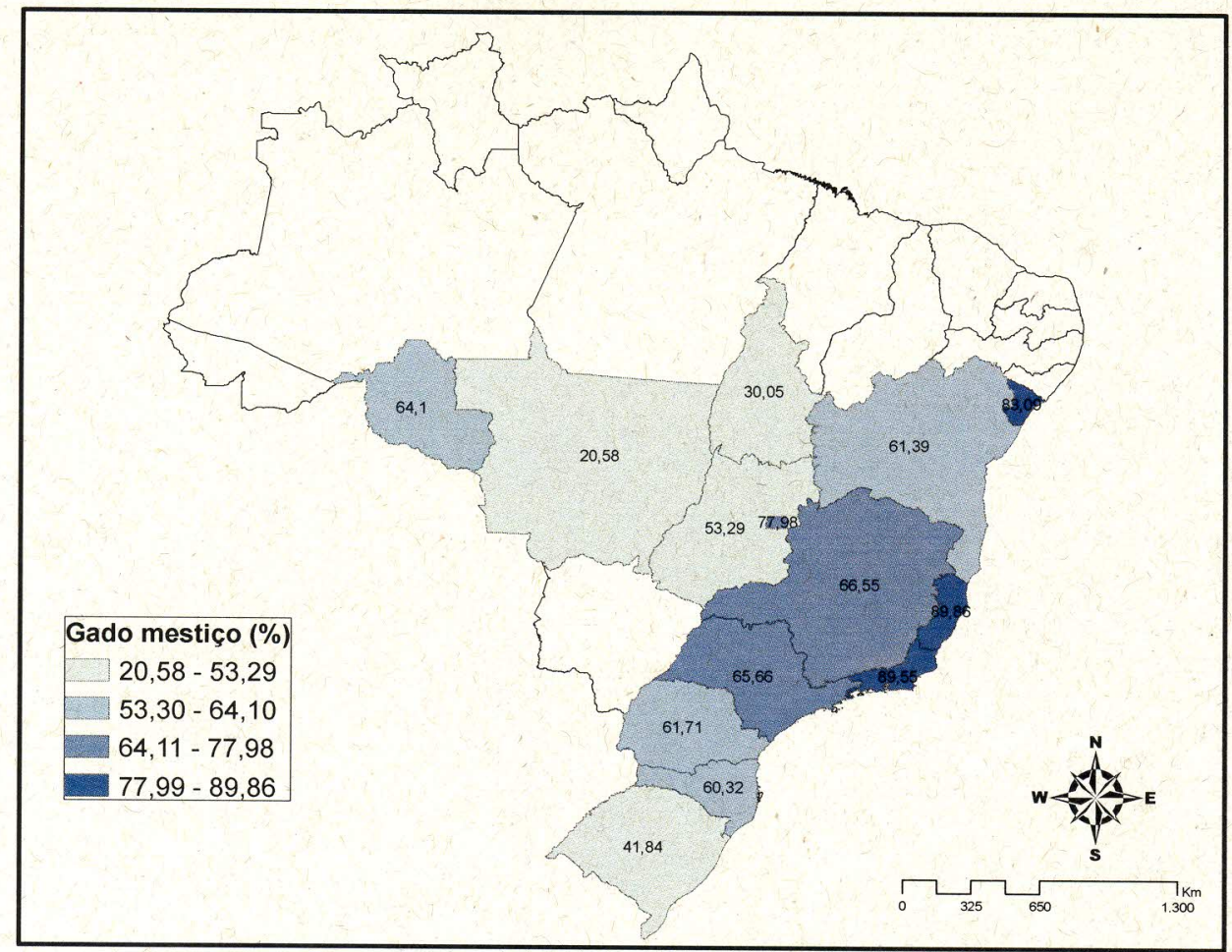

Mapa 27- Distribuição das frequências estaduais estimadas de propriedades que utilizam predominantemente o gado mestiço- Brasil - out 2001dez 2004

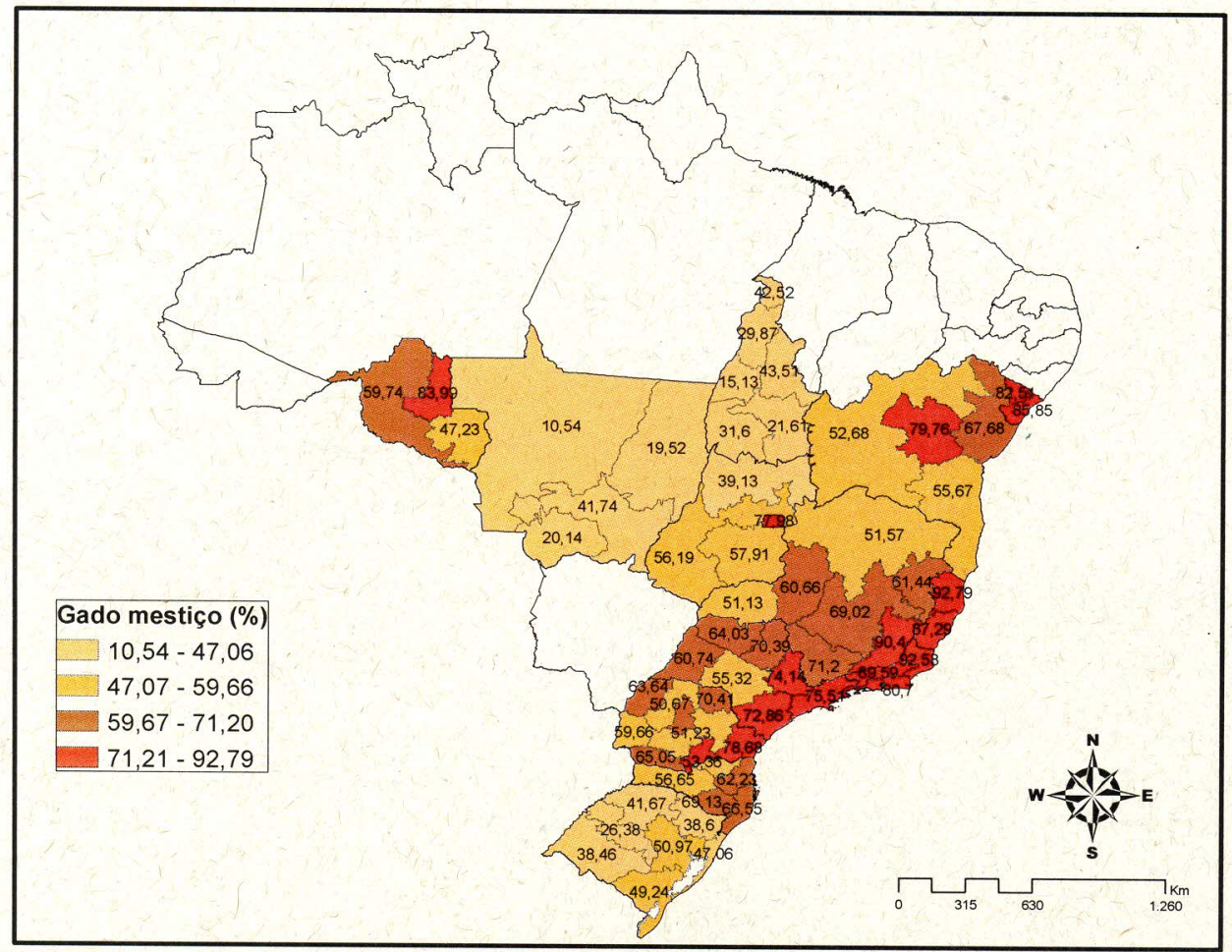

Mapa 28- Distribuição das frequências estimadas por circuito de propriedades que utilizam predominantemente o gado mestiço- Brasil - out 2001dez 2004 


\subsubsection{Outras raças}

As raças oriundas de cruzamento industrial ou que não poderiam ser classificadas como sendo taurinas ou indianas, apresentaram valores estaduais entre $0,17 \%[0,02 \% ; 1,22 \%]$ no Mato Grosso e chegaram a $10,41 \%[9,19 \% ; 11,76 \%]$ das criações de Minas Gerais. Apesar da maioria dos circuitos terem demonstrado baixas frequências de utilização destas raças, alguns circuitos apresentaram proporções que superaram significativamente a frequência geral encontrada para as 14 UFs (Mapa 29). Nos circuitos pecuários do extremo norte do Tocantins, Triângulo Mineiro e na mesorregião paulista de São José do Rio Preto e Araçatuba as proporções de propriedades que utilizam predominantemente estas raças, apresentaram valores de $32,99 \%$ [27,85\%; 38,58\%], 23,30\% [18,91\%; 28,35\%] e $20,86 \%$ [14,88\%; 28,44\%], respectivamente. Nestes locais especificamente, a frequência de utilização destes animais apenas foi inferior às frequências de rebanhos de gado mestiço (Mapa 30 ).

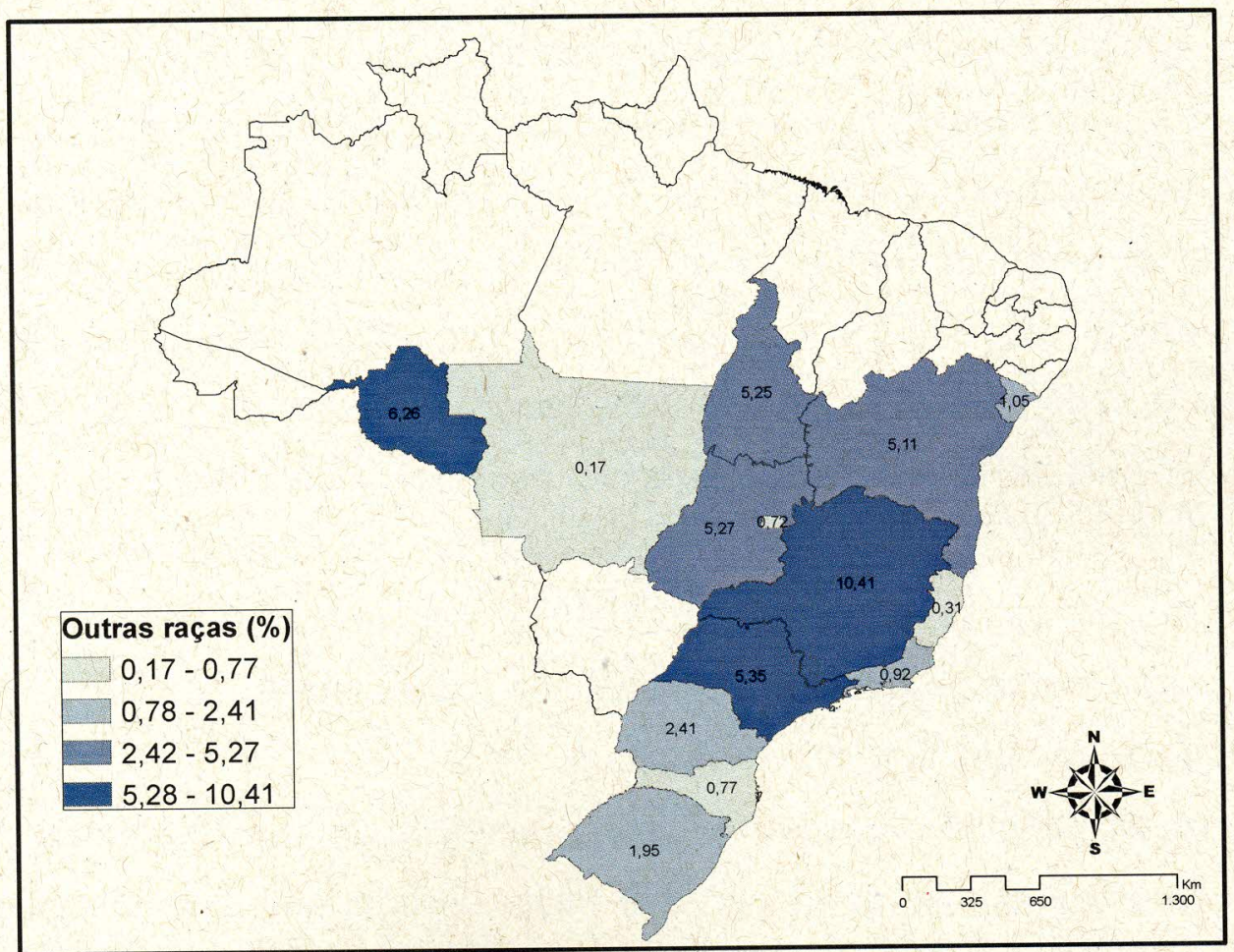

Mapa 29- Distribuição das frequências estaduais estimadas de propriedades que utilizam predominantemente outras raças- Brasil - out 2001-dez 2004 


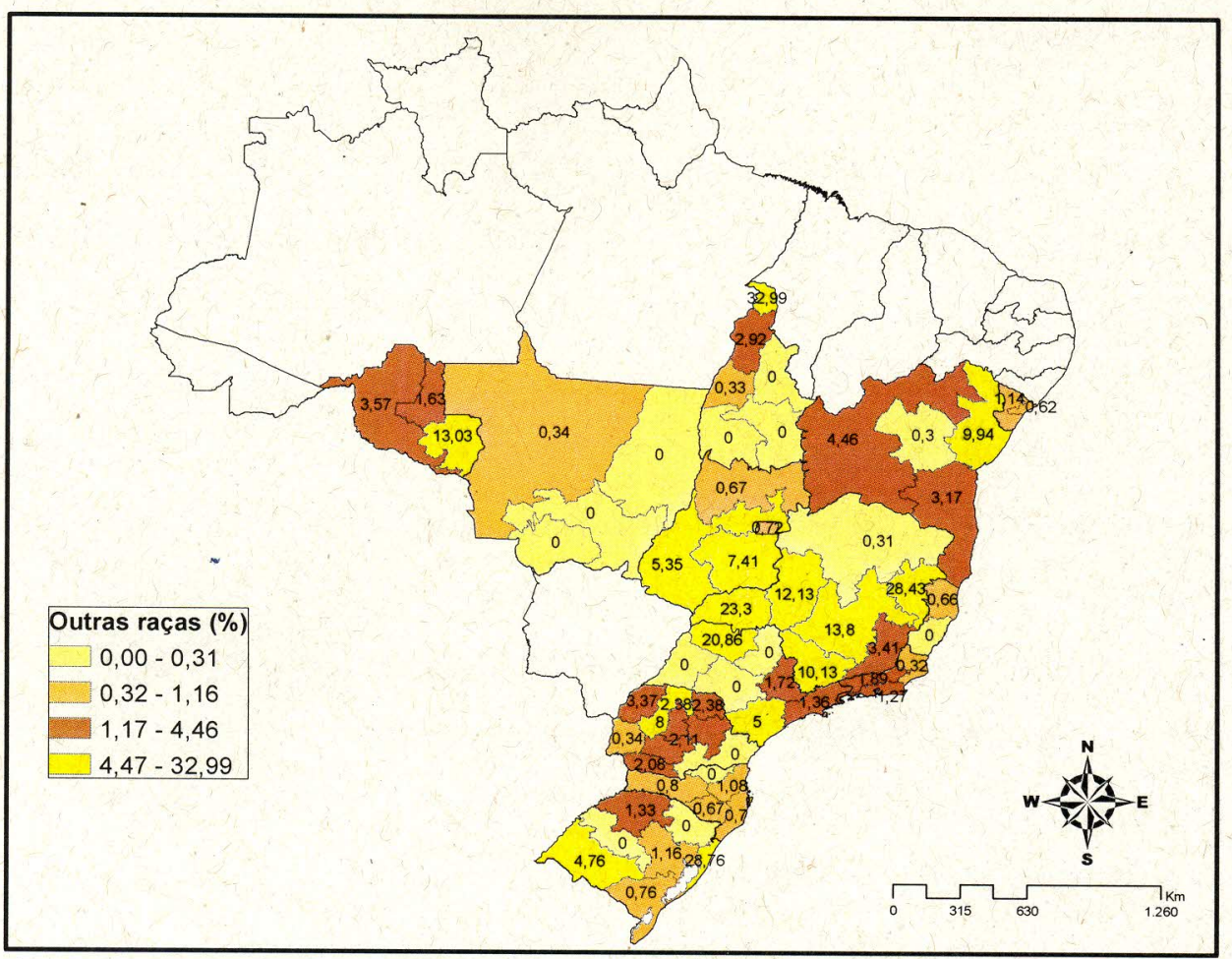

Mapa 30- Distribuição das frequências estaduais estimadas de propriedades que utilizam predominantemente outras raças- Brasil - out 2001-dez 2004

Os resultados demonstram que os animais mestiços permanecem distribuídos por todo o território estudado e as altas proporções de rebanhos que utilizam raças zebuínas revelaram-se, geralmente, junto das áreas de maior predominância de explorações de corte, com exceção do sul do Rio Grande do Sul, onde as raças de européias demonstraram ser utilizadas com frequências superiores aos valores normalmente encontrados para os outros Estados. Josahkian (1999) estimou que aproximadamente $80 \%$ do rebanho bovino nacional é constituido por animais de origem zebuína, sejam eles puros ou resultantes de cruzamentos. Estimativas semelhantes publicadas por Machado (2001), demonstraram que nos rebanhos leiteiros do país cerca de $80 \%$ dos animais são provenientes de cruzamentos entre gado zebuíno e europeu em diferentes graus.

As raças zebuínas, em geral, são caracterizadas pela presença de chifres curtos ou longos e cupim, pêlos curtos e finos, barbela ampla e pele pigmentada. Estas raças geralmente são bem adaptadas às regiões de clima tropical, o que facilita a sua sobrevivência em regiões muito quentes (DOMINGUES, 1973). Já o gado europeu, geralmente possui chifres curtos, pele clara, pelos mais longos e apresentam alta especialização para a produção de leite ou carne. Todavia, as raças 
européias especializadas são exigentes quanto às condições tropicais, nutricionais e de manejo, com diminuição do rendimento produtivo devido ao estresse térmico, doenças parasitárias, baixa qualidade do alimento e manejo inadequado (FACÓ et al., 2005; EGITO, 2007). As temperaturas mais amenas e as propriedades mais especializadas (em corte e leite) do Sul do país podem justificar a maior concentração destas raças na região.

Alguns produtores, na intenção de contrabalancear as vantagens e desvantagens entre o gado zebuíno e europeu, utilizam o acasalamento entre eles, tanto pela melhor adaptação geográfica da progênie quanto pela otimização dos efeitos da heterose e de complementaridade de raças (BAKER et al., 1989; GUIMARÃES; ALVEZ; COSTA, 2002).

\subsubsection{Variáveis relacionadas à atividade leiteira}

As propriedades que relataram realizar a ordenha dos animais, foram questionadas a respeito do número de ordenhas realizadas diariamente e o tipo de ordenha utilizada. Cabe salientar, que alguns dos rebanhos classificados como sendo prioritariamente de corte também estão presentes nestes resultados. Isto se deve ao fato de que alguns destes locais relataram a presença de alguns animais para produção de leite dentro da propriedade. Isto não descaracterizaria esse rebanho como sendo de corte, desde que a produção leiteira não fosse considerada uma das principais atividades econômicas da propriedade. Um dado que demonstra isto, é o fato de que $83,70 \%$ [81,07\%; 86,03\%] dos estabelecimentos de corte que possuíam vacas em lactação, relataram não entregar o leite produzido. Este dado sugere que a maior parte dos estabelecimentos de corte que produz leite, em geral, o faz para consumo próprio ou como uma pequena fonte de renda extra, insignificante se comparada à exploração de carne.

\subsubsection{Número de ordenhas diárias}

Nas explorações de corte, estimou-se que 66,23\% [64,43\%; 67,98\%] das propriedades não ordenha os animais e 31,09\% [29,40\%; 32,84\%] a realizam uma 
única vez ao dia. Uma parcela pequena do total ordenha duas ou mais vezes por dia (2,68\% [2,01\%; 3,56\%]) (Tabela 9).

Nos rebanhos de exploração prioritária de leite, estimou-se que 53,19\% [51,86\%; 54,52\%] realizam duas ou mais ordenhas diárias e que os $46,81 \%$ [45,48\%; 48,14\%] restantes praticam a ordenha uma única vez ao dia. As propriedades de exploração mista, no entanto, demonstraram realizar o manejo da ordenha duas ou mais vezes por dia em 26,62\% [25,25\%; \%28,03] das propriedades, sendo que em 73,38\% [71,97\%-74,75\%] delas, a ordenha é realizada apenas uma vez ao dia.

Estes dados demonstram que nas propriedades de pecuária mista, em geral, o manejo leiteiro não é realizado de maneira tão intensificada como nos locais que exploram o leite de maneira prioritária. Sugere-se que a diversificação entre explorações de corte e leite em um mesmo estabelecimento, divide as atenções entre um e outro setor de exploração e consequentemente, pode ser a causa de um processo de desaceleração do investimento em intensificação do manejo e de outros processos determinantes de um bom rendimento na produção de leite.

Tabela 9- Distribuição das frequências estimadas do número de ordenhas diárias realizadas nas propriedades segundo o tipo de exploração pecuária- Brasil - out 2001-dez 2004

\begin{tabular}{ccccccccc}
\hline \multicolumn{7}{c}{ Tipo de Exploração } \\
\hline $\begin{array}{c}N^{\circ} \\
\text { ordenhas/dia }\end{array}$ & $\begin{array}{c}\text { Corte } \\
(\%)\end{array}$ & IC 95\% & $\begin{array}{c}\text { Leite } \\
(\%)\end{array}$ & IC 95\% & $\begin{array}{c}\text { Mista } \\
(\%)\end{array}$ & IC 95\% & $\begin{array}{c}\text { Total } \\
(\%)\end{array}$ & IC 95\% \\
\hline $\begin{array}{c}\text { Não ordenha } \\
\text { 1 vez/dia }\end{array}$ & 66,23 & 64,$43 ; 67,98$ & - & - & - & - & 14,06 & 13,$50 ; 14,65$ \\
$\begin{array}{c}2 \\
\text { ou 3 }\end{array}$ & 31,09 & 29,$40 ; 32,84$ & 46,81 & 45,$48 ; 48,14$ & 73,38 & 71,$97 ; 74,75$ & 53,38 & 52,$57 ; 54,18$ \\
vezes/dia & 2,68 & 2,$01 ; 3,56$ & 53,19 & 51,$86 ; 54,52$ & 26,62 & 25,$25 ; 28,03$ & 32,56 & 31,$87 ; 33,26$ \\
\hline Total & 100,00 & & 100,00 & & 100,00 & & 100,00 \\
\hline
\end{tabular}

Os circuitos que ordenham apenas uma vez ao dia e que integraram o quartil superior (prevalência >76,21\%), foram encontrados no centro-norte de Rondônia; Pantanal mato-grossense; noroeste tocantinense; norte e sudeste goianos; centronorte e oeste da Bahia; norte do Espírito Santo; Vale do Mucuri em Minas Gerais; mesorregiões paulistas de Ribeirão Preto/Araçatuba, Presidente Prudente e litoral sul e na região Catarinense da Serrana (Mapa 31).

Quanto aos locais onde a ordenha é realizada mais de uma vez ao dia, os circuitos que integram o quartil superior (>35,81\%) foram localizados em quase todo o Rio Grande do Sul (exceto os circuitos do sudoeste e litoral); todos os circuitos 
catarinenses com exceção da região Serrana; regiões oeste, sul e sudeste do Paraná; centro-sul fluminense e nas regiões mineiras do centro-oeste e centro-sul (Mapa 32).

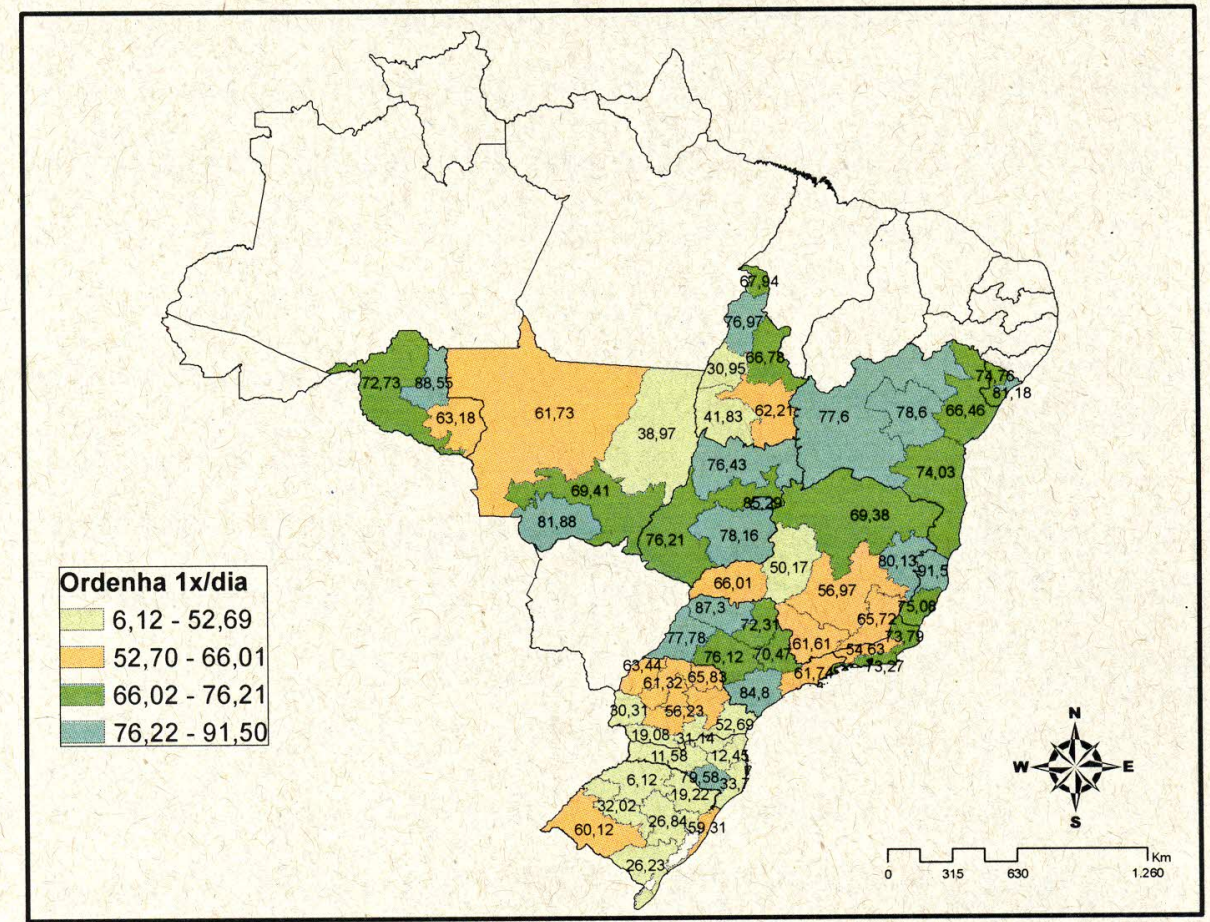

Mapa 31- Distribuição das frequências estimadas por circuito de propriedades que realizam o manejo da ordenha apenas uma vez por dia- Brasil - out 2001-dez 2004

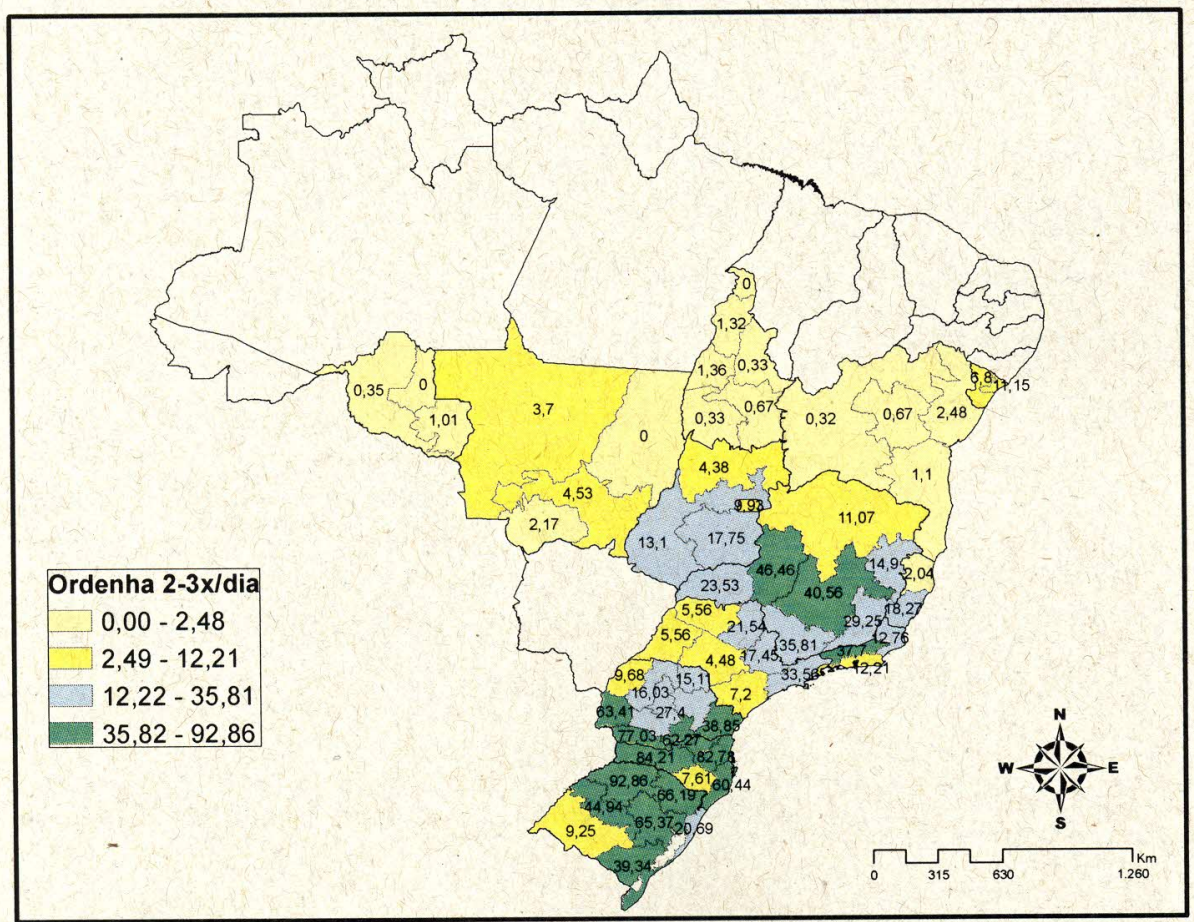

Mapa 32- Distribuição das frequências estimadas por circuito de propriedades que realizam o manejo da ordenha duas ou mais vezes por dia- Brasil - out 2001-dez 2004 
Um dado que demonstra a associação entre maiores produções de leite com investimento em intensificação dos manejos, são os índices produtivos encontrados entre as propriedades que ordenham apenas uma vez ao dia em relação às que ordenham duas ou mais vezes. As propriedades que demonstraram realizar mais de uma ordenha diária, apresentaram valores significativamente maiores de produção leiteira se comparadas às que ordenham apenas uma vez ao dia $(p=0,000)$ (Tabela 10).

Tabela 10 - Valores de média e mediana de produção diária de leite por animal e por rebanho segundo o número de ordenhas diárias- Brasil - out 2001-dez 2004

\begin{tabular}{|c|c|c|c|c|c|c|c|c|}
\hline & \multicolumn{4}{|c|}{ Produção diária do rebanho (litros) } & \multicolumn{4}{|c|}{ Produção diária por vaca (litros) } \\
\hline $\begin{array}{c}\mathbf{N}^{\circ} \\
\text { ordenhas/dia }\end{array}$ & $\begin{array}{c}\mathbf{N}^{\circ} \text { de } \\
\text { propriedades }\end{array}$ & Média & Mediana & $\mathbf{M}-\mathbf{W}^{*}$ & $\begin{array}{c}\mathbf{N}^{\circ} \text { de } \\
\text { propriedades }\end{array}$ & Média & Mediana & $\mathbf{M}-\mathbf{W}^{*}$ \\
\hline $1 \mathrm{vez} / \mathrm{dia}$ & 9431 & 52,11 & 28,00 & \multirow[b]{2}{*}{$p=0,000$} & 9315 & 4,14 & 3,95 & \multirow[b]{2}{*}{$P=0,000$} \\
\hline $\begin{array}{c}2 \text { ou } 3 \\
\text { vezes/dia }\end{array}$ & 3595 & 162,61 & 60,00 & & 3577 & 8,73 & 8,00 & \\
\hline
\end{tabular}

\subsubsection{Tipo de ordenha}

Os tipos de ordenha avaliados foram: manual, mecânica com balde ao pé e mecânica em sala de ordenha. Seguindo o exemplo do número de ordenhas diárias, este parâmetro foi avaliado separadamente por tipo de exploração pecuária (corte, leite ou mista), para uma melhor visualização de sua representatividade em cada um destes locais (Tabela 11).

Tabela 11 - Distribuição das frequências estimadas de tipo de ordenha utilizado nas propriedades segundo o tipo de exploração pecuária- Brasil - out 2001-dez 2004

\begin{tabular}{ccccccccc}
\hline \multicolumn{7}{c}{ Tipo de Exploração } \\
\hline $\begin{array}{c}\text { Tipo de } \\
\text { ordenha }\end{array}$ & $\begin{array}{c}\text { Corte } \\
(\%)\end{array}$ & IC 95\% & $\begin{array}{c}\text { Leite } \\
(\%)\end{array}$ & IC 95\% & $\begin{array}{c}\text { Mista } \\
(\%)\end{array}$ & IC 95\% & $\begin{array}{c}\text { Total } \\
(\%)\end{array}$ & IC 95\% \\
\hline $\begin{array}{c}\text { Não ordenha } \\
\text { Manual }\end{array}$ & 66,55 & 64,$75 ; 68,30$ & - & - & - & - & 14,22 & 13,$65 ; 14,81$ \\
$\begin{array}{c}\text { Mecânica balde } \\
\text { ao pé }\end{array}$ & 0,55 & 0,$29 ; 1,02$ & 18,09 & 16,$77 ; 19,49$ & 3,87 & 3,$21 ; 4,65$ & 9,04 & 8,$43 ; 9,69$ \\
$\begin{array}{c}\text { Mecânica em } \\
\text { sala de ordenha }\end{array}$ & 0,02 & 0,$00 ; 0,13$ & 6,36 & 5,$51 ; 7,33$ & 0,89 & 0,$64 ; 1,23$ & 2,97 & 2,$59 ; 3,39$ \\
\hline Total & 100,00 & 100,00 & 100,00 & 100,00 & 100,00 & 100,00 & 100,00 & 100,00 \\
\hline
\end{tabular}


A principal técnica de ordenha utilizada nos estabelecimentos de corte é a ordenha manual que foi estimada em 32,89\% [31,15\%; 34,67\%] do total de propriedades amostradas. As ordenhas dos tipos, mecânica com balde ao pé e mecânica em sala de ordenha, foram encontradas em algumas destas criações apresentando resultados de 0,55\% [0,29\%; 1,02\%] e 0,02\% [0,00\%; 0,13\%], respectivamente. Considerando a exploração prioritária de carne por parte destes estabelecimentos e o pequeno número de vacas em lactação, um baixo investimento em tecnologias de ordenha já seria esperado.

Das propriedades de exploração exclusivamente leiteira, estimou-se que 75,55\% [74,07\%; 76,97\%] delas ainda utilizam a técnica manual de ordenha, enquanto que o sistema mecânico com balde ao pé e o sistema mecânico em sala de ordenha, são utilizados em 18,09\% [16,77\%; 19,49\%] e 6,36\% [5,51\%; 7,33\%] destes estabelecimentos, respectivamente. Nas propriedades de exploração mista, o sistema de ordenha predominante também foi a manual, sendo a sua utilização estimada em 95,24\% [94,42\%; 95,95\%] dos estabelecimentos. Estas explorações apresentaram frequências de utilização de ordenhas mecanizadas ainda menores do que as explorações exclusivas de leite. A prevalência de estabelecimentos que utilizam a ordenha mecânica com balde ao pé foi de 3,87\% [3,21\%; 4,65\%] e de ordenha mecânica em sala de ordenha de 0,89\% [0,64\%; 1,23\%]. Estes valores revelam que o investimento em tecnologias de ordenha ainda é pouco empregado nestes tipos de exploração.

Os mapas 33, 34 e 35 demonstram as frequências destes três tipos de ordenha encontradas nos circuitos produtores. Através deles observa-se que os circuitos do quartil superior que mais utilizam ordenhas mecanizadas se encontram, de maneira geral, nos circuitos onde a atividade leiteira é mais explorada, ou seja, principalmente nos diversos circuitos do sul e sudeste do país. 


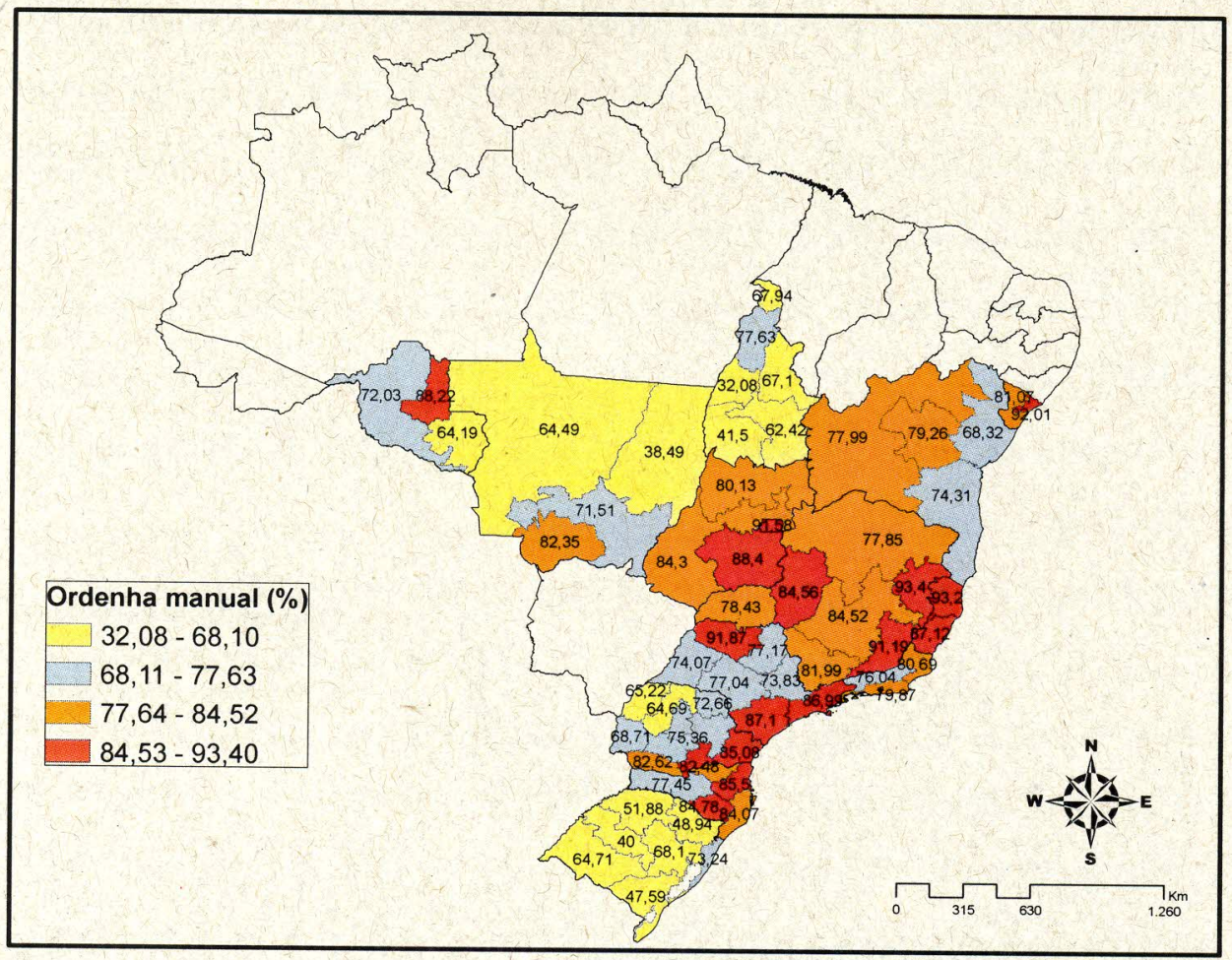

Mapa 33- Distribuição das frequências estimadas por circuito de propriedades que realizam a ordenha manual- Brasil - out 2001-dez 2004

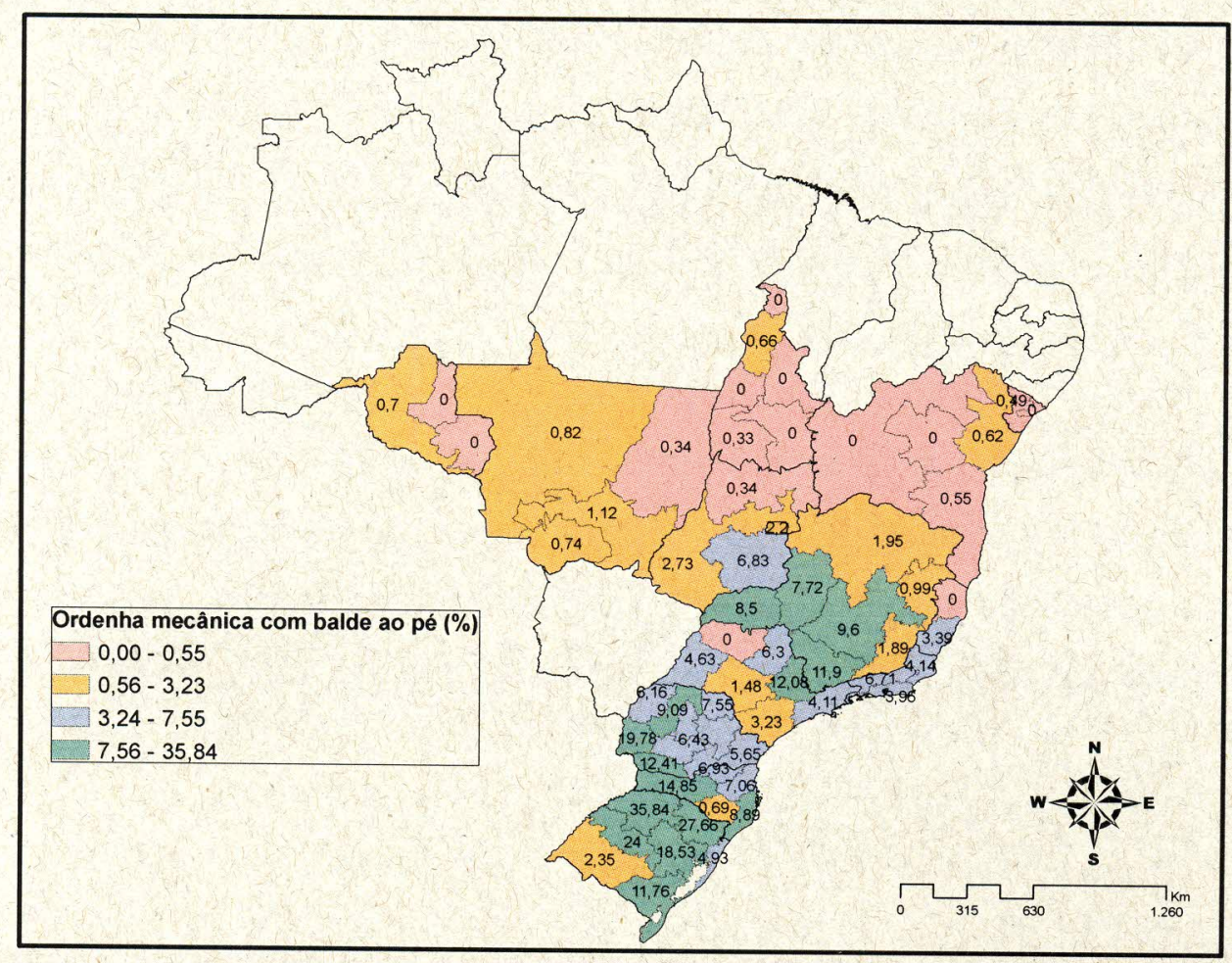

Mapa 34- Distribuição das frequências estimadas por circuito de propriedades que realizam a ordenha mecânica com balde ao pé- Brasil - out 2001-dez 2004 


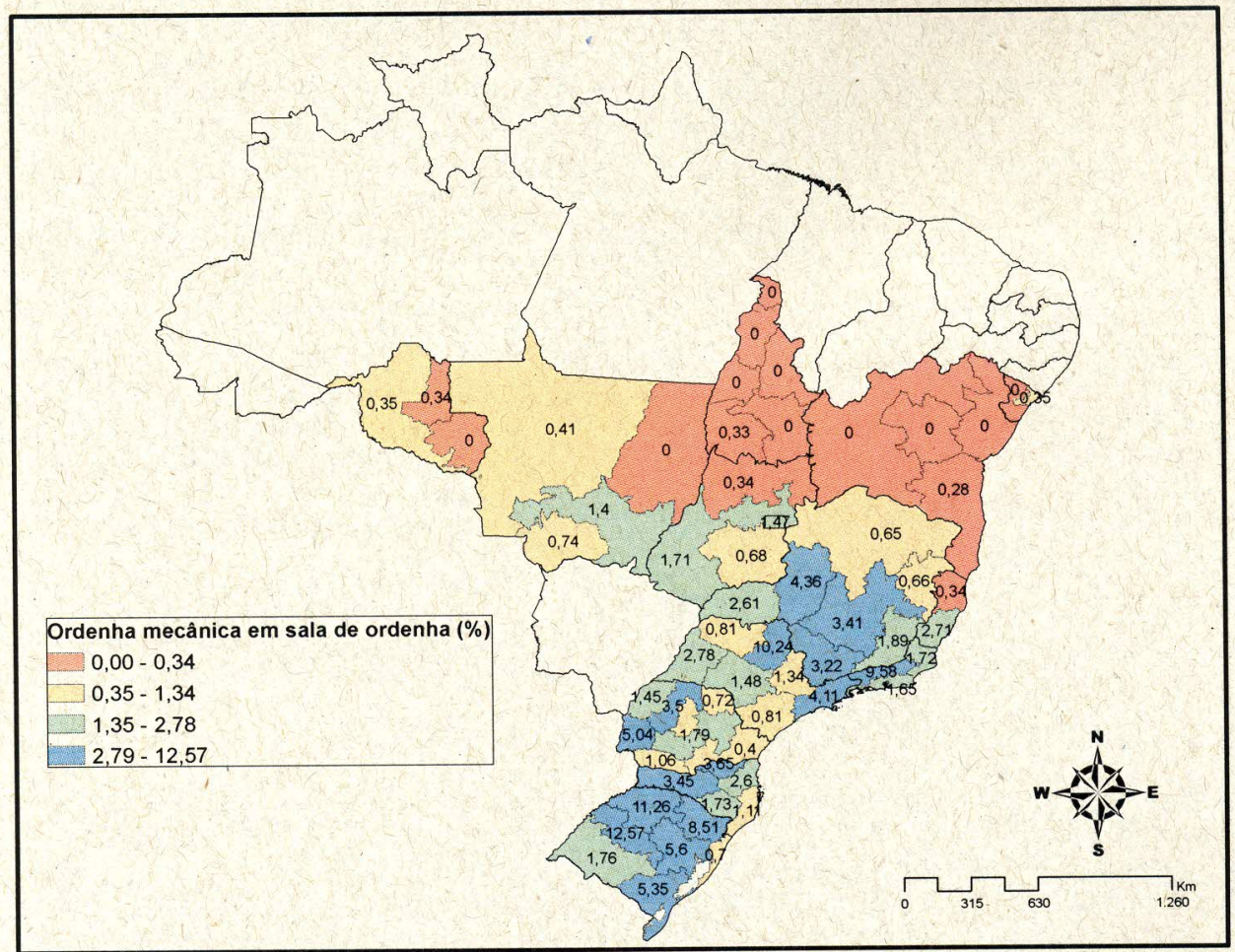

Mapa 35- Distribuição das frequências estimadas por circuito de propriedades que realizam a ordenha mecânica em sala de ordenha- Brasil - out 2001-dez 2004

4.1.5.3 Tipo de ordenha e número de ordenhas diárias

Cruzando os dados de tecnologia de ordenha com o número de ordenhas praticadas, estimou-se que $71,39 \%[70,45 \% ; 72,30 \%]$ dos locais onde a ordenha manual é empregada, esta é realizada apenas uma vez ao dia e em $28,61 \%$ dos rebanhos restantes, a ordenha é realizada duas ou mais vezes durante o dia. Comparativamente, os rebanhos que utilizam as ordenhas mecanizadas, realizam em geral mais de uma ordenha durante o dia com 93,19\% [91,46\%; 94,59\%] e 96,78 $[94,40 \% ; 98,17 \%]$, respectivamente para ordenhas mecânicas com balde ao pé e mecânicas em sala de ordenha (Tabela 12).

Os resultados demonstram que 0 investimento em tecnologias de ordenha, via de regra, é realizado mais frequentemente em rebanhos leiteiros com manejos de ordenha mais intensivos e consequentemente, de maior produtividade. Estes argumentos concordam com os trabalhos de Picinin (2003) e Gomes (2006), os quais identificaram que quanto maior a produção dos rebanhos, maior o investimento em frequência e mecanização das ordenhas. 
Tabela 12- Distribuição das frequências estimadas do número de ordenhas realizadas nas segundo o tipo de ordenha adotada- Brasil - out 2001-dez 2004

\begin{tabular}{ccccccccc}
\multicolumn{70}{c}{ Segundo 0 tipo de ordenha adotada- Brasil - out 2001-dez 2004 } \\
\hline $\begin{array}{c}N^{\circ} \\
\text { ordenhas/dia }\end{array}$ & $\begin{array}{c}\text { Manual } \\
\text { (\%) }\end{array}$ & IC 95\% & $\begin{array}{c}\text { Mecânica } \\
\text { ao pé } \\
(\%)\end{array}$ & IC 95\% & $\begin{array}{c}\text { Mecânica } \\
\text { em sala de } \\
\text { ordenha } \\
(\%)\end{array}$ & IC 95\% & $\begin{array}{c}\text { Total } \\
(\%)\end{array}$ & IC 95\% \\
\hline $\begin{array}{c}1 \text { vez/dia } \\
\text { 2 ou 3 } \\
\text { vezes/dia }\end{array}$ & 71,39 & 70,$45 ; 72,30$ & 6,81 & 5,$41 ; 8,54$ & 3,22 & 1,$83 ; 5,60$ & 53,39 & 52,$58 ; 54,20$ \\
\hline Total & 28,61 & 27,$70 ; 29,55$ & 93,19 & 91,$46 ; 94,59$ & 96,78 & 94,$40 ; 98,17$ & 32,41 & 31,$71 ; 33,12$ \\
\hline
\end{tabular}

\subsubsection{Resfriamento do leite}

A temperatura de armazenamento do leite após a ordenha é um dos principais fatores que determinam a taxa de crescimento bacteriano neste produto. Além dos fatores relacionados à higiene da ordenha, o emprego de técnicas de resfriamento, seguida da coleta e transporte em veículos isotérmicos, são fatores que podem aumentar significativamente a qualidade do leite produzido. Sendo assim, as propriedades foram interrogadas a respeito da utilização deste manejo pós-ordenha. No geral, estimou-se que 25,76\% [24,95\%; 26,59\%] das criações que exploram o leite, declararam resfriar o leite logo após o manejo da ordenha (Tabela 13).

Tabela 13- Distribuição das frequências estimadas de propriedades que realizam o resfriamento do leite após a ordenha segundo os tipos de exploração pecuária- Brasil - out 2001-dez 2004

\begin{tabular}{ccccccccc|}
\hline \multicolumn{1}{c|}{ Tipo de Exploração } \\
\hline $\begin{array}{c}\text { Resfriamento } \\
\text { do leite }\end{array}$ & $\begin{array}{c}\text { Corte } \\
\mathbf{( \% )}\end{array}$ & IC $\mathbf{9 5 \%}$ & $\begin{array}{c}\text { Leite } \\
\mathbf{( \% )}\end{array}$ & IC 95\% & $\begin{array}{c}\text { Mista } \\
\mathbf{( \% )}\end{array}$ & IC 95\% & $\begin{array}{c}\text { Total } \\
\mathbf{( \% )}\end{array}$ & IC 95\% \\
\hline Não & 97,43 & 96,$59 ; 98,06$ & 55,71 & 54,$18 ; 57,24$ & 82,41 & 81,$15 ; 83,60$ & 74,24 & 73,$41 ; 75,05$ \\
Sim & 2,57 & 1,$94 ; 3,41$ & 44,29 & 42,$76 ; 45,82$ & 17,59 & 16,$40 ; 18,85$ & 25,76 & 24,$95 ; 26,59$ \\
\hline Total & 100,00 & & 100,00 & & 100,00 & & 100,00 \\
\hline
\end{tabular}

Estratificando por tipo de exploração, observa-se que as propriedades de corte que possuem animais em lactação no rebanho e que resfriam o leite logo após a ordenha, foram pouco representativas no total de criações desta exploração $(2,57 \%$ [1,94\%; 3,41\%]). Pelo fato destes rebanhos não se utilizarem da exploração 
leiteira como uma importante fonte de renda e na maioria dos casos o leite produzido serve para consumo próprio, provavelmente o investimento em tecnologias para a melhoria da qualidade do leite não seja comumente empregado.

O tipo de exploração onde o emprego do resfriamento leiteiro apresentou-se mais frequente, foi nas criações onde a exploração econômica reside prioritariamente na produção leiteira, nas quais 44,29\% [42,76\%; 45,82\%] destes rebanhos este manejo pós-ordenha foi encontrado. Nas criações mistas, este manejo foi representativo em $17,59 \%$ [16,40\%; 18,85\%] destes locais e nas de corte em $2,57 \%[1,94 \% ; 3,41 \%]$.

O Estado onde a prevalência de resfriamento do leite pós-ordenha apresentou o maior resultado foi o Rio Grande do Sul, onde aproximadamente metade dos estabelecimentos que produzem leite, realizam o seu resfriamento $(50,57 \%$ [47,60\%; $53,53 \%$ ]) (Mapa 36). O quartil superior com as maiores proporções entre os circuitos pecuários (>28,66\%) foi integrado pelas regiões centro-norte do Rio Grande do Sul; oeste de Santa Catarina; oeste Paranaense; região centro-sul fluminense; sul do Espírito Santo; Zona da Mata, centro-oeste e Triângulo Mineiro em Minas Gerais e regiões do centro-sul de Goiás (Mapa 37).

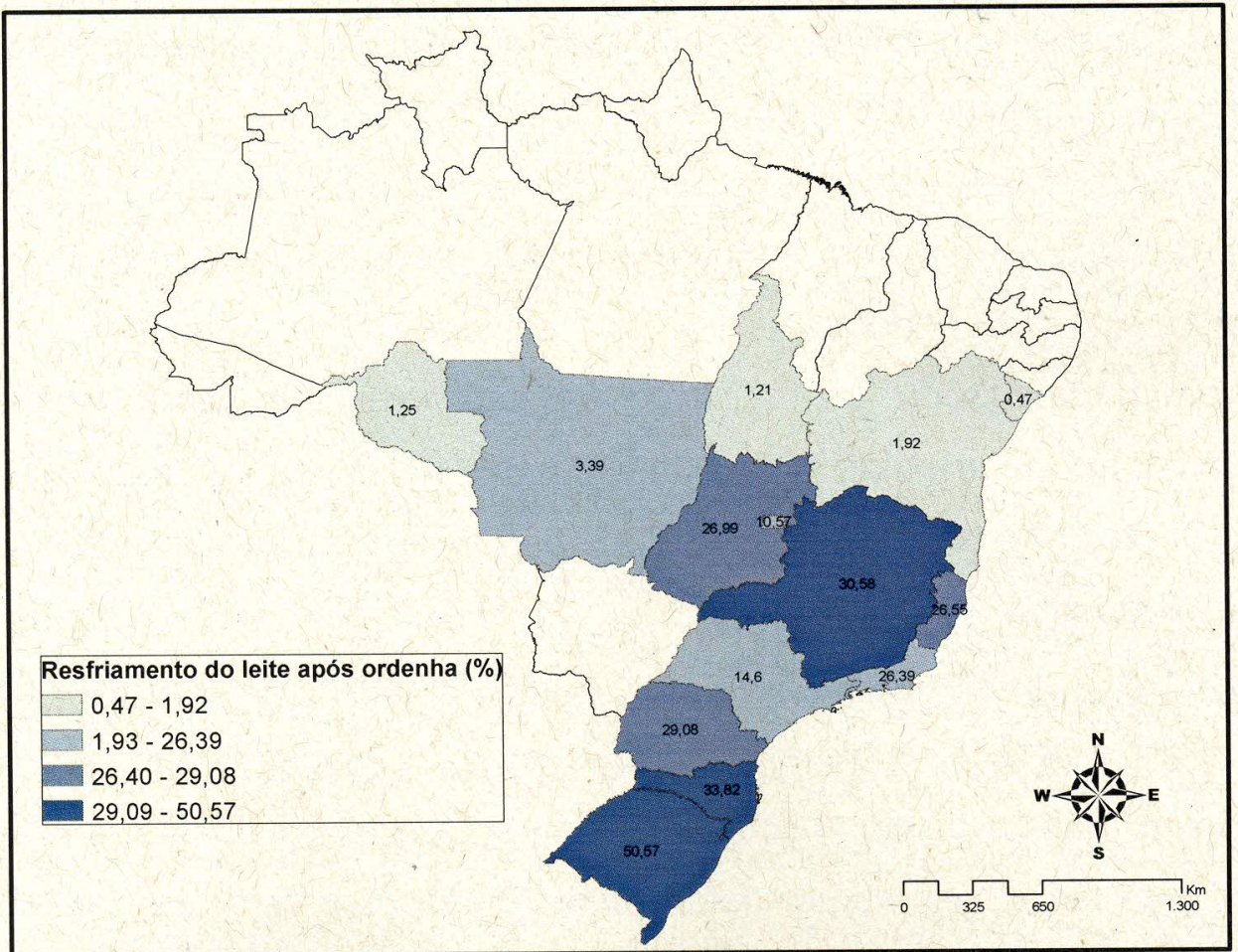

Mapa 36- Distribuição das frequências estimadas de propriedades que realizam o resfriamento do leite após a ordenha nos EstadosBrasil - out 2001-dez 2004 


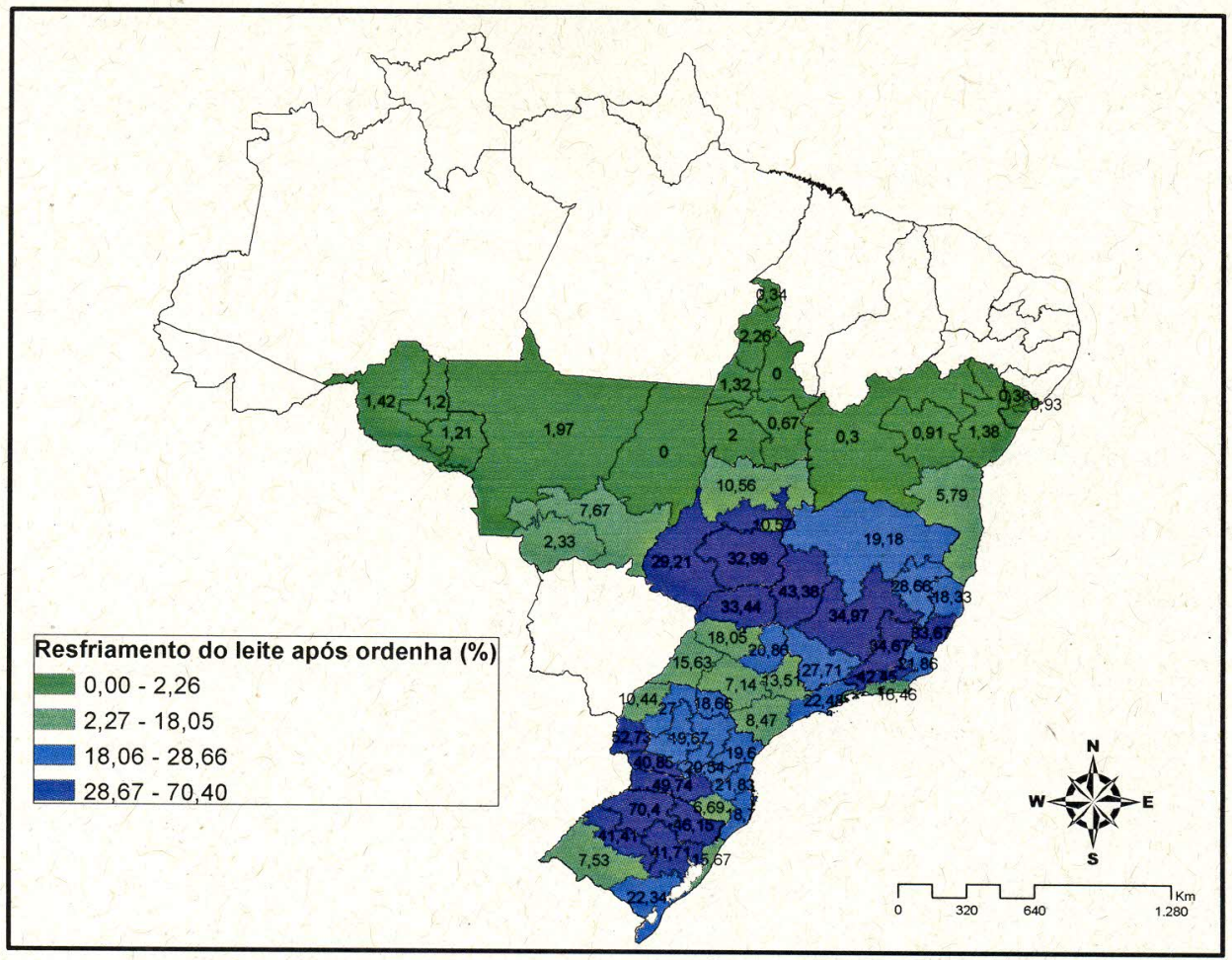

Mapa 37- Distribuição das frequências estimadas de propriedades que realizam o resfriamento do leite após a ordenha nos EstadosBrasil - out 2001-dez 2004

Estas mesmas propriedades foram questionadas quanto ao método de resfriamento do leite que utilizavam, podendo ser em tanques de expansão próprios ou em tanques coletivos. Os tanques de expansão, também chamados de tanques de resfriamento ou tanques de expansão direta, são equipamentos que recebem e armazenam o leite a granel, promovendo o seu resfriamento direto. Estes tanques são instalados em propriedades rurais ou em comunidades, visando atender um produtor em particular ou a grupos de produção de leite. A implementação da estocagem do refrigerado nas fontes de produção iniciou-se no Brasil na década de 90 e acabou sendo regulamentada em 2002 pelo Ministério da Agricultura através da Instrução Normativa $n^{\circ} 51$ (BRASIL, 2002). Esta prática representa algumas vantagens, tanto do ponto de vista econômico quanto do lado sanitário já que desacelera a proliferação excessiva de agentes microbiológicos no leite no período compreendido entre a ordenha e o beneficiamento e reduz custos operacionais de produção ao evitar as perdas por deterioração do produto pela atividade acidificante de bactérias mesófilas (PINTO; MARTINS; VANETTI, 2006). 
A maior parte das propriedades resfria o leite na propriedade, o faz através de tanques de expansão próprios (88,56\% [87,29\%; 89,72\%]). Em relação aos tipos de exploração, não foram encontrados valores díspares entre eles, sendo que tanto nas propriedades de corte, de leite ou mistas que realizam o resfriamento do leite produzido, a maior parte demonstrou realizar o processo através de tanques de resfriamento próprios (Tabela 14).

Tabela 14- Distribuição das frequências estimadas de locais onde o leite é resfriado segundo o tipo de exploração- Brasil - out 2001-dez 2004

\begin{tabular}{ccccccccc}
\hline \multicolumn{7}{c}{ Tipo de Exploração } \\
\hline Como resfria & $\begin{array}{c}\text { Corte } \\
(\%)\end{array}$ & IC 95\% & $\begin{array}{c}\text { Leite } \\
(\%)\end{array}$ & IC 95\% & $\begin{array}{c}\text { Mista } \\
(\%)\end{array}$ & IC 95\% & $\begin{array}{c}\text { Total } \\
(\%)\end{array}$ & IC 95\% \\
\hline $\begin{array}{c}\text { Resfriador ou } \\
\text { tanque próprio } \\
\begin{array}{c}\text { Resfriador ou } \\
\text { tanque coletivo }\end{array}\end{array}$ & 87,86 & 75,$70 ; 94,38$ & 90,47 & 89,$02 ; 91,75$ & 83,39 & 80,$49 ; 85,93$ & 88,56 & 87,$29 ; 89,72$ \\
\hline Total & 12,14 & 5,$62 ; 24,30$ & 9,53 & 8,$25 ; 10,98$ & 16,61 & 14,$07 ; 19,51$ & 11,44 & 10,$28 ; 12,71$ \\
\hline
\end{tabular}

Apesar da utilização de tanques de resfriamento próprios representaram uma evolução na tentativa dos produtores para garantir a qualidade do produto e/ou atenderem as exigências feitas pelos laticínios, nem todos possuem condições financeiras para investir neste tipo de tecnologia. Em uma cadeia produtiva onde os custos médios de produção são regulados ao máximo, como no caso da pecuária leiteira, toda intenção em investir em tecnologia pode ser limitada simplesmente por conta das suas implicações financeiras nos custos de produção. Partindo deste pressuposto, uma alternativa interessante para produtores que não têm condição de adquirir e instalar um tanque de expansão próprio, seria a associação com outros em comunidades onde o leite poderia ser resfriado em tanques coletivos localizados estrategicamente.

Melo e Reis (2007), consideram os tanques de expansão coletivos uma alternativa de desenvolvimento regional para produtores familiares, demonstrando que as principais variáveis motivacionais indicadas pelos produtores para a implantação de tanques comunitários foram as exigências por parte dos laticínios, o poder de barganha no preço dos seus excedentes, a redução nos custos de transporte e o cumprimento de normais legais. Isto implica que para se adaptar às novas injunções propostas à cadeia agroindustrial, os atores do sistema tendem a se reorganizar e encontrar novas estratégias para satisfazer os requisitos impostos. 
Outra possível vantagem decorrente da adoção de tanques de expansão coletivos em comunidades de agropecuária familiar, seria a implicação indireta no aumento da renda das comunidades de produtores quando da adoção desta tecnologia. Oliveira et al. (2008) ao estudar os impactos dos tanques coletivos na inserção de produtores familiares de Unaí (MG) no mercado, encontrou que após alguns anos da instalação dos tanques de expansão nas comunidades, a renda obtida através da venda do leite aumentou em virtude da maior quantidade e qualidade do produto comercializado. Devido ao aumento da capitalização, os produtores ficaram estimulados a melhorar a produção investindo na redução de custos desnecessários, higiene da ordenha, alimentação de qualidade aos animais e na qualidade zootécnica dos rebanhos.

\subsubsection{Destino do leite produzido}

Os estabelecimentos onde se produzia leite, foram questionados também a respeito do seu destino. Os destinos possíveis abordados no questionário epidemiológico poderiam ser: não entrega, entrega às cooperativas, entrega em laticínios ou entregam direto ao consumidor. Importante ressaltar que neste caso, mais de uma opção poderia ser assinalada durante a entrevista.

Uma parcela de 43,81\% [42,84\%; 44,79\%] dos locais que possuem vacas em lactação, afirmou que não entrega o leite produzido. Dos que oferecem um destino para o leite, 31,49\% [30,57\%; 32,42\%] o faz para laticínios, seguido das entregas para cooperativas $(16,72 \%[15,93 \% ; 17,53 \%])$ e com menor frequência, as entregas direto ao consumidor $(7,98 \%[7,47 \% ; 8,52 \%])$ (Tabela 15).

Tabela 15- Distribuição das frequências estimadas do destino de entrega do leite segundo o tipo de exploração pecuária- Brasil - out 2001-dez 2004

\begin{tabular}{|c|c|c|c|c|c|c|c|c|}
\hline \multirow[b]{2}{*}{ Destino do leite } & \multicolumn{8}{|c|}{ Tipo de Exploração } \\
\hline & $\begin{array}{c}\text { Corte } \\
(\%)\end{array}$ & IC $95 \%$ & $\begin{array}{l}\text { Leite } \\
(\%)\end{array}$ & IC $95 \%$ & $\begin{array}{c}\text { Mista } \\
(\%)\end{array}$ & IC $95 \%$ & $\begin{array}{c}\text { Total } \\
(\%)\end{array}$ & IC 95\% \\
\hline Não entrega & 83,70 & 81,$07 ; 86,03$ & 25,41 & 24,$11 ; 26,76$ & 55,22 & 53,$77 ; 56,66$ & 43,81 & 42,$84 ; 44,79$ \\
\hline Cooperativa & 2,95 & 1,$87 ; 4,61$ & 25,14 & 23,$73 ; 26,60$ & 10,66 & 9,$74 ; 11,66$ & 16,72 & 15,$93 ; 17,53$ \\
\hline Laticínio & 10,58 & 8,$76 ; 12,73$ & 40,52 & 38,$98 ; 42,07$ & 26,15 & 24,$94 ; 27,41$ & 31,49 & 30,$57 ; 32,42$ \\
\hline $\begin{array}{c}\text { Direto ao } \\
\text { consumidor }\end{array}$ & 2,77 & 1,$86 ; 4,12$ & 8,93 & 8,$14 ; 9,79$ & 7,97 & 7,$22 ; 8,79$ & 7,98 & 7,$47 ; 8,52$ \\
\hline Total & 100,00 & & 100,00 & & 100,00 & & 100,00 & \\
\hline
\end{tabular}


Nos tipos de exploração, verifica-se que nos estabelecimentos de corte poucos entregam o leite que é produzido na propriedade sendo que cerca de $83,70 \%$ [81,07\%; 86,03\%] dos locais não realiza a entrega. Da pequena parcela que o faz, a maior parte entrega em laticínios.

Nas propriedades de produção exclusivamente leiteira, a maioria realiza a entrega para laticínios 40,52\% [38,98\%; 42,07\%], cerca de 25,14\% [23,73\%; 26,60\%] entrega o leite para cooperativas. As entregas feitas diretamente aos consumidores demonstraram-se menos frequentes. Uma parcela considerável de $25,41 \%$ [24,11\%; 26,76\%] dos locais, apesar da exploração leiteira ser a atividade principal do rebanho, alegou não entregar o leite produzido na propriedade.

Nas criações de exploração mista, a maior parte alegou não entregar o leite produzido na propriedade $(55,22 \%[53,77 \% ; 56,66])$, sendo que o destino mais comum entre elas também foi os laticínios 26,15\% [24,94\%; 27,41\%], seguido das cooperativas $(10,66 \%[9,74 \% ; 11,66 \%])$ e por fim, as entregas direcionadas aos consumidores (7,97\% [7,22\%; 8,79\%]).

Observa-se na análise geral que a proporção de leite que possivelmente é comercializado de maneira informal (o leite que não é entregue somado ao leite que é comercializado diretamente aos consumidores), apresentou valores que se aproximam de $50 \%$ do leite produzido nas propriedades. Os resultados se assemelham com estimativas descritas por alguns autores a respeito do mercado de leite no país, os quais descrevem dois tipos de mercado leiteiro existentes no Brasil: o formal e o informal. Ambos economicamente expressivos considerando que alguns apontam que o mercado informal de leite representa aproximadamente $45 \%$ de toda a produção no país (estimativa calculada através da diferença produção total e a produção de leite inspecionado). Todavia, ao retirar deste total o leite para consumo próprio, ou seja, que é consumido no próprio estabelecimento, sugerem que o mercado informal representaria cerca de $15 \%$ do volume de leite produzido no país (JUNIOR, 2001; GOMES, 1999; VILELA, 1999). Outras estatísticas à respeito do comércio informal de leite, apontam para proporções de informalidade que ficam em torno de 30 a $40 \%$ do volume total de leite produzido no país (ANUALPEC, 2002; FARINA et al., 2000)

Junior (2001) relata que o leite formalmente comercializado no país se dá através de indústrias particulares e cooperativas, as quais em geral, possuem 
fiscalização quanto à qualidade e ao recolhimento de impostos. Quanto ao mercado informal, este não é fiscalizado sob nenhum aspecto e pode neste caso representar diversos riscos sanitários para os consumidores.

O comércio informal apresenta-se como uma realidade presente em diversos setores econômicos, sendo que em alguns deles é mais ativa e preocupante. Esta característica em, muitos casos, está vinculada às atividades marginais ou residuais da sociedade, contudo, considerada como aspecto central das dinâmicas econômicas e sociais de qualquer país, principalmente daqueles em desenvolvimento, como o Brasil (GOMES, 2000; BANKUTI; SCHIAVI; SOUZA FILHO, 2005).

No setor lácteo, além dos problemas decorrentes da não arrecadação de impostos e da não geração de novos empregos, as altas taxas de informalidade incorrem em problemas de saúde pública e da segurança de alimentos, tendo em vista que diversos agentes infecciosos podem ser veiculados e transmitidos através do leite, destacando-se as intoxicações e infecções bacterianas (brucelose, tuberculose, listeriose, clostridioses, toxina estafilocócica, toxina estreptocócica, salmonelose) e as ricketisioses (febre Q), além do potencial de veiculação de toxinas, metais pesados, fármacos e inseticidas (BRANDÃO, 1994).

\subsubsection{Produtividade leiteira}

Os estabelecimentos visitados foram questionados a respeito do número de vacas em lactação e do total de leite produzido diariamente na propriedade. Através da divisão desta por aquela, foi obtida a variável de produção diária média de leite por vaca.

Nos rebanhos de exploração prioritária de leite, a quantidade produzida em média pelas propriedades foi de 114,07 litros por dia e a mediana desta produção foi de 50 litros. O número médio de vacas em lactação nestas propriedades foi de 15,65, com uma mediana de 10 e a produção média de leite por vaca foi de 6,51 litros por dia, com uma mediana de cinco litros (Tabela 16). 
Tabela 16- Valores de produção diária de leite por estabelecimento e por vaca em lactação e do número de vacas em lactação segundo os tipos de exploração pecuária - Brasil - out 2001-dez 2004

\begin{tabular}{|c|c|c|c|c|c|}
\hline & & & Vacas em lactação & Produção total (Itrs.) & $\begin{array}{c}\text { Produção média por } \\
\text { vaca/dia }\end{array}$ \\
\hline \multirow{5}{*}{ 崩 } & \multirow{2}{*}{\multicolumn{2}{|c|}{$\begin{array}{c}\text { Média } \\
\text { Mediana }\end{array}$}} & 15,65 & 114,07 & 6,51 \\
\hline & & & 10,00 & 50,00 & 5,00 \\
\hline & \multirow{3}{*}{ 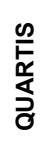 } & 25 & 4,00 & 20,00 & 3,75 \\
\hline & & 50 & 10,00 & 50,00 & 5,00 \\
\hline & & 75 & 20,00 & 120,00 & 8,00 \\
\hline \multirow{5}{*}{$\frac{0}{\frac{0}{5}}$} & \multirow{2}{*}{\multicolumn{2}{|c|}{$\begin{array}{c}\text { Média } \\
\text { Mediana }\end{array}$}} & 12,89 & 59,19 & 4,70 \\
\hline & & & 6,00 & 25,00 & 4,00 \\
\hline & \multirow{3}{*}{$\begin{array}{l}\frac{\omega}{\sigma} \\
\frac{\alpha}{\alpha} \\
\frac{\alpha}{\partial}\end{array}$} & 25 & 2,00 & 9,00 & 3,00 \\
\hline & & 50 & 6,00 & 25,00 & 4,00 \\
\hline & & 75 & 15,00 & 60,00 & 5,71 \\
\hline
\end{tabular}

Os maiores números de vacas em lactação por estabelecimento leiteiro, foram encontrados nas UFs de Goiás e do Tocantins (Gráfico 11), contudo, estes mesmos Estados demonstraram as menores eficiências de produção diária média de leite por vaca (Gráfico 13). Nas UFs de Goiás e Minas Gerais se encontraram as propriedades que produziram os maiores volumes de leite por dia (Gráfico 12).

Estes dados demonstram a expansão da pecuária leiteira para as áreas de cerrado. Diversos trabalhos vêm citando este processo contínuo de migração da exploração de leite do sudeste para estes locais a partir da década de 90 , sendo que as principais hipóteses para este fenômeno são os menores custos de produção obtidos nestes locais por conta dos menores preços dos insumos, da redução dos custos de terra e oportunidades de financiamentos (VILELA; CALEGAR, 1997; JANK; GALAN, 1999; GOMES, 1997; BRESSAN; VILELA, 1999; GOMES, 1999; FERNANDES et al., 2004). No entanto, apesar dos maiores tamanhos de rebanho, sugere-se que nestes locais os animais são criados predominantemente de maneira extensiva, com um grande número de animais por propriedade e com baixos investimentos no incremento da produtividade.

Os maiores índices de produtividade leiteira por vaca em lactação foram observados nos Estados do Sul (Rio Grande do Sul e Santa Catarina) e indicam que o maior investimento na genética dos rebanhos, sistemas de ordenha e tecnologias, proporcionaram as maiores produções individuais por animal já que nestes locais, geralmente, foram encontradas as maiores frequências de utilização de raças 
especializadas, sistemas de ordenha mais extensivos e investimento em técnicas como a inseminação artificial.

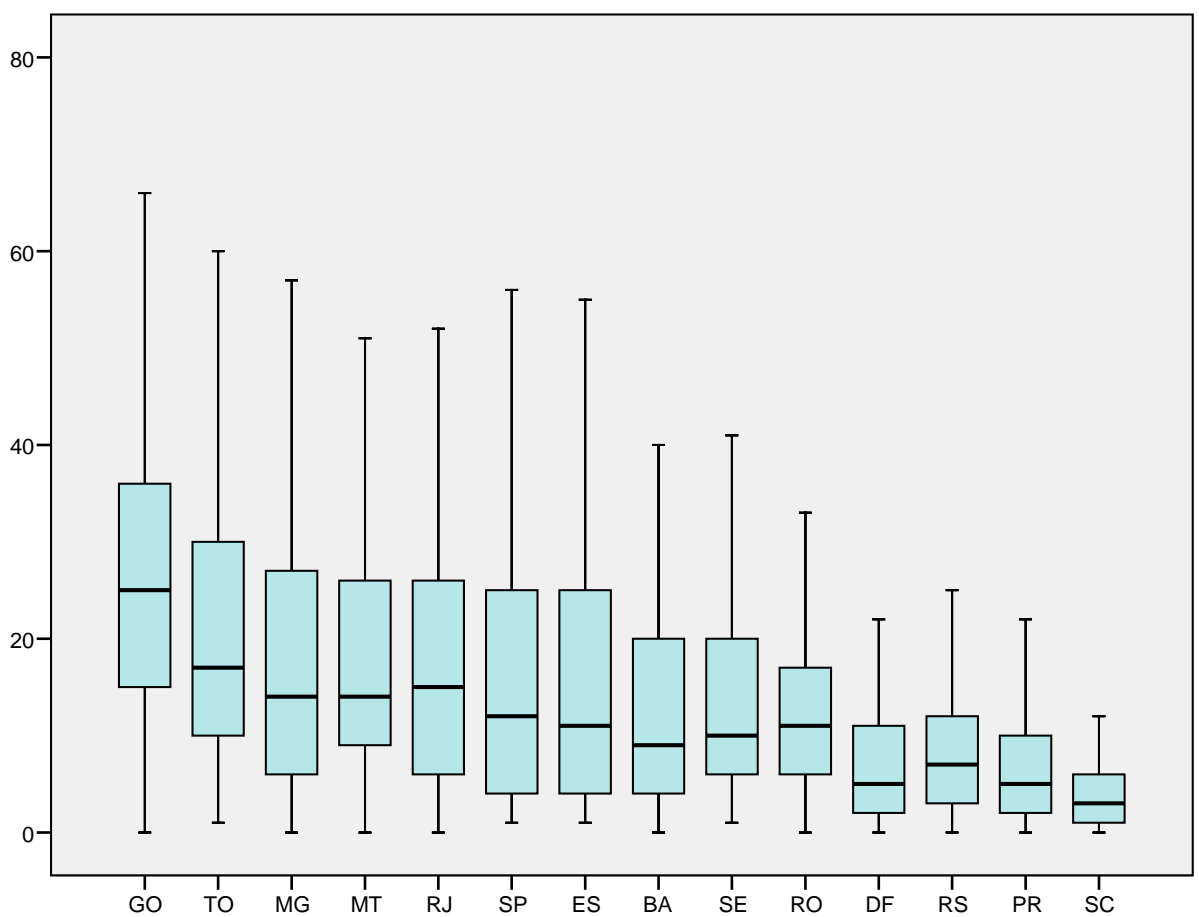

Gráfico 11- Diagrama de caixas do número de vacas em lactação nas explorações de leite por Unidade Federativa- Brasil - out 2001dez 2004

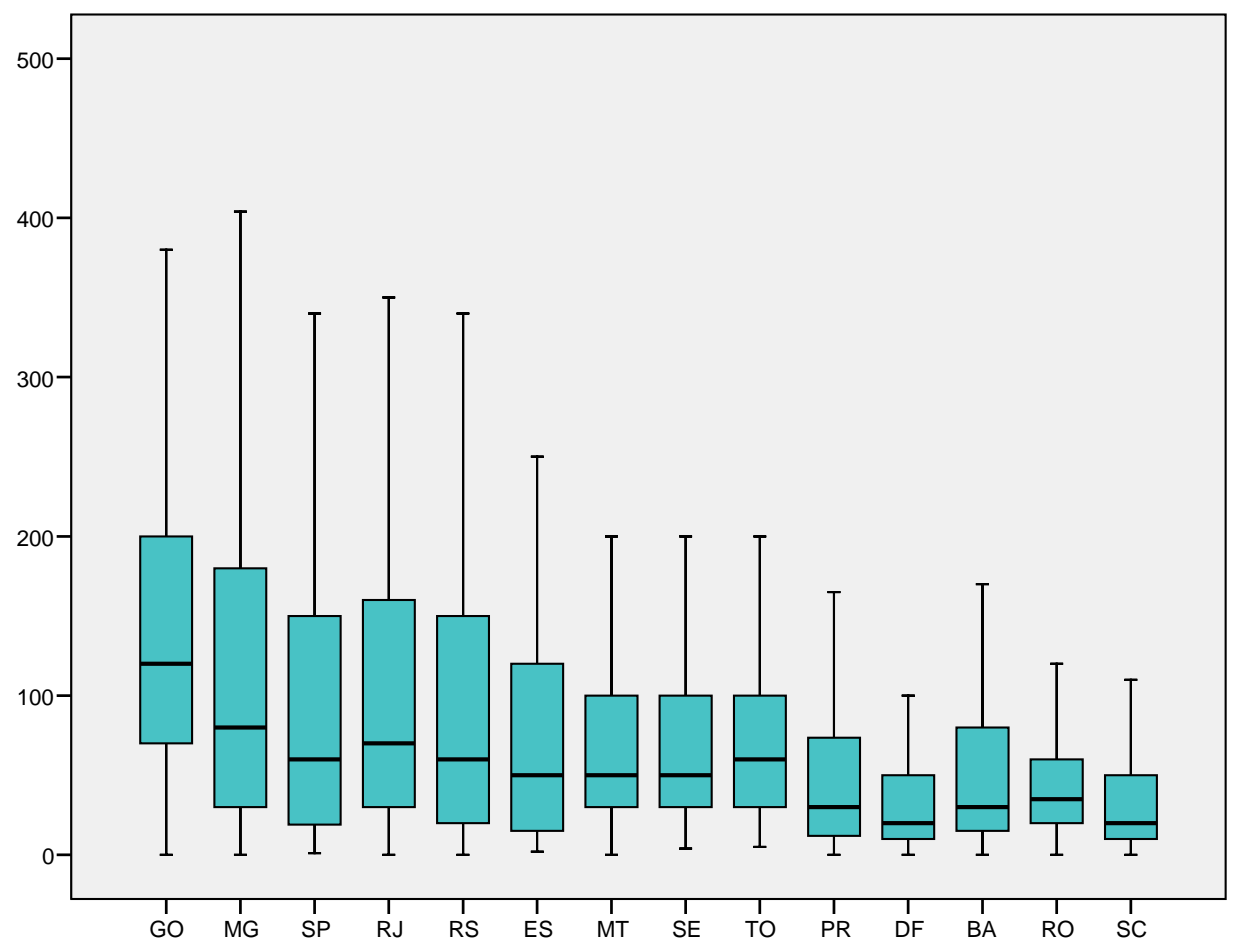

Gráfico 12- Diagrama de caixas da produção diária média de leite (litros) nos estabelecimentos de exploração leiteira por Unidade FederativaBrasil - out 2001-dez 2004 


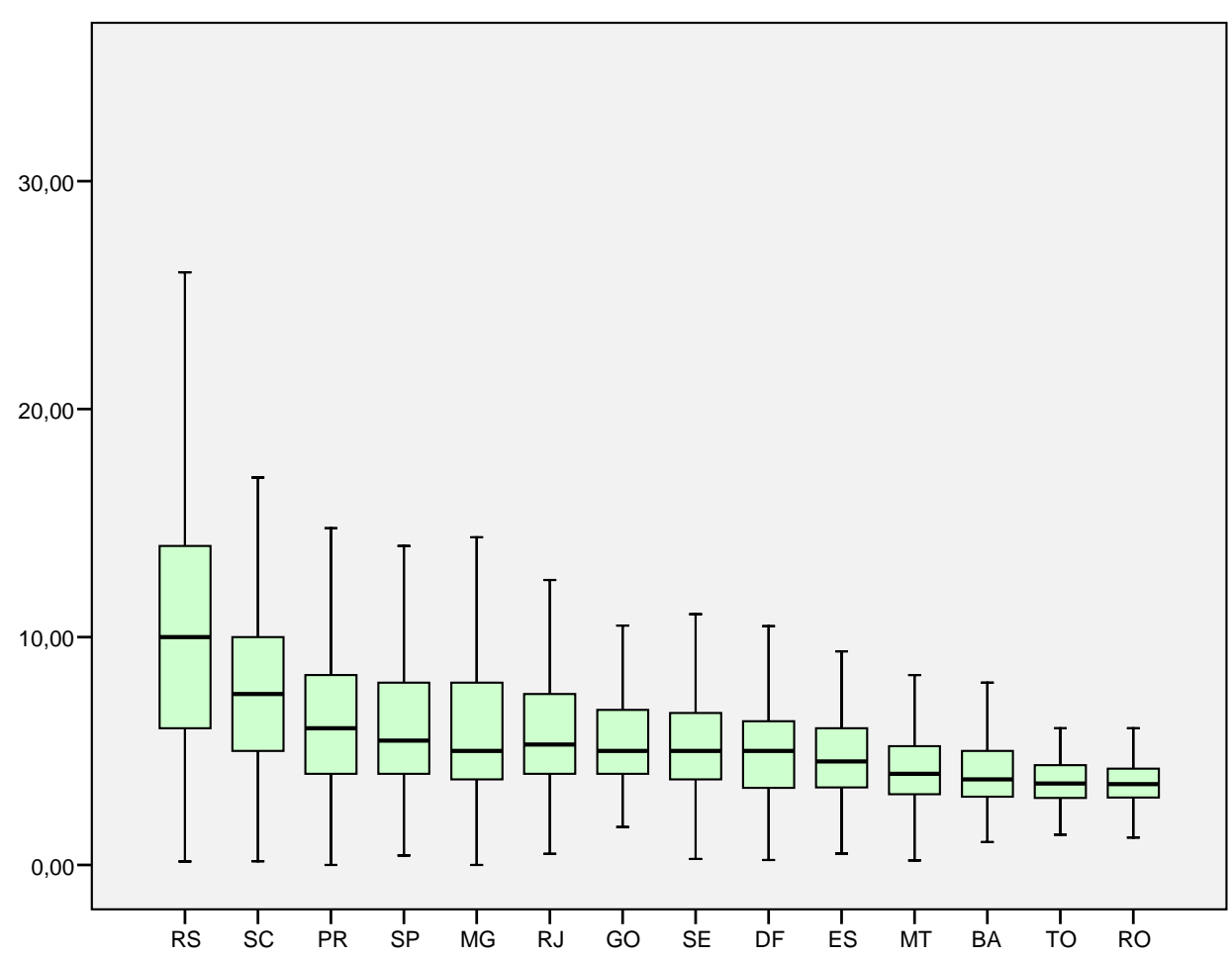

Gráfico 13- Diagrama de caixas da produção diária média de leite (litros) por vaca em lactação nas explorações leiteiras por Unidade Federativa- Brasil - out 2001-dez 2004

Os rebanhos mistos apresentaram uma média de 12,89 vacas em lactação por propriedade, sendo que 50\% destas possuem no máximo 6 vacas lactantes. A média da produção de leite total por estabelecimento foi de 59,19 litros com uma mediana de 25 litros. A produção de leite média por vaca em lactação foi de 4,70 com uma mediana de 4 litros (Tabela 16). Em todos estes casos os valores encontrados para os rebanhos mistos foram estatisticamente menores em relação às criações prioritariamente leiteiras $(p=0,000)$.

Nos rebanhos mistos, Goiás foi a UF que apresentou os maiores valores de vacas em lactação e de produção leiteira por propriedade (Gráficos 14 e 15). Quanto a produtividade média diária por vaca, o Rio Grande do Sul e Santa Catarina apresentaram os maiores índices (Gráfico 16). 


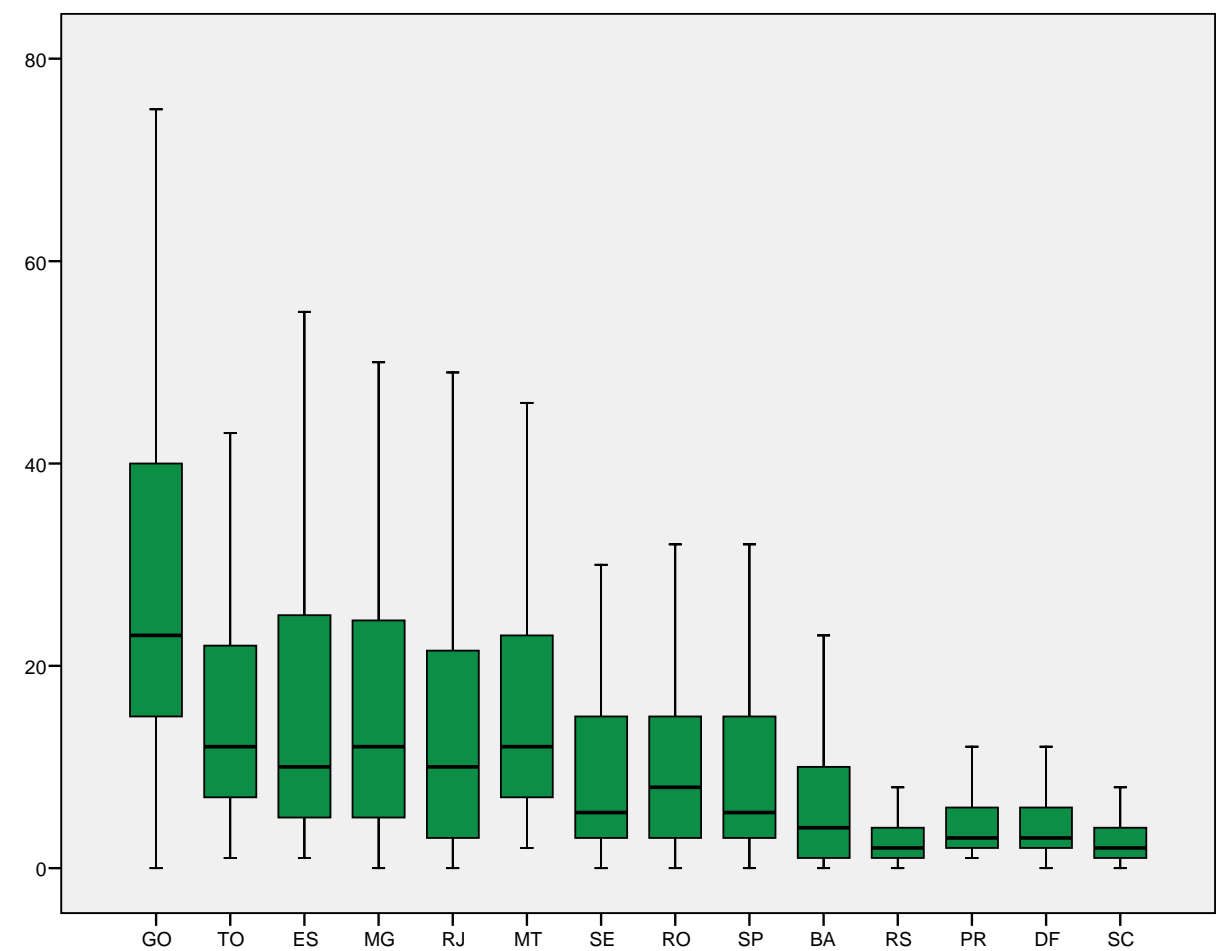

Gráfico 14- Diagrama de caixas do número de vacas em lactação nas explorações mistas por Unidade Federativa- Brasil - out 2001dez 2004

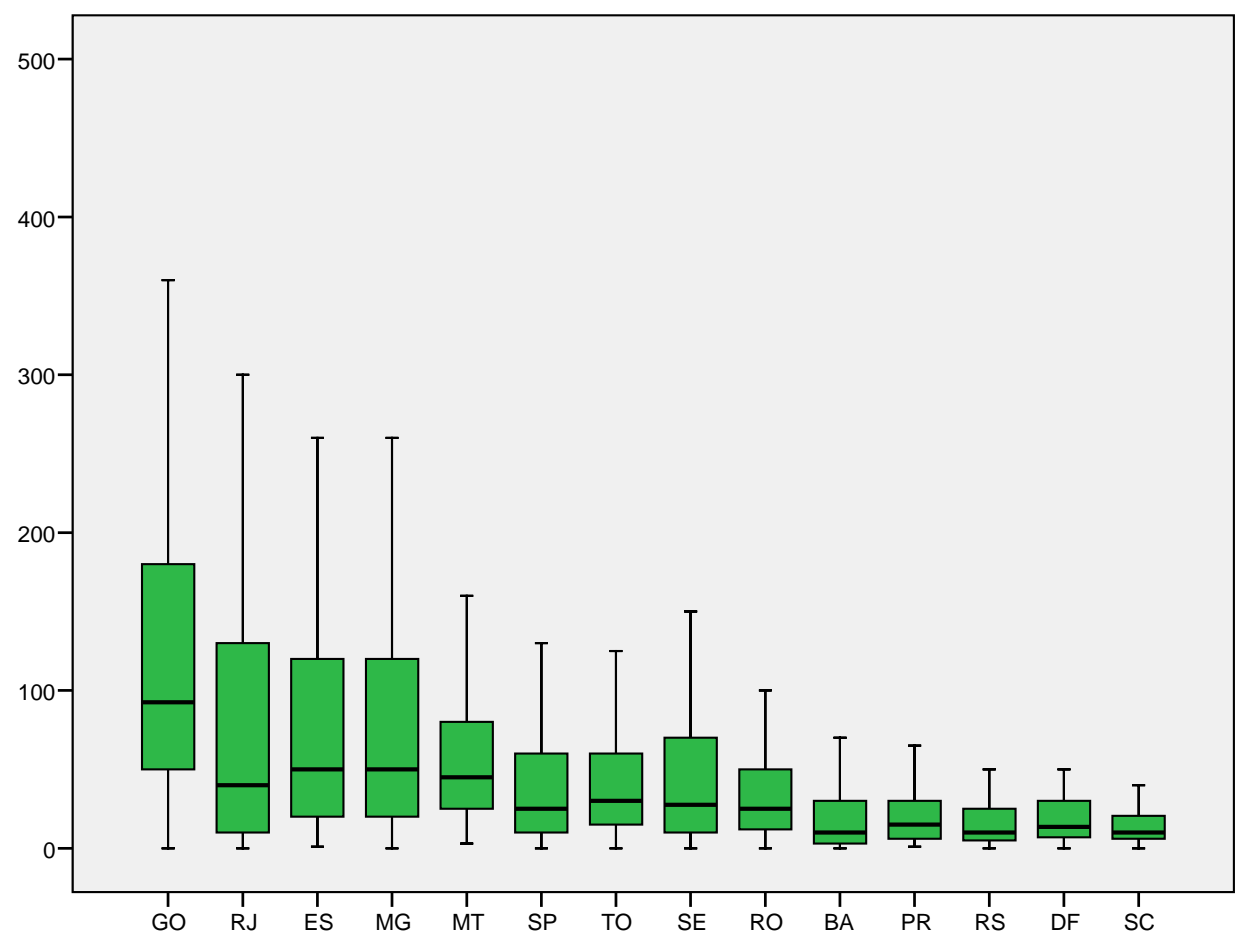

Gráfico 15- Diagrama de caixas da produção diária média de leite (litros) nos estabelecimentos de exploração mista por Unidade FederativaBrasil - out 2001-dez 2004 


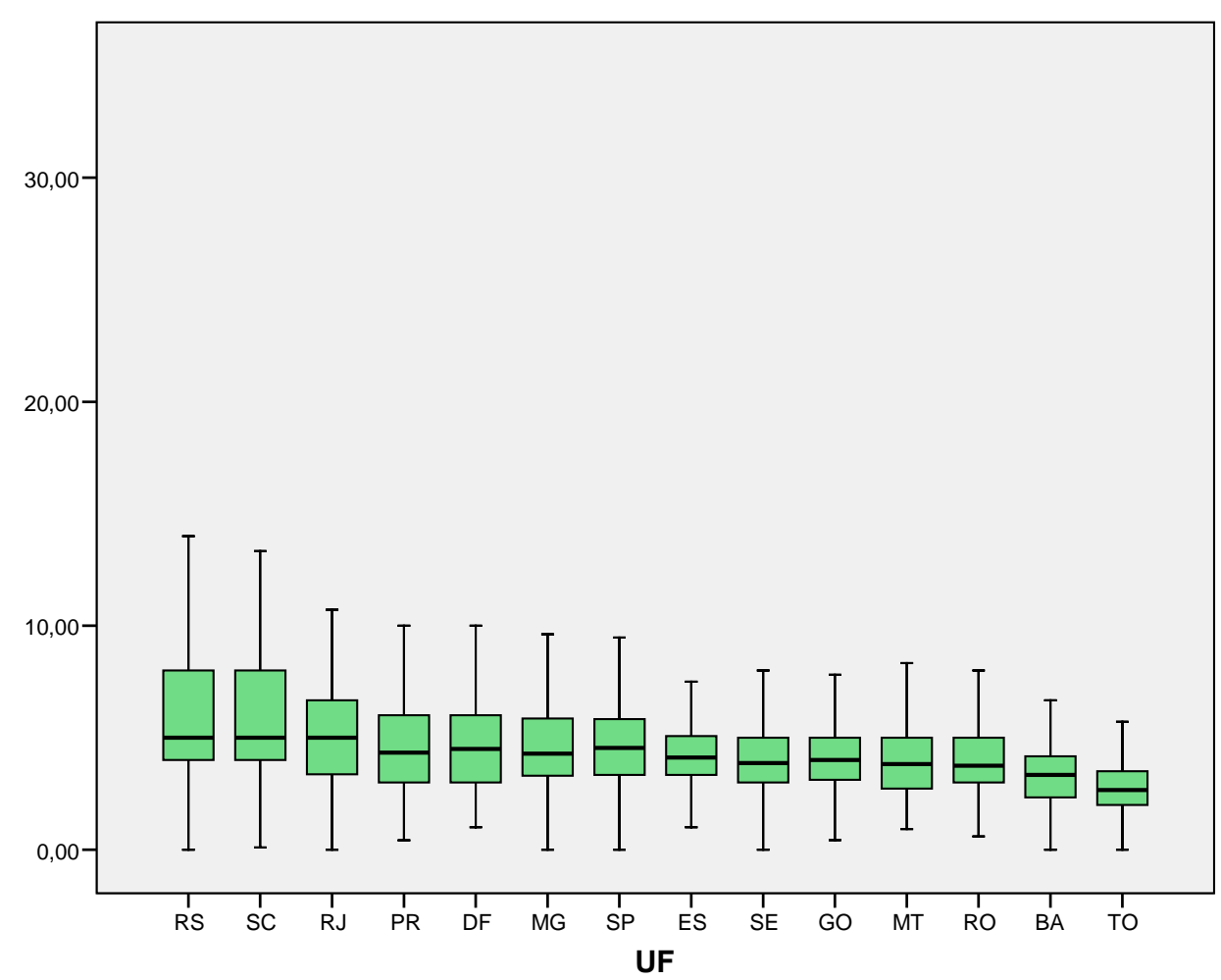

Gráfico 16- Diagrama de caixas da produção diária média de leite (litros) por vaca em lactação nas explorações mistas por Unidade Federativa- Brasil - out 2001-dez 2004

\subsection{CARACTERÍSTICAS DE IMPORTÂNCIA SANITÁRIA NOS REBANHOS}

As propriedades foram avaliadas em relação a algumas características que poderiam influenciar no perfil sanitário dos rebanhos, como: a presença de orientação técnica realizada por Médico Veterinário, utilização de piquetes maternidade, compra e venda de animais pra reprodução, presença de pastos em comum com outras propriedades, áreas de pastagens alugadas, pastos alagados com acesso livre pelo gado, ocorrência de abortos nos 12 meses anteriores, o destino dado aos restos de aborto e a utilização da inseminação artificial.

\subsubsection{Presença de assistência veterinária}

O resultado da análise geral das UFs revelou uma proporção estimada de 34,89\% [34,06; 35,73] de propriedades que possuem assistência veterinária periódica. O tipo de exploração pecuária que demonstrou as maiores frequências foi 
o de leite, com aproximadamente $44 \%$ de locais assistidos por Médicos Veterinários. As proporções de rebanhos de corte e misto que possuem orientação técnica foram parecidas e ficaram em cerca de $28 \%$ (Tabela 17 ).

Tabela 17- Distribuição das proporções estimadas de propriedades que possuem assistência técnica veterinária segundo o tipo de exploração pecuária- Brasil - out 2001-dez 2004

\begin{tabular}{ccccccccc}
\hline \multicolumn{7}{c}{ Tipo de exploração } \\
\hline $\begin{array}{c}\text { Assistência } \\
\text { Veterinária }\end{array}$ & $\begin{array}{c}\text { Corte } \\
(\mathbf{\%})\end{array}$ & IC $\mathbf{9 5 \%}$ & $\begin{array}{c}\text { Leite } \\
\mathbf{( \% )}\end{array}$ & IC $\mathbf{9 5 \%}$ & $\begin{array}{c}\text { Misto } \\
(\mathbf{\%})\end{array}$ & IC 95\% & $\begin{array}{c}\text { Total } \\
\text { (\%) }\end{array}$ & IC 95\% \\
\hline Não & 72,14 & 70,$55 ; 73,68$ & 55,75 & 54,$23 ; 57,27$ & 70,45 & 69,$06 ; 71,80$ & 65,11 & 64,$27 ; 65,94$ \\
Sim & 27,86 & 26,$32 ; 29,45$ & 44,25 & 42,$73 ; 45,77$ & 29,55 & 28,$20 ; 30,94$ & 34,89 & 34,$06 ; 35,73$ \\
\hline Total & 100,00 & & 100,00 & & 100,00 & & 100,00 \\
\hline
\end{tabular}

Quanto ao tipo de assistência veterinária nos locais assistidos, 54,93\% [53,22\%; 56,62\%] dos rebanhos possuem veterinários particulares, enquanto que nas 45,07\% [43,38\%; 46,78\%] de propriedades restantes o atendimento é realizado através de veterinários de cooperativa. Nos rebanhos de corte a maior parte dos atendimentos demonstraram ser realizados através de profissionais particulares, os quais participaram em $83 \%$ dos locais. No caso das propriedades de exploração leiteira e mista as diferenças entre os dois tipos de orientação técnica não demonstraram ser tão diferentes entre si, com valores próximos de 50\% em ambos os casos (Tabela 18).

Tabela 18- Distribuição do tipo de assistência veterinária segundo o tipo de exploração pecuária- Brasil - out 2001-dez 2004

\begin{tabular}{ccccccccc}
\hline \multicolumn{7}{c}{ Tipo de exploração } \\
\hline $\begin{array}{c}\text { Tipo de } \\
\text { assistência }\end{array}$ & $\begin{array}{c}\text { Corte } \\
\text { (\%) }\end{array}$ & IC 95\% & $\begin{array}{c}\text { Leite } \\
\text { (\%) }\end{array}$ & IC 95\% & $\begin{array}{c}\text { Misto } \\
\text { (\%) }\end{array}$ & IC 95\% & $\begin{array}{c}\text { Total } \\
\text { (\%) }\end{array}$ & IC 95\% \\
\hline $\begin{array}{l}\text { Veterinário } \\
\text { cooperativa } \\
\text { Veterinário } \\
\text { particular }\end{array}$ & 16,14 & 13,$67 ; 18,95$ & 54,48 & 51,$87 ; 57,06$ & 46,15 & 43,$18 ; 49,14$ & 45,07 & 43,$38 ; 46,78$ \\
\hline Total & 83,86 & 81,$05 ; 86,33$ & 45,52 & 42,$94 ; 48,13$ & 53,85 & 50,$86 ; 56,82$ & 54,93 & 53,$22 ; 56,62$ \\
\hline
\end{tabular}

Entre as UFs, as frequências de rebanhos com assistência veterinária apresentaram valores que variaram entre 5,98\% [3,89\%; 9,08\%] em Sergipe e 59,32\% [56,69\%; 61,89] no Rio Grande do Sul. As maiores frequências foram observadas na região sul do país e no Distrito Federal. Em contrapartida, os Estados do centro-oeste, norte e nordeste demonstraram as menores proporções de criações com orientação técnica (Mapa 38). Assim como foi observado para as estimativas 
estaduais, os circuitos pecuários que integraram o quartil superior $(>42,14 \%)$ foram encontrados principalmente nos Estados do sul e sudeste do Brasil (Mapa 39).

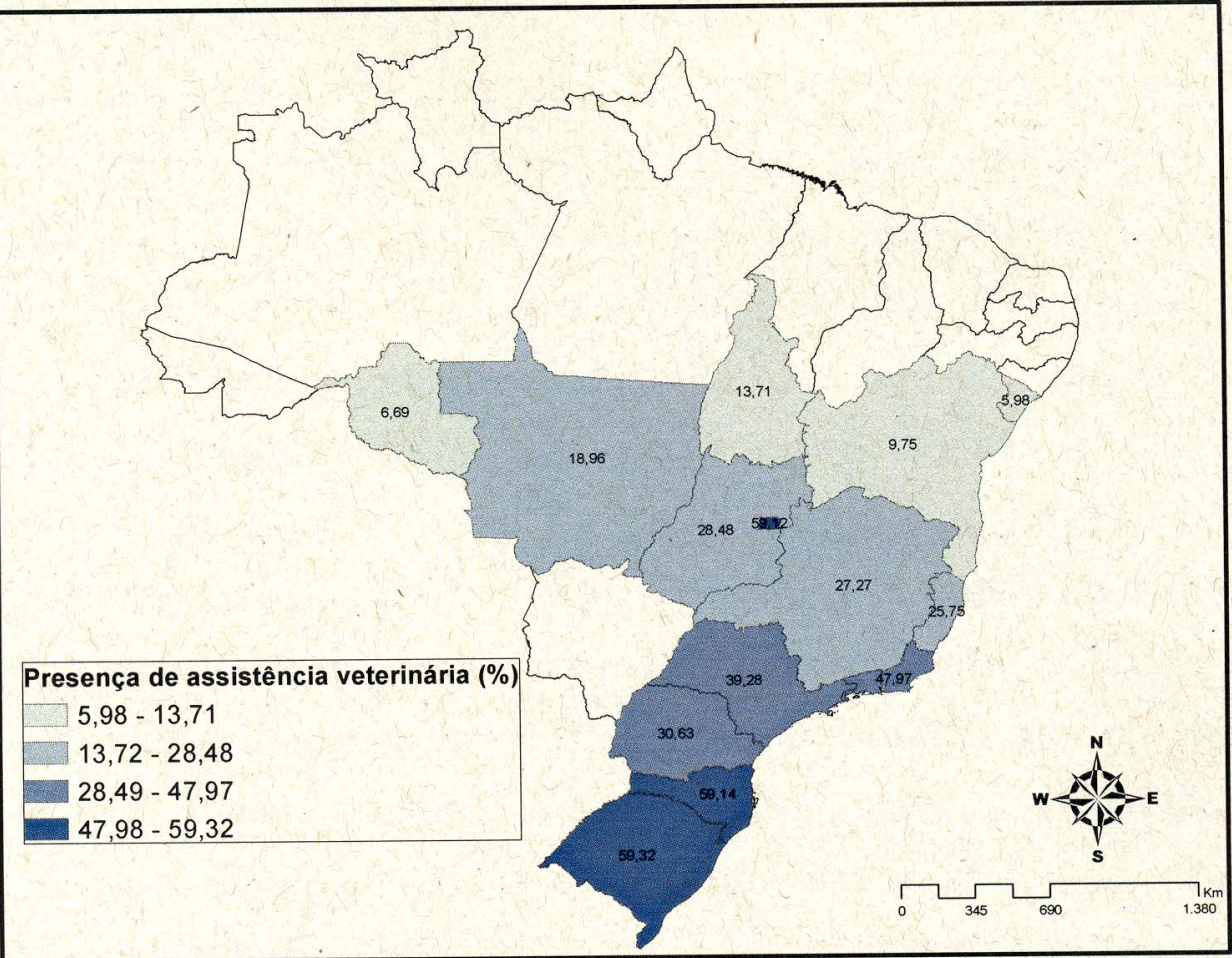

Mapa 38- Distribuição das frequências estimadas de propriedades que possuem assistência técnica veterinária nos Estados- Brasil - out 2001-dez 2004

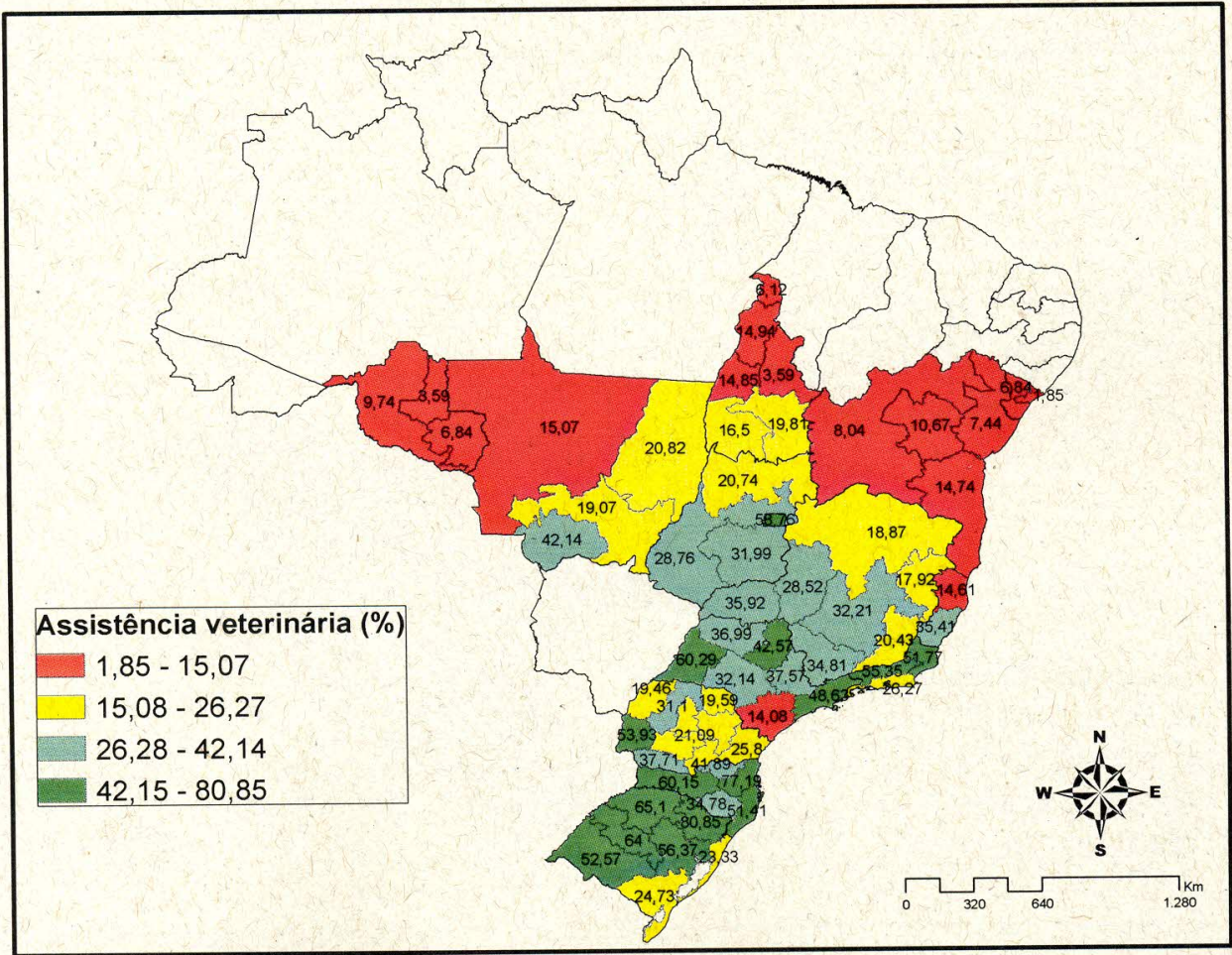

Mapa 39- Distribuição das frequências estimadas de propriedades que possuem assistência técnica veterinária nos circuitos pecuáriosBrasil - out 2001-dez 2004 
As assistências realizadas por veterinários particulares demonstraram as maiores proporções estimadas nos Estados do Centro-oeste, Norte e Nordeste (Mapa 40), sendo que a maior parte dos circuitos que fizeram parte do quartil superior com as maiores frequências $(>86,57 \%)$ foi encontrada nestes locais. Também participaram deste quartil as regiões do litoral sul paulista, sudeste paranaense e região Serrana de Santa Catarina (Mapa 41).

Por ser uma variável dicotômica, a situação imediatamente oposta ocorre para as criações onde a assistência é realizada através de veterinários de cooperativas. As maiores frequências deste tipo de orientação técnica foram encontradas nas UFs do Sul, Sudeste e em Goiás (Mapa 42). Os circuitos pecuários onde foram encontradas frequências de propriedades que se situaram no quartil superior (>45,57\%) foram observadas no noroeste do Rio Grande do Sul, oeste, norte e Vale do Itajaí catarinenses, Vale do Paraiba paulista, centro-sul de Goiás, Zona da Mata, Vale do Mucuri, centro-oeste e Triângulo mineiros, centro-sul e norte fluminenses e ambos os circuitos do Espírito Santo. Nestes locais, mais da metade das assistências realizadas são feitas por veterinários contratados por cooperativas (Mapa 43).

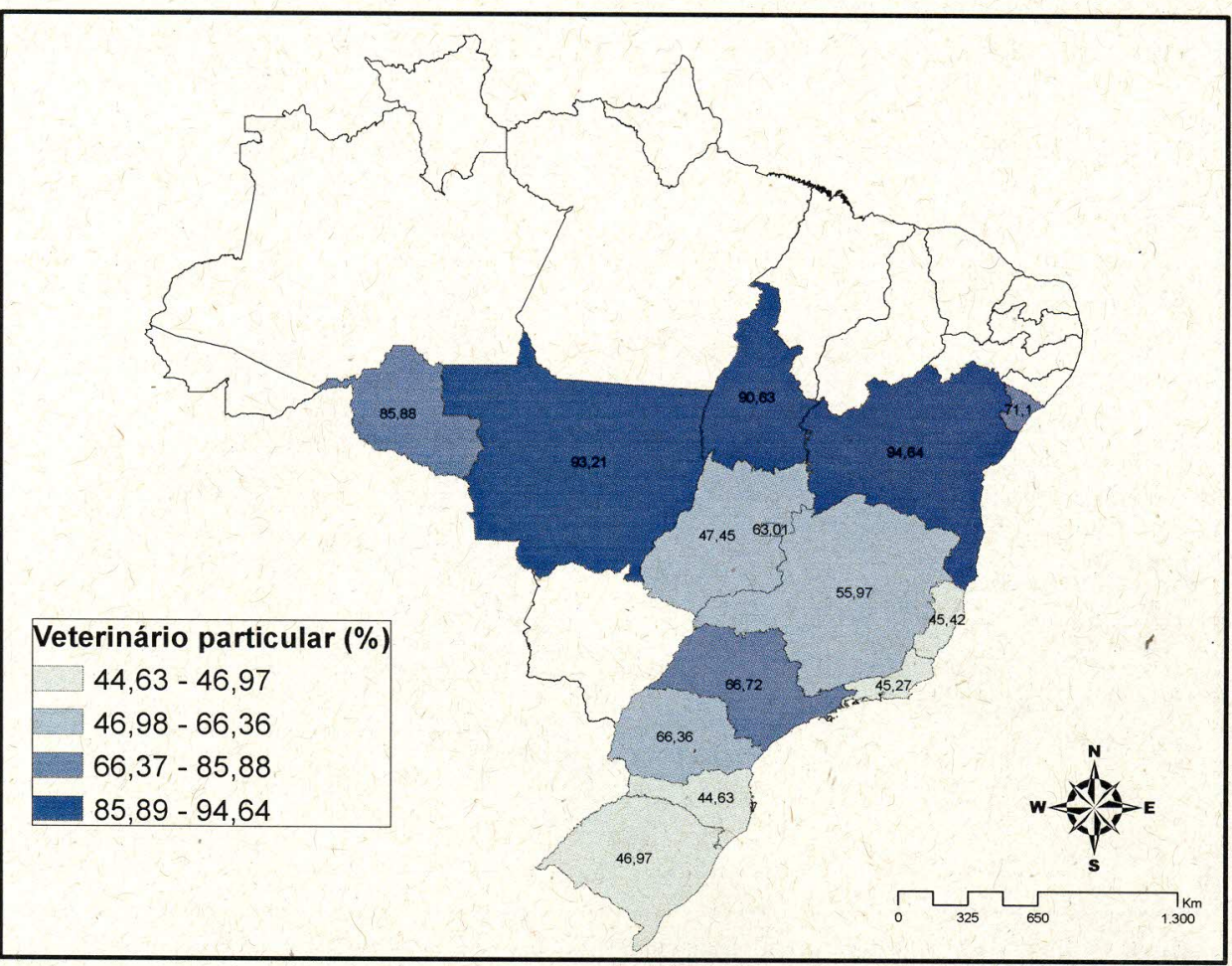

Mapa 40- Distribuição estadual das frequências estimadas de propriedades onde a assistência técnica é realizada por Veterinários particulares- Brasil - out 2001-dez 2004 


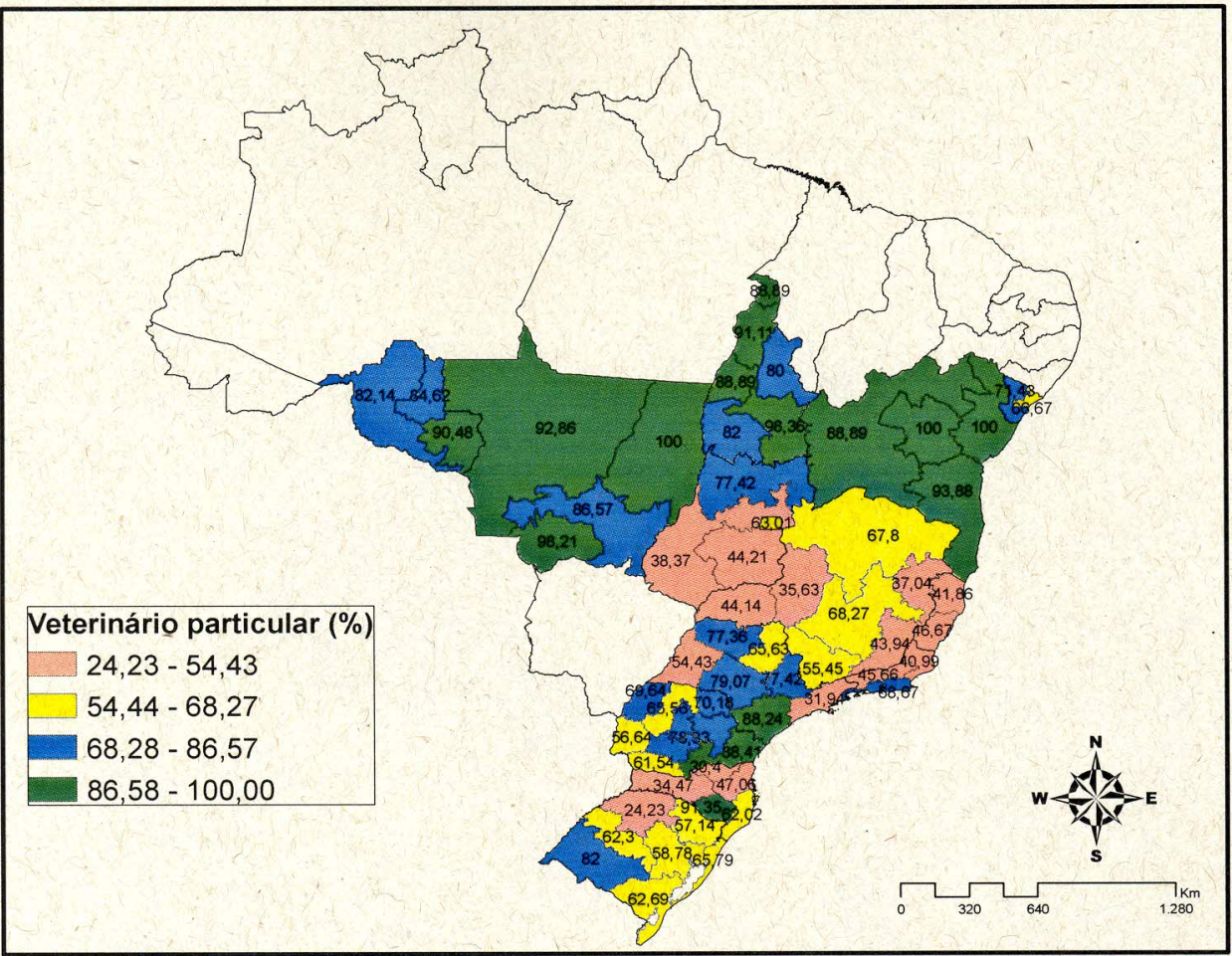

Mapa 41- Distribuição por circuito pecuário das frequências estimadas de propriedades onde a assistência técnica é realizada por veterinários particulares- Brasil - out 2001-dez 2004

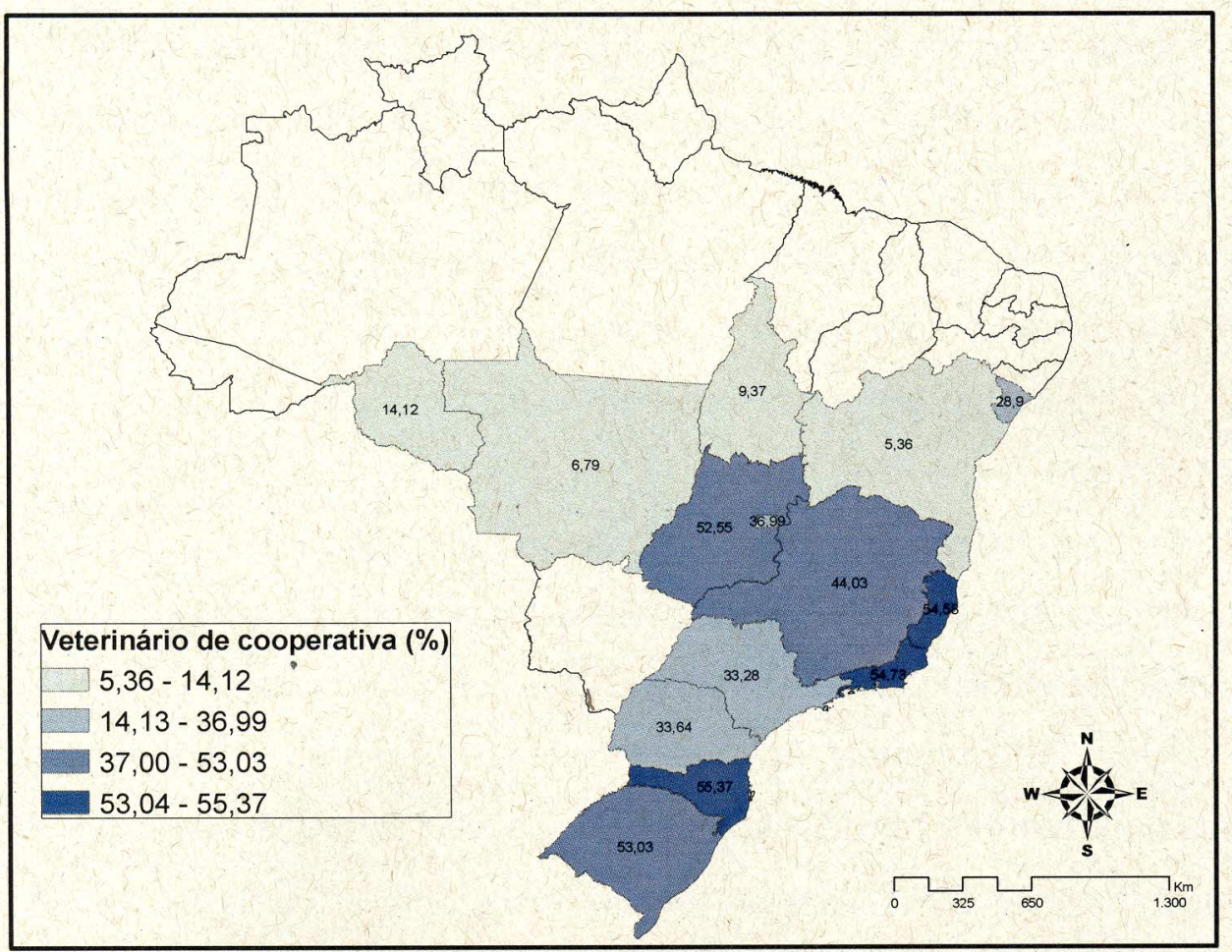

Mapa 42- Distribuição estadual das frequências estimadas de propriedades onde a assistência técnica é realizada por Veterinários de cooperativa- Brasil - out 2001-dez 2004 


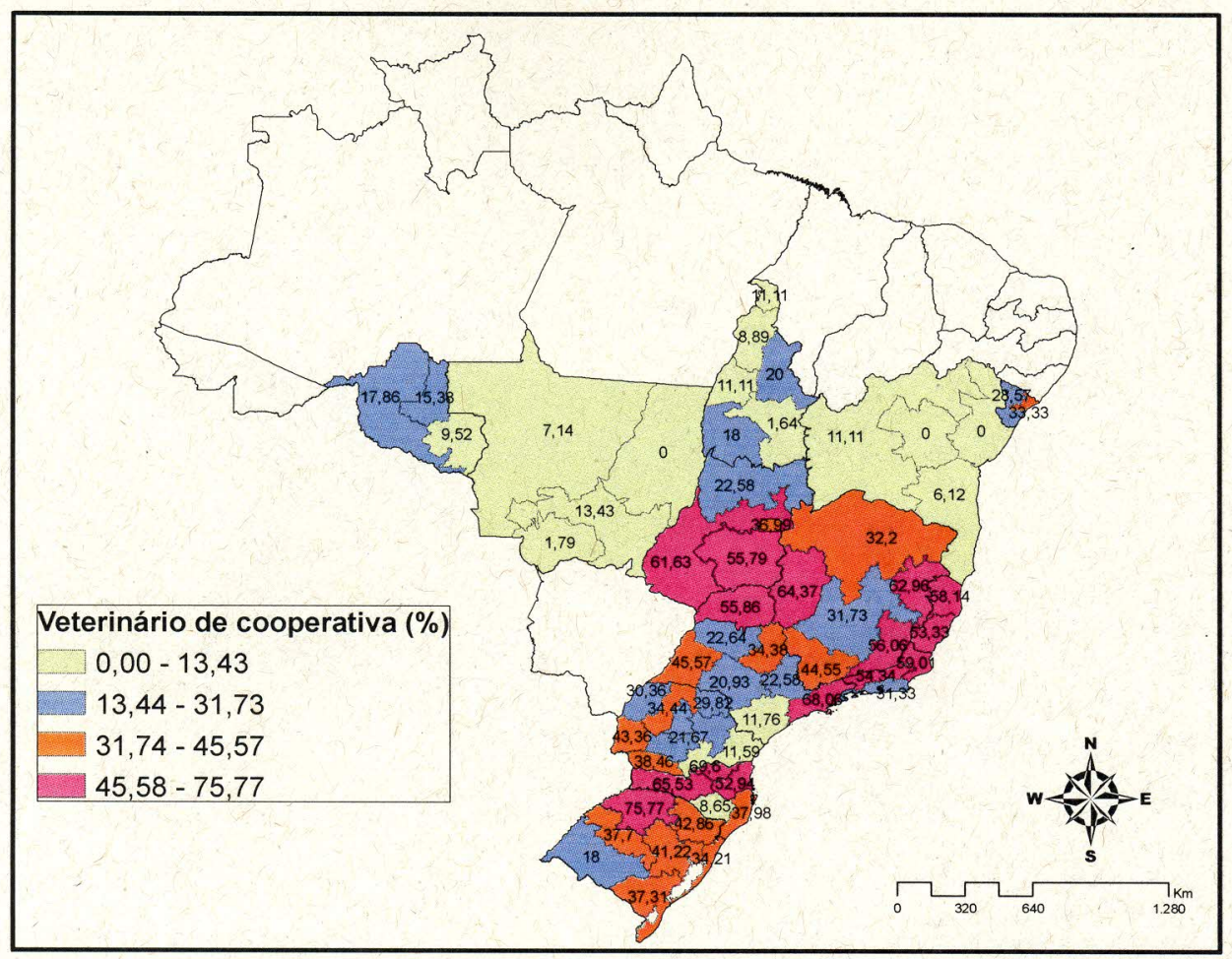

Mapa 43- Distribuição por circuito pecuário das frequências estimadas de propriedades onde a assistência técnica é realizada por Veterinários de cooperativa- Brasil - out 2001-dez 2004

Os dados demonstram que o acesso dos pecuaristas à assistência técnica ainda é limitada. Estimativas similares foram encontradas pelo IBGE (2006), onde encontraram que do total de propriedades do país, aproximadamente $78 \%$ não possui acesso a qualquer tipo de orientação técnica (por profissionais de ciências agrárias). Neste mesmo trabalho, também foram traçadas algumas comparações entre a presença de assistência e o tamanho de terras, nas quais observaram que os $22 \%$ de estabelecimentos que demonstraram possuir assistência técnica, correspondiam por $46 \%$ das terras exploradas no país. O tamanho médio das propriedades assistidas foi de 228 hectares, enquanto que no grupo de estabelecimentos não assistidos foi de 42 hectares. Isto demonstra que o acesso à assistência técnica está ligado às propriedades de maior porte.

O IBGE (2006) ainda encontrou que a presença de orientação técnica apresentou uma estreita relação com o grau de escolaridade dos produtores, sendo que do total de produtores que participaram do censo, somente $19,6 \%$ possuíam ensino fundamental completo ou um nível maior de instrução. Daqueles com instrução igual ou inferior ao ensino médio incompleto, cerca de 16,8\% receberam orientação técnica, enquanto que os produtores com ensino fundamental completo 
este percentual subiu para $31,7 \%$ e no caso daqueles com nível superior, excetuando-se aqueles com formação em ciências agrárias e veterinária, a assistência técnica alcança $44,7 \%$ dos estabelecimentos (Gráfico 17).

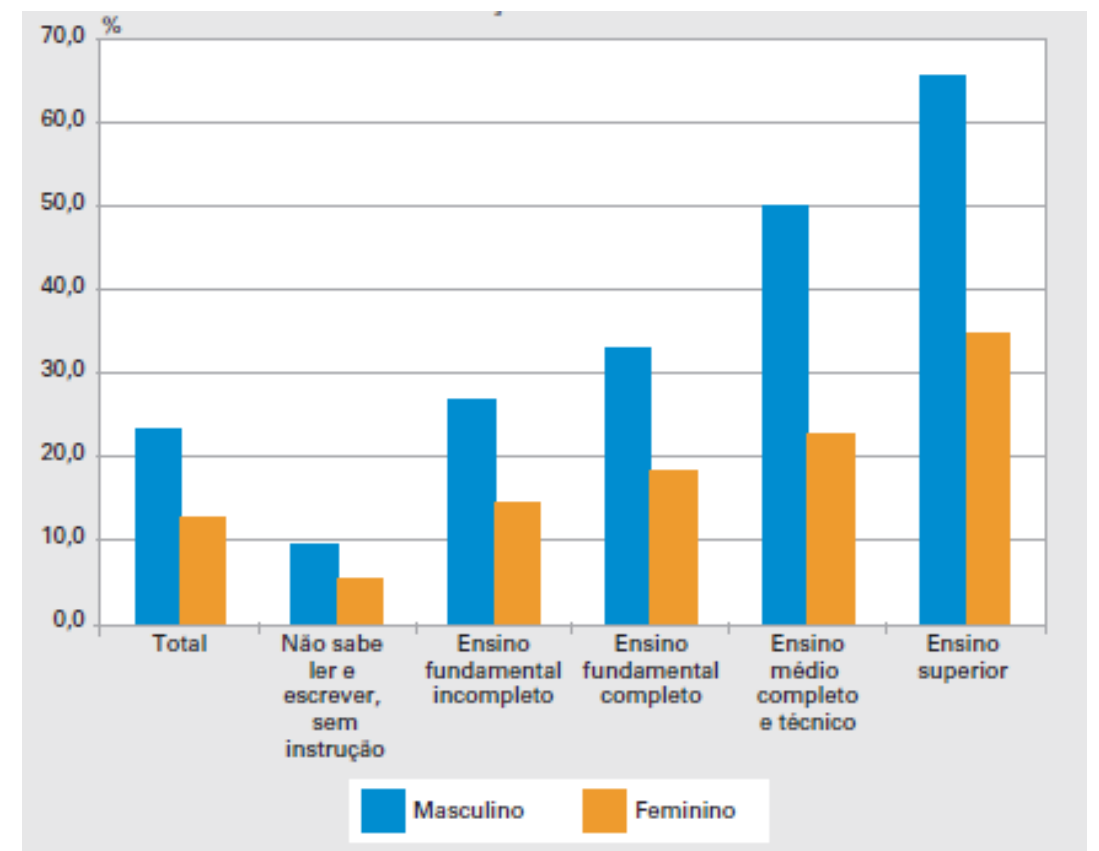

Fonte: IBGE (2006)

Gráfico 17- Proporções de estabelecimentos agropecuários que possuem assistência técnica segundo o sexo e nível de escolaridade. Brasil, 2006.

\subsubsection{Movimentação de reprodutores}

Os Estados participantes foram avaliados em relação às trocas comerciais de animais para reprodução. Para tanto, foram questionados a respeito da compra e venda de reprodutores e dos locais onde estes animais são comercializados. Este questionamento foi feito na intenção de avaliar a forma de introdução ou de saída dos reprodutores nos rebanhos, considerando que nos casos em que os critérios sanitários de movimentação de animais não são adotados, estas trocas comerciais podem representar uma importante forma de introdução ou de exportação de doenças entre as criações. 
4.2.2.1 Compra de reprodutores

A compra de reprodutores, foi observada em 49,26\% [48,35\%; 50,18\%] das propriedades, sendo assim, aproximadamente metade dos rebanhos costuma realizar a introdução de vacas ou touros dentro de suas criações para fins reprodutivos, podendo adquiri-los das seguintes formas: através de leilões, exposições, comerciantes de animais ou diretamente de outras propriedades. As propriedades de corte apresentaram as maiores frequências de propriedades que compram estes animais, sendo realizada por aproximadamente 58\% delas. As propriedades de leite ou mistas apresentaram proporções em torno de $47 \%$ e $45 \%$, respectivamente (Tabela 19).

Tabela 19- Proporção estimada de propriedades que compram de animais para reprodução segundo o tipo de exploração- Brasil - out 2001-dez 2004

\begin{tabular}{|c|c|c|c|c|c|c|c|c|}
\hline \multirow[b]{2}{*}{$\begin{array}{c}\text { Compra } \\
\text { reprodutores }\end{array}$} & \multicolumn{8}{|c|}{ Tipo de exploração } \\
\hline & $\begin{array}{c}\text { Corte } \\
(\%)\end{array}$ & IC $95 \%$ & $\begin{array}{c}\text { Leite } \\
(\%)\end{array}$ & IC $95 \%$ & $\begin{array}{c}\text { Misto } \\
(\%)\end{array}$ & IC $95 \%$ & $\begin{array}{c}\text { Total } \\
(\%)\end{array}$ & IC $95 \%$ \\
\hline Não & 41,84 & 40,$13 ; 43,58$ & 52,43 & 50,$85 ; 54,01$ & 55,27 & 53,$81 ; 56,72$ & 50,74 & 49,$82 ; 51,56$ \\
\hline Sim & 58,16 & 56,$42 ; 59,87$ & 47,57 & 45,$99 ; 49,15$ & 44,73 & 43,$28 ; 46,19$ & 49,26 & 48,$35 ; 50,18$ \\
\hline Total & 100,00 & & 100,00 & & 100,00 & & 100,00 & \\
\hline
\end{tabular}

Para os locais que afirmaram comprar animais para a reprodução, foram calculadas as frequências estimadas dos principais locais de origem destes animais. É importante lembrar que durante a aplicação do questionário, os produtores poderiam escolher mais de uma alternativa referente à forma de aquisição destes animais, podendo adquirir os reprodutores em diferentes locais.

Observou-se que a forma mais comum de aquisição dos reprodutores é realizada através da compra direta de outras propriedades, seguida das compras de comerciantes, leilões e em menores proporções, através de feiras ou exposições agropecuárias (Tabela 20).

Tabela 20- Locais de origem dos animais adquiridos para a reprodução- Brasil - out 2001-dez 2004

\begin{tabular}{ccccccccc}
\hline \multicolumn{10}{c}{ Origem dos reprodutores } \\
\hline & $\begin{array}{c}\text { Outras } \\
\begin{array}{c}\text { Propriedades } \\
(\%)\end{array}\end{array}$ & IC 95\% & $\begin{array}{c}\text { Comerciantes } \\
\mathbf{( \% )}\end{array}$ & IC 95\% & $\begin{array}{c}\text { Leilões } \\
\mathbf{( \% )}\end{array}$ & IC 95\% & $\begin{array}{c}\text { Exposição } \\
\mathbf{( \% )}\end{array}$ & IC 95\% \\
\hline Não & 25,44 & 24,$34 ; 26,58$ & 80,95 & 79,$90 ; 81,96$ & 89,19 & 88,$40 ; 89,92$ & 95,70 & 95,$17 ; 96,18$ \\
Sim & 74,56 & 73,$42 ; 75,66$ & 19,05 & 18,$04 ; 20,10$ & 10,81 & 10,$08 ; 11,60$ & 4,30 & 3,$82 ; 4,83$ \\
\hline Total & 100,00 & & 100,00 & & 100,00 & & 100,00 & \\
\hline
\end{tabular}


Verificando as frequências estaduais destas formas de aquisição, observa-se que em geral a maioria dos locais que compram reprodutores o faz diretamente a partir de outras propriedades (Mapa 44). Estas estimativas ficaram entre $62,50 \%$ no Distrito Federal [50,82\%; 72,89\%] e 90,19\% [87,32\%; 92,46\%] em Rondônia. Os circuitos produtores nos quais as frequências fizeram parte do último quartil (>81,37\%), foram encontrados principalmente nos Estados de Rondônia; nordeste baiano; centro-sul e Zona da Mata de Minas Gerais; na maior parte dos circuitos paulistas; regiões centrais e do sudeste de paranaense; Vale do Itajaí e Noroeste do Rio Grande do Sul (Mapa 45).

As frequências de propriedades que compram reprodutores de comerciantes de animais, variaram de 11,55\% [9,22\%; 14,36\%] no Rio Grande do Sul e chegaram a 40,58\% [34,23\%; 47,27\%] das propriedades de São Paulo (Mapa 46). Os circuitos produtores que participam do quartil superior (>25,95\%) estão presentes nos circuitos do centro-sul de Santa Catarina; norte Pioneiro e região central do Paraná; em praticamente todas as regiões paulistas; região do Rio de Janeiro e das baixadas; centro-oeste e sudoeste mineiros; regiões centro-oeste e nordeste de Tocantins e Vale do São Francisco na da Bahia (Mapa 47).

No caso da aquisição de reprodutores em leilões, as UFs que demonstraram as três maiores frequências de aquisição de reprodutores desta maneira foram os Estados do Estado do Mato Grosso, São Paulo e Goiás (Mapa 48). Todavia, ao estratificar as análises estaduais por circuitos de produção, observa-se que as estimativas que participaram do último quartil (>15,59\%) estiveram presentes além destes Estados, no sudoeste do Tocantins e no Rio Grande do Sul, principalmente nas regiões do sul, centro-ocidental e região litorânea deste Estado (Mapa 49).

A aquisição de reprodutores em exposições e/ou feiras agropecuárias demonstrou ser a maneira menos frequente de comprar estes animais. As maiores proporções estaduais foram encontradas no Mato Grosso, onde se estimou que $8,93 \%[6,69 \% ; 11,83 \%]$ das propriedades adquirem reprodutores desta maneira (Mapa 50). Em relação aos circuitos pecuários, as frequências do último quartil (>5,38\%), foram encontradas no sul e porção centro-ocidental do Rio Grande do Sul; região Serrana de Santa Catarina; regiões paulistas de Bauru/Marília/Assis e de Campinas/Piracicaba; Vale do Mucuri mineiro; Centro-sul da Bahia; regiões do 
noroeste, nordeste, sudeste de Tocantins; norte goiano; e regiões mato-grossenses do Pantanal e do Noroeste (Mapa 51).

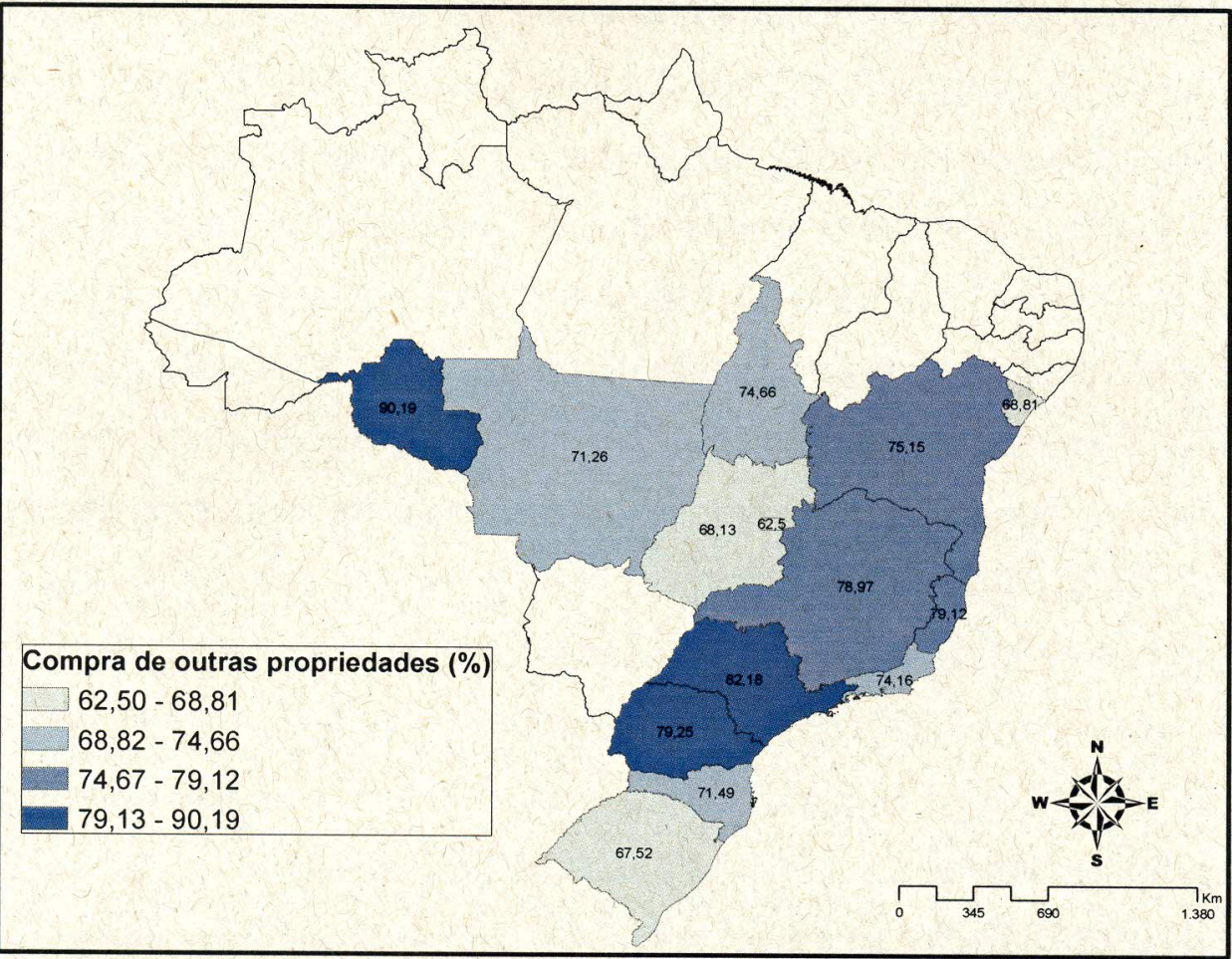

Mapa 44- Distribuição estadual das frequências estimadas de propriedades que compram reprodutores diretamente de outras propriedades- Brasil - out 2001-dez 2004

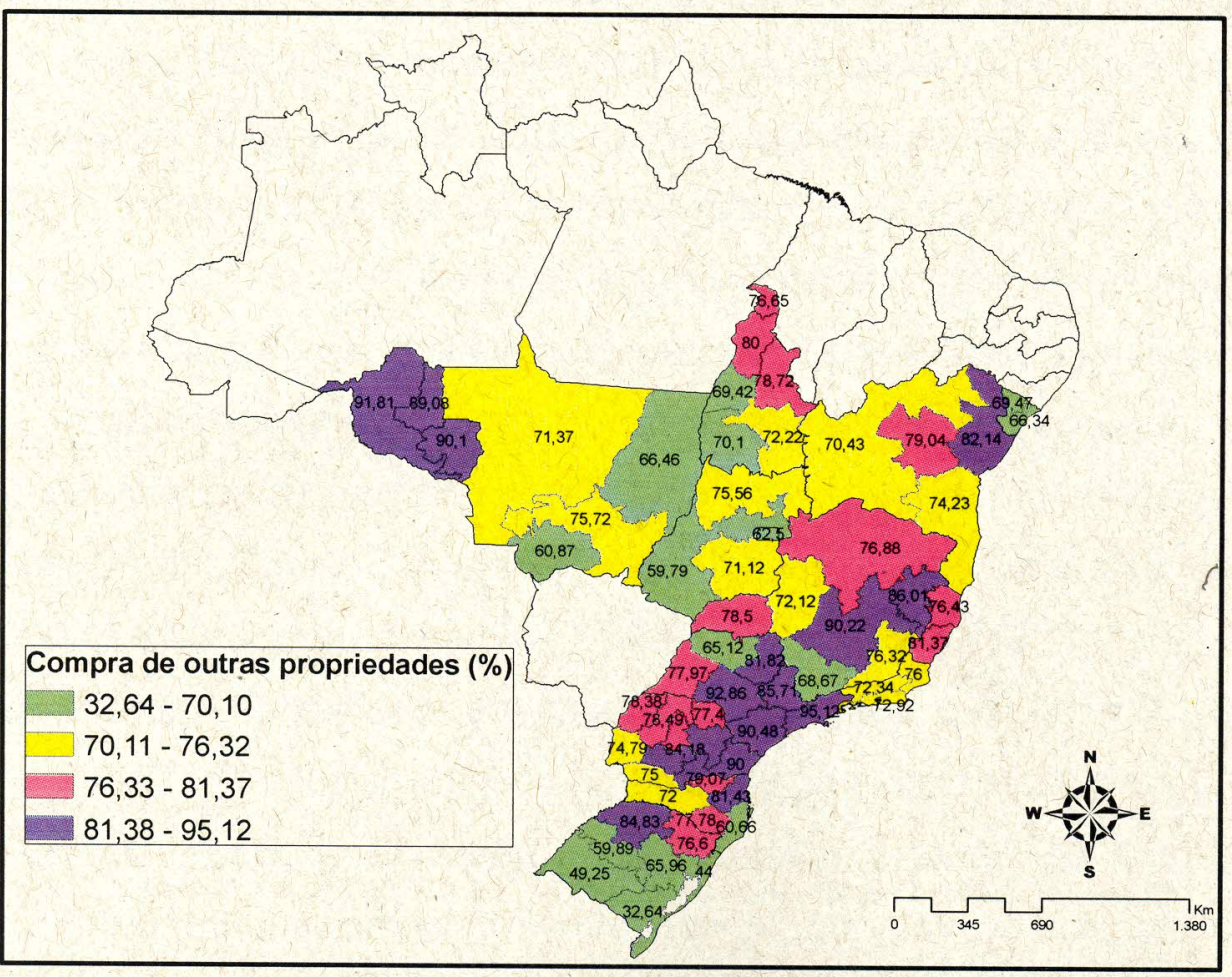

Mapa 45- Distribuição por circuito pecuário das frequências estimadas de propriedades que compram reprodutores diretamente de outras propriedades- Brasil - out 2001-dez 2004 


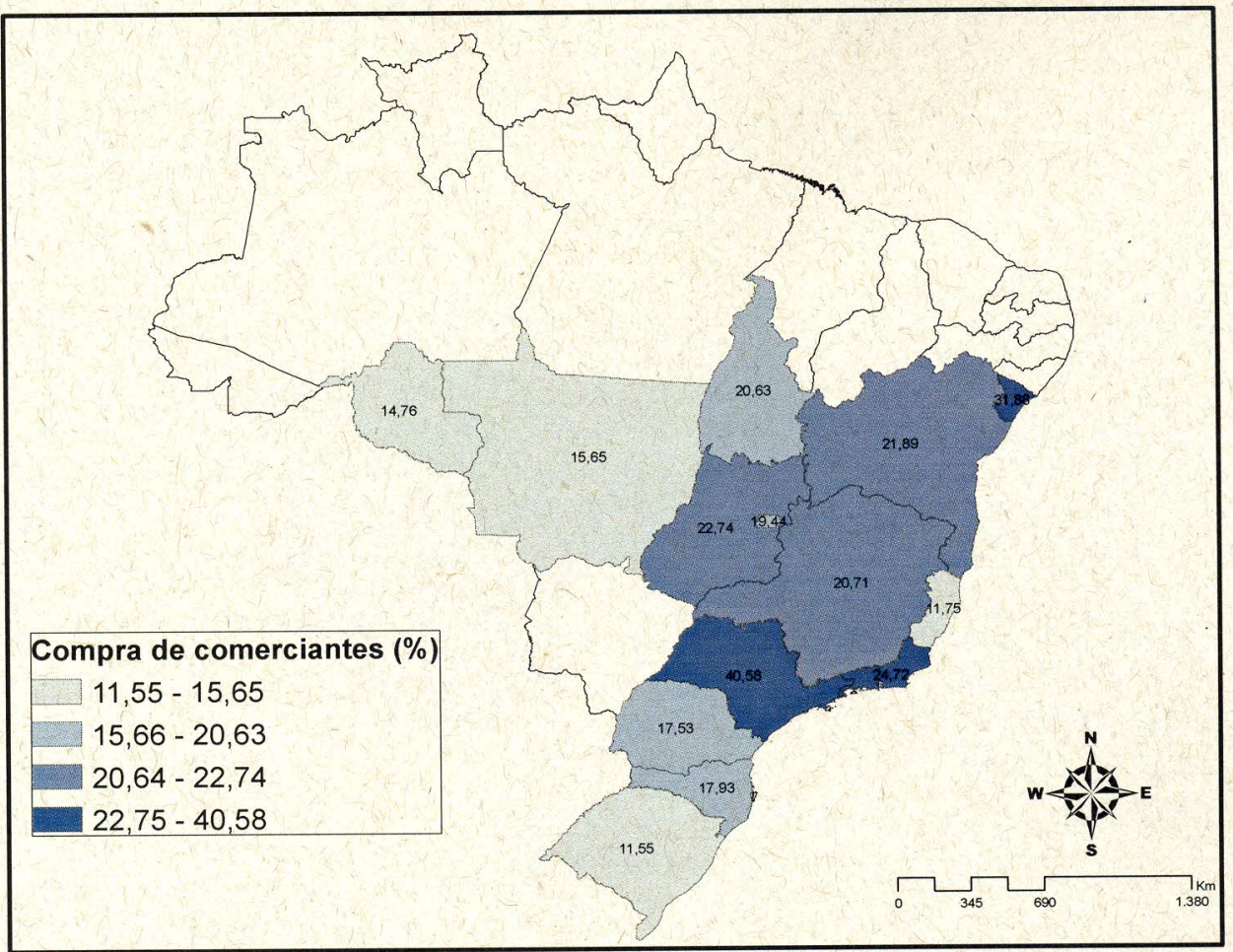

Mapa 46- Distribuição estadual das frequências estimadas de propriedades que compram reprodutores diretamente de comerciantesBrasil - out 2001-dez 2004

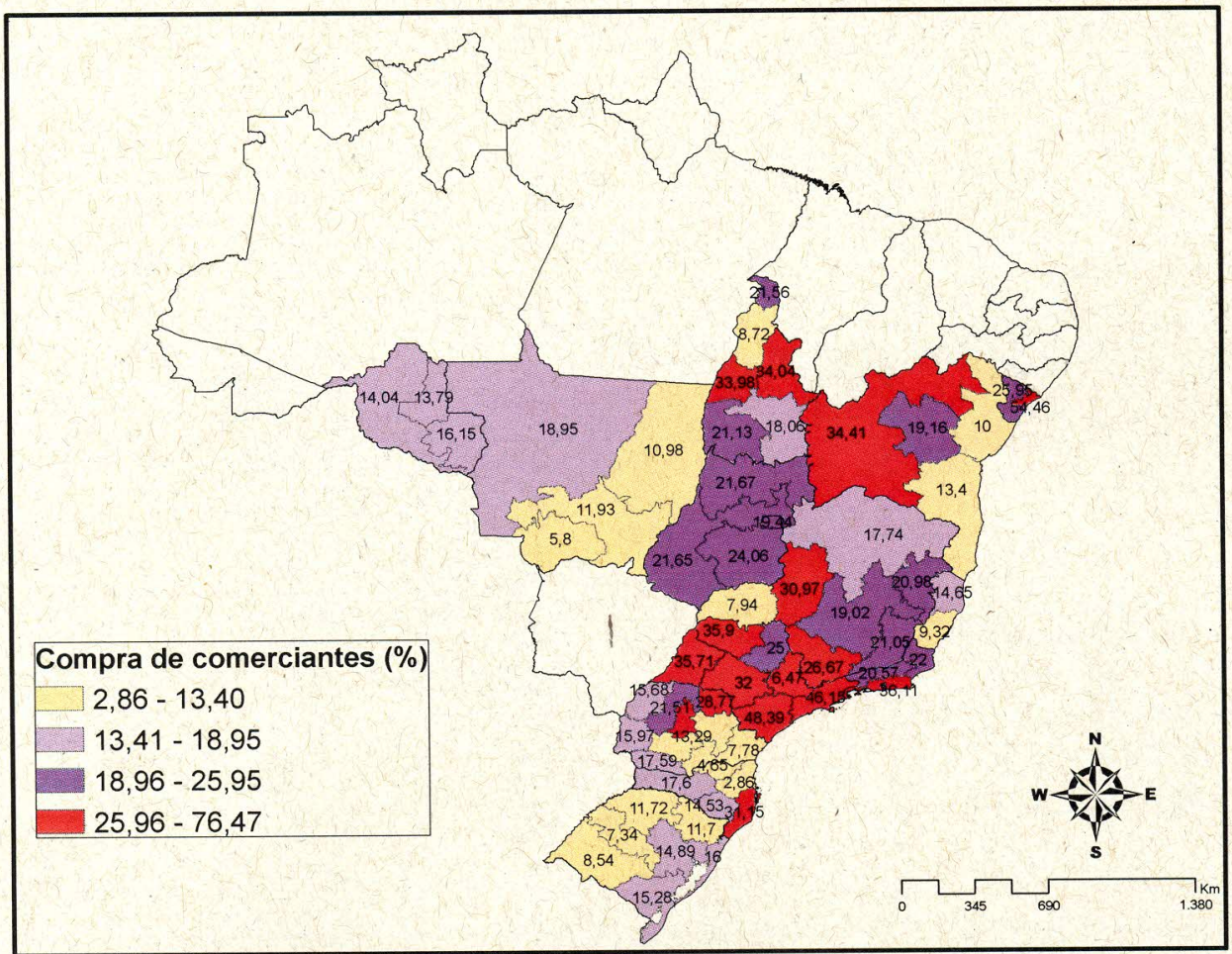

Mapa 47- Distribuição das frequências estimadas de propriedades que compram reprodutores diretamente de comerciantes nos circuitos pecuários- Brasil - out 2001-dez 2004 
Compra em leilões (\%)

$1,16-5,21$

$5,22-7,24$

$7,25-13,37$

$13,38-22,13$
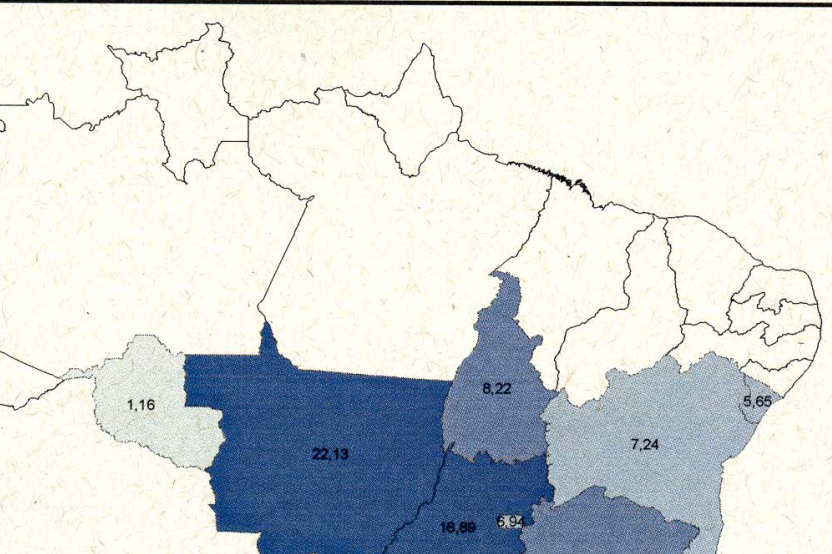

13.37

$7_{3.30} \mathrm{~km}$

Mapa 48- Distribuição estadual das frequências estimadas de propriedades que compram reprodutores em leilões- Brasil - out 2001-dez 2004

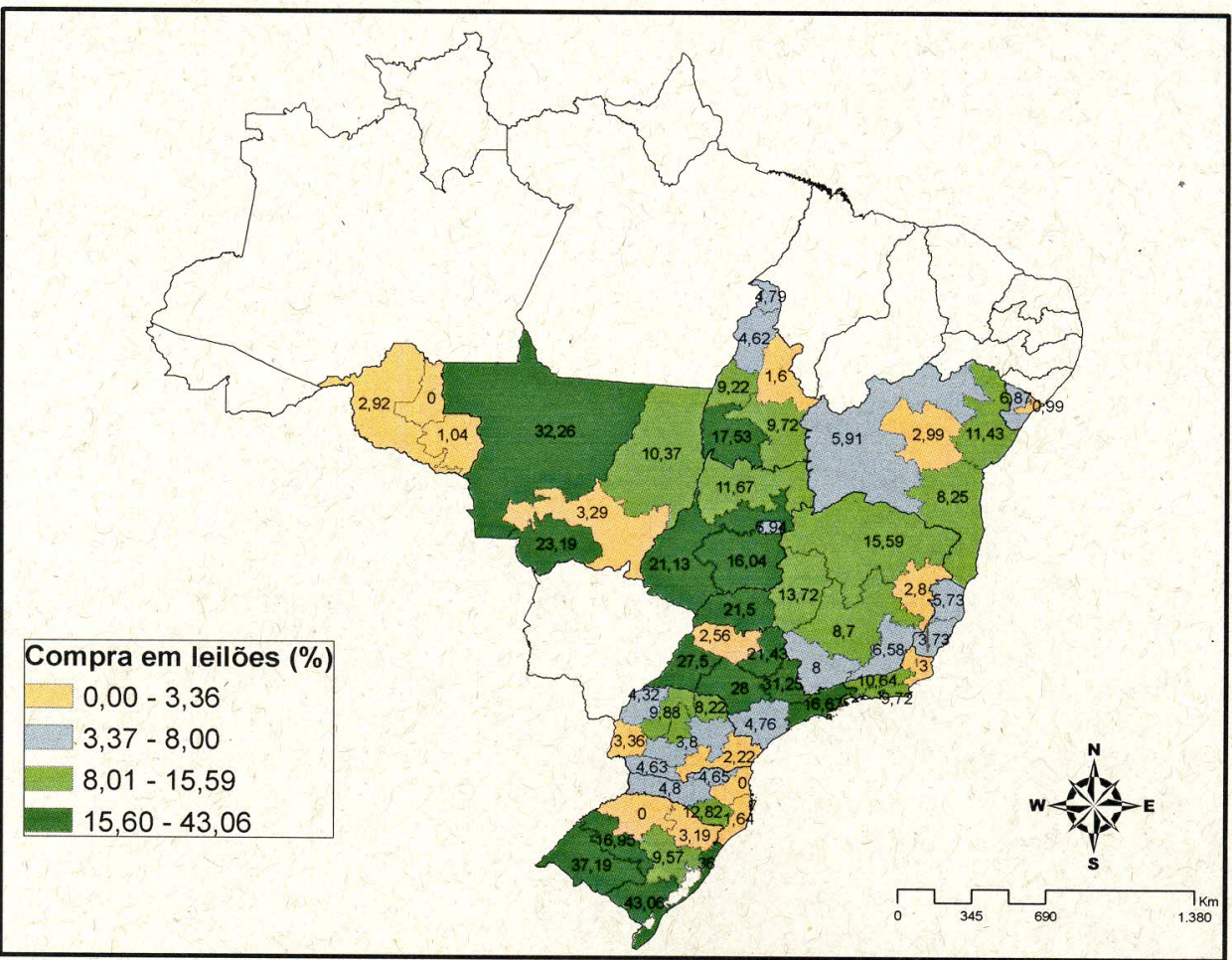

Mapa 49- Distribuição das frequências estimadas de propriedades que compram reprodutores em leilões- Brasil - out 2001-dez 2004 


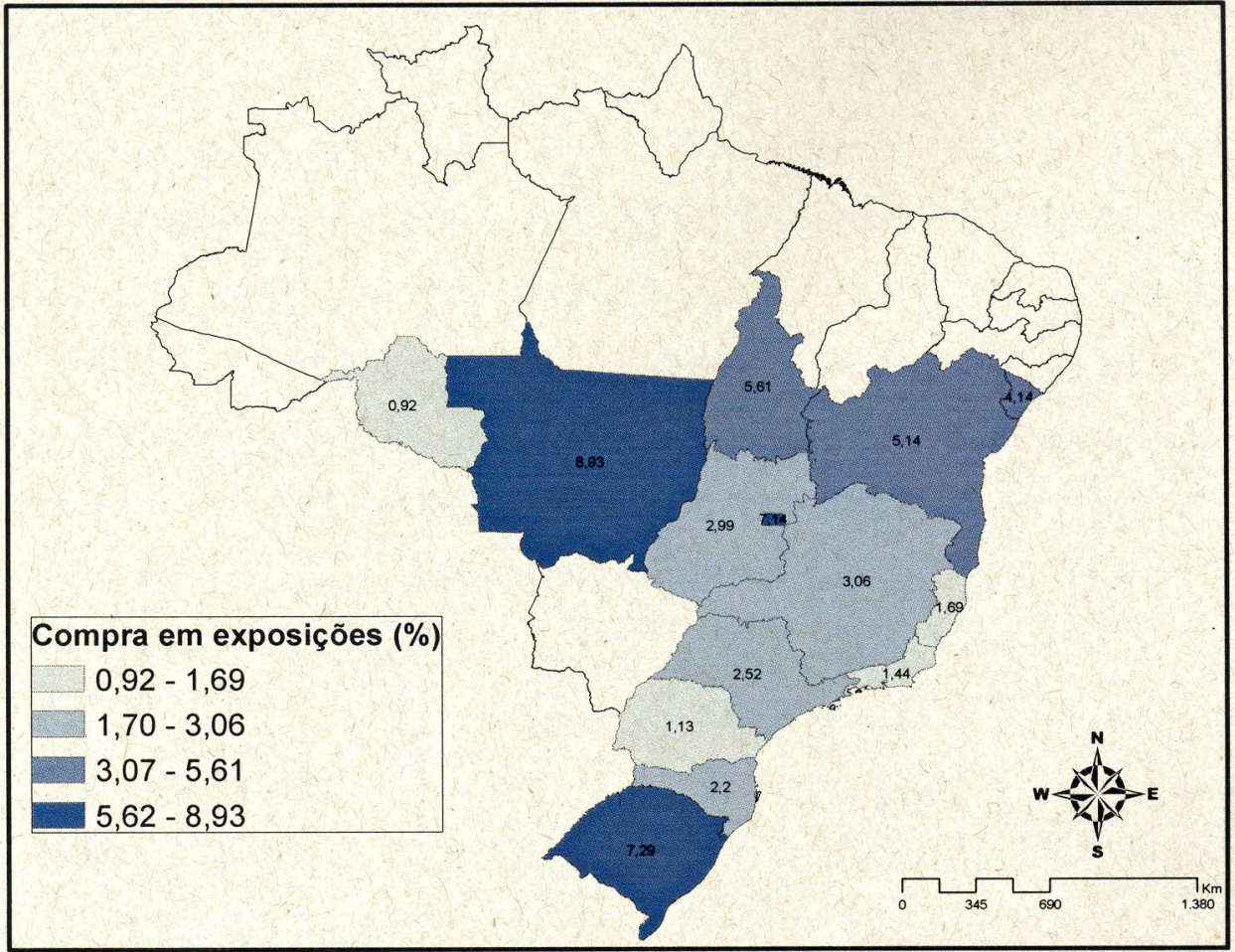

Mapa 50- Distribuição estadual das frequências estimadas de propriedades que compram reprodutores em exposições- Brasil - out 2001-dez 2004

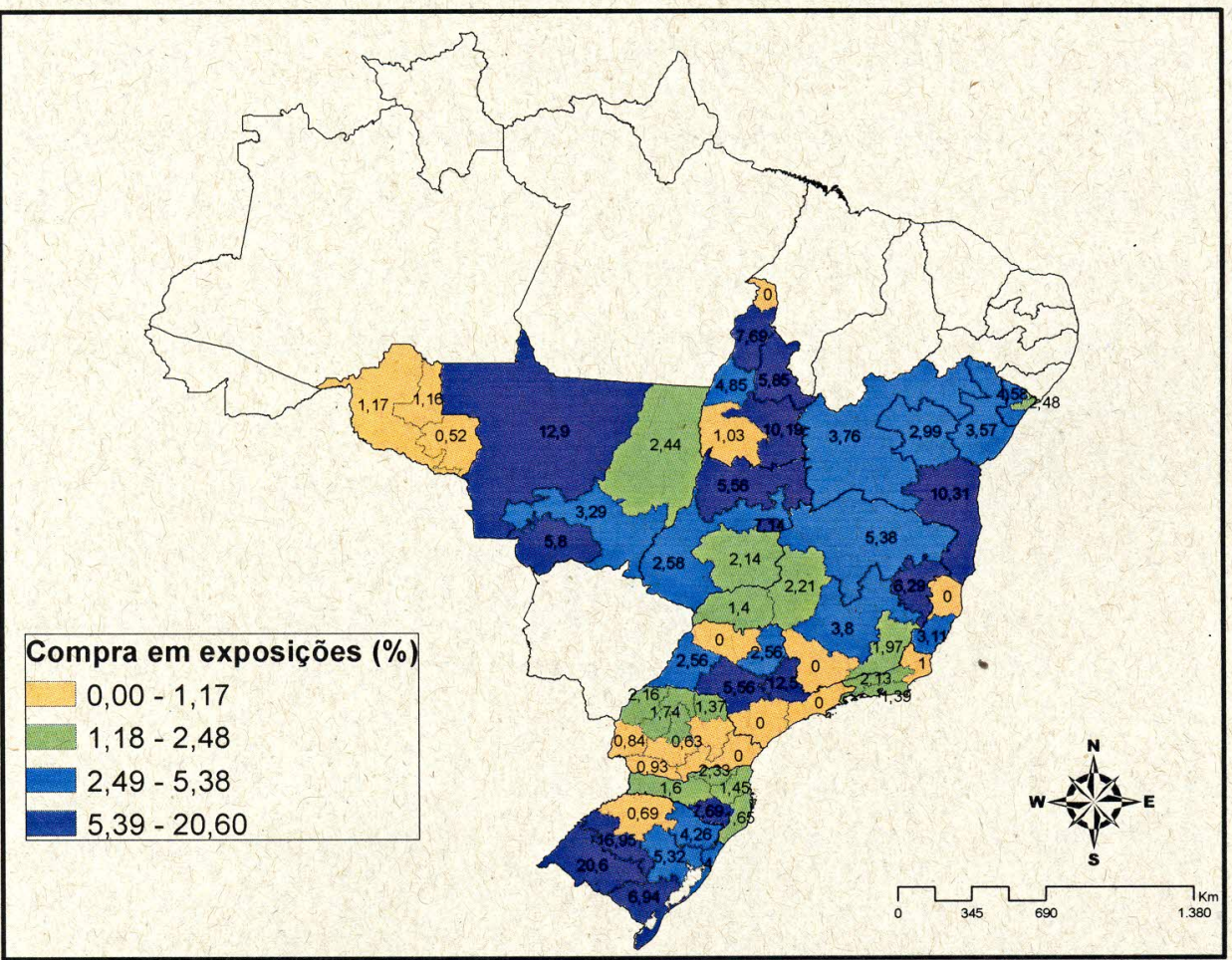

Mapa 51- Distribuição das frequências estimadas de propriedades que compram reprodutores em exposições nos circuitos pecuáriosBrasil - out 2001-dez 2004 
A proporção geral de propriedades que realizam a venda de reprodutores foi estimada em $27,49 \%$ [26,69\% ; 28,32\%]. As explorações especializadas em corte e leite apresentaram as maiores frequências de propriedades que vendem estes animais, sendo parecidas em ambas e próximas de 30\%. Os rebanhos mistos demonstraram uma frequência menor e próxima de 23\% (Tabela 21).

Tabela 21- Proporção estimada de propriedades que vendem reprodutores segundo o tipo de exploração- Brasil - out 2001-dez 2004

\begin{tabular}{ccccccccc}
\hline \multicolumn{7}{c}{ Tipo de exploração } \\
\hline $\begin{array}{c}\text { Vende } \\
\text { reprodutores }\end{array}$ & $\begin{array}{c}\text { Corte } \\
\mathbf{( \% )}\end{array}$ & IC 95\% & $\begin{array}{c}\text { Leite } \\
\text { (\%) }\end{array}$ & IC 95\% & $\begin{array}{c}\text { Misto } \\
\text { (\%) }\end{array}$ & IC 95\% & $\begin{array}{c}\text { Total } \\
\text { (\%) }\end{array}$ & IC 95\% \\
\hline Não & 68,67 & 67,$04 ; 70,25$ & 70,25 & 68,$78 ; 71,68$ & 76,71 & 75,$44 ; 77,94$ & 72,51 & 71,$68 ; 73,31$ \\
Sim & 31,33 & 29,$75 ; 32,96$ & 29,75 & 28,$32 ; 31,22$ & 23,29 & 22,$06 ; 24,56$ & 27,49 & 26,$69 ; 28,32$ \\
\hline Total & 100,00 & & 100,00 & & 100,00 & & 100,00 & \\
\hline
\end{tabular}

Os estabelecimentos que comercializam reprodutores foram também avaliados quanto aos locais de destino destes animais, podendo a venda ser realizada em um ou mais dos seguintes locais: leilões, exposições, comerciantes ou outras propriedades (Tabela 22). Os dados demonstram que da mesma maneira que ocorre na compra de reprodutores, a forma mais comum de comercialização destes animais é através da venda direta entre as próprias propriedades (67,06\% [65,45\%; $68,64 \%])$, seguida de venda para comerciantes (30,34\% [28,82\%; 31,92\%]), leilões $(12,46 \%$ [11,41\%; 13,59\%]) e em menor frequência, em exposições (2,92\% [2,40\%; $3,55 \%])$.

Tabela 22- Locais de destino dos reprodutores comercializados- Brasil - out 2001-dez 2004

\begin{tabular}{ccccccccc}
\hline \multicolumn{7}{c}{ Destino dos reprodutores } \\
\hline $\begin{array}{c}\text { Outras } \\
\begin{array}{c}\text { Propriedades } \\
(\mathbf{\%})\end{array}\end{array}$ & IC $\mathbf{9 5 \%}$ & $\begin{array}{c}\text { Comerciantes } \\
\mathbf{( \% )}\end{array}$ & IC 95\% & $\begin{array}{c}\text { Leilões } \\
\mathbf{( \% )}\end{array}$ & IC 95\% & $\begin{array}{c}\text { Exposição } \\
\mathbf{( \% )}\end{array}$ & IC 95\% \\
\hline Não & 32,94 & 31,$36 ; 34,55$ & 69,66 & 68,$08 ; 71,18$ & 87,54 & 86,$41 ; 88,59$ & 97,08 & 96,$45 ; 97,60$ \\
Sim & 67,06 & 65,$45 ; 68,64$ & 30,34 & 28,$82 ; 31,92$ & 12,46 & 11,$41 ; 13,59$ & 2,92 & 2,$40 ; 3,55$ \\
\hline Total & 100,00 & & 100,00 & & 100,00 & & 100,00 \\
\hline
\end{tabular}

As estimativas por UF, demonstraram em todas elas mais da metade das propriedades realizam a venda diretamente para outros estabelecimentos (Mapa 52). Na estratificação por circuitos, é possível visualizar que as regiões com as maiores frequências de venda de reprodutores diretamente para outras propriedades 
(quartil superior: $>75,24 \%$ ) estão localizadas no norte do Rio Grande do Sul; norte catarinense; centro-sudeste paranaense; regiões paulistas de Bauru/Marília/Assis, de Campinas/Piracicaba, do litoral sul e do Vale do Ribeira; Vale do Mucuri e centrosul de Minas; norte fluminense e sul do do Espírito Santo e região do centro-sudeste do Mato Grosso (Mapa 53).

As maiores estimativas de propriedades que realizam a venda de reprodutores para comerciantes de animais foram encontradas nos Estados de São Paulo e Sergipe, onde pelo menos metade dos criadores comercializa reprodutores desta forma (Mapa 54). O quartil superior de circuitos com as maiores frequências de venda de reprodutores para comerciantes $(>41,96 \%)$ foi integrado por: todas as regiões paulistas; pelo norte central, oeste central e norte pioneiro do Paraná; região oeste e do vale do rio São Francisco na Bahia; centro-oeste tocantinense; região sudeste de Rondônia e pelo oeste Sergipano (Mapa 55).

As estimativas por UF da venda de reprodutores através de leilões demonstraram que os três Estados com as maiores frequências de comercialização deste tipo foram encontradas nos Estados de Goiás, Mato Grosso e São Paulo (Mapa 56). Os circuitos onde as frequências estimadas situaram-se no quartil superior (>17,78\%), localizaram-se no sul do Rio Grande do Sul; região do centro-sul e centro-leste paranaenses; na maioria dos circuitos paulistas (com exceção de São José do Rio Preto/Araçatuba e Ribeirão Preto/Araraquara); uma região que agrupa o centro-sul de Goiás e as regiões do centro-oeste e do Triângulo em Minas Gerais; Pantanal e noroeste do Mato Grosso e região nordeste da Bahia (Mapa 57).

As frequências estaduais de estabelecimentos que vendem reprodutores em exposições e/ou feiras, apresentaram resultados menores em comparação às outras formas de comercialização já descritas, demonstrando resultados que variaram entre 0,62\% [0,14\%; 2,71\%] em Santa Catarina e chegaram a 11,21\% [7,30\%; 16,84\%] no Mato Grosso (Mapa 58). O quartil superior $(>3,75 \%$ ) de circuitos que vendem animais em exposições, foi localizado no sul e na porção centro-oriental do Rio Grande do Sul; regiões paulistas de Presidente Prudente, Campinas/Piracicaba e litoral sul; norte, Vale do Mucuri e região centro-sul de Minas; centro-sul do Espírito Santo; noroeste do Mato Grosso e centro-oeste do Tocantins (Mapa 59). 


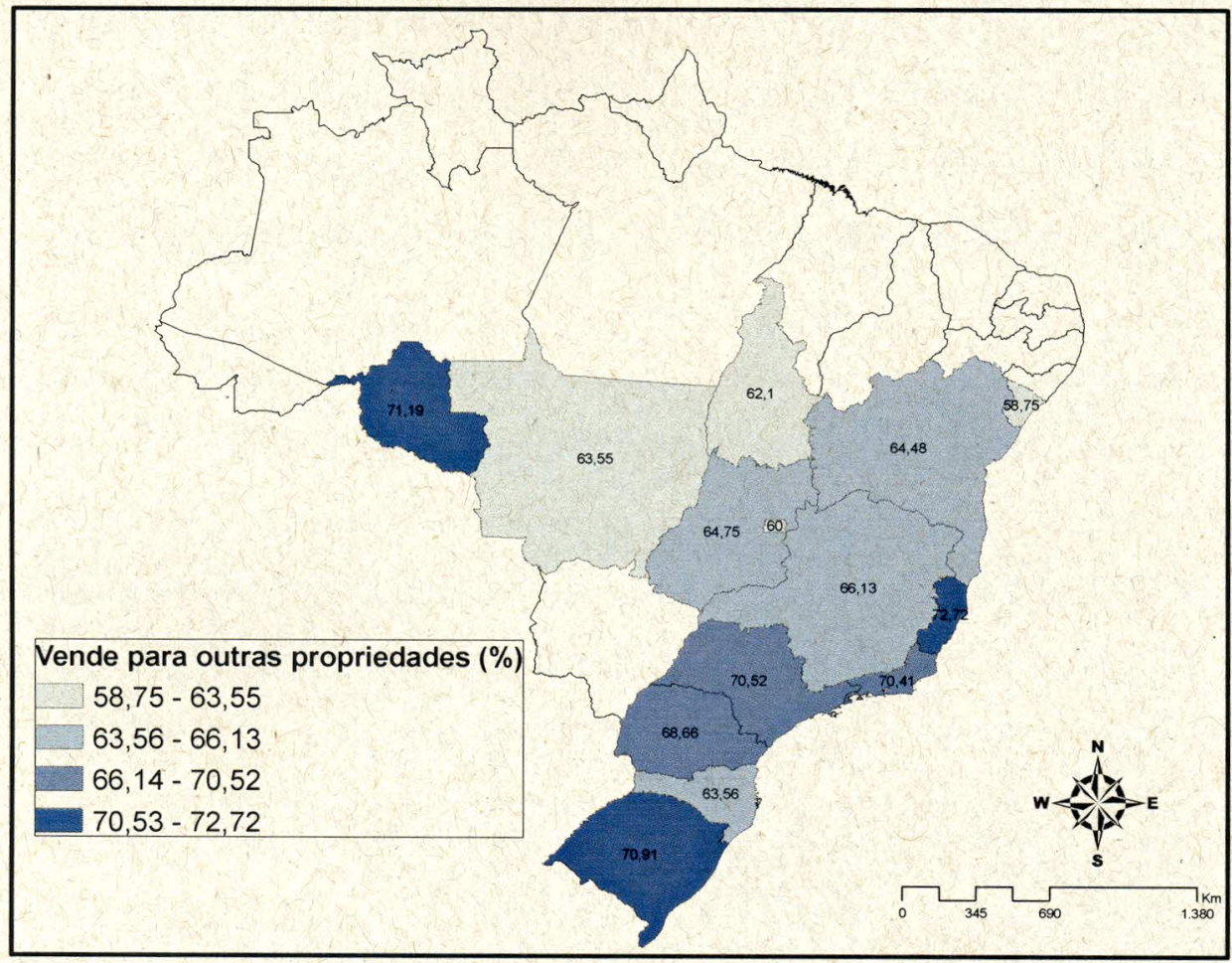

Mapa 52- Distribuição estadual das frequências estimadas de propriedades que vendem reprodutores diretamente para outros rebanhosBrasil - out 2001-dez 2004

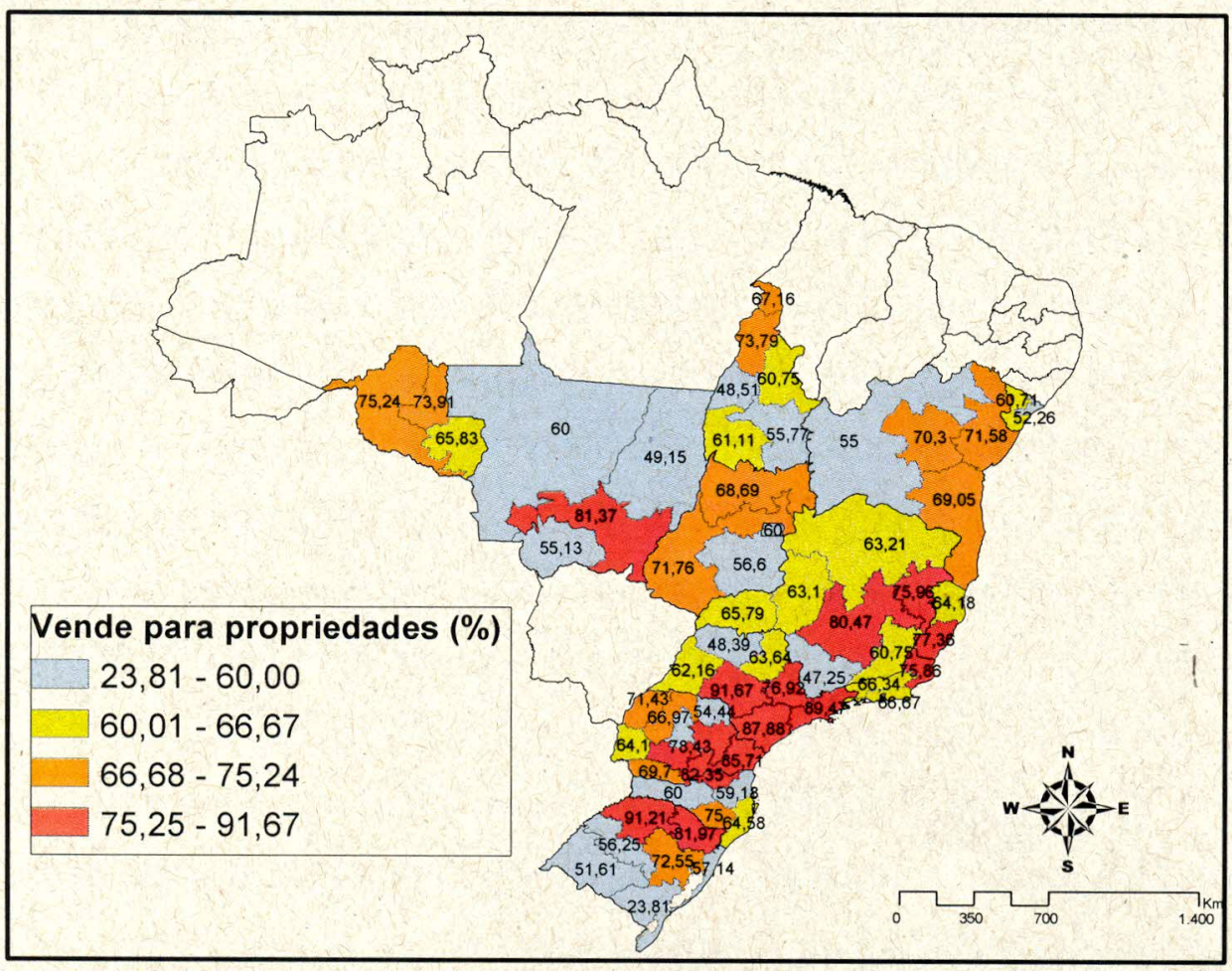

Mapa 53- Distribuição por circuito das frequências estimadas de propriedades que vendem reprodutores diretamente para outros rebanhos- Brasil - out 2001-dez 2004 


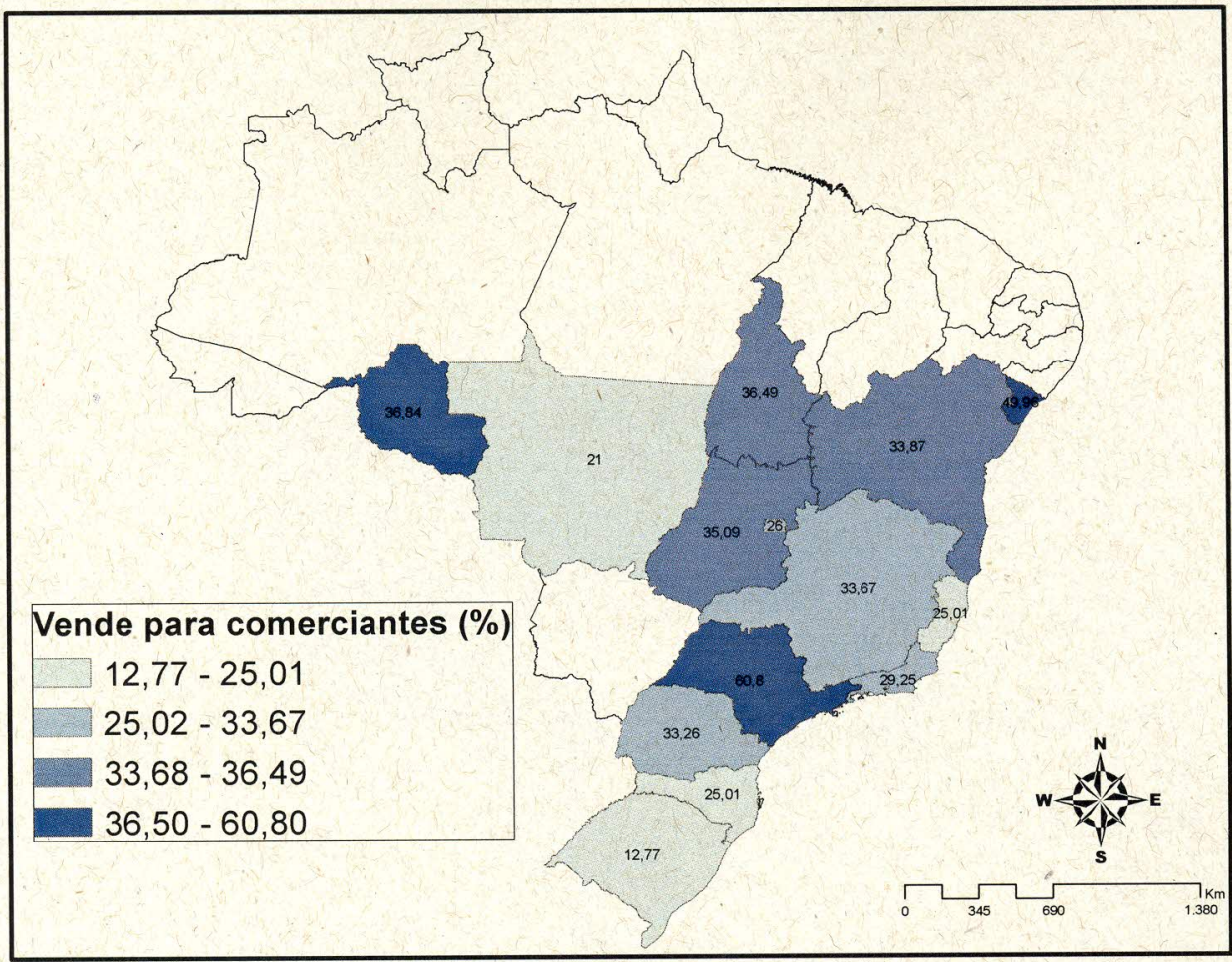

Mapa 54- Distribuição estadual das frequências estimadas de propriedades que vendem reprodutores diretamente para comerciantesBrasil - out 2001-dez 2004

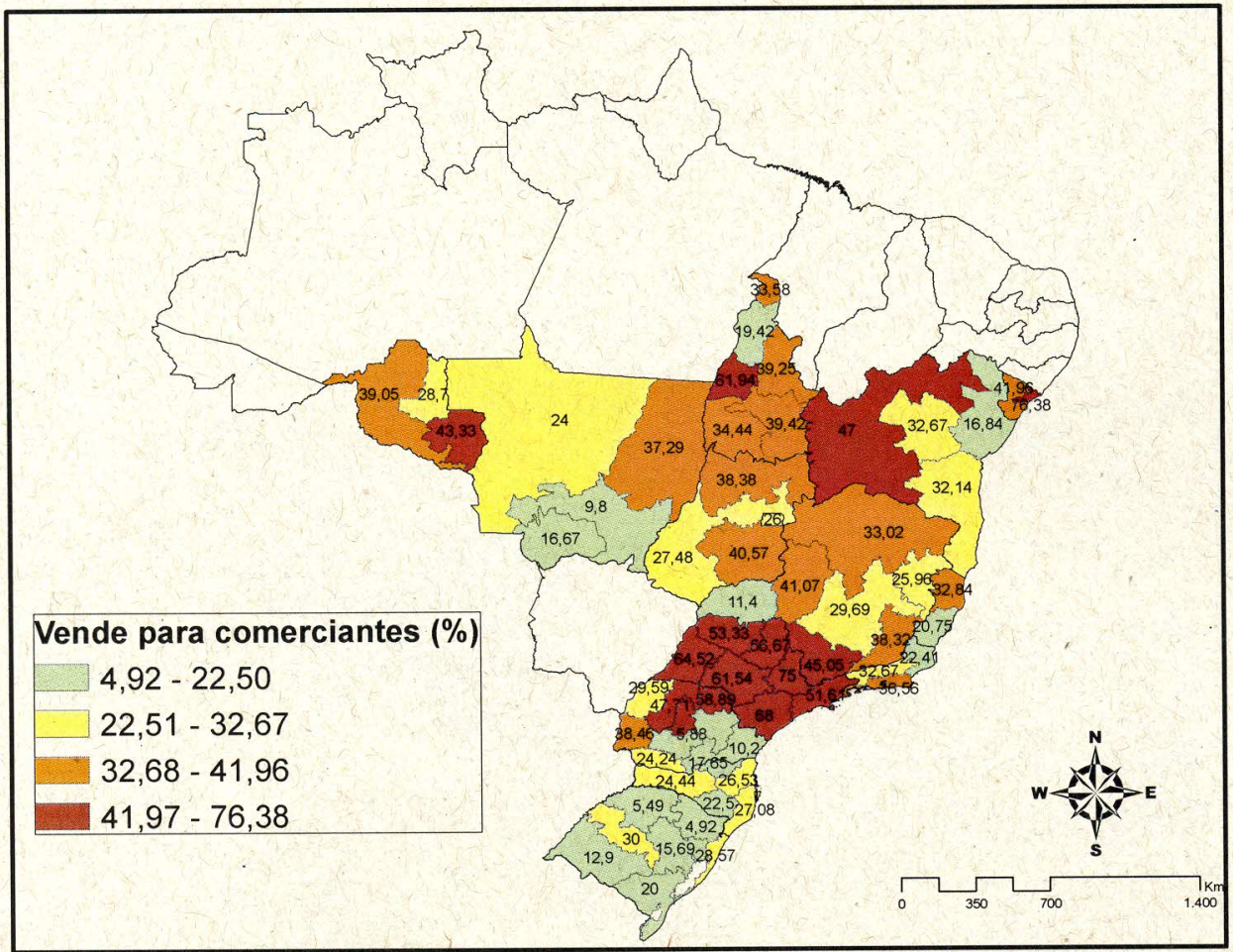

Mapa 55- Distribuição por circuito das frequências estimadas de propriedades que vendem reprodutores diretamente para comerciantes- Brasil - out 2001-dez 2004 


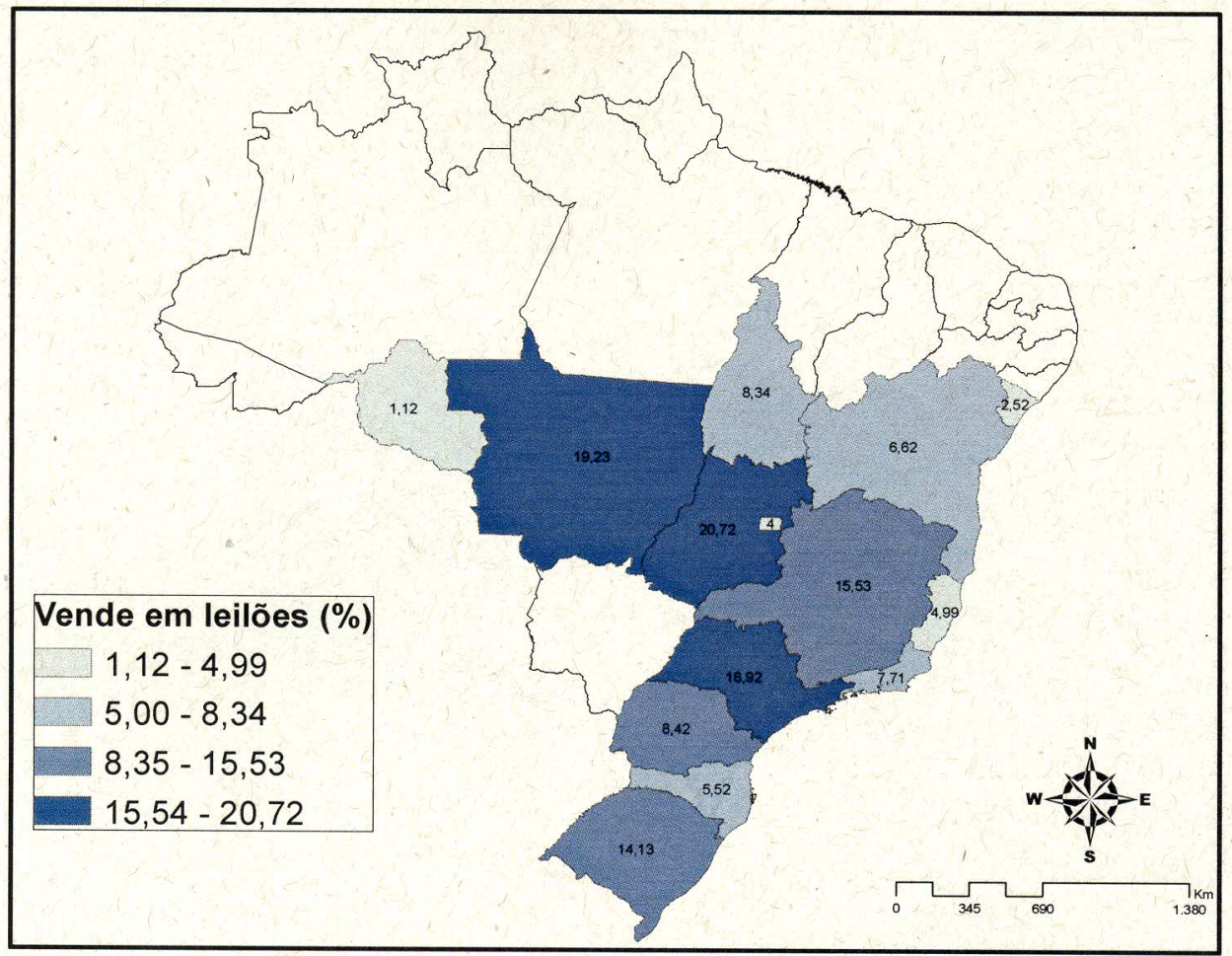

Mapa 56- Distribuição estadual das frequências estimadas de propriedades que vendem reprodutores em leilões- Brasil - out 2001-dez 2004

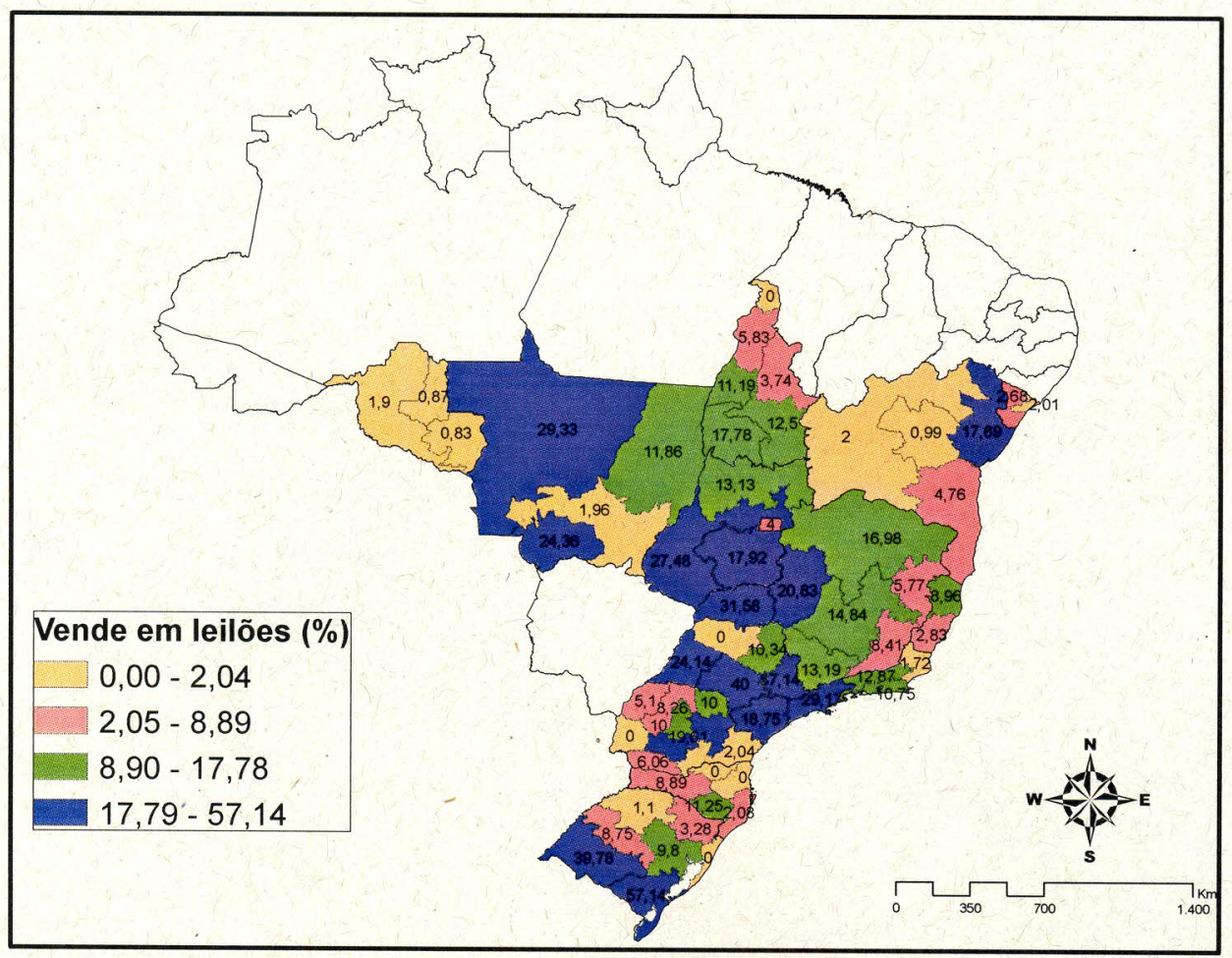

Mapa 57- Distribuição por circuito das frequências estimadas de propriedades que vendem reprodutores em leilões- Brasil - out 2001-dez 2004 
Vende em exposições (\%)

$0,62-1,32$

$1,33-2,51$

$2,52-3,74$

$3,75-11,21$
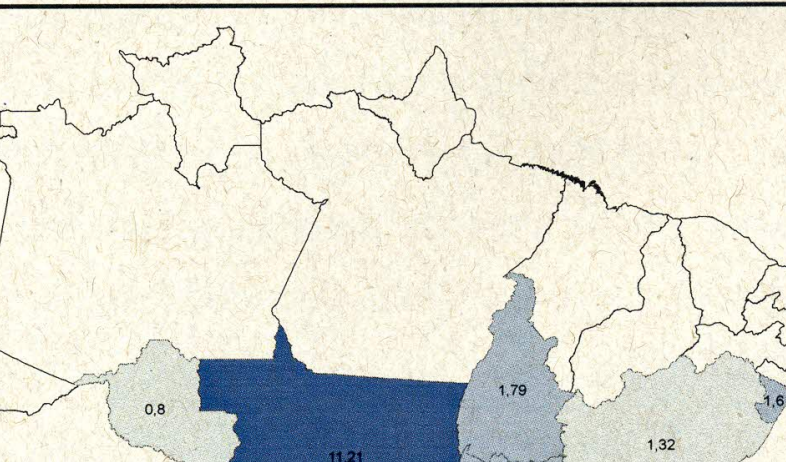

0,8
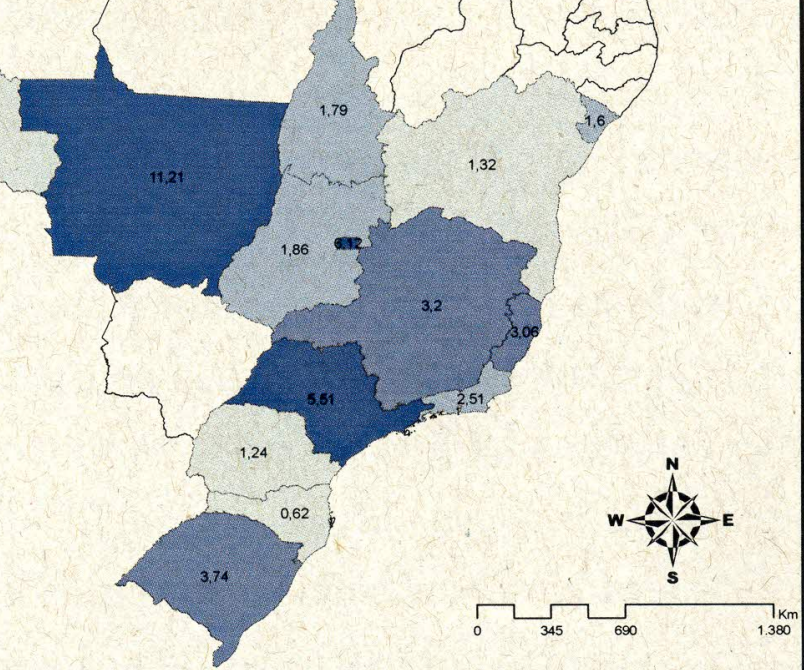

Mapa 58- Distribuição estadual das frequências estimadas de propriedades que vendem reprodutores em exposições- Brasil - out 2001-dez 2004

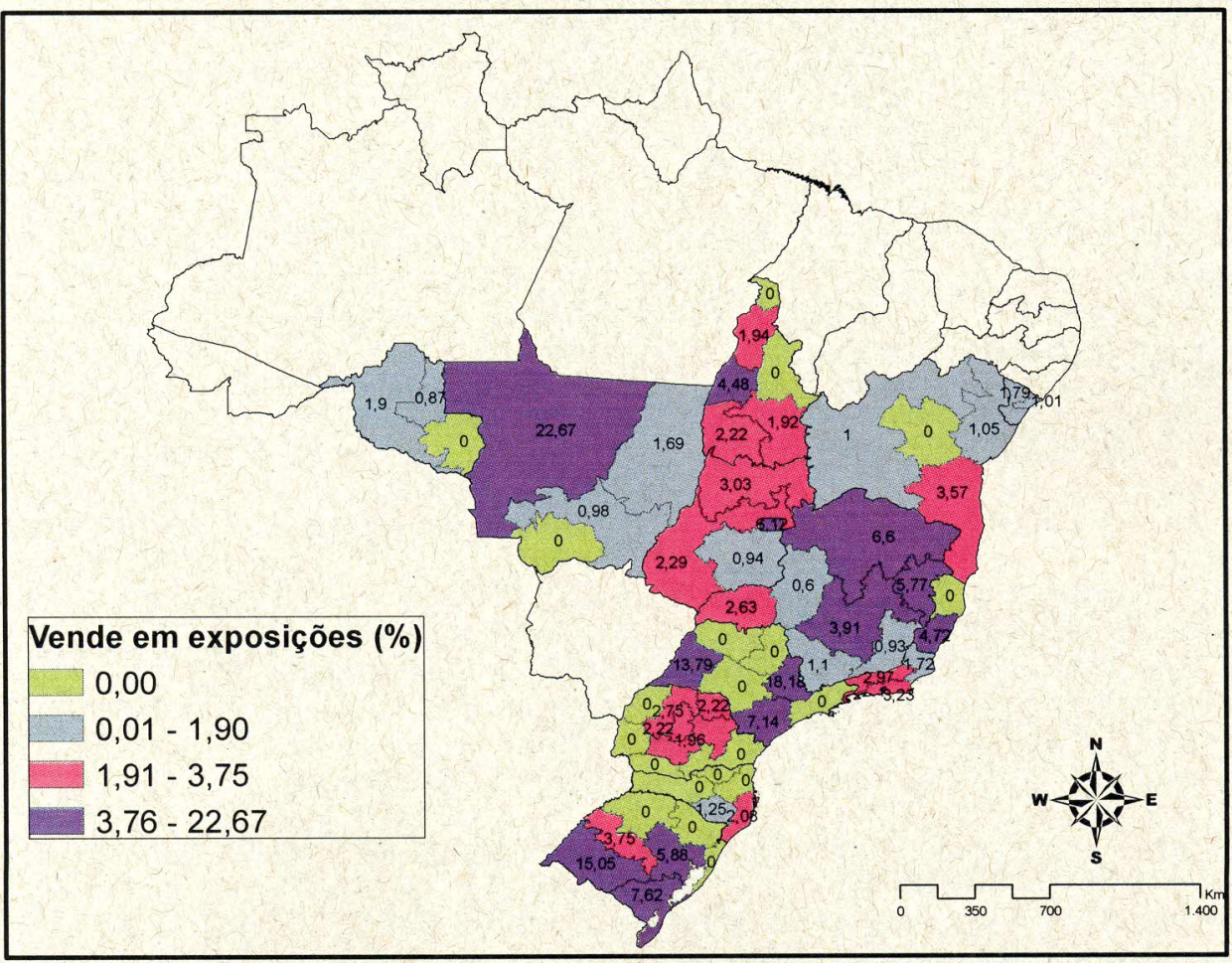

Mapa 59- Distribuição por circuito das frequências estimadas de propriedades que vendem reprodutores em exposições- Brasil - out 2001-dez 2004 
A compra e venda animais pode oferecer o risco de introdução ou de difusão de enfermidades entre os rebanhos. Nos casos dos reprodutores, esta questão se agrava pelo fato de serem animais que permanecem por períodos prolongados dentro das criações podendo representar importantes fontes de infecção de determinadas doenças, principalmente àquelas relacionadas de alguma maneira com a redução da eficiência reprodutiva, podendo citar: a brucelose, rinotraqueíte infecciosa bovina (IBR), diarréia viral bovina (BVD), tricomonose, leptospirose, campilobacteriose, micoplasmose (NASCIMENTO et al., 2005; JUNQUEIRA; ALFIERI, 2006; DIAS et al., 2008).

$\mathrm{Na}$ intenção de reduzir a incidência e a prevalência destas doenças no país, o MAPA instituiu legislações específicas que regulamentam o trânsito de reprodutores e as normas sanitárias para a participação de exposições, feiras, leilões e outras locais de aglomeração animal (BRASIL, 1994; BRASIL, 2010).

Diversos levantamentos sorológicos realizados em diferentes regiões do país, demonstraram que grandes proporções de animais provenientes de rebanhos com atividade reprodutiva, são positivos sorologicamente para um ou mais agentes etiológicos simultaneamente (LILENBAUM, 1996; ROCHA; GOUVEIA; LEITE, 1998; LEITE, 1999; RICHTZENHAIN et al., 1999; MÉDICI; ALFIERI; ALFIERI, 2000; TAKIUCHI; ALFIERI; ALFIERI, 2001; DIAS, 2008).

Considerando os diversos custos gerados pela introdução destas doenças nos rebanhos pela redução da eficiência reprodutiva (menor número de bezerros nascidos e extensão do intervalo entre partos), a avaliação do perfil sanitário das criações e dos animais que serão introduzidos nas mesmas, representam ações úteis para a adoção estratégica de medidas de controle e profilaxia de doenças, podendo citar a vacinação (IBR, BVD, brucelose, leptospirose), tratamento de touros infectados (campilobacteriose, tricomonose), descanso reprodutivo (campilobacteriose, tricomonose) ou mesmo a eliminação das fontes de infecção (brucelose) (JUNQUEIRA; ALFIERI, 2006).

\subsubsection{Aluguel de pastagens}

A prática de alugar pastagens pode favorecer a transmissão de diversas doenças que até então não existiam nos rebanhos, tanto por parte do locatário como por parte do locador do terreno. $\mathrm{Na}$ análise geral, estimou-se que 21,36\% [20,67\%; 
22,07\%] alugam pastos de/ou para outros produtores. Os rebanhos de corte apresentaram a maior frequência de aluguel de pastagens (26,09\% [24,58\%; $27,67 \%]$ ) enquanto os rebanhos mistos e de leite apresentaram frequências em torno de $20 \%$, não havendo diferença entre eles (Tabela 23).

Tabela 23- Proporção de propriedades que realizam o aluguem de pastos segundo o tipo de exploração pecuária- Brasil - out 2001-dez 2004

\begin{tabular}{ccccccccc}
\hline \multicolumn{7}{c}{ Tipo de Exploração } \\
\hline Aluga pastos & $\begin{array}{c}\text { Corte } \\
(\mathbf{\%})\end{array}$ & IC 95\% & $\begin{array}{c}\text { Leite } \\
\mathbf{( \% )}\end{array}$ & IC 95\% & $\begin{array}{c}\text { Mista } \\
\mathbf{( \% )}\end{array}$ & IC 95\% & $\begin{array}{c}\text { Total } \\
\mathbf{( \% )}\end{array}$ & IC 95\% \\
\hline Não & 73,91 & 72,$33 ; 75,42$ & 80,33 & 79,$18 ; 81,44$ & 79,60 & 78,$41 ; 80,73$ & 78,64 & 77,$93 ; 79,33$ \\
Sim & 26,09 & 24,$58 ; 27,67$ & 19,67 & 18,$56 ; 20,82$ & 20,40 & 19,$27 ; 21,59$ & 21,36 & 20,$67 ; 22,07$ \\
\hline Total & 100,00 & & 100,00 & & 100,00 & & 100,00 & \\
\hline
\end{tabular}

Nas UFs, as frequências oscilaram entre 6,27\% [5,10\%; 7,70\%] em Santa Catarina e 37,41\% [34,18\%; 40,75\%] em Goiás (Mapa 60). O quartil superior $(>29,74 \%)$ de circuitos com as maiores frequências de aluguel de pastagens foram encontrados, em todas as regiões de Goiás; sudeste e extremo norte de Tocantins; noroeste mato-grossense; leste sergipano; centro-oeste, oeste e Vale do São Francisco e nordeste da Bahia, Triângulo Mineiro, centro-oeste, norte e sudoeste de Minas Gerais e sudoeste do Rio Grande do Sul (Mapa 61).

O aluguel de pastagens é uma prática que pode facilitar a disseminação de doenças entre os rebanhos, considerando que o arrendatário tem pouco controle da condição sanitária do ambiente em que vai colocar os seus animais. Tendo em vista que diversos agentes (infecciosos e parasitários) podem permanecer viáveis durante algum tempo no solo, cochos, pastagens e na água, recomenda-se que uma atenção especial seja dada ao ambiente e ao histórico sanitário dos rebanhos que passaram por estes locais.

No ano de 2006, estimou-se que existiam no país 86.583 propriedades de exploração pecuária que utilizavam terras arrendadas e que cobriam uma área de aproximadamente 4,74 milhões de hectares, o correspondente a 2,3\% da área total utilizada. As UFs do Rio Grande do Sul, Minas Gerais e do Ceará apresentaram o maior número de propriedades ocupando áreas arrendadas, sendo responsáveis por aproximadamente $46 \%$ do total destas criações (IBGE, 2006b). 


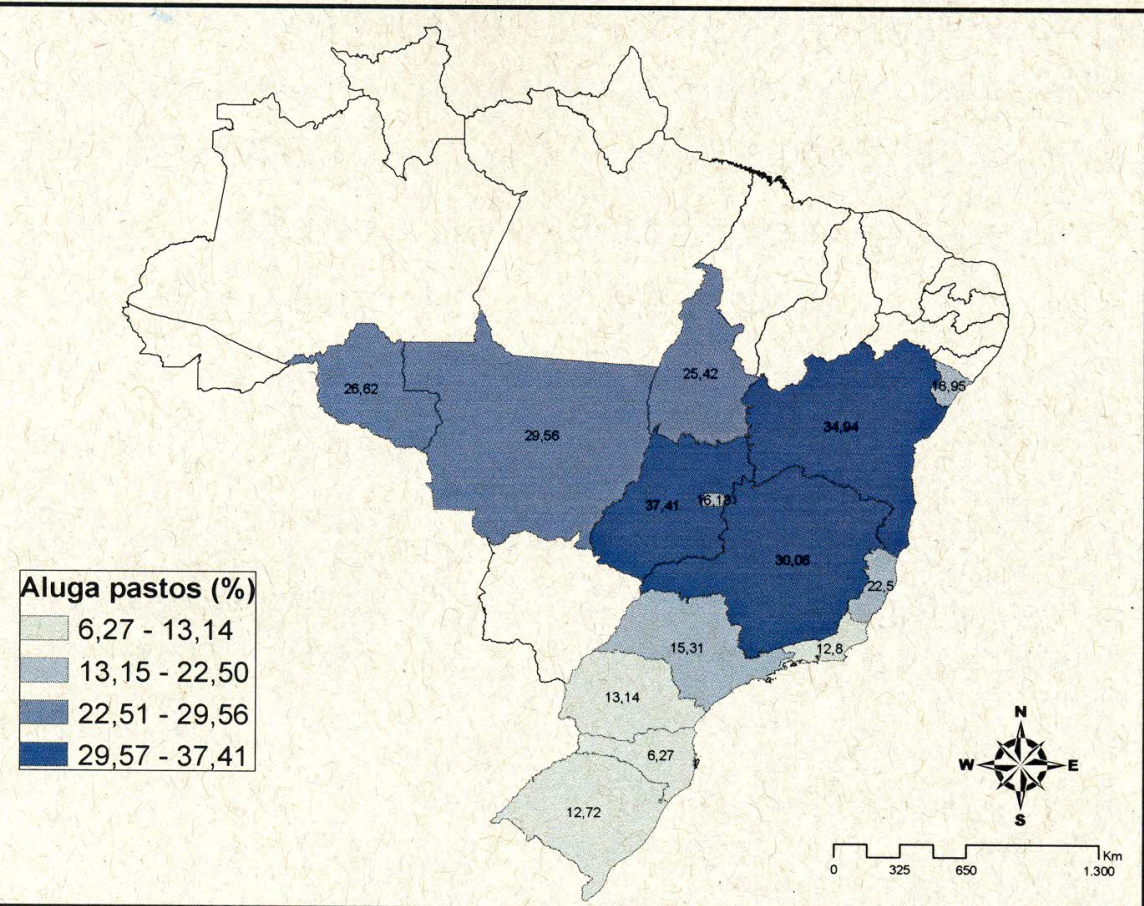

Mapa 60- Distribuição estadual das frequências estimadas de propriedades que alugam pastos em alguma época do ano- Brasil - out 2001-dez 2004

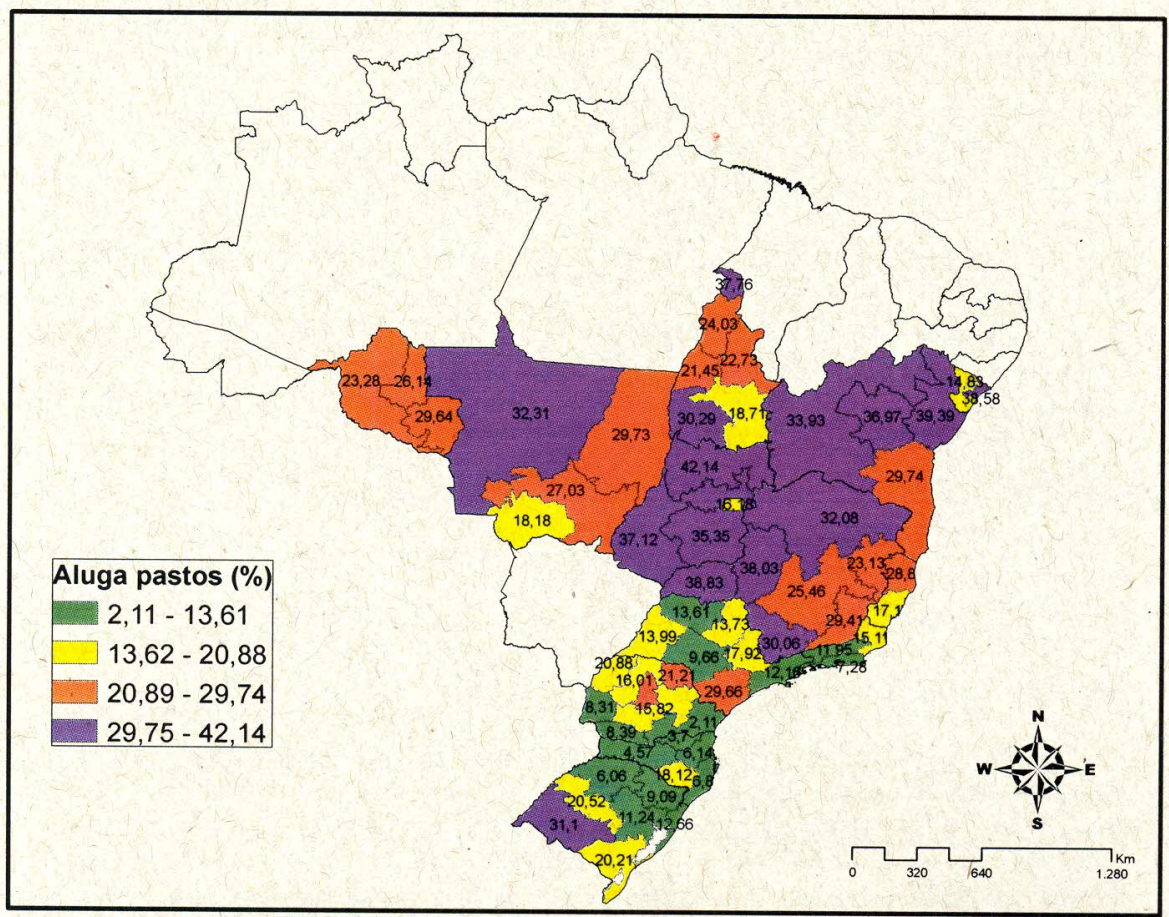

Mapa 61- Distribuição por circuito das frequências estimadas de propriedades que alugam pastos em alguma época do anoBrasil - out 2001-dez 2004 


\subsubsection{Pastos em comum}

Uma proporção estimada de 13,96\% [13,37\%; 14,58\%] das propriedades, descreveram possuir áreas de pastagem em comum com outras criações. Não foram observadas diferenças significativas de proporções de aluguel de pastagens entre os tipos de exploração (Tabela 24).

Tabela 24- Proporção estimada de estabelecimentos que possuem áreas de pastagem em comum com outras propriedades segundo o tipo de exploração- Brasil - out 2001-dez 2004

\begin{tabular}{ccccccccc}
\hline \multicolumn{10}{c}{ Tipo de Exploração } \\
\hline $\begin{array}{c}\text { Pastos em } \\
\text { comum }\end{array}$ & $\begin{array}{c}\text { Corte } \\
\mathbf{( \% )}\end{array}$ & IC $\mathbf{9 5 \%}$ & $\begin{array}{c}\text { Leite } \\
\mathbf{( \% )}\end{array}$ & IC $\mathbf{9 5 \%}$ & $\begin{array}{c}\text { Mista } \\
\mathbf{( \% )}\end{array}$ & IC 95\% & $\begin{array}{c}\text { Total } \\
\mathbf{( \% )}\end{array}$ & IC 95\% \\
\hline Não & 85,01 & 83,$72 ; 86,21$ & 86,80 & 85,$78 ; 87,76$ & 85,87 & 84,$84 ; 86,84$ & 86,04 & 85,$42 ; 86,63$ \\
Sim & 14,99 & 13,$79 ; 16,28$ & 13,20 & 12,$24 ; 14,22$ & 14,13 & 13,$16 ; 15,16$ & 13,96 & 13,$37 ; 14,58$ \\
\hline Total & 100,00 & & 100,00 & & 100,00 & & 100,00 & \\
\hline
\end{tabular}

As três maiores frequências estaduais de criações que dividem o mesmo pasto com outras propriedades foram encontradas nos Estados do Espírito Santo, Bahia e Rondônia (Mapa 62), sendo que o quartil superior (>19,22\%) de circuitos produtores que apresentaram as maiores prevalências foi constituído dos circuitos do Espírito Santo; no norte fluminense; Zona da Mata, centro-oeste e sudoeste de Minas Gerais; centro-norte, oeste e Vale do São Francisco na Bahia; regiões nordeste, centro-oeste e extremo norte tocantinense; sudeste e centro-norte rondoniense e nas regiões do centro-sul e do centro-leste paranaenses (Mapa 63).

Estimativas do IBGE (2006b), demonstraram que no ano de 2006 haviam cerca de 36.185 propriedades de exploração pecuária que criavam animais em pastos comuns a outros proprietários (parceiros), ocupando cerca de 850.336 mil hectares de pastagens. Os mesmos riscos de disseminação de enfermidades entre os animais relacionados anteriormente à prática de aluguel de pastagens, também valem para as criações que possuem pastos em comum com outras propriedades, com o agravante que em alguns destes casos rebanhos diferentes ocupam a mesma área. Esta situação pode aumentas significativamente a taxa de contato entre animais com procedências, manejos e características sanitárias diferentes. Nestes casos sugere-se que a parceria entre os criadores não se limite à utilização das terras, mas também envolva atuações frente ao manejo e a qualidade sanitária dos animais. 


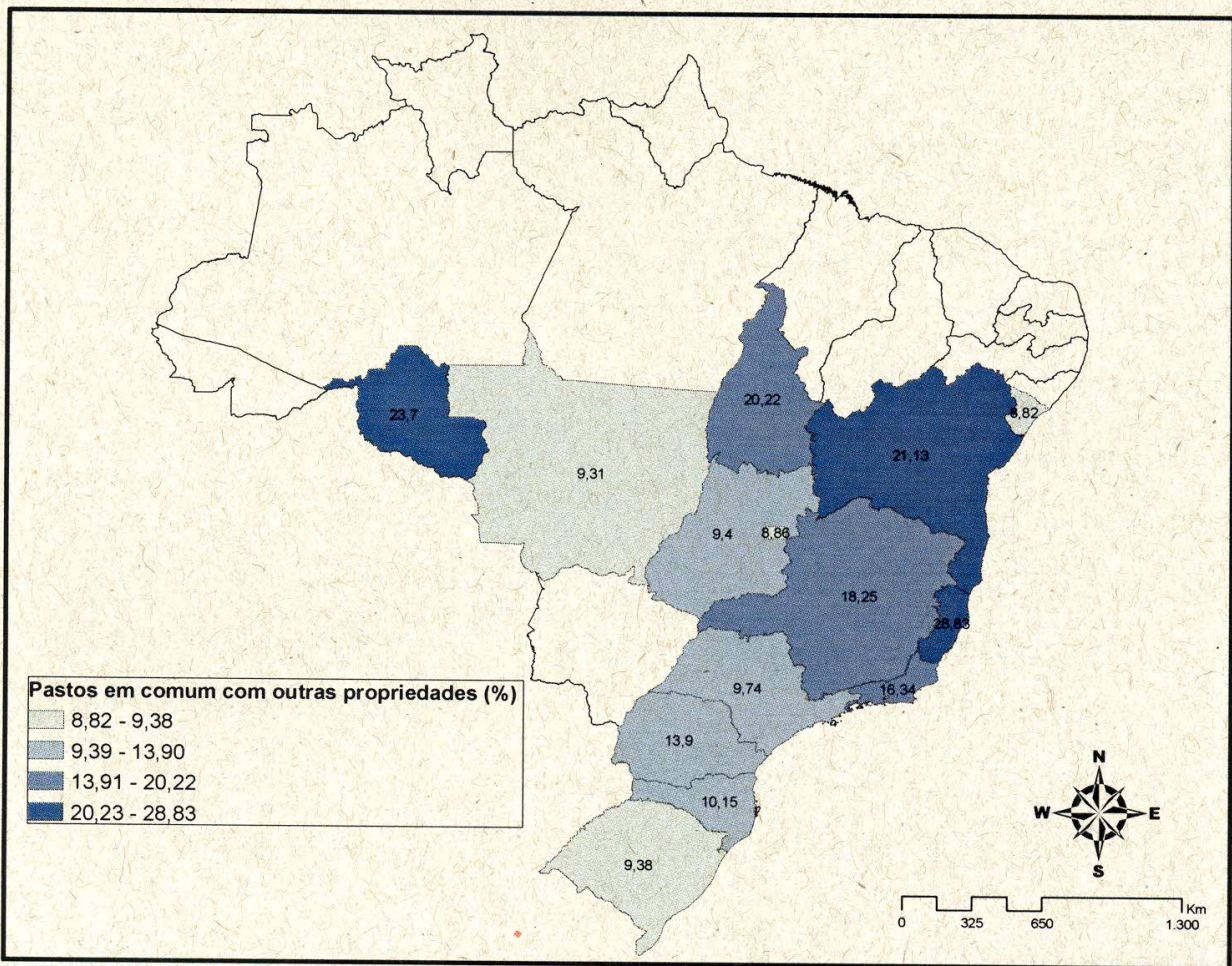

Mapa 62- Distribuição estadual das frequências estimadas de criações que possuem pastos em comum com outras propriedades- Brasil - out 2001-dez 2004

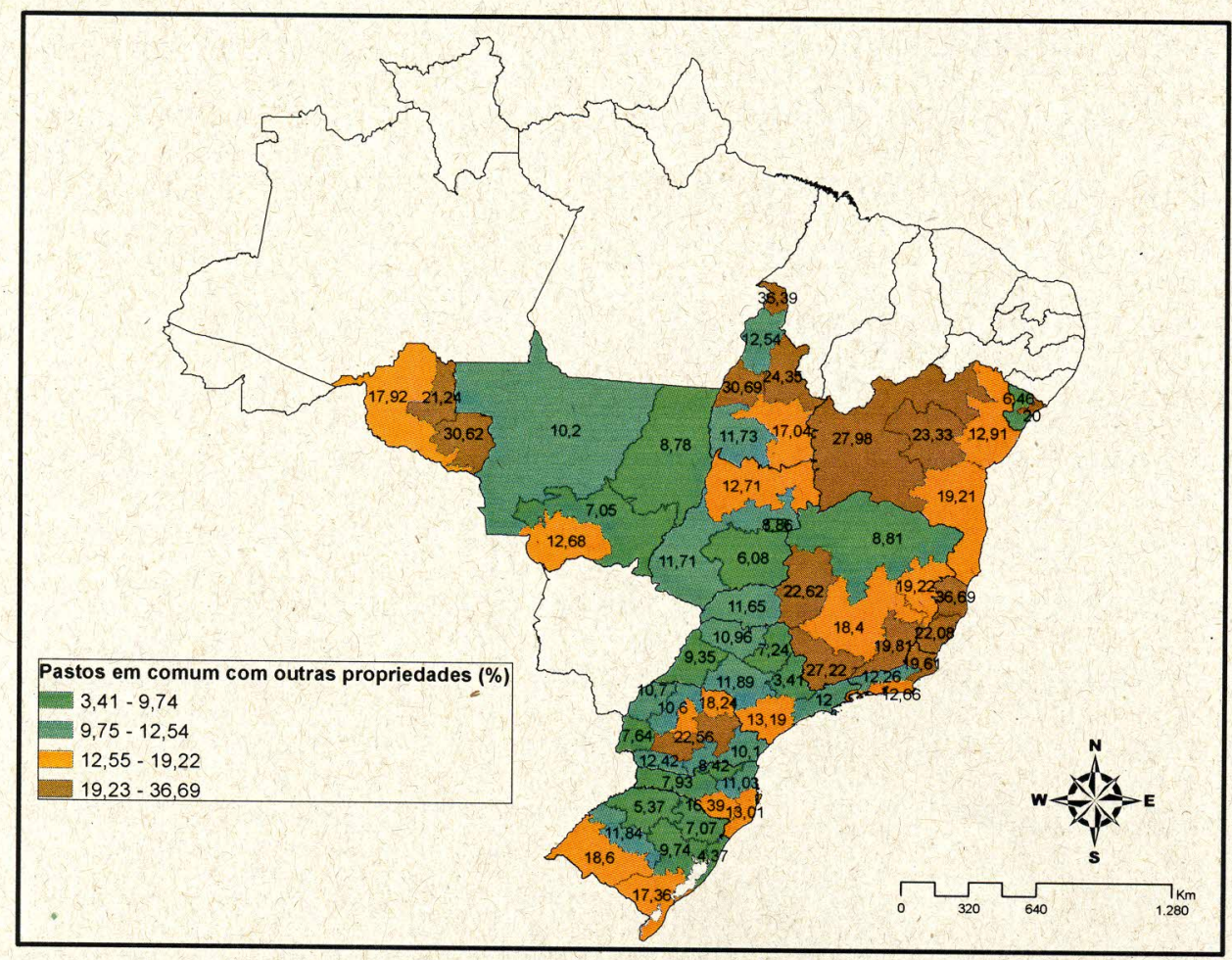

Mapa 63- Distribuição por circuito das frequências estimadas de criações que possuem pastos em comum com outras propriedadesBrasil - out 2001-dez 2004 


\subsection{5 Áreas alagadas}

Propriedades que possuem áreas de pastagens alagadas durante períodos do ano e que o gado tem acesso foram estimadas em $30,33 \%$ [29,50\%; $31,18 \%]$ do total das criações. Nas análises estaduais estas frequências variaram de $20,97 \%$ [16,50\%; 26,28\%] no Distrito Federal a $47,14 \%$ [43,93\%; $50,36 \%]$ no Estado de Rondônia (Mapa 64). Os circuitos que integraram o quartil superior (>36,99\%) com as maiores proporções foram encontrados no centro-norte e sudeste rondonienses; Pantanal mato-grossense; centro-sul baiano; ambos os circuitos pecuários do Espírito Santo; Vale do Mucuri e centro-sul mineiros; região litorânea sul e baixada fluminense; litoral sul paulista; sudeste Paranaense; região da grande Florianópolis e sul de Santa Catarina e sudoeste, região centro-ocidental e litoral do Rio Grande do Sul (Mapa 65).

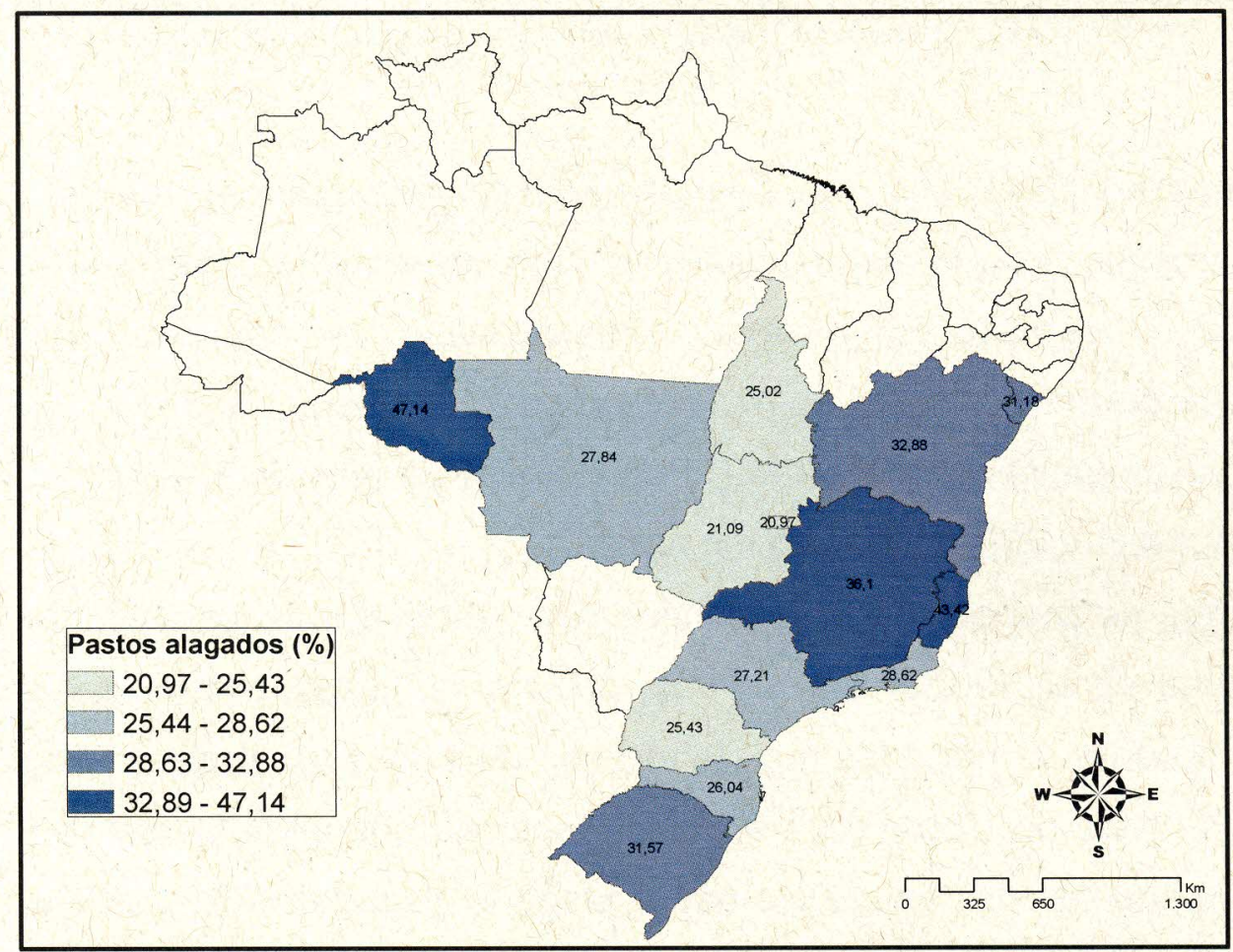

Mapa 64- Distribuição estadual das frequências estimadas de propriedades que possuem áreas alagadiças às quais o gado tem acessoBrasil - out 2001-dez 2004 


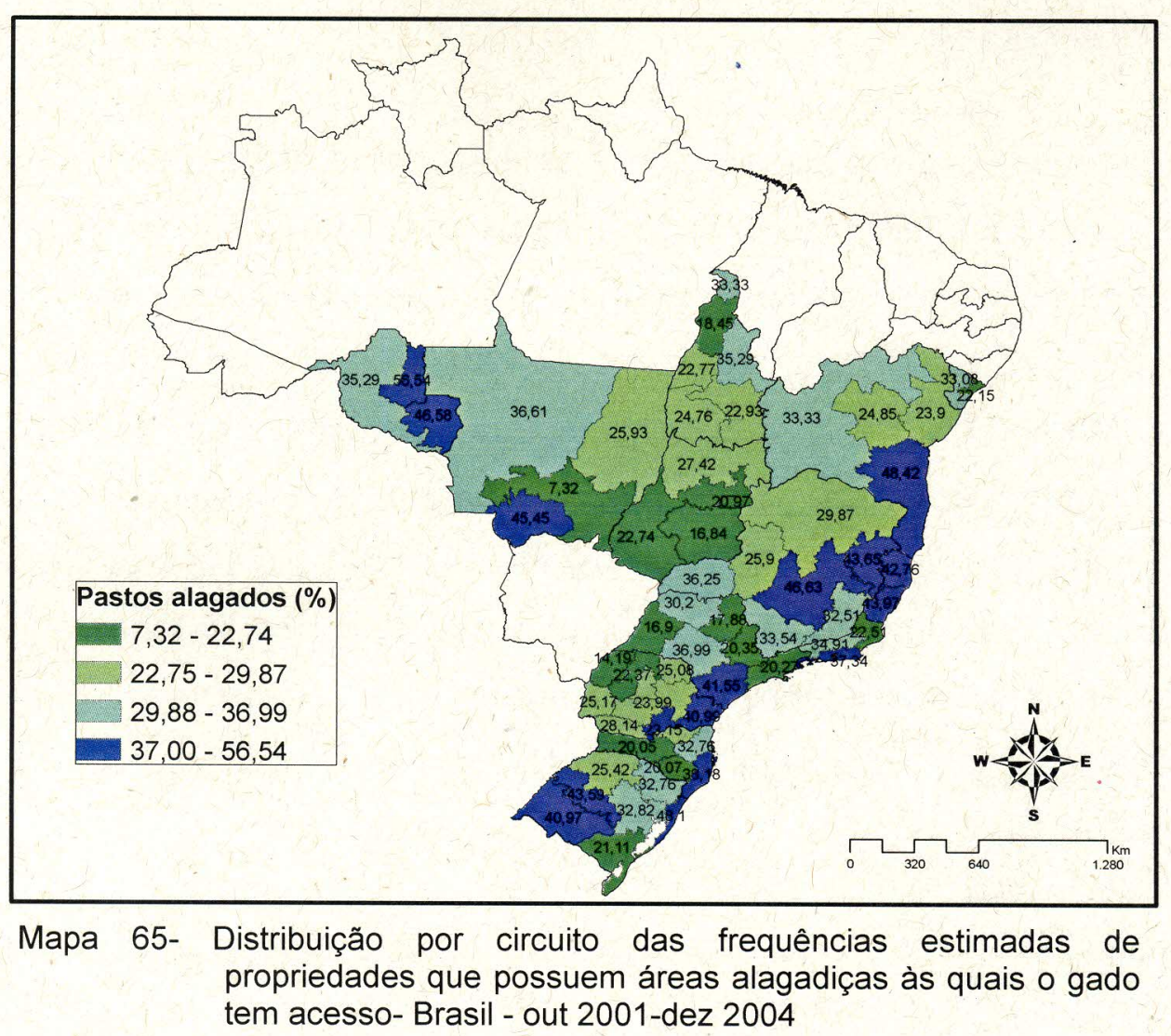

Áreas de pastagens que permanecem alagadas durante certas épocas do ano, determinam um ambiente propício para a sobrevivência de diversos agentes infecciosos e parasitários e podem representar um ambiente facilitador na transmissão de enfermidades como, por exemplo: leptospirose, brucelose, pitiose e a fasciolose hepática (BEER, 1999; PELLEGRIN et al., 1999; LEAL et al., 2001; OLIVEIRA; FILHA, 2009; GRECCO et al., 2009).

Surtos de morte súbita de bovinos por deficiência de cobre foram descritos por Marques et al. (2003) em animais criados em pastagens que permanecem alagadas durante os períodos mais chuvosos do ano. Este problema é decorrente dos baixos níveis de Cobre $(\mathrm{Cu})$ em contraposição aos altos níveis de Ferro $(F)$ e Enxofre (S) encontrados na água e nas pastagens alagadas (RAMIREZ, et al., 1998; MARQUES et al., 2003). 


\subsubsection{Piquete maternidade}

A proporção estimada de propriedades que mantêm as fêmeas durante as fases de pré-parto e puerpério em piquetes separados, foi de 34,31\% [33,50\%; $35,13 \%]$. As explorações de corte apresentaram uma frequência propriedades que utilizam piquetes maternidade de 41,04\% [39,36\%; 42,74\%], as leiteiras de $34,77 \%$ [33,32\%; 36,25\%] e os rebanhos mistos de 30,06\% [28,80\%; 31,34\%] (Tabela 24).

Tabela 25- Distribuição das proporções de propriedades que utilizam os piquetes maternidade segundo o tipo de exploração- Brasil - out 2001-dez 2004

\begin{tabular}{ccccccccc}
\hline \multicolumn{10}{c}{ Tipo de Exploração } \\
\hline $\begin{array}{c}\text { Piquete } \\
\text { Maternidade }\end{array}$ & $\begin{array}{c}\text { Corte } \\
\mathbf{( \% )}\end{array}$ & IC 95\% & $\begin{array}{c}\text { Leite } \\
\mathbf{( \% )}\end{array}$ & IC 95\% & $\begin{array}{c}\text { Mista } \\
(\mathbf{\%})\end{array}$ & IC 95\% & $\begin{array}{c}\text { Total } \\
(\%)\end{array}$ & IC 95\% \\
\hline Não & 58,96 & 57,$26 ; 60,64$ & 65,23 & 63,$75 ; 66,68$ & 69,94 & 68,$66 ; 71,20$ & 65,64 & 64,$82 ; 66,45$ \\
Sim & 41,04 & 39,$36 ; 42,74$ & 34,77 & 33,$32 ; 36,25$ & 30,06 & 28,$80 ; 31,34$ & 34,36 & 33,$55 ; 35,18$ \\
\hline Total & 100,00 & & 100,00 & & 100,00 & & 100,00 & \\
\hline
\end{tabular}

Os resultados estaduais variaram entre 14,41\% [12,58\%; 16,46\%] em Santa Catarina e 67,26\% [63,98\%; 70,38\%] em Goiás (Mapa 66). Entre os circuitos produtores, o quartil superior de circuitos pecuários $(>49,17 \%)$ com as maiores prevalências de utilização de piquetes maternidade, foram encontrados na região Serrana de Santa Catarina; litoral sul e Vale do Ribeira em São Paulo; centro-oeste e centro-sul de Minas Gerais; nos circuitos do Espírito Santo e norte fluminense; nordeste, centro-oeste e extremo norte do Tocantins; noroeste e sudeste matogrossense; sudeste Rondoniense (Mapa 67). 


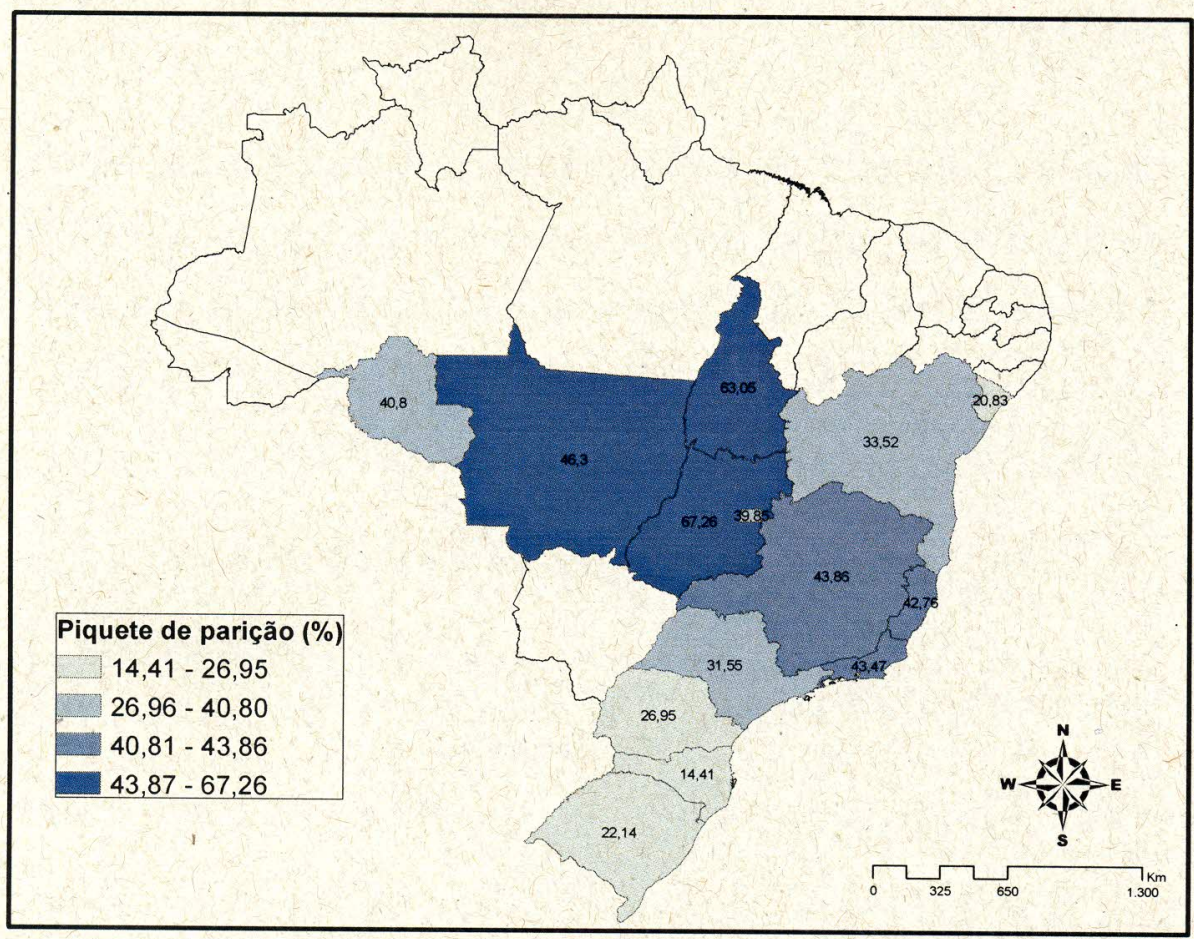

Mapa 66- Distribuição estadual das frequências estimadas de propriedades que possuem piquete separado para fêmeas na fase de parto e/ou pós-parto- Brasil - out 2001-dez 2004

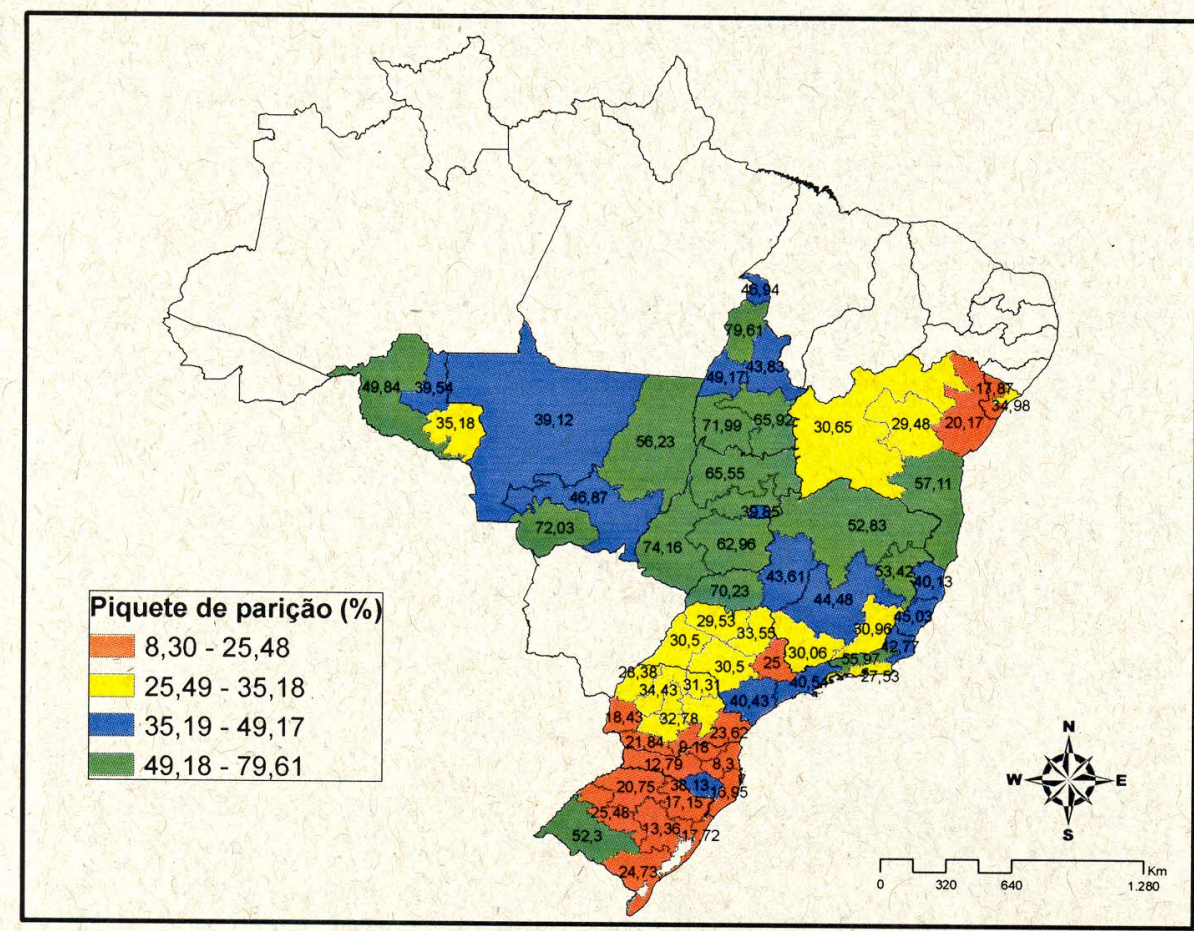

Mapa 67- Distribuição por circuito das frequências estimadas de propriedades que possuem piquete separado para fêmeas na fase de parto e/ou pós-parto- Brasil - out 2001-dez 2004

A utilização de piquete-maternidade para as fêmeas na fase pré e/ou pósparto, pode oferecer vantagens sob diversos aspectos. Primeiro, pelo fato de que o 
isolamento das fêmeas em nestes locais facilita possíveis intervenções durante o parto e cuidados com os recém-nascidos (BRITO et al., 2007). Do ponto de vista sanitário e do controle de doenças que possuem nos restos de tecido placentário uma importante via de eliminação (brucelose e leptospirose), a utilização de piquetes separados para o parto pode diminuir a probabilidade de que outros animais do rebanho sejam expostos à doença (NICOLETTI, 1980; BEER, 1999).

\subsubsection{Relato de aborto nos últimos 12 meses}

Os criadores foram questionados a respeito da observação da ocorrência de aborto no rebanho nos 12 meses anteriores à entrevista. A estimativa encontrada foi que em 20,19\% $[19,45 ; 20,95]$ das propriedades foram avistados casos de aborto. Do restante, 76,23\% [75,43\%; 77,02\%] alegou não ter ocorrido e 3,58\% [3,27\%; 3,91\%] disse não saber. As estimativas segundo o tipo de exploração demonstraram que entre as explorações de corte e leite as proporções de casos de aborto foram comparáveis sendo de, respectivamente, em 21,79\% [20,40;23,25\%] e 23,84\% $[22,46 \% ; 25,27 \%]$. Nos rebanhos mistos, a estimativa foi de 15,68\% [14,64\%; 16,79\%] (Tabela 26).

Tabela 26- Distribuição das proporções de casos de aborto nos últimos 12 meses segundo o tipo de exploração pecuária- Brasil - out 2001-dez 2004

\begin{tabular}{ccccccccc}
\hline \multicolumn{7}{c}{ Tipo de Exploração } \\
\hline $\begin{array}{c}\text { Casos de } \\
\text { aborto }\end{array}$ & $\begin{array}{c}\text { Corte } \\
\mathbf{( \% )}\end{array}$ & IC $\mathbf{9 5 \%}$ & $\begin{array}{c}\text { Leite } \\
\mathbf{( \% )}\end{array}$ & IC $\mathbf{9 5 \%}$ & $\begin{array}{c}\text { Mista } \\
\mathbf{( \% )}\end{array}$ & IC 95\% & $\begin{array}{c}\text { Total } \\
\mathbf{( \% )}\end{array}$ & IC 95\% \\
\hline Não & 72,54 & 70,$97 ; 74,06$ & 73,79 & 72,$32 ; 75,20$ & 80,75 & 79,$57 ; 81,88$ & 76,23 & 75,$43 ; 77,02$ \\
Sim & 21,79 & 20,$40 ; 23,25$ & 23,84 & 22,$46 ; 25,27$ & 15,68 & 14,$64 ; 16,79$ & 20,19 & 19,$45 ; 20,95$ \\
Não sabe & 5,67 & 4,$90 ; 6,55$ & 2,37 & 1,$98 ; 2,85$ & 3,56 & 3,$08 ; 4,12$ & 3,58 & 3,$27 ; 3,91$ \\
\hline Total & 100,00 & & 100,00 & & 100,00 & & 100,00 & \\
\hline
\end{tabular}

As frequências estaduais de estabelecimentos que visualizaram abortos demonstraram valores que variaram de 12,04\% [8,68\%; 16,47\%] na UF de Brasília a 38,07\% [34,85\%; 41,39\%] em Mato Grosso (Mapa 68). Os circuitos produtores que participaram do quartil superior com as maiores frequências de casos de aborto foram observados na região norte do Rio Grande do Sul, uma área que compreende o Vale do Ribeira paulista, sudoeste, centro-oeste e o centro-sul de Minas Gerais; na 
região centro-sudoeste de Goiás; e a maioria dos circuitos do Tocantins, Mato Grosso e Rondônia (Mapa 69).

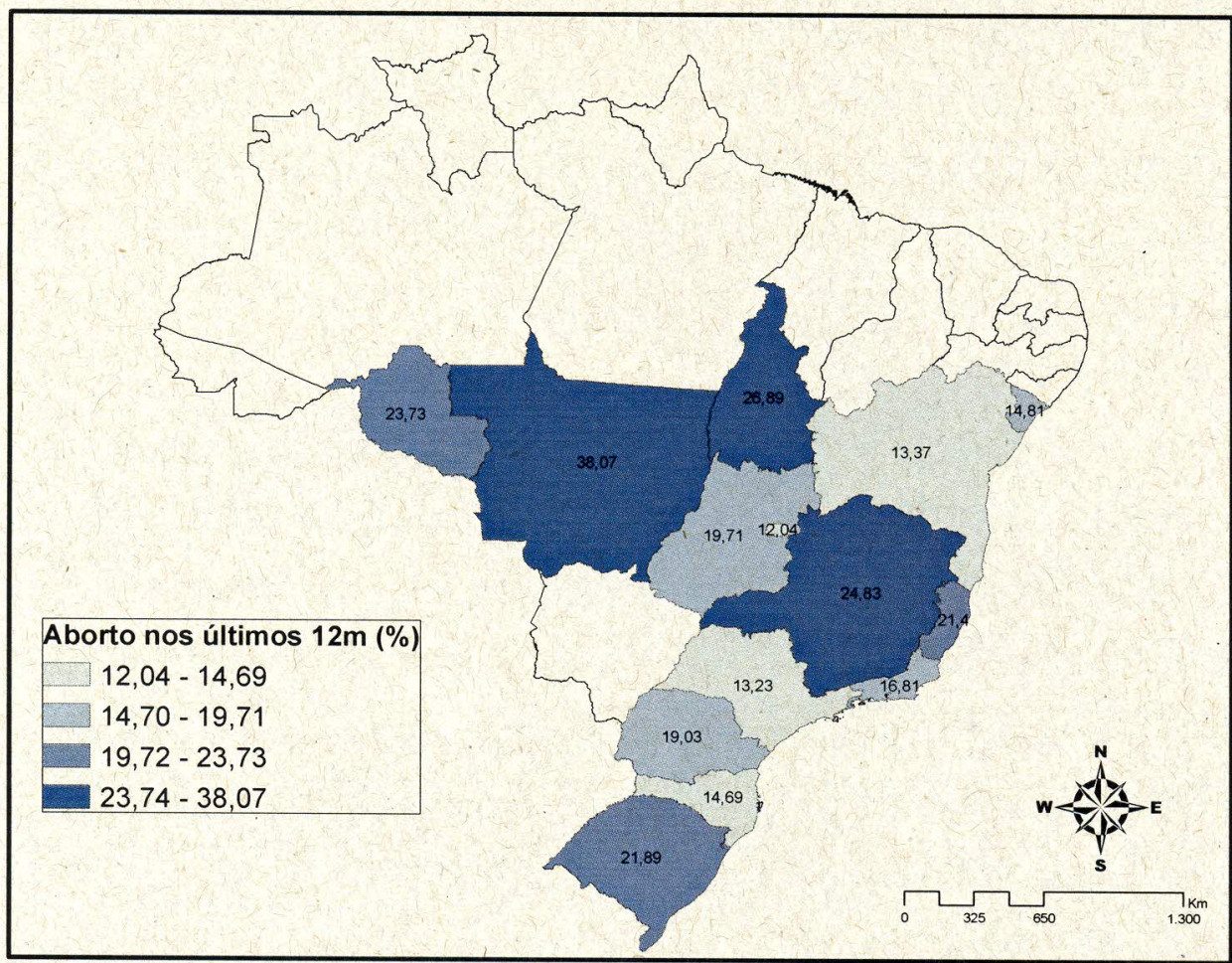

Mapa 68- Distribuição estadual das frequências estimadas de propriedades onde foram avistados casos de aborto nos doze meses que antecederam a entrevista- Brasil - out 2001-dez 2004

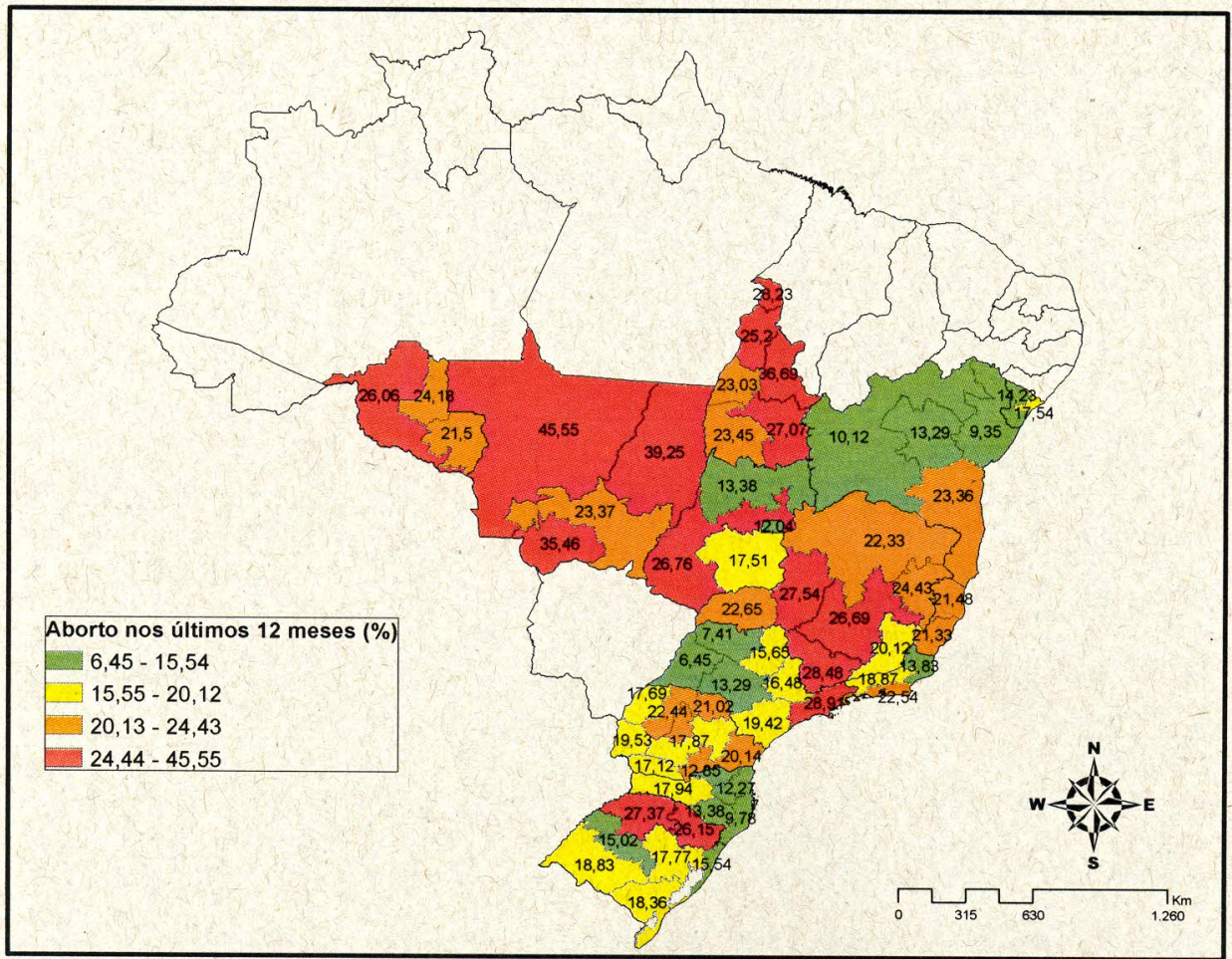

Mapa 69- Distribuição estadual das frequências estimadas de propriedades onde foram avistados casos de aborto nos doze meses que antecederam a entrevista- Brasil - out 2001-dez 2004 
A ocorrência de aborto é um fator preocupante nos rebanhos, tendo em vista que envolve tanto os fatores econômicos relacionados aos custos de produção de bezerros abortados quanto os riscos de disseminação de doenças entre os animais, já que outros animais podem ter acesso ao material abortado e podem se infectar através da inalação ou ingestão dos restos placentários. Algumas enfermidades infecciosas como a brucelose e a leptospirose podem ser transmitidas através do contato com os restos do aborto (BEER, 1999).

\subsubsection{Destino do aborto}

A estimativa geral revelou que a maioria das propriedades $(64,8 \%[63,82 \%$; $65,74 \%]$ não toma providencias ao observar restos de aborto nas pastagens. Uma pequena parcela de 2,93\% [2,55\%; 3,35\%] mencionou que deixa este material disponível para alimentação dos animais. Em relação à prevalência de criações onde são tomadas atitudes apropriadas frente a este problema (enterrar, jogar fora ou queimar) representaram 32,29\% [31,37\%; 33,23\%]. Quanto aos tipos de exploração, a frequência de locais que não oferecem um destino adequado diante dos restos de aborto, apresentou valores acima de 60\% em todos eles. (Tabela 27).

Tabela 27- Distribuição das proporções de destino dado aos restos de aborto encontrados nas propriedade segundo o tipo de exploração - Brasil - out 2001-dez 2004

\begin{tabular}{ccccccccc}
\hline \multicolumn{10}{c}{ Tipo de exploração } \\
\hline Destino do Aborto & $\begin{array}{c}\text { Corte } \\
(\mathbf{\%})\end{array}$ & IC $\mathbf{9 5 \%}$ & $\begin{array}{c}\text { Leite } \\
\mathbf{( \% )}\end{array}$ & IC 95\% & $\begin{array}{c}\text { Mista } \\
\text { (\%) }\end{array}$ & IC 95\% & $\begin{array}{c}\text { Total } \\
\text { (\%) }\end{array}$ & IC 95\% \\
\hline Não faz nada & 69,96 & 68,$14 ; 71,71$ & 59,23 & 57,$52 ; 60,92$ & 67,50 & 65,$97 ; 68,99$ & 64,78 & 63,$82 ; 65,74$ \\
Alimenta animais & 1,46 & 1,$00 ; 2,13$ & 4,04 & 3,$32 ; 4,91$ & 2,67 & 2,$15 ; 3,32$ & 2,93 & 2,$55 ; 3,35$ \\
Enterra/joga/queima & 28,58 & 26,$86 ; 30,36$ & 36,73 & 35,$09 ; 38,40$ & 29,83 & 28,$38 ; 31,32$ & 32,29 & 31,$37 ; 33,23$ \\
\hline Total & 100,00 & & 100,00 & & 100,00 & & 100,00 \\
\hline
\end{tabular}

As frequências estaduais de propriedades que não tomam qualquer atitude ao encontrar sobras do material abortado foram consideravelmente altas em boa parte das UFs, chegando a $88,05 \%$ [86,25\%; 89,65] no Tocantins (Mapa 70). O quartil superior de circuitos com as maiores frequências $(>78,47 \%)$, foram encontrados nos circuitos de Tocantins; nordeste baiano; Pantanal e sudeste mato-grossense; norte, Vale do Mucuri e Zona da Mata de Minas Gerais; na região Serrana de Santa Catarina e nas regiões do centro-oriental e sudeste do Rio Grande do Sul (Mapa 71). 
A proporção de propriedades que mencionaram que os produtos do aborto pudessem ser utilizados de alguma maneira como alimento para outros animais, como cães e suínos, foram baixas em comparação às outras atitudes descritas, sendo que os valores estaduais oscilaram entre $0,08 \%[0,01 \% ; 0,60 \%]$ no Rio de Janeiro e $5,48 \%$ [3,93\%; $7,58 \%$ ] no Rio Grande do Sul e nos circuitos foram nulas em diversos circuitos e chegaram a $15,43 \%$ [10,93\%; $21,33 \%]$ no sudoeste paranaense (Mapas 71 e 72).

Quanto aos lugares que oferecem um destino adequado aos restos do aborto, estes foram encontrados com as maiores frequências nos Estados do Espírito Santo, Santa Catarina e São Paulo ( $>50 \%$ das criações) (Mapa 74 ). O quartil superior de circuitos $(>44,72 \%)$, foi encontrado no sudeste, norte e Vale do Itajaí catarinenses; na maioria das regiões paulistas; nos circuitos do Espírito Santo e no noroeste mato-grossense (Mapa 75).

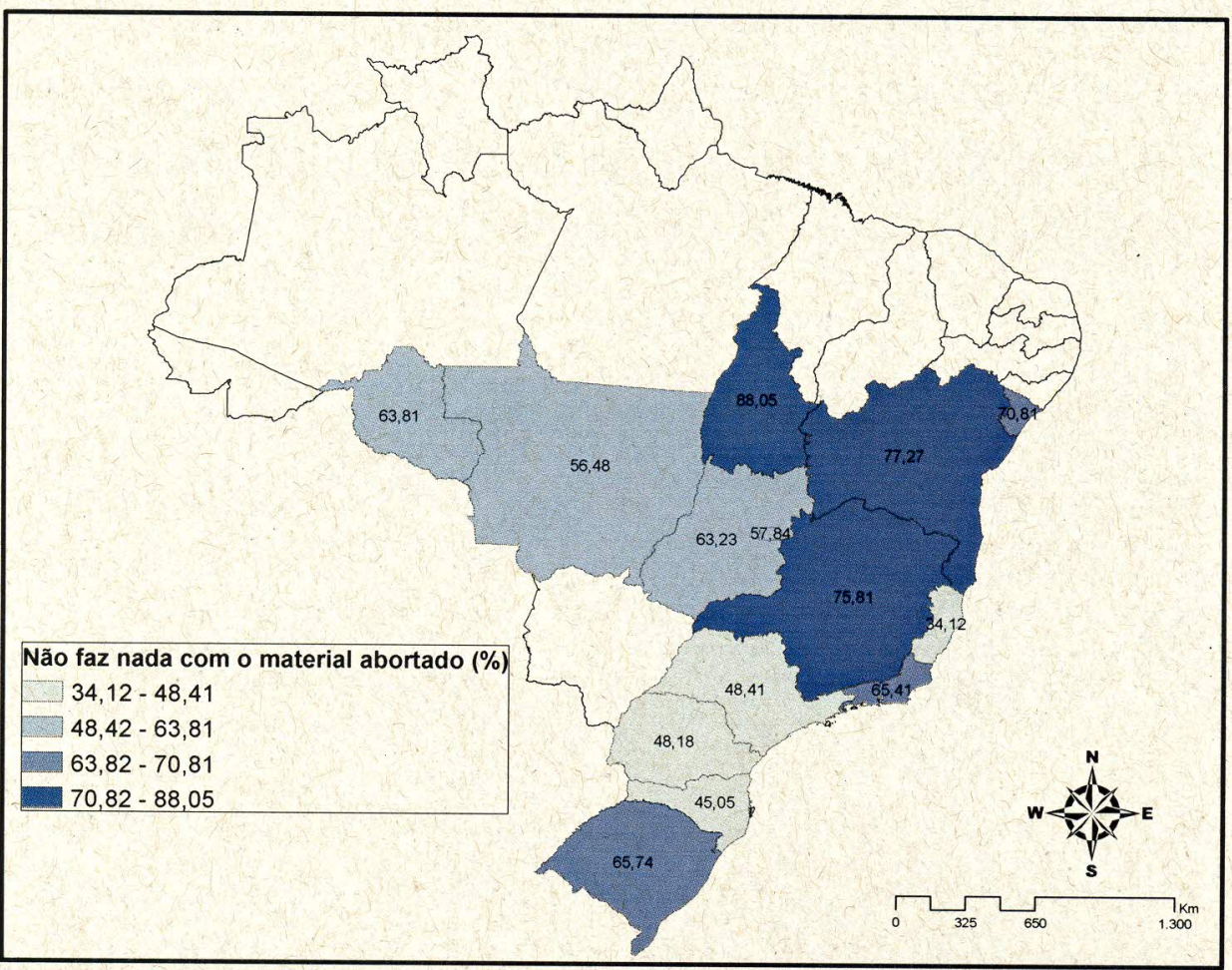

Mapa 70- Distribuição estadual das frequências estimadas de propriedades onde nada é feito com o material abortado- Brasil - out 2001-dez 2004 


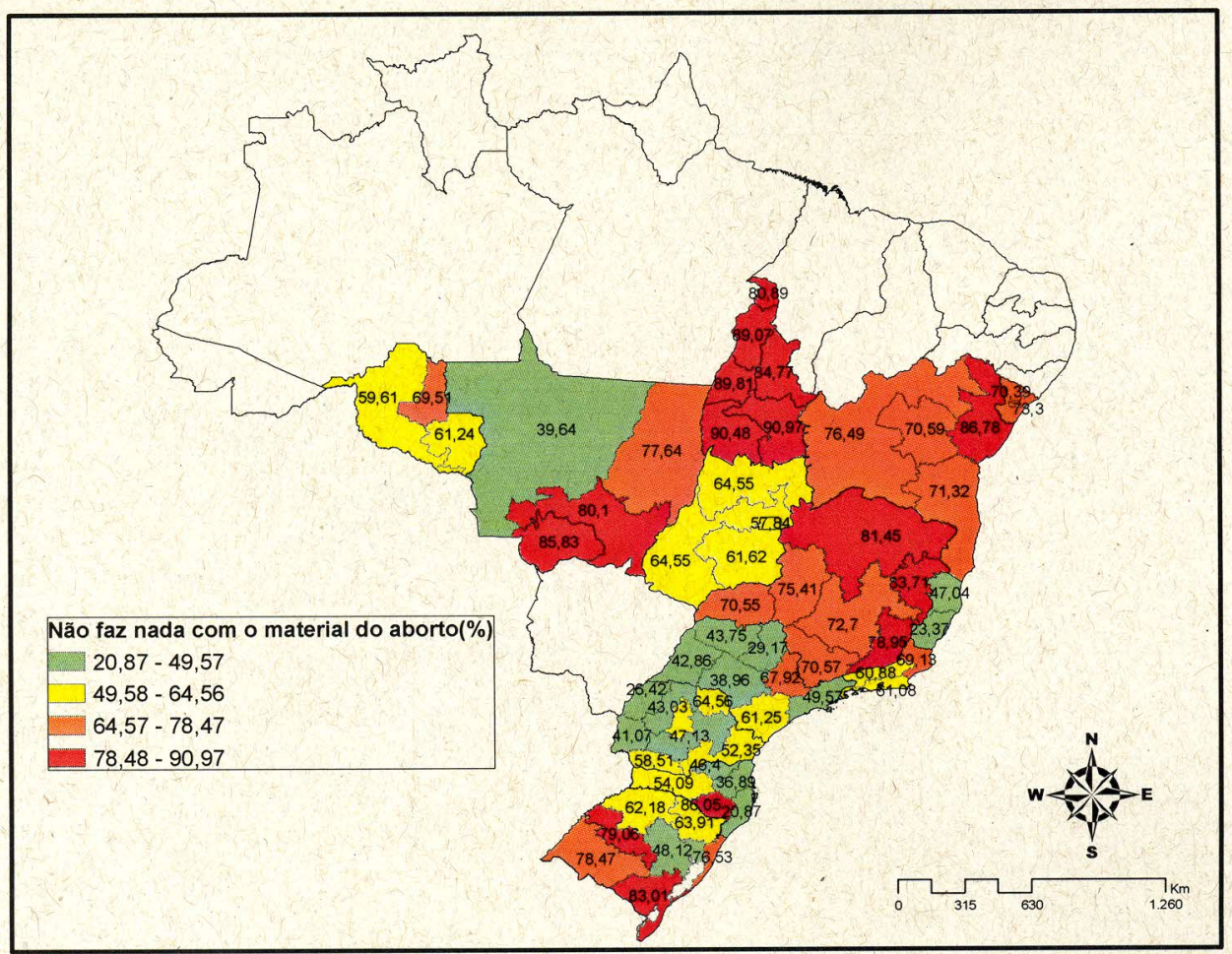

Mapa 71- Distribuição por circuito das frequências estimadas de propriedades onde nada é feito com o material abortado- Brasil out 2001-dez 2004

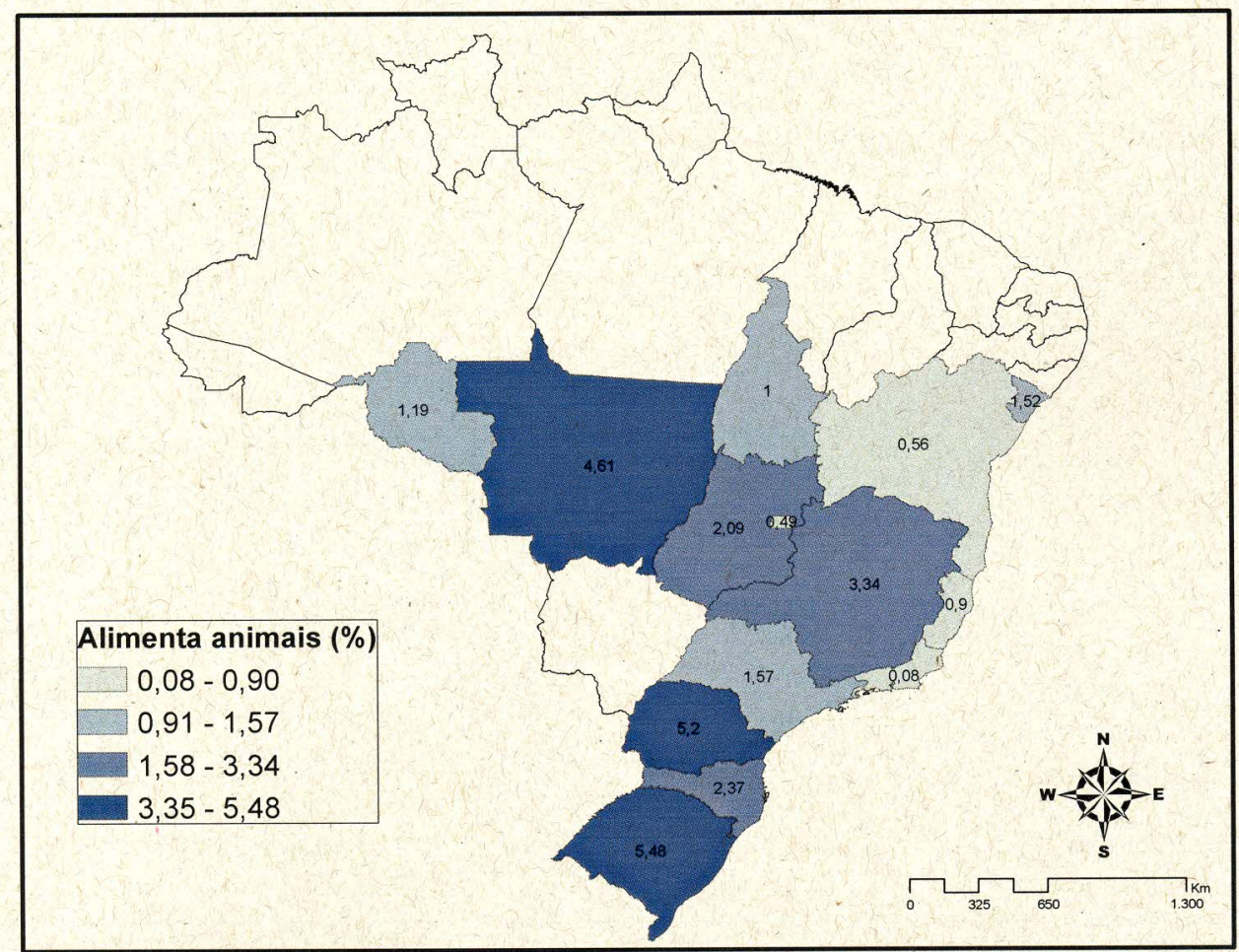

Mapa 72- Distribuição estadual das frequências estimadas de propriedades onde se permite que outras espécies de animais se alimentem do material abortado- Brasil - out 2001-dez 2004 


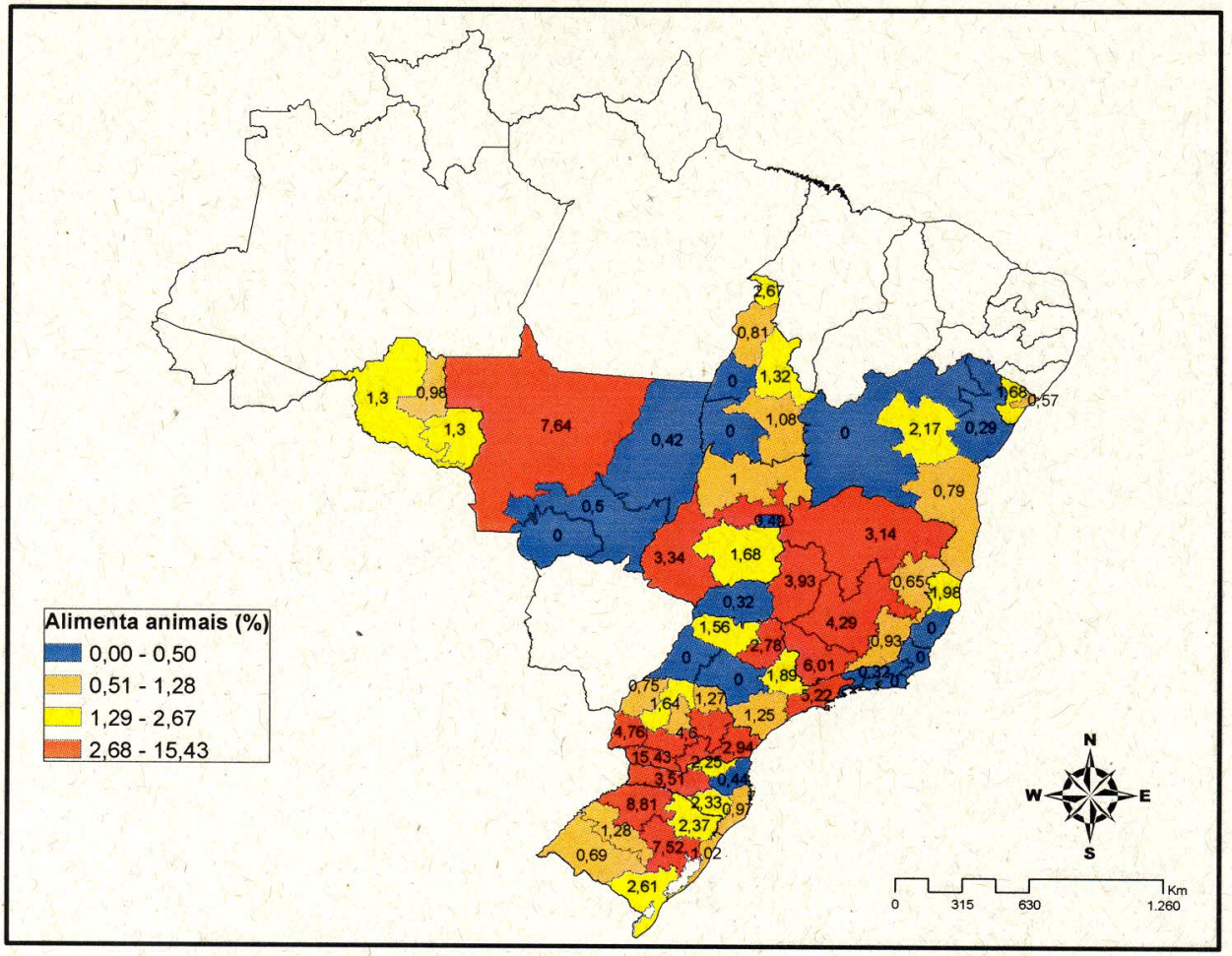

Mapa 73- Distribuição por circuito das frequências estimadas de propriedades onde se permite que outras espécies de animais se alimentem do material abortado- Brasil - out 2001-dez 2004

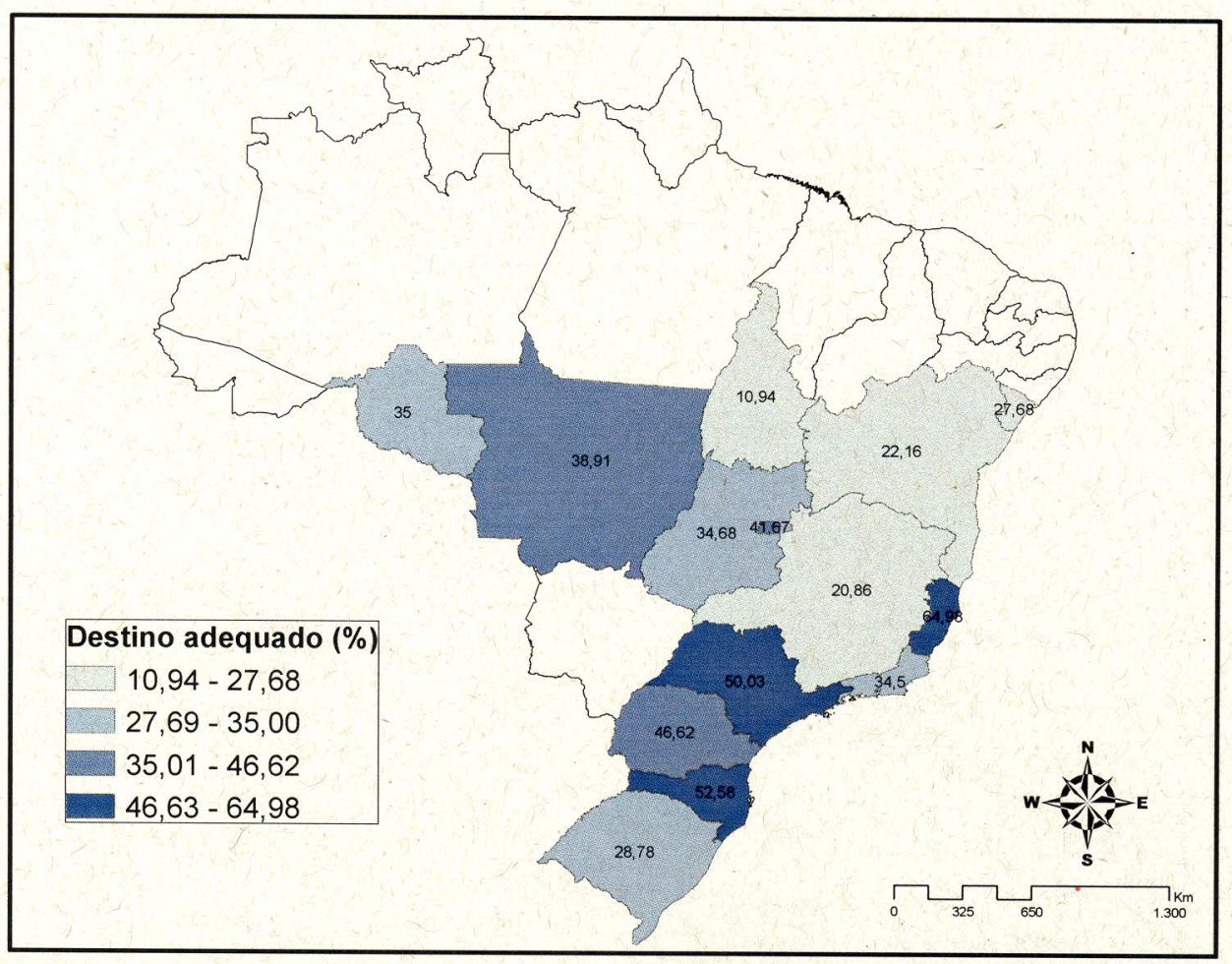

Mapa 74- Distribuição estadual das frequências estimadas de propriedades onde o material abortado recebe um destino adequado (enterra, joga fora, queima)- Brasil - out 2001-dez 2004 


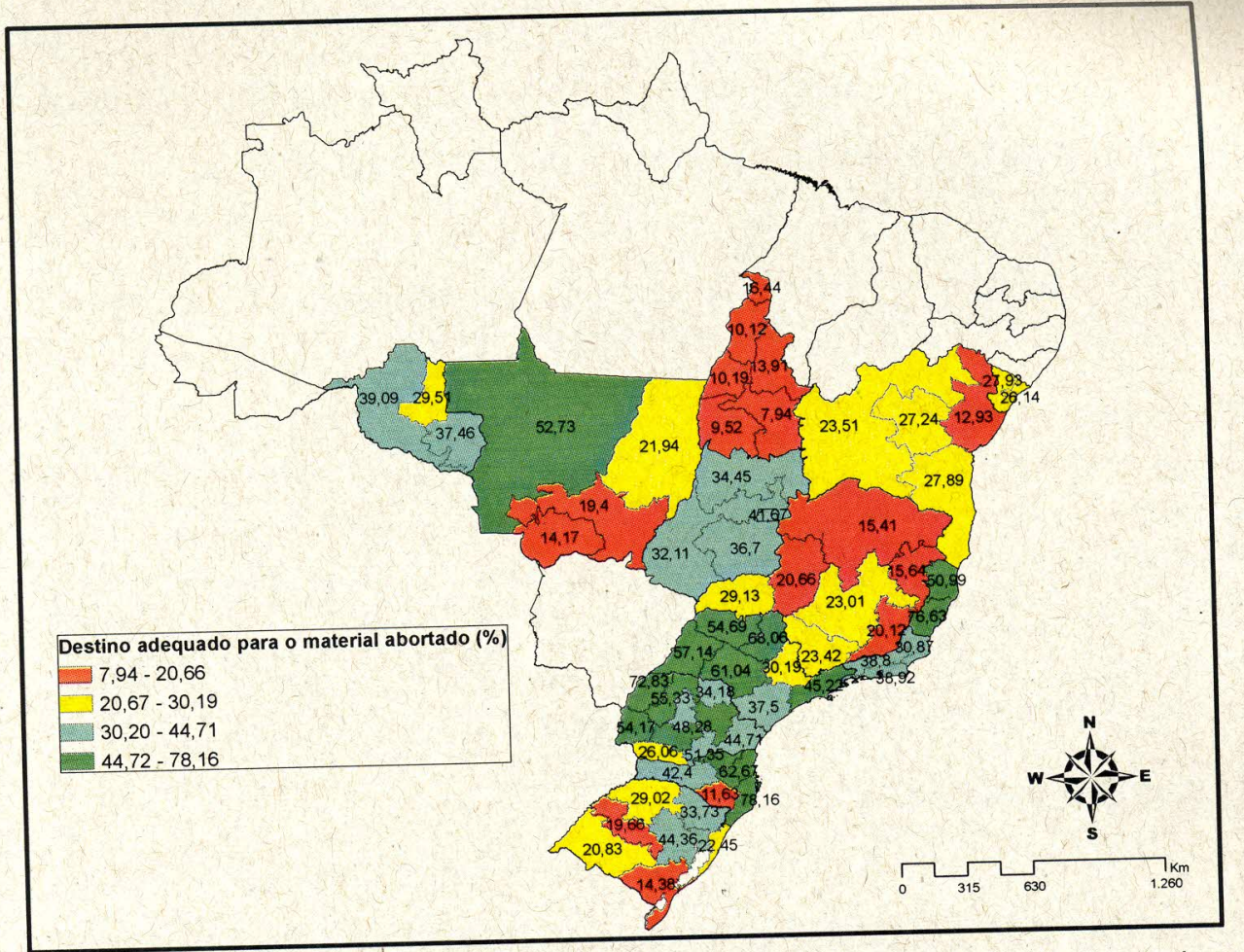

Mapa 75- Distribuição por circuito das frequências estimadas de propriedades onde 0 material abortado recebe um destino adequado (enterra, joga fora, queima)- Brasil - out 2001-dez 2004

Conforme já observado, os restos placentários podem oferecer diversos riscos de transmissão de doenças aos animais, portanto, dar um destino adequado para estes matérias, como queimar, enterrar ou jogar fora em local adequado, é uma boa maneira de prevenir que outros animais do rebanho sejam infectados (BEER, 1999).

\subsubsection{Utilização de inseminação artificial}

As estimativas calculadas demonstraram que esta técnica reprodutiva ainda permanece pouco empregada em boa parte das propriedades do país (Tabela 28). As estimativas revelaram que $80,60 \%$ [79,84\%; $81,30 \%]$ das propriedades rurais visitadas não utilizam a inseminação artificial na reprodução dos animais e quando esta é utilizada, em $11,93 \%$ [11,33\%; 12,63\%] delas é realizada em associação com a monta natural. As propriedades onde a reprodução dos animais é feita exclusivamente através das técnicas de inseminação representaram 7,48\% [6,94\%; 
8,05\%] do total. Entre as explorações pecuárias as propriedades exclusivamente leiteiras demonstraram ser as que utilizam a inseminação com mais frequência, tanto de maneira isolada como associada à monta natural. As propriedades de corte e mistas apresentaram resultados menores e comparáveis entre si.

Tabela 28- Distribuição das proporções de utilização da inseminação artificial segundo os tipos de exploração pecuária. Brasil - out 2001-dez 2004

\begin{tabular}{|c|c|c|c|c|c|c|c|c|}
\hline \multirow[b]{2}{*}{ Inseminação artificial } & \multicolumn{8}{|c|}{ Tipo de exploração } \\
\hline & $\begin{array}{c}\text { Corte } \\
(\%)\end{array}$ & IC $95 \%$ & $\begin{array}{c}\text { Leite } \\
(\%)\end{array}$ & IC $95 \%$ & $\begin{array}{c}\text { Mista } \\
(\%)\end{array}$ & IC $95 \%$ & $\begin{array}{c}\text { Total } \\
(\%)\end{array}$ & IC $95 \%$ \\
\hline Não utiliza & 89,79 & 88,$65 ; 90,83$ & 68,22 & 66,$73 ; 69,67$ & 87,72 & 86,$61 ; 88,75$ & 80,60 & 79,$84 ; 81,30$ \\
\hline Inseminação + Touro & 8,81 & 7,$85 ; 9,89$ & 17,13 & 15,$86 ; 18,49$ & 8,50 & 7,$63 ; 9,46$ & 11,93 & 11,$33 ; 12,63$ \\
\hline Apenas Insemina & 1,40 & 1,$02 ; 1,91$ & 14,65 & 13,$45 ; 15,95$ & 3,78 & 3,$18 ; 4,49$ & 7,48 & 6,$94 ; 8,05$ \\
\hline Total & 100,00 & & 100,00 & & 100,00 & & 100,00 & \\
\hline
\end{tabular}

\subsubsection{Não utiliza inseminação}

Na maioria dos Estados a utilização da inseminação artificial demonstrou ser pouco utilizada, sendo que em boa parte deles a ausência desta técnica atingiu valores superiores a 90\% (Mapa 76). Isto é um indício de que a monta natural ainda é a forma predominante de reprodução em diversas regiões do País (mediana= $90,51 \%)$. Os circuitos que menos utilizam esta técnica reprodutiva foram localizados nas UFs do Centro-oeste, Norte, Nordeste e algumas regiões do Estado de São Paulo (Mapa 77). 


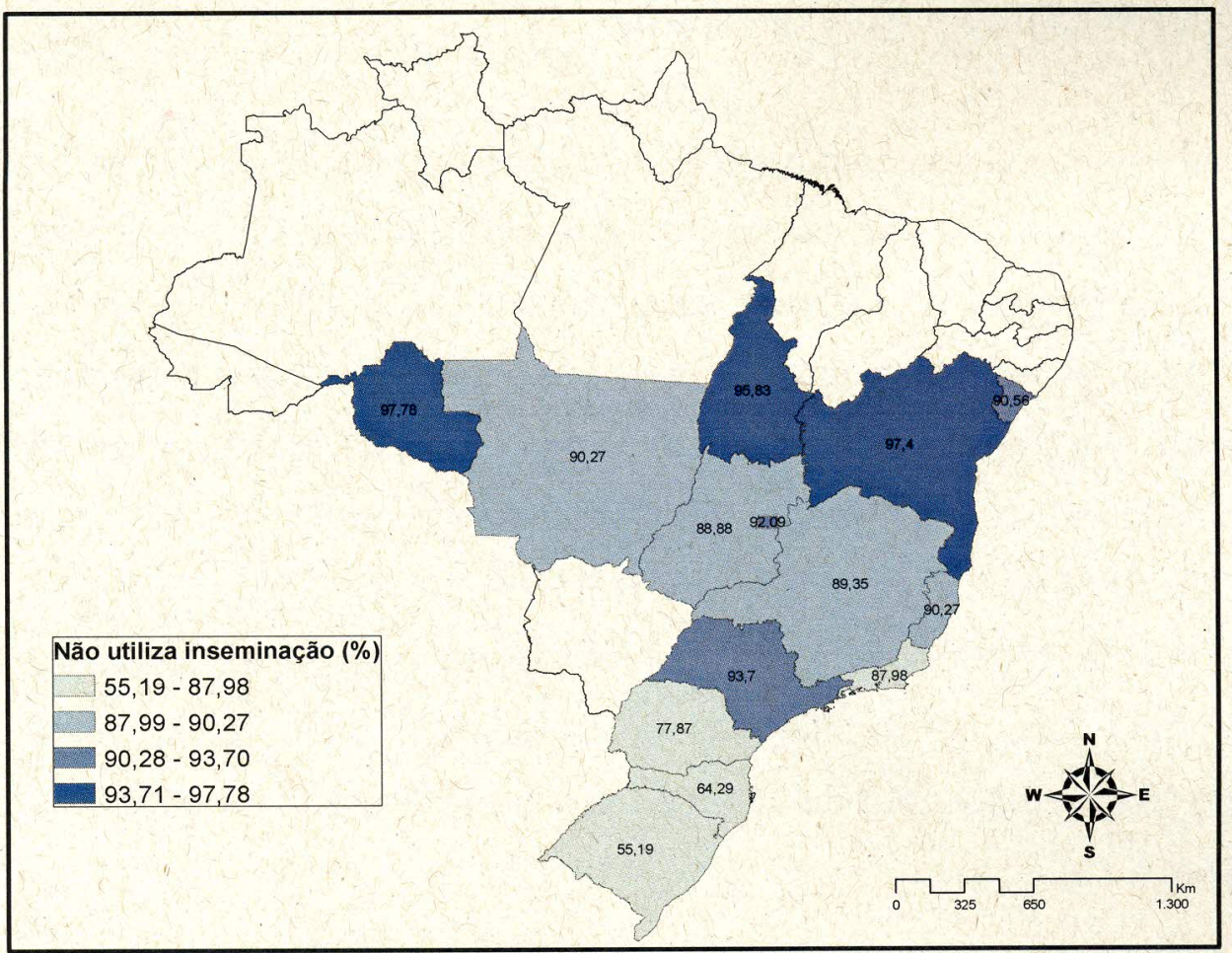

Mapa 76- Distribuição estadual das frequências estimadas de propriedades que não utilizam a inseminação artificial- Brasil - out 2001-dez 2004

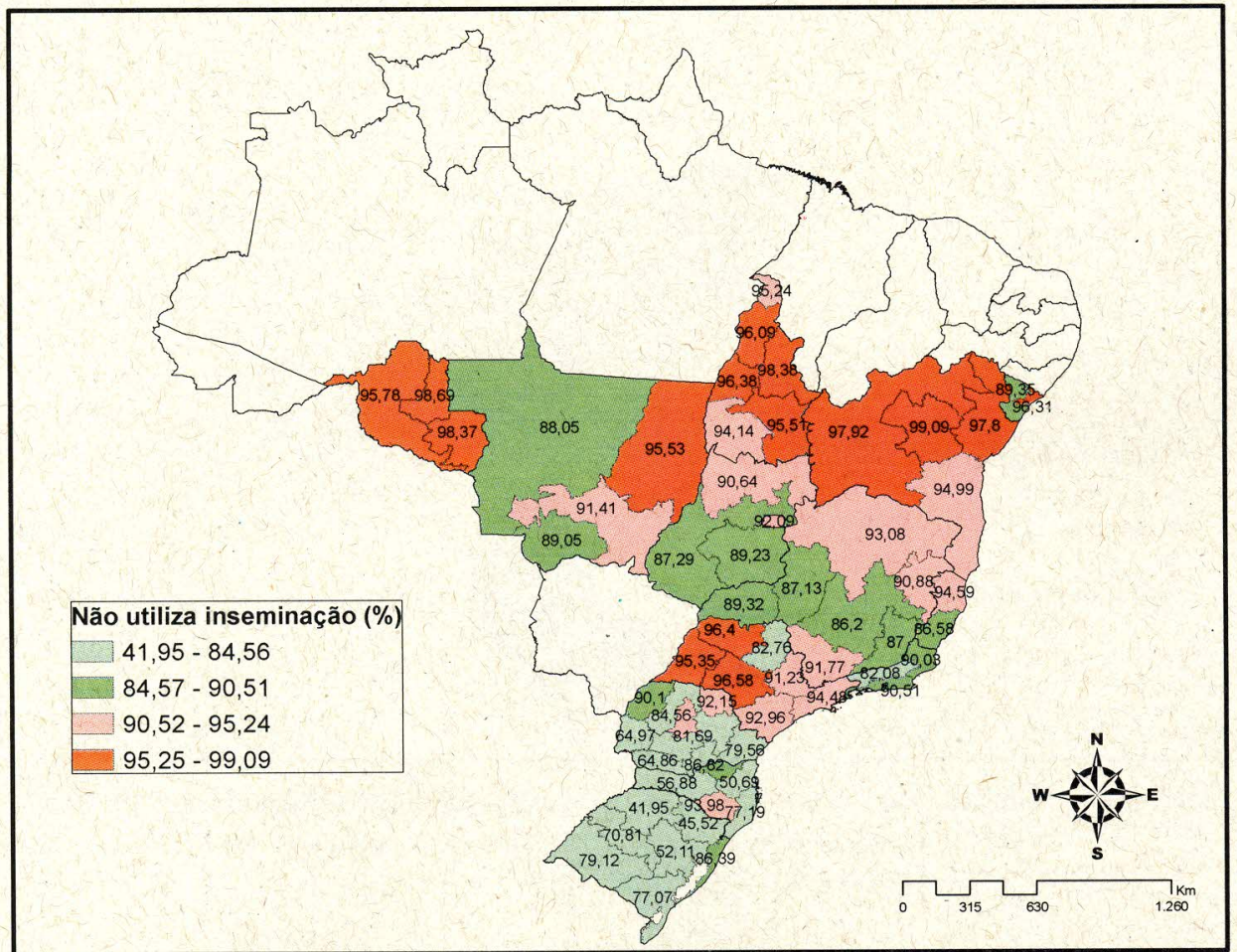

Mapa 77- Distribuição estadual das frequências estimadas de propriedades que não utilizam a inseminação artificial- Brasil - out 2001-dez 2004 
A técnica de inseminação artificial, muitas das vezes, é utilizada em conjunto com a monta natural. Nestes casos, o criador opta por realizar a inseminação no lote de fêmeas em idade reprodutiva e, posteriormente, utiliza os chamados "touros de repasse" para a cobertura das fêmeas que não se tornaram gestantes após a inseminação. As maiores frequências deste tipo de manejo reprodutivo foram encontradas no sul do país (Mapa 78). Os circuitos produtores apresentaram valores entre $0,60 \%$ [0,15\%; $2,39 \%$ e $33,22 \%$ [28,10\%; 38,78\%], sendo que participou do último quartil de regiões com as maiores frequências deste manejo reprodutivo (>10,96\%), uma faixa de circuitos que se estende do sul do Paraná até o Sul do Rio Grande do Sul; região paulista de Ribeirão Preto/Araraquara e noroeste do Mato Grosso (Mapa 79).

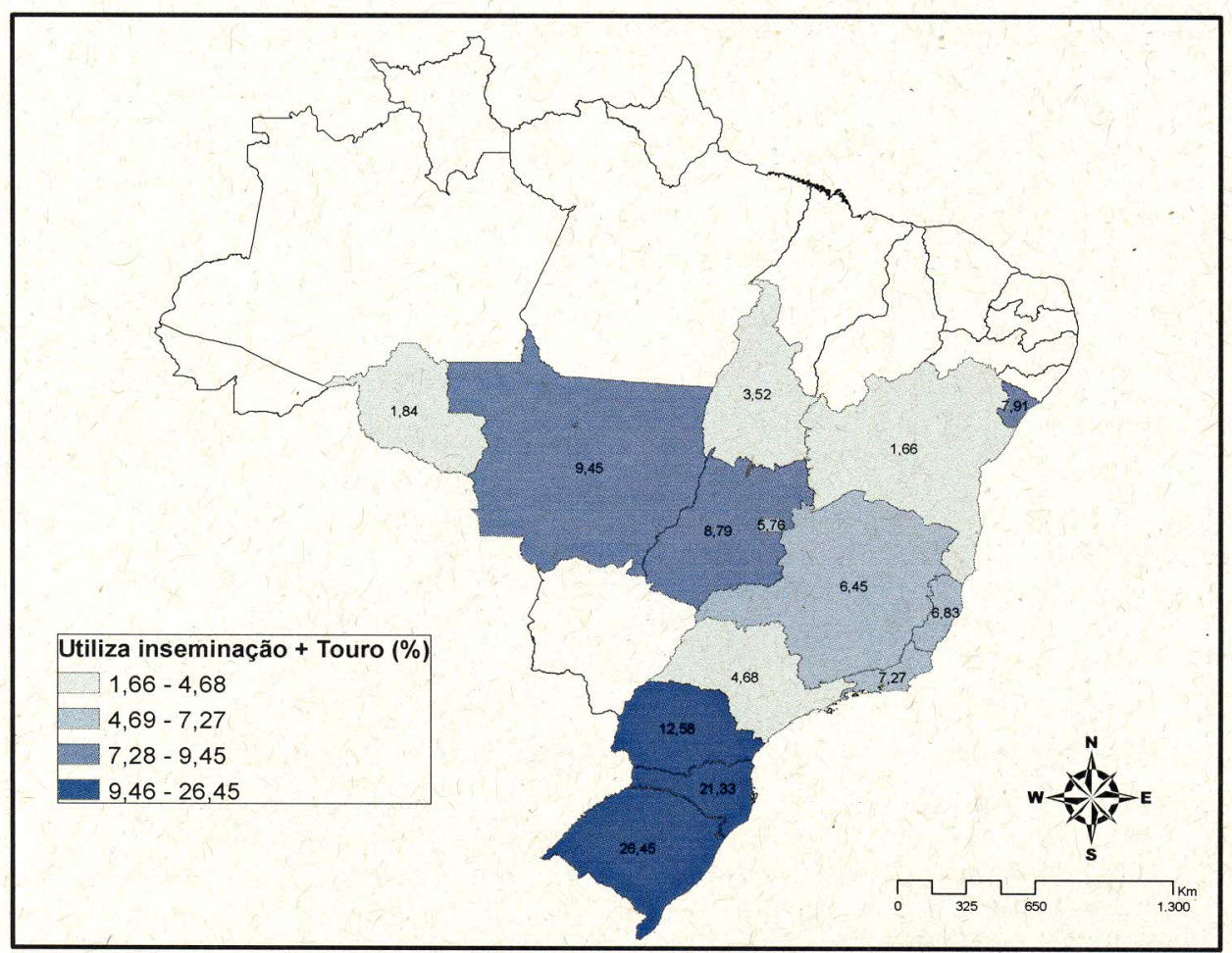

Mapa 78- Distribuição estadual das frequências estimadas de propriedades onde a inseminação artificial é utilizada juntamente com a monta natural- Brasil - out 2001-dez 2004 


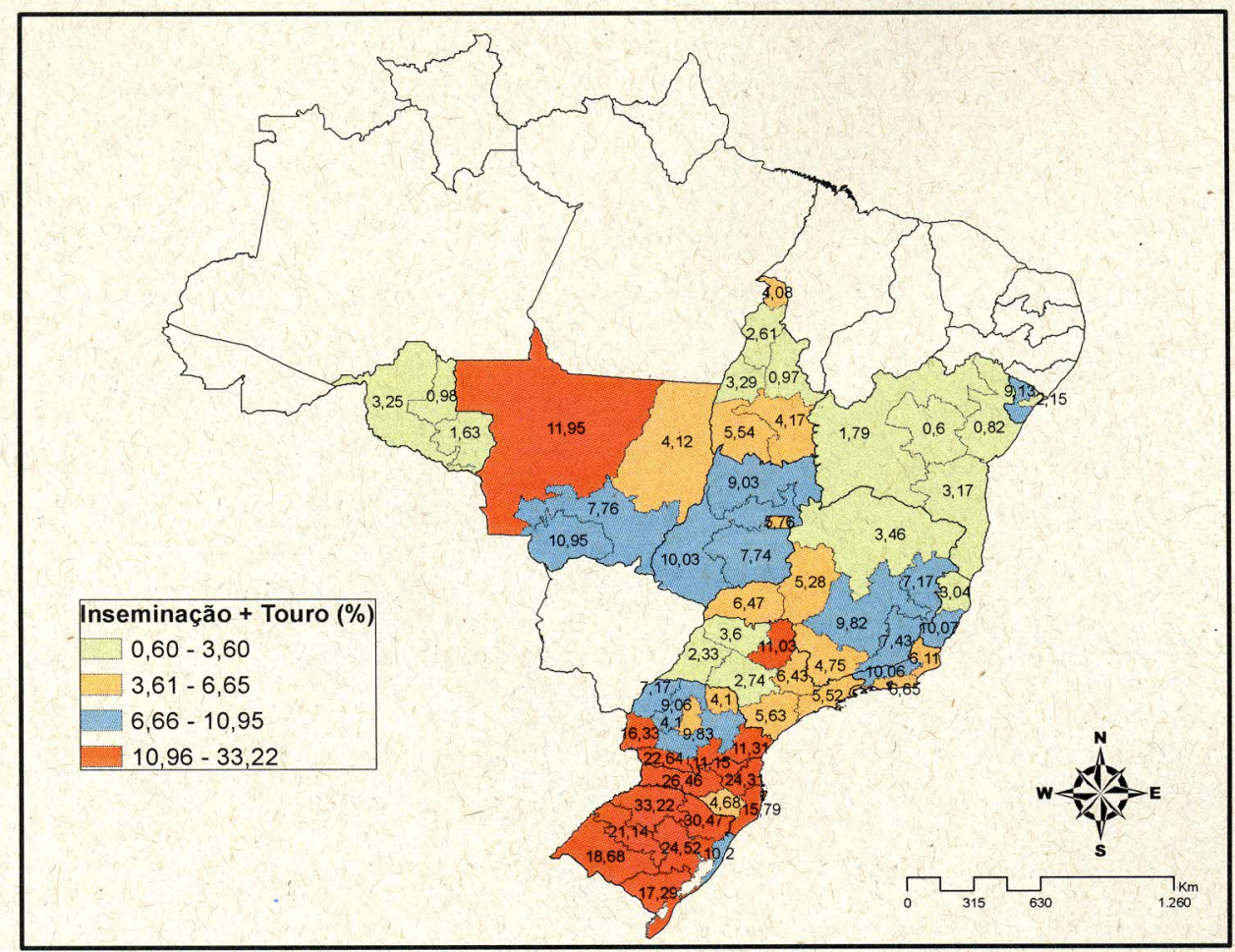

Mapa 79- Distribuição por circuito das frequências estimadas de propriedades onde a inseminação artificial é utilizada juntamente com a monta natural- Brasil - out 2001-dez 2004

\subsubsection{Somente inseminação}

A distribuição de Estados com as maiores frequências de utilização exclusiva da inseminação artificial, a exemplo do item anterior, foi encontrada nos Estados do Sul onde o Rio Grande do Sul apresentou a maior estimativa de utilização desta técnica com 18,36\% [16,23\%; 20,71], seguido de Santa Catarina (14,38\% [12,39\%; $16,63 \%$ ) e Paraná $(9,55 \% \quad[8,27 \% ; 11,00 \%]$ ) (Mapa 80 ). Os circuitos que participaram do quartil superior $(>5,64 \%$ ) de circuitos, foram encontradas em uma faixa que engloba a maior parte do Paraná e desce até a região central do Rio Grande do Sul; mesorregião de Ribeirão Preto/Araraquara paulista; centro-oeste mineiro e centro-sul fluminense (Mapa 81). 


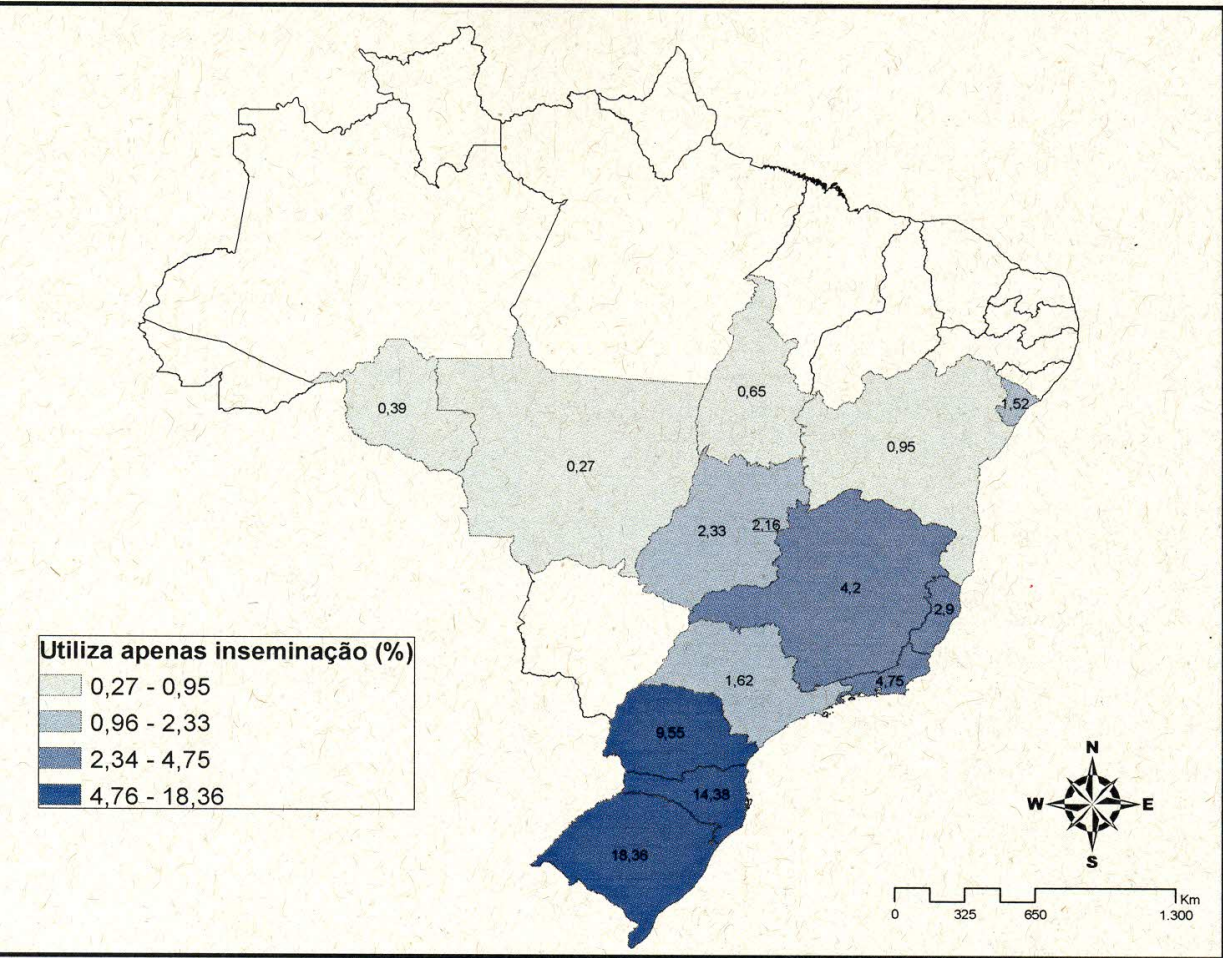

Mapa 80- Distribuição estadual das frequências estimadas de propriedades onde se utiliza somente a inseminação artificial- Brasil - out 2001-dez 2004

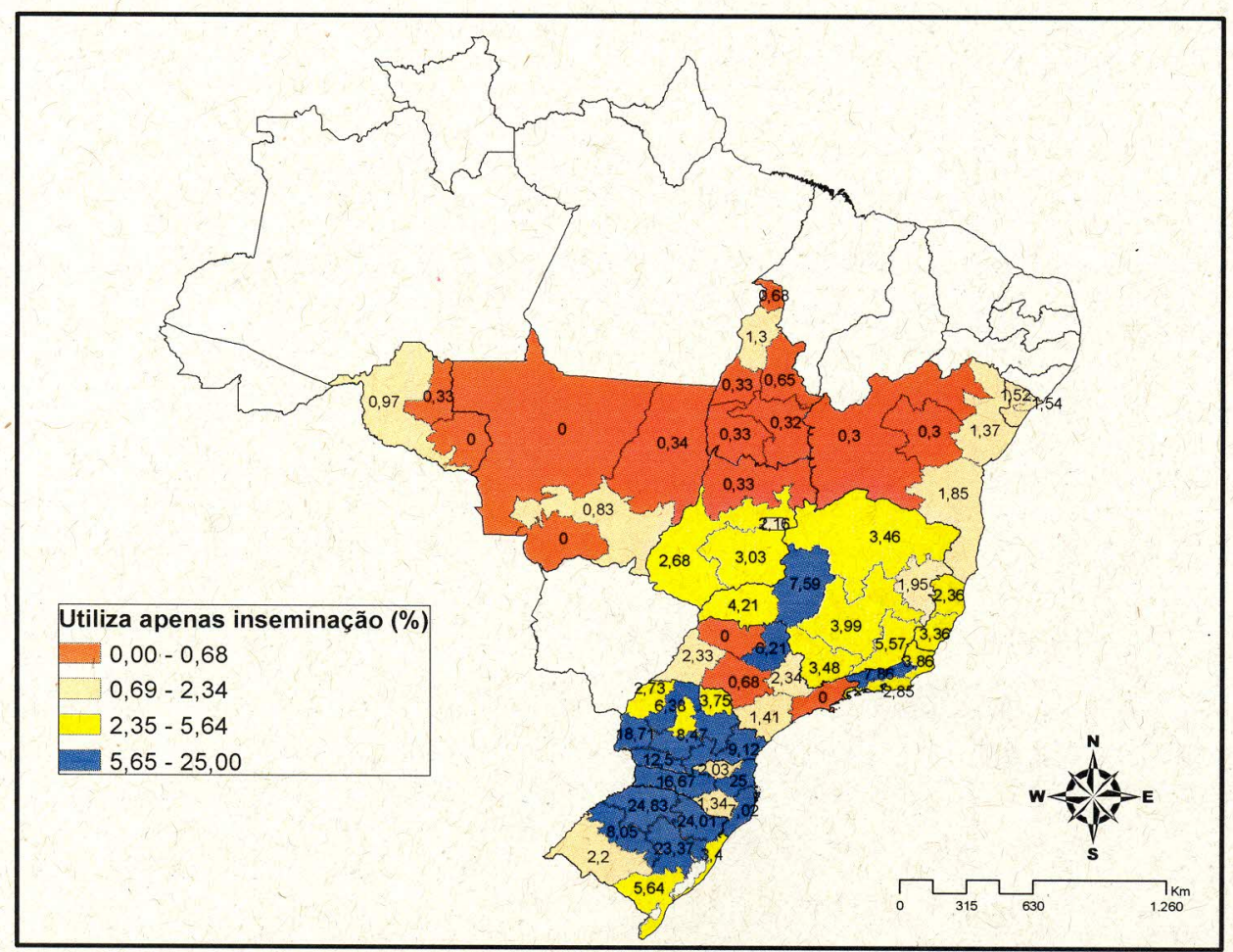

Mapa 81- Distribuição por circuito das frequências estimadas de propriedades onde se utiliza somente a inseminação artificial- Brasil - out 2001dez 2004 
Apesar dos baixos índices de utilização da inseminação artificial, um aumento gradativo da utilização desta técnica tem sido observado, considerando que entre 2000 e 2004 ocorreu um aumento de aproximadamente $22,8 \%$ no número de doses de sêmen comercializadas no país, sendo que em 2004 foram comercializadas cerca 7,5 milhões de doses. Dados mais recentes, apontam que em 2009 mais de 9 milhões de doses foram vendidas no país (ASBIA, 2010).

Levando em conta que a eficiência reprodutiva dos rebanhos é um dos fatores que mais afeta a sua produtividade e lucratividade (BINELLI et al., 2006) e que a taxa de prenhez estimada para o rebanho nacional no ano de 2003 ficou em torno de 60\% (ANUALPEC, 2004), a inseminação artificial constitui-se como uma alternativa para a melhoria da base genética do rebanho por meio da utilização de sêmen de reprodutores de elevada capacidade produtiva e reprodutiva e que possuam habilidade de transmitir características de importância econômica (VALLE, 1998). Indiretamente, a IA quando adequadamente empregada revela também algumas vantagens decorrentes da sua implementação, como por exemplo: controle de diversas doenças da esfera reprodutiva (brucelose, vibriose, tricomonose, vaginite, leptospirose, campilobacteriose, IBR, BVD), adequação do manejo (sanitário e nutricional) e a necessidade de implementação de instrumentos de controle zootécnico (SILVA et al., 2007). No entanto, é necessário citar que a inseminação artificial quando realizada de maneira inadequada, ou seja, através da utilização de sêmen sem idoneidade quanto a sua procedência, pode representar um modo eficiente de transmissão de doenças reprodutivas. Isto ocorre, tendo em vista que na inseminação o sêmen é depositado diretamente no útero da vaca, não sofrendo a ação natural dos mecanismos de defesa presentes na vagina (VASCONCELLOS; ITO; CÔRTES, 1987).

A proporção de propriedades que utilizam a IA de alguma maneira demonstrou ser superior nos rebanhos de exploração leiteira. Valle (1998), descreve que o grande impacto da introdução desta técnica ocorreu na pecuária de leite e que os reduzidos números de adoção desta técnica por parte das propriedades de corte podem ser explicados pela dificuldade de adoção em sistemas extensivos de criação, onde a dificuldade na observação diária dos cios por longos períodos é presente. Como alternativa a este problema, surgiram diversos protocolos de 
sincronização de cios através de fármacos, as chamadas "Inseminação artificial em tempo fixo" (IATF), os quais têm como objetivo concentrar os cios em um curto período de tempo para facilitar o manejo da técnica.

Vários trabalhos têm sido publicados a respeito da rentabilidade econômica entre os diversos métodos reprodutivos, sendo que resultados diversos têm sido encontrados ao comparar diferentes protocolos de realização da monta natural, IA e IATF, assim como, tempos de inseminação pós-parto e avaliação de diferentes treinamentos de equipes de inseminadores (ARRUDA, 1990; FERRAZ, 1996; FERNANDES JR., 2001; BARUSELLI, 2002; GOULART, 2002; AMARAL, 2003; PEREZ, 2003; MARTINEZ, 2005; SILVA et al., 2007; GOTTSCHALL, 2008).

\subsection{VARIÁVEIS DE IMPORTÂNCIA PARA A SAÚDE PÚBLICA}

Algumas atitudes tomadas por parte dos pecuaristas, podem representar possíveis riscos à saúde pública. Neste caso, os produtores foram indagados a respeito de algumas delas, como: o consumo de leite cru, o local de abate dos animais no final da vida reprodutiva e a fabricação e comercialização de derivados do leite foram avaliadas

\subsubsection{Consumo de leite cru}

A frequência de propriedades onde a prática de consumir de leite cru é realizada, foi estimada em 21,33\% [20,61\%; 22,07\%]. Entre os tipos de exploração pecuária, não houve diferenças muito amplas entre as frequências de consumo de leite cru variando de aproximadamente $17 \%$ nos estabelecimentos de corte a cerca de $22 \%$ nos estabelecimentos mistos e de leite (Tabela 29).

Tabela 29- Distribuição das estimativas de frequência de propriedades que alegaram consumir leite cru, segundo os tipos de exploração- Brasil - out 2001-dez 2004

\begin{tabular}{ccccccccc}
\hline \multicolumn{7}{c}{ Tipo de exploração } \\
\hline $\begin{array}{c}\text { Consumo de } \\
\text { leite cru }\end{array}$ & $\begin{array}{c}\text { Corte } \\
\mathbf{( \% )}\end{array}$ & IC 95\% & $\begin{array}{c}\text { Leite } \\
\mathbf{( \% )}\end{array}$ & IC $\mathbf{9 5 \%}$ & $\begin{array}{c}\text { Mista } \\
\text { (\%) }\end{array}$ & IC 95\% & $\begin{array}{c}\text { Total } \\
\text { (\%) }\end{array}$ & IC 95\% \\
\hline Não & 82,98 & 81,$55 ; 84,32$ & 76,78 & 75,$50 ; 78,01$ & 78,07 & 76,$85 ; 79,24$ & 78,61 & 77,$87 ; 79,33$ \\
Sim & 17,02 & 15,$68 ; 18,45$ & 23,22 & 21,$99 ; 24,50$ & 21,93 & 20,$76 ; 23,15$ & 21,39 & 20,$67 ; 22,13$ \\
\hline Total & 100,00 & & 100,00 & & 100,00 & & 100,00 & \\
\hline
\end{tabular}


A maior frequência desta prática foi identificada no Estado de Minas Gerais, onde $36,80 \%$ [34,71\%; 38,94\%] das propriedades relataram consumir leite cru. As proporções que participaram do quartil superior de circuitos pecuários que demonstraram as maiores frequências deste tipo de prática foram encontradas nas regiões do centro-sul de Goiás; os circuitos mineiros (com exceção do norte); nas regiões paulistas do Vale do Ribeira, litoral sul e nas mesoregiões de Presidente Prudente e de São José do Rio Preto/ Araçatuba; sudoeste paranaense; região Serrana de Santa Catarina e sudoeste do Rio Grande do Sul.

Consumo de leite cru (\%)

$10,30-12,97$

$12,98-18,39$

$18,40-23,22$

$23,23-36,80$

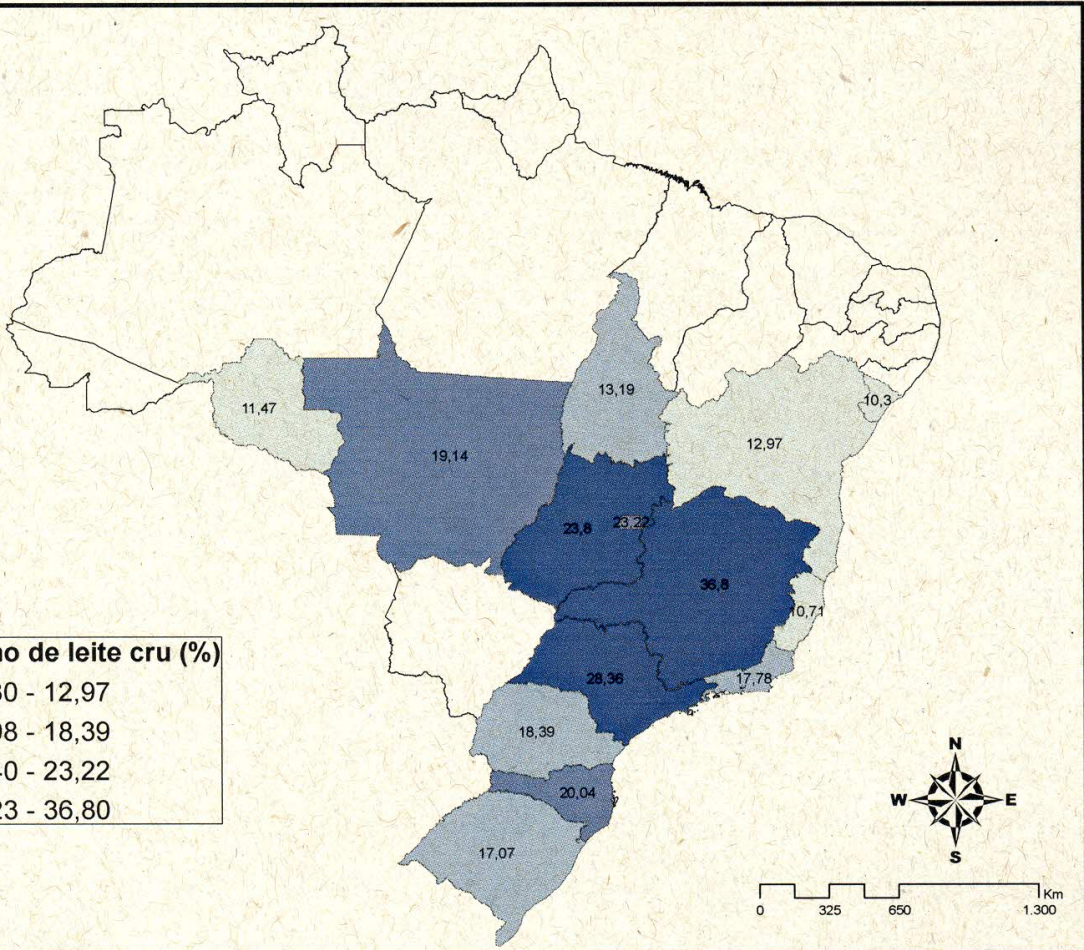

Mapa 82- Distribuição estadual das frequências estimadas de propriedades onde o consumo de leite cru foi constatado- Brasil - out 2001-dez 2004 


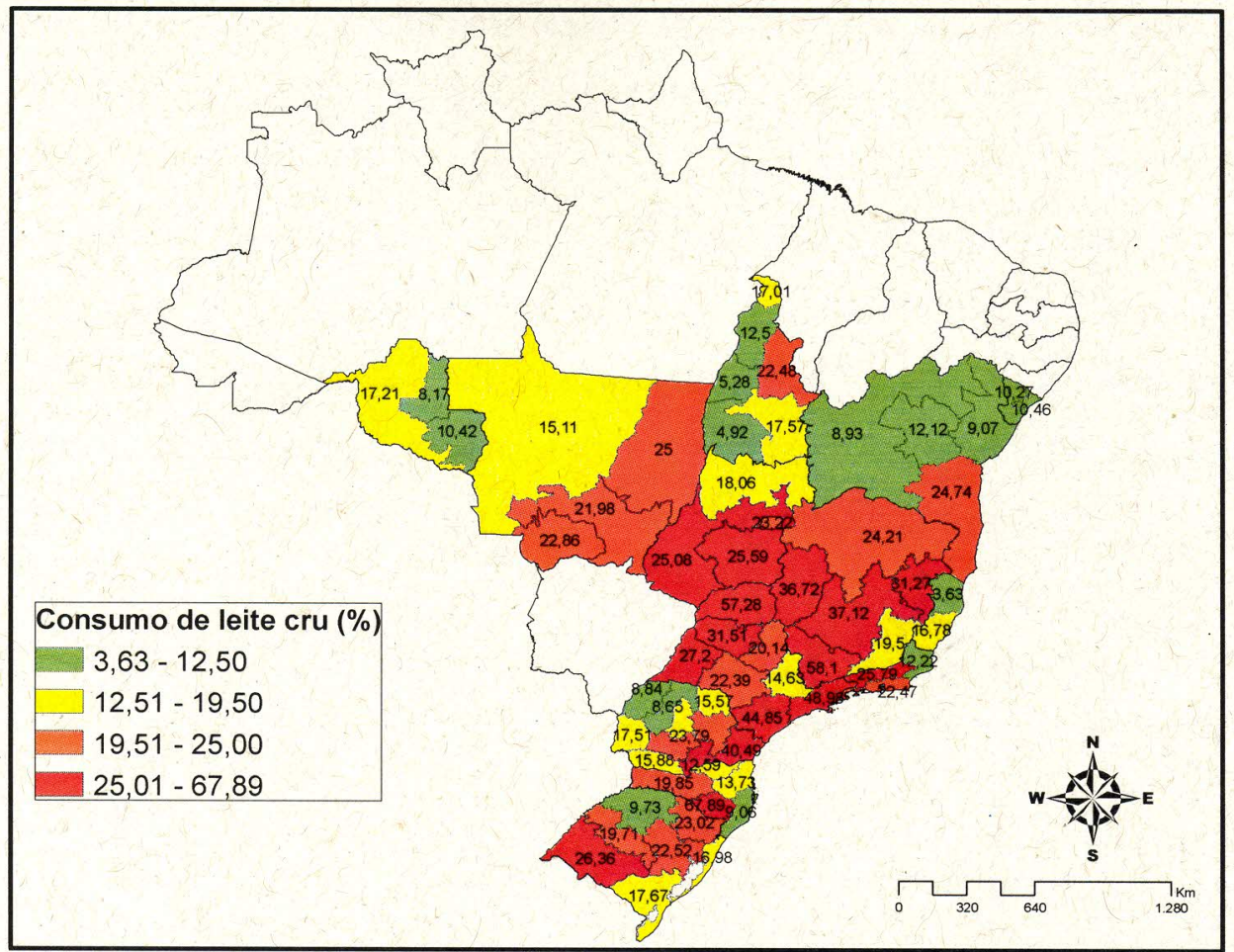

Mapa 83- Distribuição estadual das frequências estimadas de propriedades onde o consumo de leite cru foi constatado- Brasil - out 2001-dez 2004

O leite é um alimento de origem animal de valor nutritivo excepcional para o consumo humano. Esta riqueza nutritiva, da mesma maneira, constitui um excelente meio de cultura para o desenvolvimento de diversos microorganismos, sendo também considerado veículo de transmissão de diversas zoonoses como a brucelose, salmonelose, yersiniose, listeriose, tuberculose, brucelose, intoxicação estafilococica, infecções estreptocócicas, infecção por E.coli O157:H7 e toxoplasmose (PARRY, 1966; KLEEBURG, 1975; CANADA, 1976; KAUFMANN, 1977; TAYLOR; WEINSTEIN; BRYNER, 1979; TAYLOR et al., 1982; FOX; BARNHAM; THORNTON; LANGE, 1983; CDC, 1983; MARTIN et al., 1986; SCHUCHAT et al., 1991; BELOTI et al., 1999; GARCIA, 1999; CATÃO; CEBALLOS, 2001). Como forma de reduzir os problemas causados pela presença destes microorganismos no leite, se faz necessário o emprego de tratamentos térmicos, tais como a pasteurização e a esterilização, os quais interferem pouco nas qualidades físico-químicas e organolépticas do produto e aumentam a segurança do alimento (BELOTI, 1999).

Considerando que foi constatado o consumo de leite cru em 20,93\% [18,74\%; $23,29 \%$ ] dos estabelecimentos que foram diagnosticados como foco de brucelose e 
levando em consideração os riscos à saúde pública envolvidos nesta prática, propõe-se o investimento em educação e conscientização da população frente aos malefícios que o consumo de leite que não passou por qualquer tratamento térmico pode representar.

\subsubsection{Local de abate de reprodutores}

A estimativa total para as 14 UFs demonstrou que a maior parte das propriedades $(76,39 \%[75,62 \% ; 77,15 \%])$ encaminha os reprodutores para o abate no fim da vida reprodutiva. Dentre estes, 41,23\% [40,31\%; 42,16\%] demonstrou enviar estes animais para locais de abate sem inspeção oficial realizada por Médico veterinário e 22,50\% [21,62\%; 23,40\%] afirmou que realiza o abate dos reprodutores na própria fazenda. Sendo que a proporção estimada de propriedades que abatem os reprodutores em estabelecimentos devidamente inspecionados foi de 36,27\% [35,29\%; 37,26\%]. As explorações de leite e mistas apresentaram as maiores frequências de propriedades que abatem os animais em estabelecimentos sem inspeção (em torno de 40\%) e na própria fazenda (aproximadamente 25\%) (Tabela 30).

Tabela 30- Distribuição das estimativas de frequência de abate de reprodutores segundo os tipos de exploração pecuária- Brasil - out 2001-dez 2004

\begin{tabular}{cccccccccc}
\hline & \multicolumn{5}{c}{ Tipo de exploração } \\
\hline $\begin{array}{c}\text { Abate de } \\
\text { reprodutores }\end{array}$ & $\begin{array}{c}\text { Corte } \\
(\%)\end{array}$ & IC $95 \%$ & $\begin{array}{c}\text { Leite } \\
(\%)\end{array}$ & IC 95\% & $\begin{array}{c}\text { Mista } \\
(\%)\end{array}$ & IC 95\% & $\begin{array}{c}\text { Total } \\
(\%)\end{array}$ & IC 95\% \\
\hline $\begin{array}{c}\text { Estabelecimento com } \\
\text { Inspeção }\end{array}$ & 48,51 & 46,$68 ; 50,35$ & 34,84 & 33,$02 ; 36,71$ & 29,39 & 27,$88 ; 30,95$ & 36,19 & 35,$21 ; 37,18$ \\
$\begin{array}{c}\text { Estabelecimento sem } \\
\text { Inspeção }\end{array}$ & 35,62 & 33,$85 ; 37,44$ & 41,65 & 39,$95 ; 43,38$ & 44,62 & 42,$99 ; 46,26$ & 41,28 & 40,$35 ; 42,21$ \\
Na própria fazenda & 15,87 & 14,$44 ; 17,41$ & 23,50 & 21,$90 ; 25,19$ & 25,98 & 24,$48 ; 27,55$ & 22,54 & 21,$66 ; 23,44$ \\
\hline Total & 100,00 & & 100,00 & & 100,00 & & 100,00 \\
\hline
\end{tabular}

Dentre as frequências estaduais de propriedades que abatem os animais em estabelecimentos com inspeção, a maior foi encontrada no Estado de Goiás com $44,61 \%$ [41,29\%; 47,97\%] dos estabelecimentos e a menor estimativa foi encontrada para Sergipe, onde apenas 1,22\% [0,66\%; 2,25\%] das propriedades relatou enviar os animais para abates com inspeção realizada por Médico Veterinário (Mapa 84)

A frequência de propriedades que abatem os animais de maneira inspecionada entre os circuitos pecuários apresentaram alta variabilidade, sendo 
que se em alguns deles a prevalência foi de $71,70 \%[65,97 \% ; 76,80 \%]$ (sudoeste do Rio Grande do Sul), em outros foi de $0,78 \%$ [0,05\%; 2,66\%] (oeste de Sergipe). As proporções de abates inspecionados que se posicionaram no quartil superior $(>37,46 \%)$, foram encontradas em diversas regiões do Rio Grande do Sul; em uma área que compreende o noroeste do Paraná, regiões do leste paulista e se estende até a porção central de Goiás; no noroeste de Mato Grosso e no norte e do centrosul fluminenses (Mapa 85).

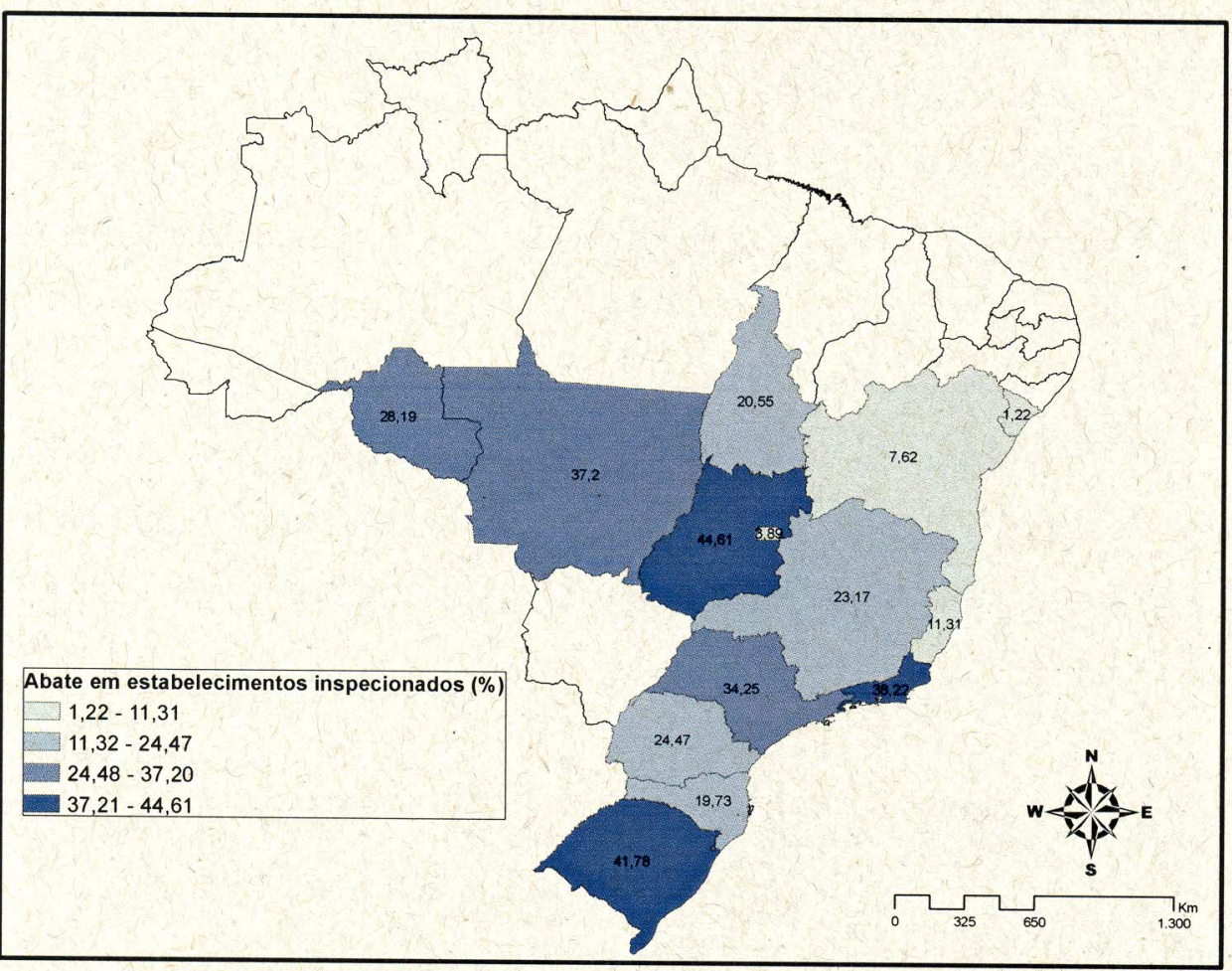

Mapa 84- Distribuição estadual das frequências estimadas de propriedades que abatem os reprodutores no fim da vida reprodutiva em estabelecimentos inspecionados- Brasil - out 2001-dez 2004 


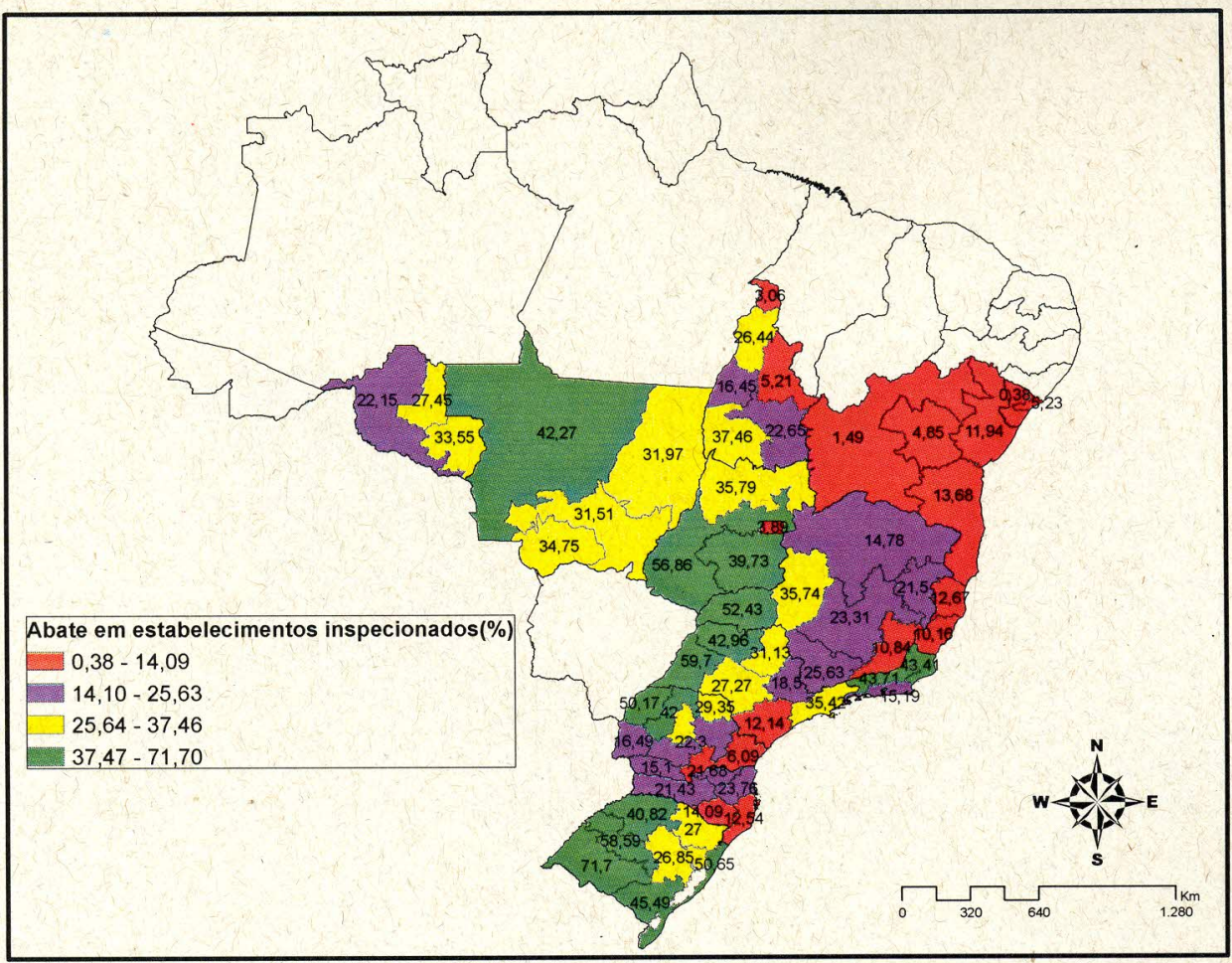

Mapa 85- Distribuição por circuito das frequências estimadas de propriedades que abatem os reprodutores no fim da vida reprodutiva em estabelecimentos inspecionados- Brasil - out 2001-dez 2004

As frequências estimadas para o abate informal nos Estados apresentaram alta variabilidade entre eles, sendo que enquanto no Distrito Federal apenas $0,78 \%$ $[0,19 \% ; 3,06 \%]$ dos locais relataram abater os animais em estabelecimentos sem inspeção oficial, em contrapartida, no Estado de Sergipe a proporção de propriedades que enviam os reprodutores para abate em locais não inspecionados foi estimada em 94,26\% [91,56\%; 96,13\%] (Mapa 86).

Os circuitos produtores que apresentaram as menores proporções de propriedades que alegaram encaminhar os reprodutores para o abate em estabelecimentos não inspecionados, foram encontrados principalmente no Rio Grande do Sul; região do vale do Itajaí em Santa Catarina; sul e sudeste paranaenses; vários circuitos do sul, sudeste e centro oeste de São Paulo e no Pantanal Mato-grossense. Em contrapartida, as maiores frequências deste tipo irregular de abate foram encontradas em boa parte do centro-oeste (Goiás, Mato Grosso e Rondônia), norte (Tocantins), nordeste (Bahia e Sergipe) e sudeste (Minas Gerais, Espírito Santo) do Brasil (Mapa 87). 


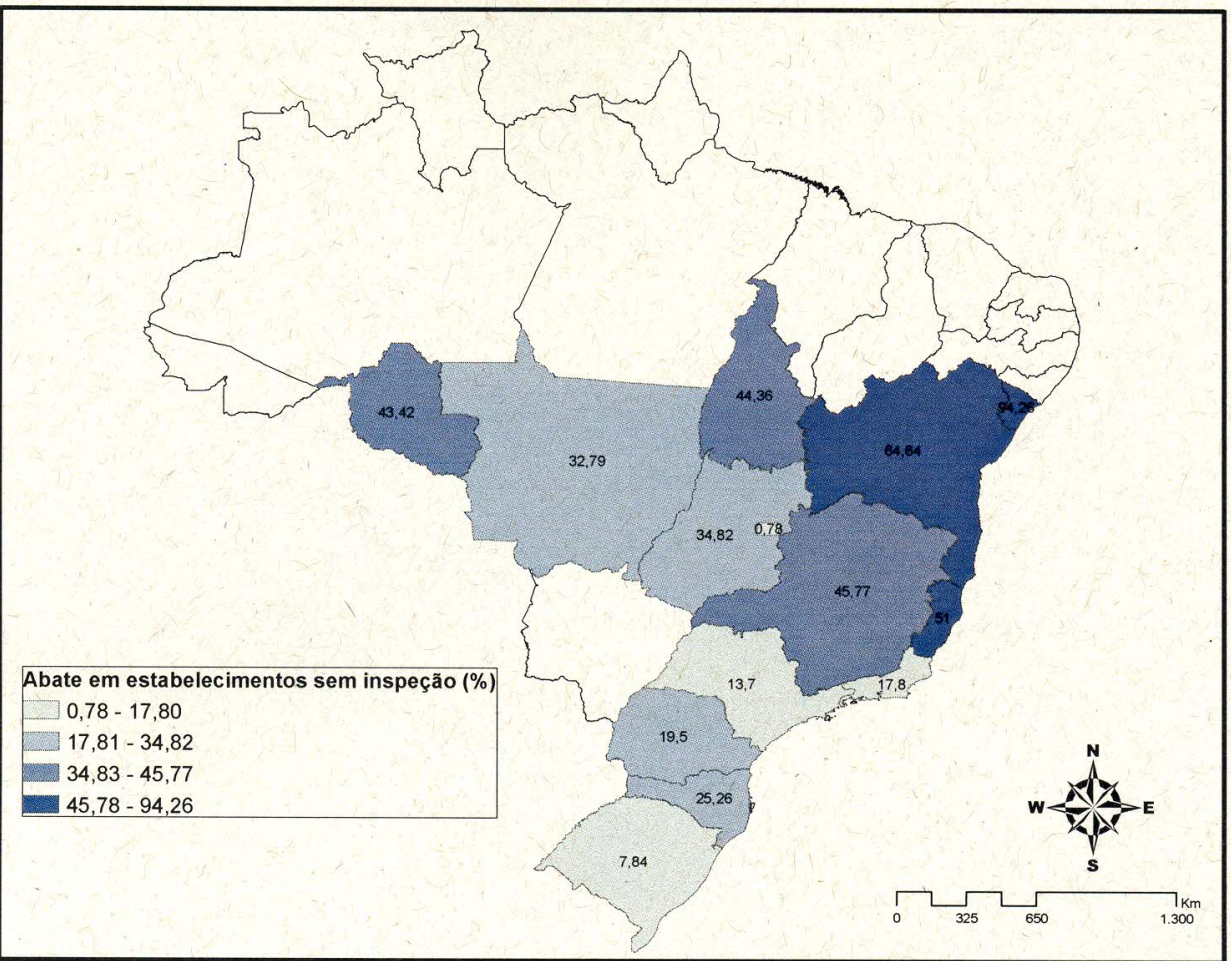

Mapa 86- Distribuição estadual das frequências estimadas de propriedades que abatem os reprodutores no fim da vida reprodutiva em estabelecimentos sem inspeção- Brasil - out 2001-dez 2004

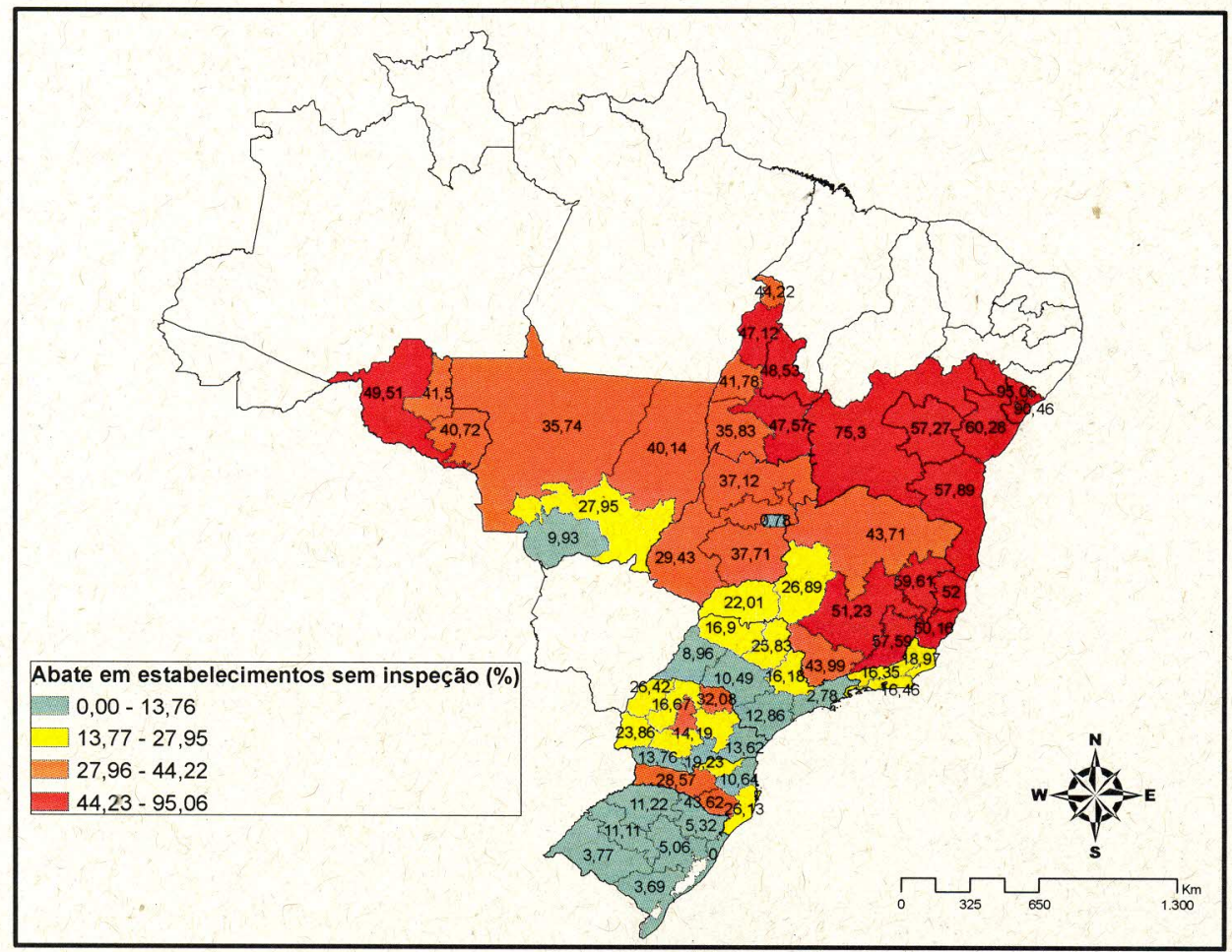

Mapa 87- Distribuição por circuito das frequências estimadas de propriedades que abatem os reprodutores no fim da vida reprodutiva em estabelecimentos sem inspeção- Brasil - out 2001-dez 2004 
As criações que abatem reprodutores no próprio estabelecimento foram encontradas em maior número nas propriedades dos Estados do sul do país (Rio Grande do Sul, Santa Catarina e Paraná), Distrito Federal, Espírito Santo e Tocantins (Mapa 88). A variabilidade nos circuitos produtores quanto ao abate dos animais dentro da própria fazenda foi extensa, apresentando valores que variaram de $0,68 \%[0,17 \% ; 2,68 \%]$ no nordeste de Mato Grosso a 52,53\% [46,41\%; $58,58 \%$ ] na porção centro-oriental do Rio Grande do Sul. Nos circuitos pecuários do centro e do norte do Rio Grande do Sul; as regiões oeste, sul e sudeste paranaenses; os dois circuitos espírito-santenses e do extremo norte, nordeste e centro-oeste do Tocantins, observou-se a realização deste tipo de abate em pelo menos $25 \%$ das propriedades, estando situados no quartil superior de circuitos onde os abates em fazendas são realizados em maiores proporções (Mapa 89).

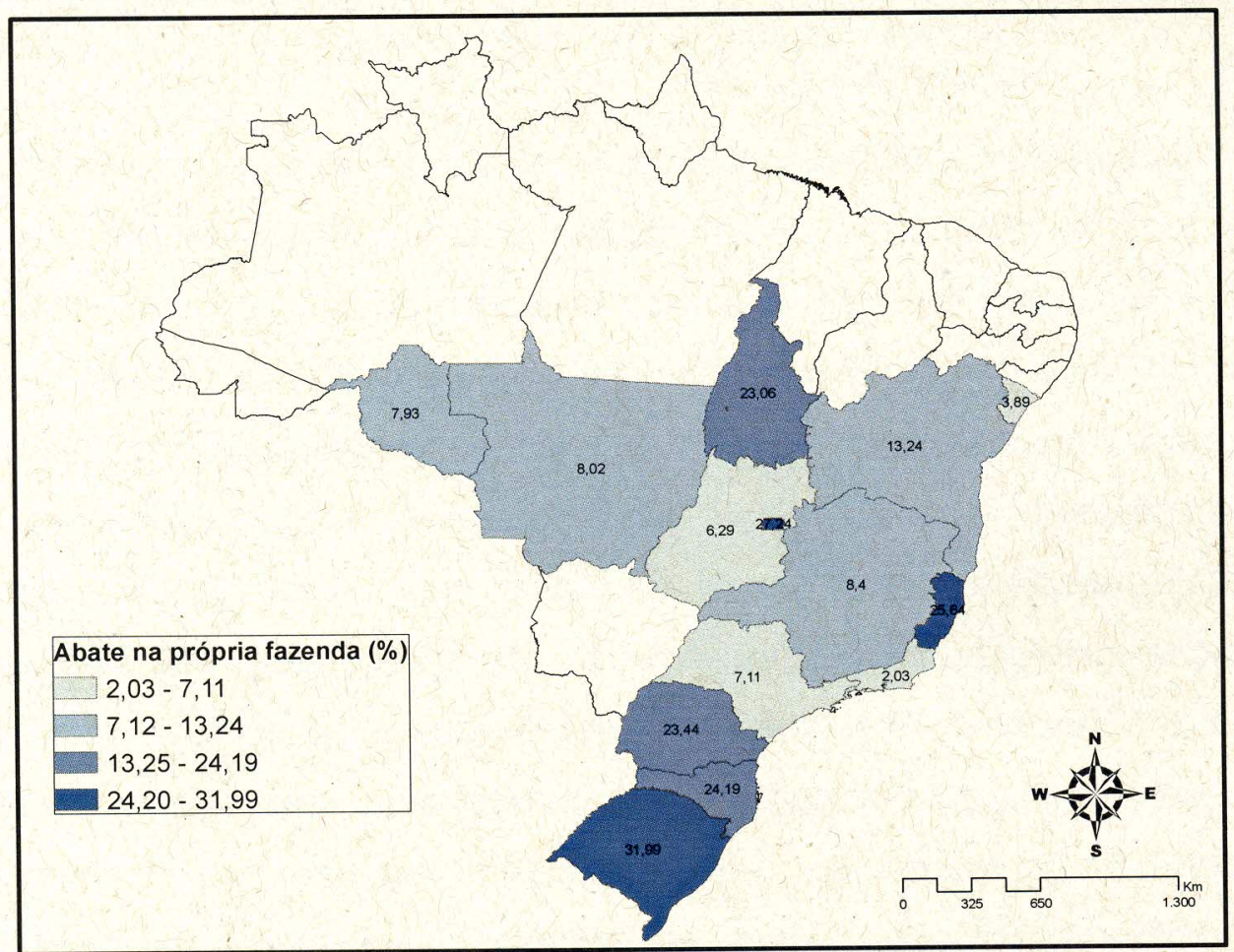

Mapa 88- Distribuição estadual das frequências estimadas de propriedades que abatem os reprodutores no fim da vida reprodutiva na própria fazendaBrasil - out 2001-dez 2004 


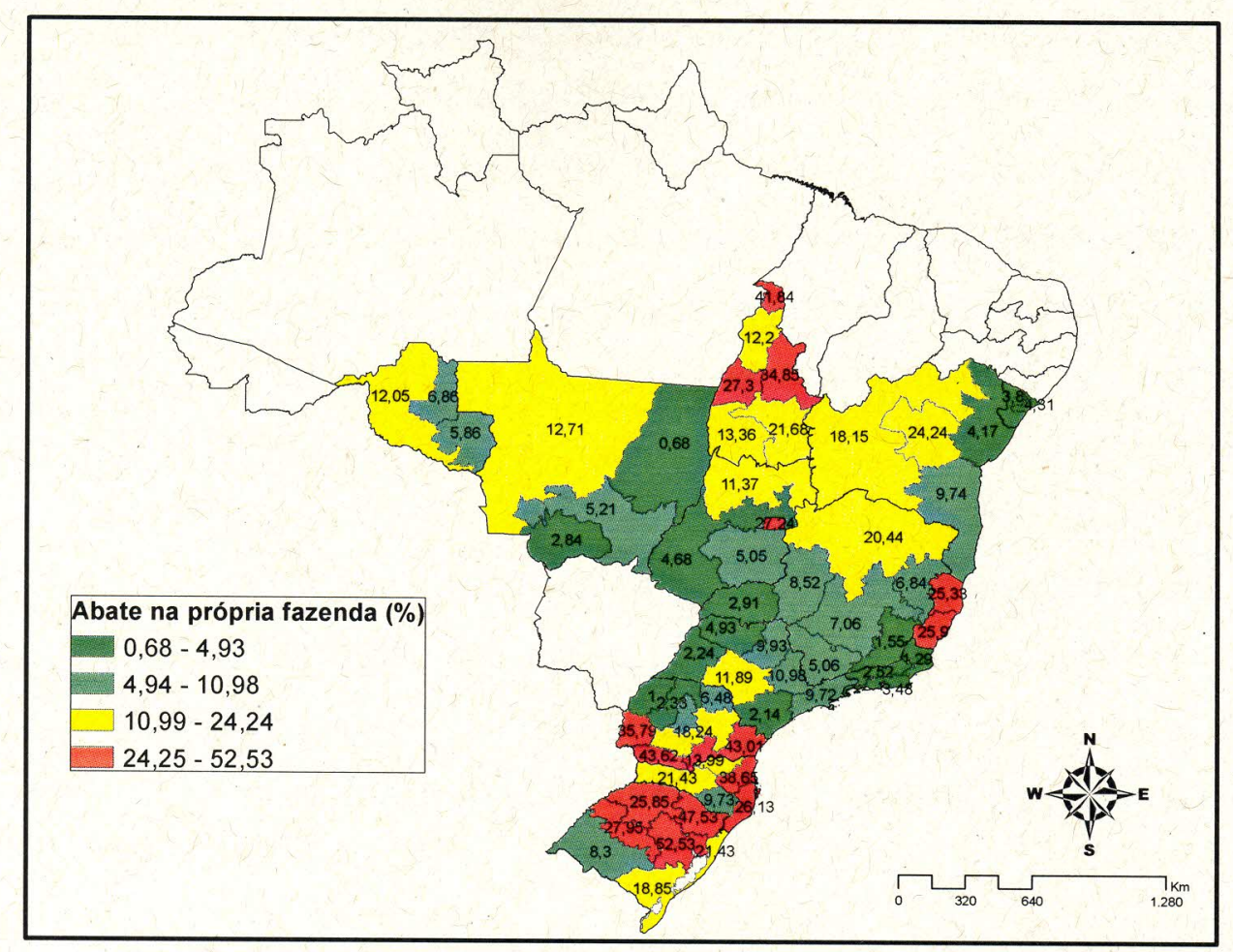

Mapa 89- Distribuição estadual das frequências estimadas de propriedades que abatem os reprodutores no fim da vida reprodutiva na própria fazendaBrasil - out 2001-dez 2004

Estes dados concordam com as estimativas descritas por Azevedo e Bankúti (2001) e Bankúti (2002), os quais citaram que os níveis de abate clandestino situaram-se em torno de $40 \%$. Os autores concordam também que ao longo da década de 90 não foram encontrados indícios de queda nos abates irregulares, mesmo após a introdução de novas legislações governamentais que buscavam contemplar aspectos fundamentais à manutenção da qualidade do produto inspecionado, desde a modernização das atividades, racionalização dos sistemas, sua obtenção, preparação e comercialização, como é o caso das portarias 304 de 22/04/96 e 145 de 04/01/99, criadas pelo Ministério da Agricultura.

É reconhecido que a carne, mesmo que seja obtida através de animais sadios, pode vir a representar um veículo em potencial de contaminantes de natureza biológica, física e química ao passar pelas diversas fases de produção, armazenamento, transporte e condições de comercialização. Em razão disto, as possibilidades de contaminação da carne pode ocorrer desde o processo de sangria, passando pelo abate até a sua comercialização em feiras-livres, açougue e demais mercados, tendo em vista que durante todo este processo a mesma pode ser manipulada por pessoas que pelo fato de não terem acesso à orientação educacional ou por simples negligência, contribuem para a baixa qualidade do 
produto comercializado em alguns pontos do varejo (OLIVEIRA; NASCIMENTO; FIORINI, 2002; FAUSTINO et al., 2003).

Levando em conta os abates de bovinos sem inspeção oficial, algumas conseqüências devem ser consideradas, dentre as quais podemos citar: os problemas sanitários relacionados com a ingestão de carne contaminada e que ocasionam custos diretos aos sistemas de saúde e indiretos relacionados à perda da capacidade de trabalho; o não recolhimento de impostos e a concorrência desleal que esta prática exerce em relação àquelas empresas que operam legalmente (AZEVEDO; BANKÚTI, 2001; BANKÚTI, 2001).

Diversos autores ao estudarem o mercado ilegal da carne, tentaram identificar as razões dos consideráveis índices de abate clandestino, dentre os quais é possível citar: o conflito entre restrições informais (hábitos culturais e de compra) e as normas estabelecidas pelo setor, a capacidade do cumprimento de normas estabelecidas nos sistemas públicos de inspeção, a elevada carga tributária, a fiscalização deficiente de órgãos de inspeção sanitária e a tradição de comercialização carnes em pequenos açougues e mercados, nos quais a fiscalização é tida como mais complexa e o consumo é mais sensível à variação de preços (JANK, 1997; AZEVEDO; BANKÚTI, 2001; BANKÚTI, 2001).

O mercado informal é regulado através de estruturas de governança particulares, entre elas a relação de confiança (trust) estabelecida entre o açougueiro e os consumidores (AZEVEDO; BANKÚTI, 2001). Uma característica comportamental interessante foi descrita por Buso (2000) Ao estudar o perfil de consumidores de carne bovina na cidade de São Paulo. Este autor encontrou uma confiança significativa por parte dos consumidores em relação à segurança deste alimento (75\%), todavia, esta relação não decorreu das certificações e legislações sanitárias impostas, mas principalmente das relações entre os consumidores com o ponto de venda.

\subsubsection{Fabricação de derivados do leite na propriedade}

Aproximadamente $37,58 \%[36,68 \% ; 38,49 \%]$ das propriedades realiza a fabricação de derivados do leite, como queijos e manteiga, dentro dos próprios 
estabelecimentos. Dentre os tipos de exploração, observa-se que as maiores proporções de criações que fabricam estes produtos, estão entre os rebanhos de leite ou mistos, onde aproximadamente $40 \%$ dos rebanhos declararam produzi-los. Os rebanhos de corte, pelas suas próprias características voltadas para a produção de carne e pelo fato de que nem todas as propriedades possuem vacas em lactação, apresentaram frequências menores de produção destes produtos (Tabela 31).

Tabela 31- Distribuição das proporções de propriedades que produzem derivados do leite dentro do próprio estabelecimento segundo os tipos de exploração- Brasil - out 2001-dez 2004

\begin{tabular}{ccccccccc}
\hline \multicolumn{10}{c}{ Tipo de exploração } \\
\hline $\begin{array}{c}\text { Produz } \\
\text { derivados do } \\
\text { leite na } \\
\text { propriedade }\end{array}$ & $\begin{array}{c}\text { Corte } \\
\mathbf{( \% )}\end{array}$ & IC 95\% & $\begin{array}{c}\text { Leite } \\
\mathbf{( \% )}\end{array}$ & IC 95\% & $\begin{array}{c}\text { Mista } \\
\text { (\%) }\end{array}$ & IC 95\% & $\begin{array}{c}\text { Total } \\
(\%)\end{array}$ & IC 95\% \\
\hline Não & 75,22 & 73,$54 ; 76,82$ & 59,96 & 58,$38 ; 61,52$ & 58,38 & 56,$89 ; 59,84$ & 62,42 & 61,$51 ; 63,32$ \\
Sim & 24,78 & 23,$18 ; 26,46$ & 40,04 & 38,$48 ; 41,62$ & 41,62 & 40,$16 ; 43,11$ & 37,58 & 36,$68 ; 38,49$ \\
\hline Total & 100,00 & & 100,00 & & 100,00 & & 100,00 & \\
\hline
\end{tabular}

Os Estados onde a prevalência da fabricação de produtos derivados do leite dentro da propriedade demonstrou ser maior que a média da frequência geral das 14 UFs, puderam ser encontrados no sul do país e no Distrito Federal, sendo que as regiões que integraram os quartil superior de circuitos produtores com as maiores frequências de propriedades que fabricam derivados do leite $(>45,10 \%)$, foram observadas nas regiões compreendidas pelos circuitos que vão do norte do Rio Grande do Sul às regiões do sul do Paraná; no Triângulo mineiro; Pantanal matogrossense; no nordeste e sudeste do Tocantins e nas regiões paulistas de compreendidas pelas mesorregiões de Bauru/Marília/Assis e Ribeirão Preto/Araraquara. 
Produz queijo/manteiga (\%)

$10,79-18,96$

$18,97-36,12$

$36,13-43,39$

$43,40-54,70$

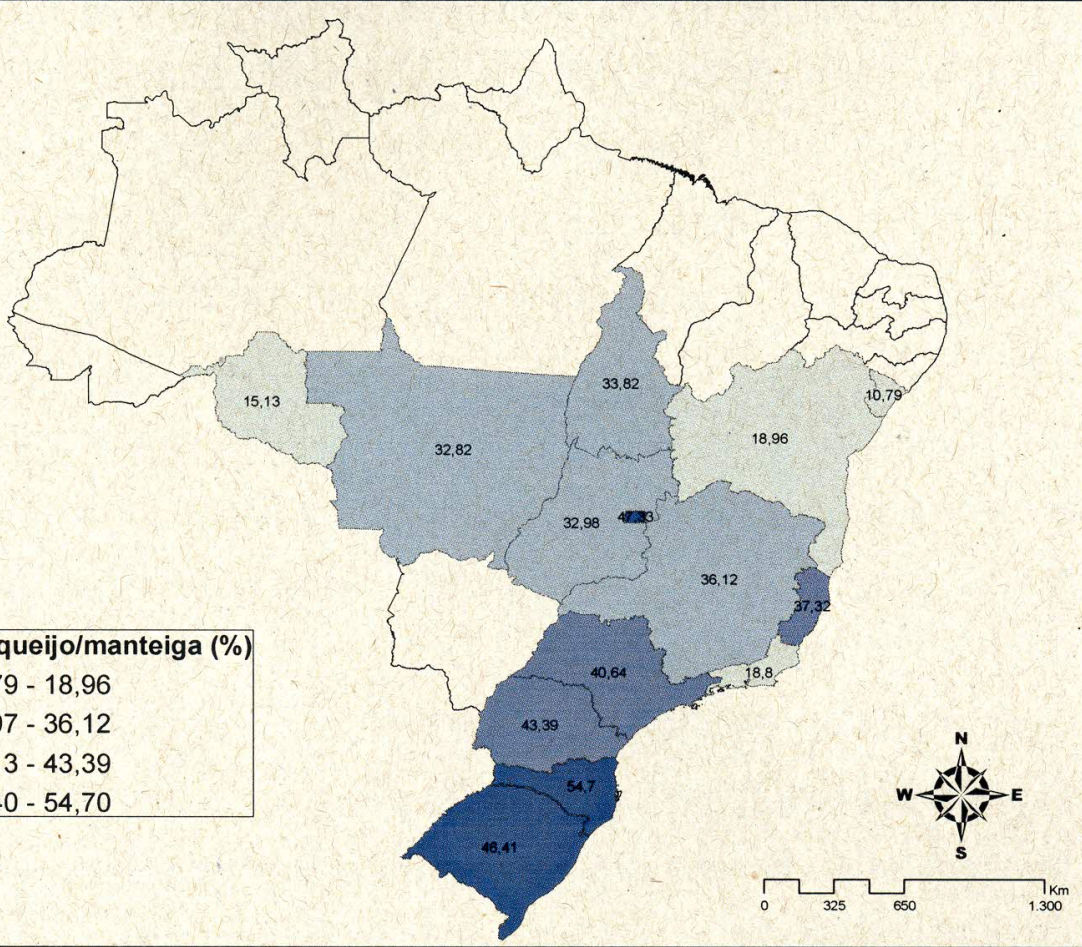

Mapa 90- Distribuição estadual das frequências estimadas de propriedades que produzem queijo e/ou manteiga na propriedade- Brasil - out 2001-dez 2004

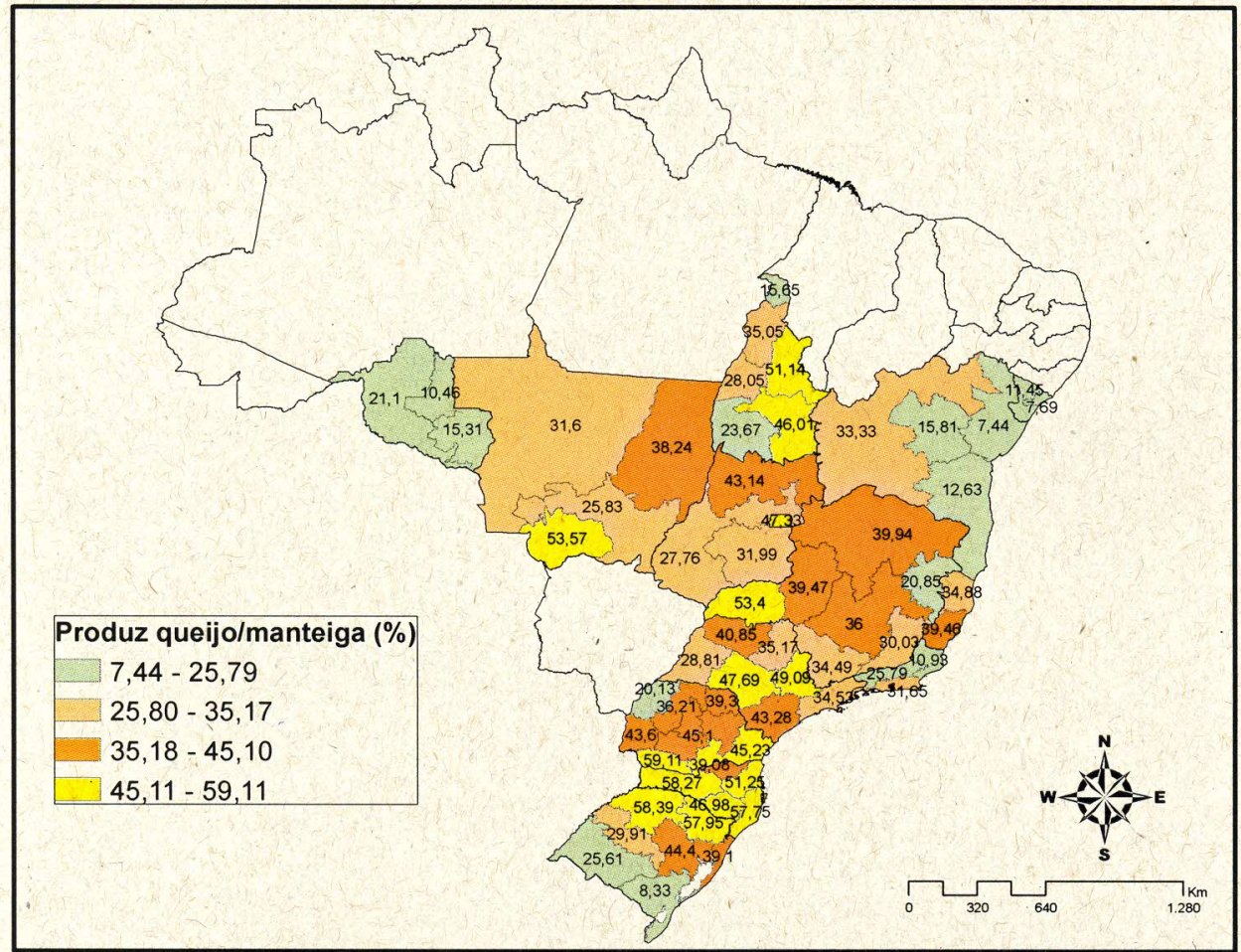

Mapa 91- Distribuição por circuito das frequências estimadas de propriedades que produzem queijo e/ou manteiga na propriedade- Brasil - out 2001-dez 2004 
Estes mesmo locais foram avaliados quanto ao destino da produção de derivados do leite e encontrou-se que a maior parte deles realiza esta fabricação somente para consumo próprio (84,45\% [83,34\%; 85,51\%]), os outros $15,55 \%$ [14,49\%; 16,66\%] realizam a comercialização dos produtos. Novamente, as explorações de leite e mistas apresentaram as maiores frequências desta característica, com resultados indicando que aproximadamente $17 \%$ das propriedades comercializam queijos e manteigas fabricados por eles. Em menor número, os estabelecimentos exclusivamente de corte que fabricam e vendem produtos lácteos, foram encontrados em 7,98\% [6,11\%; 10,36\%] dos locais com este tipo de exploração (Tabela 32).

No Sergipe foram encontradas as maiores frequências de propriedades que comercializam estes produtos (Mapa 92). Os circuitos pecuários onde as frequências de venda de derivados do leite produzidos no próprio estabelecimento situaram-se no quartil superior ( $>20,71 \%)$, estão situados nas regiões oeste e sudeste do Paraná; no Vale do Ribeira e na região de Ribeirão Preto/Araraquara de São Paulo; norte, centro-oeste, centro-sul e Vale do Mucuri de Minas Gerais; norte goiano; nordeste baiano; em ambos os circuitos de Sergipe e na região de Madeira-Guaporé no noroeste de Rondônia (Mapa 93).

Tabela 32- Finalidades da produção de derivados do leite segundo os tipos de exploração- Brasil - out 2001-dez 2004

\begin{tabular}{ccccccccc}
\hline \multicolumn{7}{c}{ Tipo de exploração } \\
\hline $\begin{array}{c}\text { Finalidade da } \\
\text { produção }\end{array}$ & $\begin{array}{c}\text { Corte } \\
(\%)\end{array}$ & IC $95 \%$ & $\begin{array}{c}\text { Leite } \\
(\%)\end{array}$ & IC $95 \%$ & $\begin{array}{c}\text { Mista } \\
(\%)\end{array}$ & IC 95\% & $\begin{array}{c}\text { Total } \\
(\%)\end{array}$ & IC 95\% \\
\hline $\begin{array}{c}\text { Consumo } \\
\text { próprio }\end{array}$ & 92,02 & 89,$64 ; 93,89$ & 83,06 & 81,$21 ; 84,76$ & 83,53 & 81,$76 ; 85,16$ & 84,45 & 83,$34 ; 85,51$ \\
Venda & 7,98 & 6,$11 ; 10,36$ & 16,94 & 15,$24 ; 18,79$ & 16,47 & 14,$84 ; 18,24$ & 15,55 & 14,$49 ; 16,66$ \\
\hline Total & 100,00 & & 100,00 & & 100,00 & & 100,00 \\
\hline
\end{tabular}




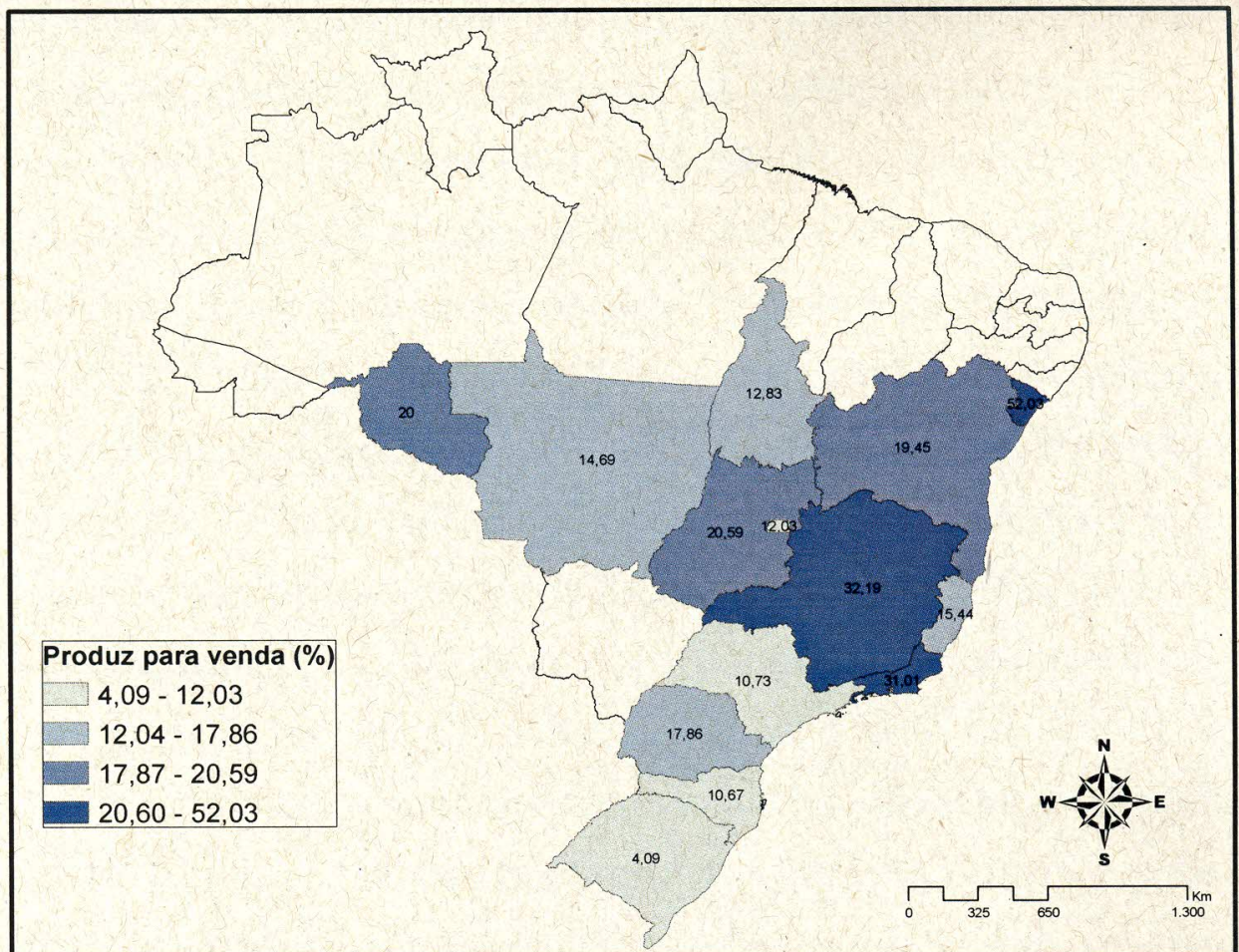

Mapa 92- Distribuição estadual das frequências estimadas de propriedades que comercializa o queijo elou manteiga produzido- Brasil - out 2001-dez 2004

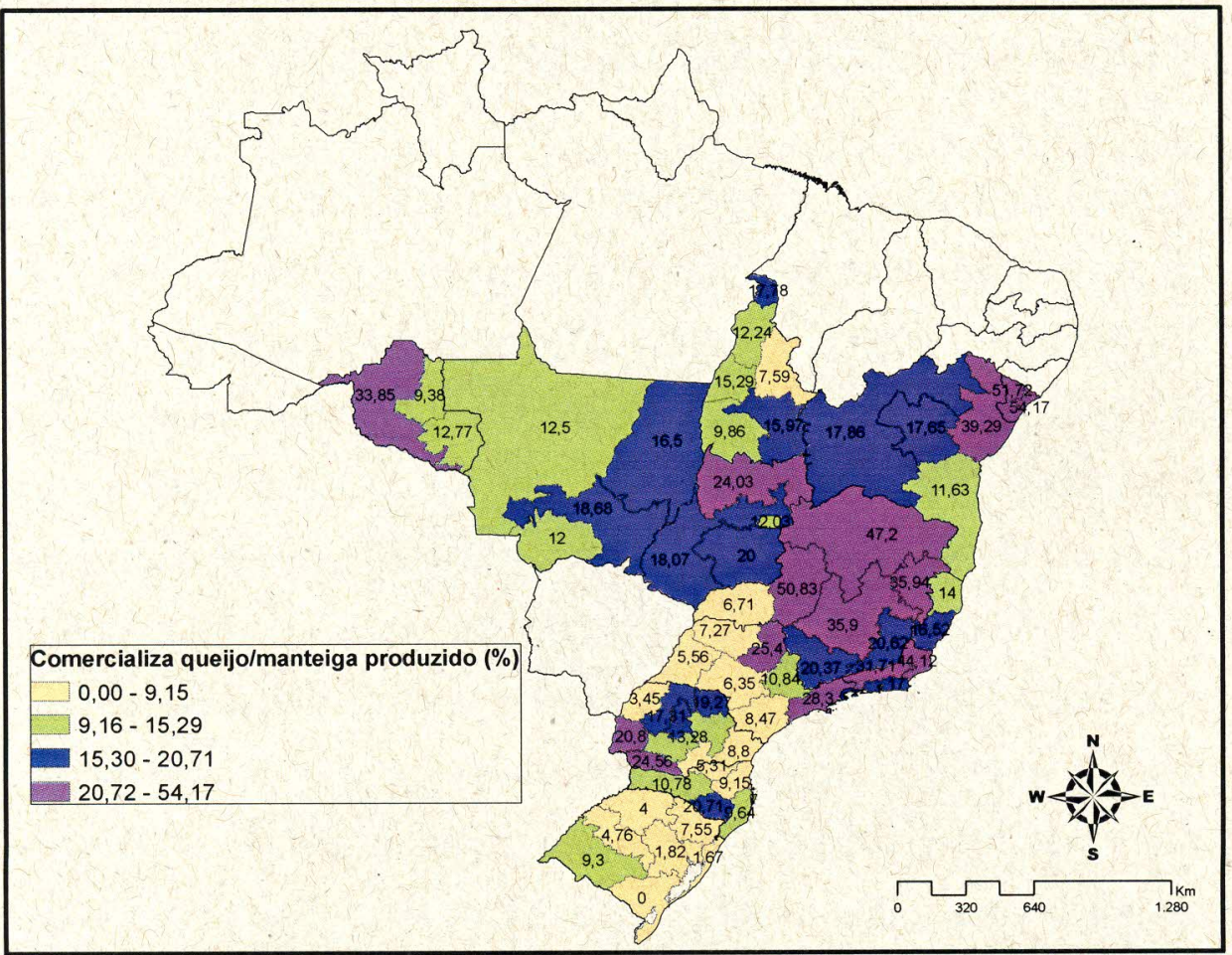

Mapa 93- Distribuição estadual das frequências estimadas de propriedades que comercializa o queijo e/ou manteiga produzido- Brasil - out 2001-dez 2004 
Considerando a perecibilidade dos produtos lácteos, a possibilidade de não utilização de leite pasteurizado na fabricação de alguns destes produtos, a capacidade de eliminação de agentes potencialmente nocivos à saúde dos consumidores e que se agrava através de processos precários de manipulação de alimentos, a fabricação de derivados lácteos dentro da própria propriedade poderia estar representando diversos riscos à saúde dos consumidores, tanto por parte dos que fabricam para consumo próprio, quanto para os que comercializam estes alimentos fora do estabelecimento pecuário (CORREA; RONCADA, 1997; BELOTI et al., 1999; CATÃO; CEBALLOS, 2001; MACIEL et al., 2008; KOMATSU, 2008). Um dado que poderia representar este risco potencial de transmissão de agentes infecciosos através do leite e seus derivados, foi obtido cruzando os dados de fabricação de derivados do leite no próprio estabelecimento com os dados de prevalência de focos de brucelose. Neste caso estimou-se que 5,9\% [5,3\%; 6,5\%] das propriedades que fabricam estes produtos, representavam focos de brucelose bovina.

\subsection{PREVALÊNCIA DE FOCOS DE BRUCELOSE}

As prevalências de focos de brucelose bovina nos circuitos, já descritas nos trabalhos de estudo da situação epidemiológica (ALVEZ et al., 2009; AZEVEDO et al., 2009; DIAS et al., 2009a,b; GONÇALVES et al., 2009a,b; ROCHA et al., 2009; NEGREIROS et al., 2009; KLEIN-GUNNEWIEK et al., 2009; MARVULO et al., 2009; OGATA et al., 2009; SIKUZAWA et al., 2009; SILVA et al., 2009; VILLAR et al., 2009), foram descritas para uma melhor compreensão espacial destas frequências e foi realizado o cálculo da prevalência geral para as 14 UFs (Mapas 94 e 95).

A prevalência geral de criações que representaram foco de brucelose nos Estados que participaram do projeto foi estimada em 8,34\% [7,94\%; 8,75\%]. Estratificando estes resultados por tipo de exploração pecuária, observa-se que as maiores frequências de focos de brucelose foram encontradas nas explorações de corte, onde 13,99\% [12,96\%; 15,09\%] destas propriedades apresentaram pelo menos um animal positivo para brucelose nos testes sorológicos. Entre as explorações de leite $(6,36 \%[5,76 \% ; 7,02 \%])$ e mistas $(7,09 \%[6,47 \% ; 7,76 \%])$, as 
frequências foram menores do que as de corte e equiparáveis entre si, havendo interposição dos seus intervalos de confiança de 95\% (Tabela 33).

Apesar da prevalência geral de focos de brucelose ter sido estimada em aproximadamente $8 \%$, as frequências estaduais apresentaram alta variabilidade, variando de resultados próximos de $0 \%$ como no caso de Santa Catarina mas que chegaram a $42,02 \%$ [38,78\%; 45,33\%] no Estado de Mato Grosso (Mapa 94). Os circuitos pecuários que participaram do último quartil de regiões com as maiores frequências de foco de brucelose, situaram-se de maneira geral por todos os Estados de Mato Grosso e Rondônia; na metade oriental do Tocantins; regiões do centro-sul de Goiás e nas regiões do centro-sul e da baixada fluminense (Mapa 95).

Tabela 33- Distribuição da estimativa da prevalência de focos de brucelose segundo os tipos de exploração pecuária- Brasil - out 2001-dez 2004

\begin{tabular}{|c|c|c|c|c|c|c|c|c|}
\hline \multirow[b]{2}{*}{$\begin{array}{c}\text { Teste } \\
\text { brucelose }\end{array}$} & \multicolumn{8}{|c|}{ Tipo de Exploração } \\
\hline & $\begin{array}{c}\text { Corte } \\
(\%)\end{array}$ & IC $95 \%$ & $\begin{array}{l}\text { Leite } \\
(\%)\end{array}$ & IC $95 \%$ & $\begin{array}{c}\text { Mista } \\
(\%)\end{array}$ & IC $95 \%$ & $\begin{array}{c}\text { Total } \\
(\%)\end{array}$ & IC $95 \%$ \\
\hline Negativo & 86,01 & 84,$91 ; 87,04$ & 93,64 & 92,$98 ; 94,24$ & 92,91 & 92,$24 ; 93,53$ & 91,66 & 91,$25 ; 92,06$ \\
\hline Positivo & 13,99 & 12,$96 ; 15,09$ & 6,36 & 5,$76 ; 7,02$ & 7,09 & 6,$47 ; 7,76$ & 8,34 & 7,$94 ; 8,75$ \\
\hline Total & 100,00 & & 100,00 & & 100,00 & & 100,00 & \\
\hline
\end{tabular}

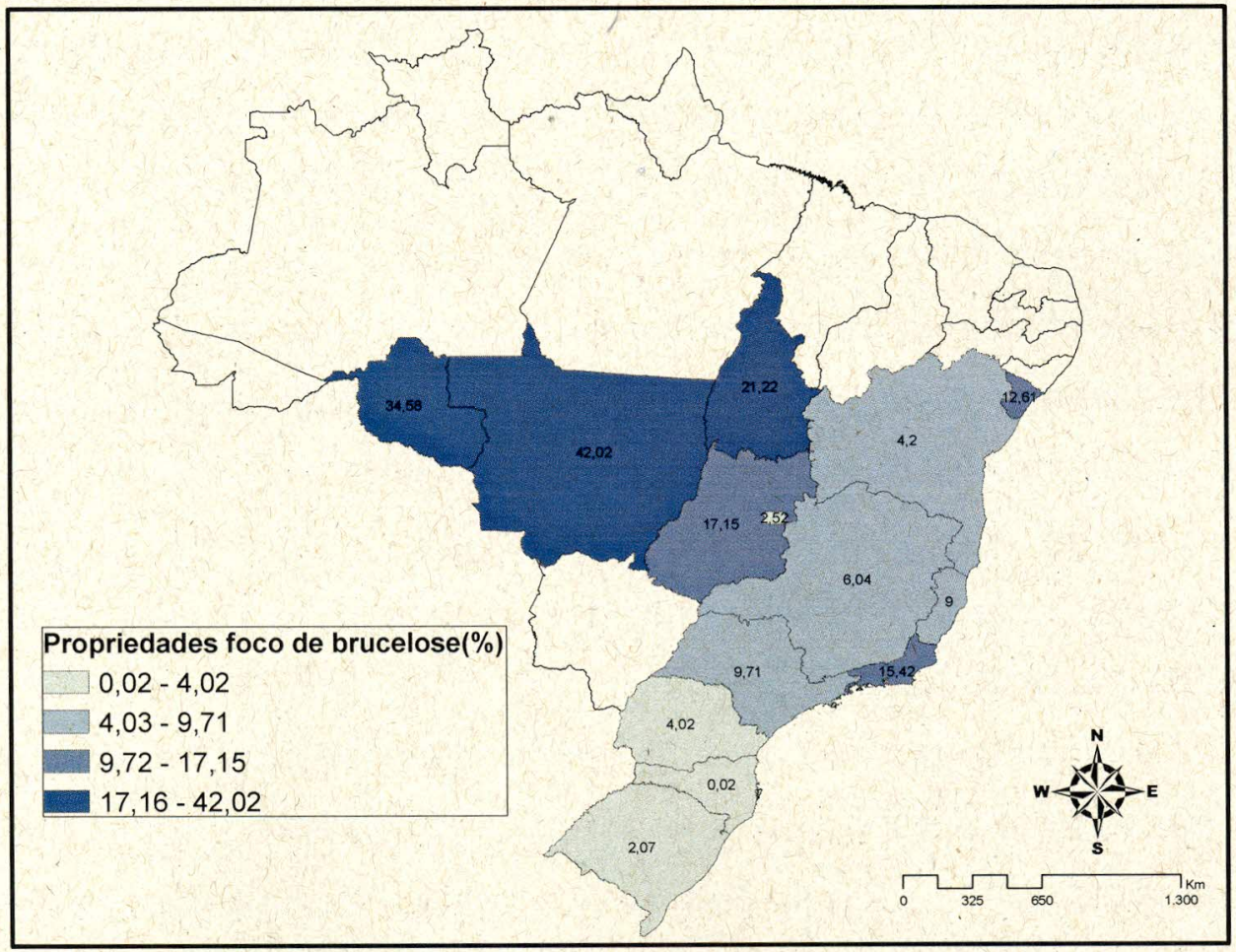

Mapa 94- Distribuição estadual das frequências estimadas de propriedades foco de brucelose bovina- Brasil - out 2001-dez 2004 


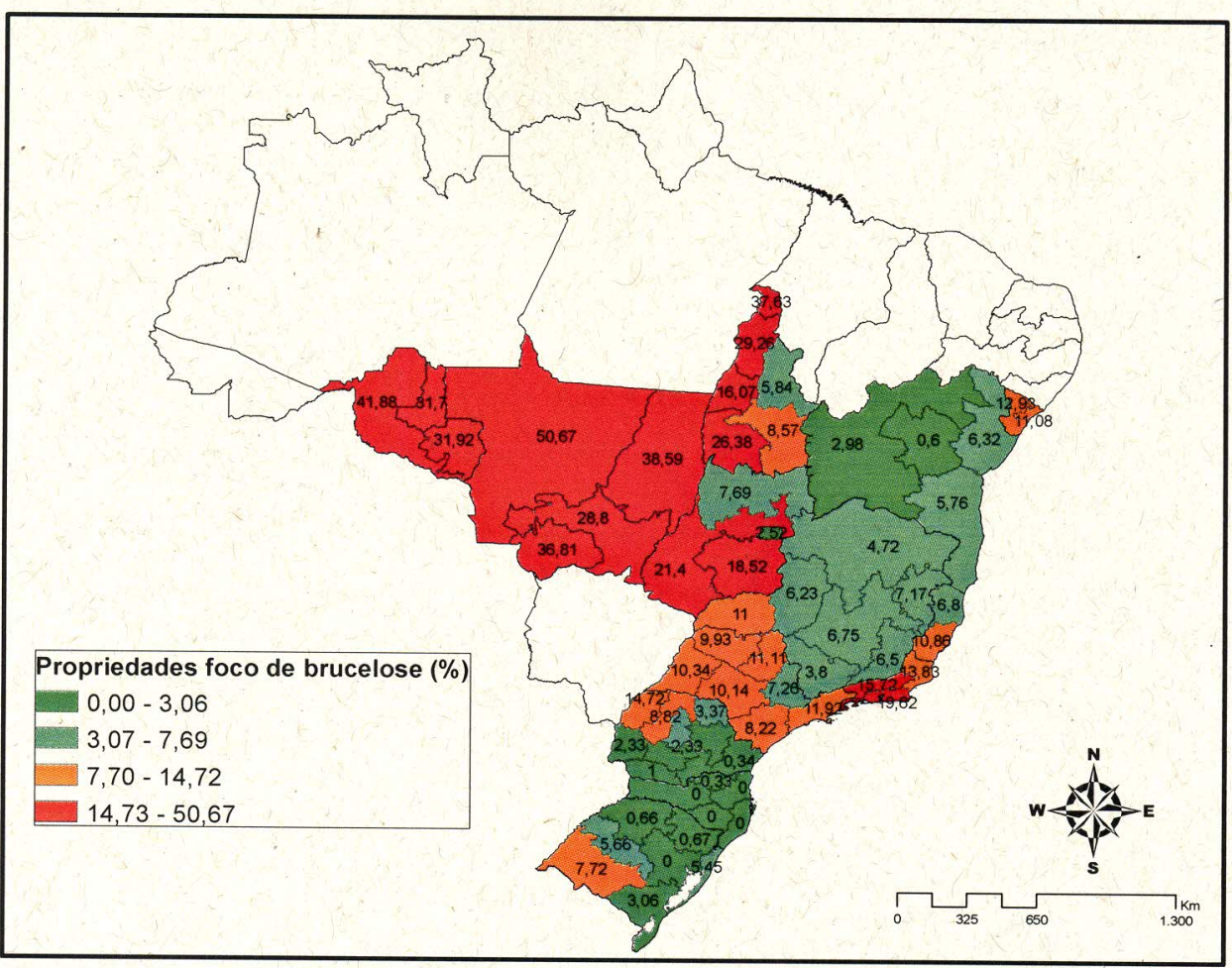

Mapa 95- Distribuição estadual das frequências estimadas de propriedades foco de brucelose bovina- Brasil - out 2001-dez 2004

Como observado, as maiores prevalências foram observadas nas UFs do Centro-oeste e Norte do país. A concentração de focos nestas áreas, parece estar relacionada com algumas características das criações locais, como criações extensivas extensivos, de exploração de corte, com um grande número de animais e entrada constante de reprodutores dentro dos rebanhos. Villar et al. (2009) e Dias et al. (2009a), estudando os fatores de risco relacionados à presença da brucelose bovina em Rondônia, citam que rebanhos muito grandes, sofrem um maior risco de introdução e espalhamento da brucelose, já que nestas propriedades a reposição de animais é frequente e devido ao tamanho das propriedades, o controle sanitário se torna mais difícil. A introdução constante de animais para a reprodução, pode ser um importante fator de risco para introdução da brucelose em rebanhos livres, sendo que o risco pode variar segundo a idoneidade da fonte de aquisição destes animais (CRAWFORD; HUBER; ADAMS, 1990).

Outro fator considerado como um importe fator de risco para a presença da brucelose nas regiões afetadas é a quantidade de fêmeas maiores do que 24 meses nas propriedades (DIAS, 2004; AZEVEDO, 2006; NEGREIROS, et al., 2009; VILLAR, et al., 2009). O Mapa 96, demonstra as medianas do número de fêmeas nesta faixa etária nos circuitos. Tanto machos como fêmeas são susceptiveis à 
doença, porém as fêmeas gestantes permanecem cronicamente infectadas devido à permanência das brucelas nos linfonodos e no útero possuindo um importante papel na disseminação da doença, através dos produtos do abortamento (PAULIN e FERREIRA NETO, 2003).

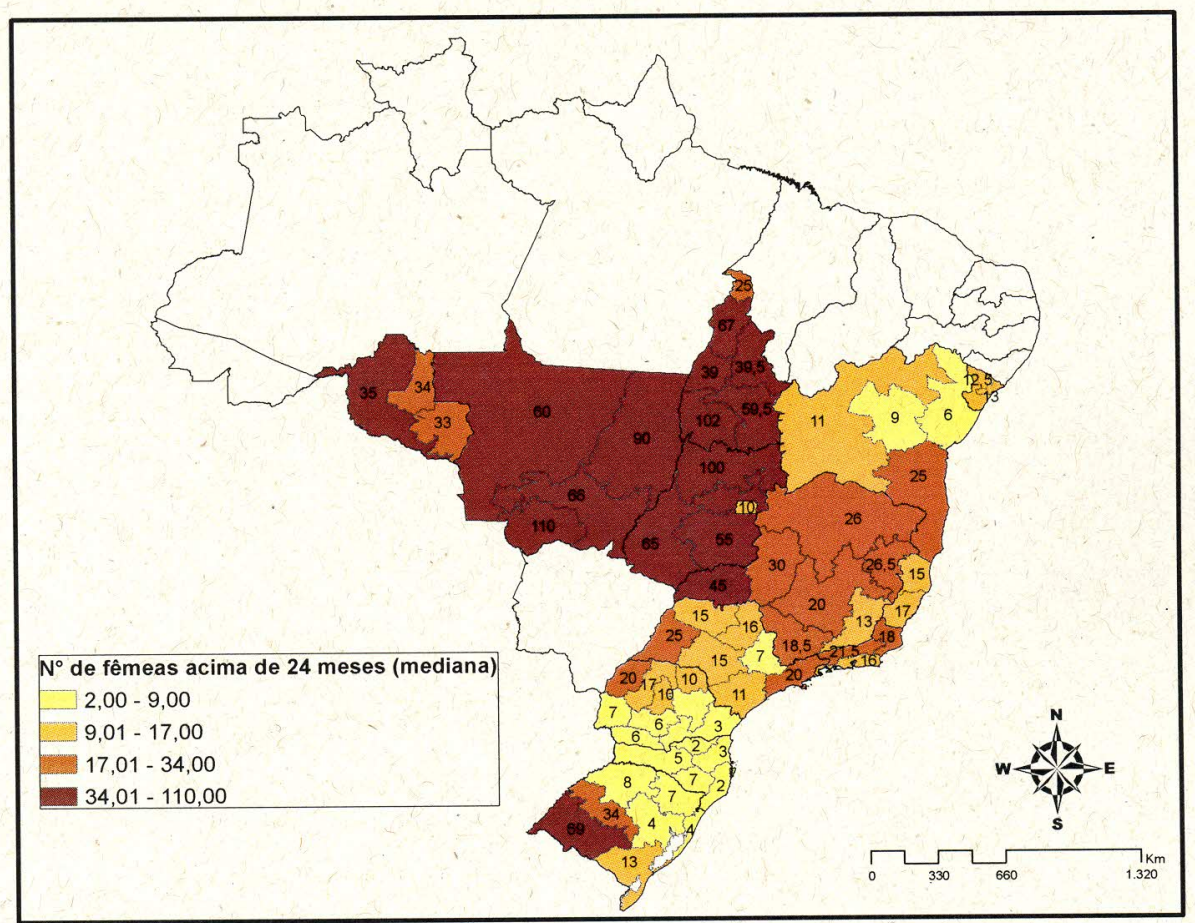

Mapa 96- Distribuição das medianas do número de fêmeas maiores do que 24 meses nos circuitos produtores- Brasil - out 2001-dez 2004 


\section{CONCLUSÃO}

Apesar da extensa quantidade de informações fornecidas através da aplicação do questionário epidemiológico, procurou-se reconhecer e respeitar as suas limitações, analisando e fazendo inferências de maneira cuidadosa afim de evitar possíveis vieses durante a interpretação das análises que pudessem de alguma maneira interferir na elaboração dos resultados e nas discussões do trabalho.

Ressalta-se que apesar das equipes de atuação local terem recebido treinamento para a realização do inquérito epidemiológico, a interpretação e condução das perguntas por parte de alguns entrevistadores poderiam induzir alguns produtores a respostas enviesadas, e posteriormente, na interpretação dos dados obtidos. Um exemplo, seria o questionamento sobre a assistência veterinária no local. Neste caso, a resposta afirmativa deveria ser considerada apenas naqueles casos em que os médicos veterinários visitavam as propriedades regularmente, com orientações específicas no manejo sanitário e produtivo dos animais. No entanto, durante as entrevistas algumas perguntas podem não ter sido bem direcionadas, incluindo proprietários que procuravam assistência apenas em casos emergenciais. A inclusão destas respostas, resultou em problemas durante os cálculos de fatores de risco para a brucelose bovina em alguns trabalhos de estudo epidemiológico da doença. Nestes casos, a presença da "assistência veterinária" apresentou-se, como sendo um fator de risco para a doença (SILVA, 2008).

Outro fator importante a ressaltar, é que pelo fato da amostra ter sido direcionada apenas para as propriedades onde havia animais em atividade reprodutiva, todas as inferências realizadas neste trabalho de caracterização dos rebanhos, dizem respeito apenas a este universo de propriedades.

Os resultados obtidos demonstraram que as criações no país ainda são exploradas predominantemente de maneira extensiva, motivadas tanto pelas características histórico-culturais de exploração pecuária, quanto pela extensão territorial e o clima favorável. A recuperação de pastagens degradadas e a expansão das áreas de pastagens cultivadas, proporcionariam maiores taxas de ocupação, crescimento do rebanho e poderiam tornar a carne e o leite produtos ambientalmente aceitáveis do ponto de vista da absorção de GEE. Estas 
características, conferem ao país um alto potencial de crescimento no setor ao oferecer carne e leite de alta qualidade e com preços competitivos no mercado nacional e internacional.

O investimento em tecnologia, intensificação dos manejos, inseminação artificial, utilização de raças especializadas, participação de assistência veterinária, demonstrou-se crescente à medida que se avança em direção aos Estados do Sul do Brasil. Isto justificaria os maiores índices de produtividade por animal, como por exemplo, os índices de produtividade leiteira. Ressalta-se aqui a importância da tecnificação dos rebanhos para a obtenção de índices de produtividade satisfatórios e controle da sanidade. Todavia, este investimento deve ser incentivado levando-se em consideração o ambiente e a disponibilidade de recursos em que os pecuaristas estão inseridos.

A tendência de expansão da pecuária de leite para os Estados do Centrooeste e Norte parece se confirmar através dos tamanhos de rebanho leiteiro e de vacas em lactação encontrados nestas regiões. Todavia, o baixo índice de produtividade destes locais sugere que estes rebanhos possuem um baixo potencial genético para a produção de leite, são criados extensivamente em propriedades de grande porte e com pouco investimento em tecnologia.

Considera-se que a associação entre pecuaristas deve ser incentivada, principalmente entre os pequenos produtores. Um exemplo das vantagens da associação, seria a utilização de tanques de expansão comunitários, tendo em vista que podem servir como elemento aglutinador e de mobilização dos produtores, não apenas do ponto de vista da produção, mas também na inserção destes produtores no mercado e no cumprimento das exigências comerciais impostas por ele. Portanto, a integração de esforços entre pequenos produtores, pode contribuir de maneira significativa para a melhoria dos processos de produção, inclusão social e no bem estar da comunidade as quais pertencem.

A compra e venda de animais para reprodução demonstrou-se intensa e realizada diretamente entre as propriedades. As estimativas da prevalência de focos de brucelose bovina e a baixa frequência de investimento em manejos sanitários observados, fazem da comercialização de reprodutores uma boa maneira de introdução e manutenção de doenças nas criações. Nestes casos, a avaliação do perfil sanitário dos animais adquiridos e a rigidez no cumprimento das normas de movimentação animal devem ser priorizadas. 
O comércio informal do leite e da carne bovina ainda corresponde por uma parcela significativa do mercado. Por conta dos riscos oferecidos aos consumidores e não tributação destes produtos, aconselha-se a necessidade de intensificação e/ou reformulação de medidas políticas e educacionais no setor, buscando a maior fiscalização deste comércio e a conscientização da população sobre os riscos à saúde envolvidos com ele.

A estratificação das UFs em circuitos produtores demonstrou a alta heterogeneidade entre os sistemas de produção regionais, tanto no manejo e tecnologia empregados quanto nas questões de atenção sanitária. Considerando a complexidade de cada região de produção animal, a elaboração de estratégias de atuação frente às doenças dos rebanhos deve levar em consideração as características regionais de cada uma. Isto tornaria mais efetiva as ações de controle e erradicação de doenças, como também auxiliaria na redução de gastos desnecessários.

Sugere-se ainda, a necessidade da criação de um sistema integrado de informações relativas às propriedades agropecuárias. Por estes locais integrarem um setor complexo e altamente dinâmico, a constante obtenção de informações nestas propriedades, seria de grande contribuição para os órgãos de atenção à saúde animal em todo o país.

Tendo em vista a pontualidade de publicações relativas à caracterização da cadeia produtiva de bovinos, reflete-se a respeito da necessidade do investimento em trabalhos com este enfoque, considerando que informações a respeito das características destes sistemas de produção, deveriam ser tomadas como ponto de partida na elaboração de estratégias de atuação frente aos problemas no setor. 


\section{REFERENCIAS}

ABIEC. ASSOCIAÇÃO BRASILEIRA DAS INDÚSTRIAS EXPORTADORAS DE CARNES. Exportações de carne bovina no Brasil. 2009. Disponível em: <http://www.abiec.com.br/download/EXP\%20JAN-DEZ\%2009.pdf>. Acesso em: 1 jun. 2010.

ACHA, P. N.; SZYFRES, B. Zoonosis y enfermedades transmisibles comunes al hombre y a los animales: bacterioses e micotes. 3. ed. Washington: OPAS, 2001. $416 \mathrm{p}$.

ALENCAR, M. M.; POTT, E. B. Criação de bovinos de corte na Região Sudeste. Embrapa Pecuária Sudeste, Sistemas de Produção, 2. Versão Eletrônica Jul/2003 Disponível em: $<$ http://sistemasdeproducao.cnptia.embrapa.br/FontesHTML/BovinoCorte/BovinoCort eRegiaoSudeste/index.htm >. Acesso em: 5 maio2010.

ALVES, C. M. Caracterização do perfil produtivo da pecuária bovina do Estado de Minas Gerais. 2009. Dissertação (Mestrado em Ciência Animal) - Universidade Federal de Minas Gerais, Belo Horizonte, 2009.

ALVEZ, A. J. S.; GONÇALVES, V. S. P.; FIGUEIREDO, V. C. F.; LÔBO, J. R.; BAHIENSE, L.; AMAKU, M.; FERREIRA, F.; FERREIRA NETO, J.S.; DIAS, R.A. Situação epidemiológica da brucelose bovina no Estado da Bahia. Arquivo Brasileiro de Medicina Veterinária e Zootécnica, v. 61, p. 6-13, 2009. Suplemento 1.

ANDRADE, J.R.A. Perfil do sistema de produção dos rebanhos bovinos na "bacia leiteira" de Goiânia-GO. 2003. 118 p. Tese (Doutorado em Ciência Animal) Escola de Veterinária, Universidade Federal de Minas Gerais, Belo Horizonte, 2003.

ANUALPEC 2002: anuário estatístico da pecuária de corte. São Paulo, SP: FNP, 2002. $400 \mathrm{p}$.

ANUALPEC 2004: anuário estatístico da pecuária de corte. São Paulo, SP: FNP, 2004. 385 p.

ANUALPEC 2005: anuário estatístico da pecuária de corte. São Paulo, SP: FNP, 2005. 340 p.

AMARAL, T. B.; COSTA, F. P.; CORREAA, E. M. Touros melhoradores ou inseminação artificial: um exercício de avaliação econômica. Campo Grande: EMBRAPA-CNPGC, 2003. 28p . (EMBRAPA-CNPGC. Documentos, 140).

ARRUDA, Z.J. de. Análise econômica dos sistemas de monta natural e de inseminação artificial na produção de bezerros de corte. Campo Grande, MS: Embrapa/CNPGC. 1990. 28 p. (EMBRAPA-CNPGC. Documentos, 40). 
ASBIA. ASSOCIAÇÃO BRASILEIRA DE INSEMINAÇÃO ARTIFICIAL. A ASBIA apresenta o relatório de comercialização de sêmen do ano 2009. Disponível em: <http://www.asbia.org.br/?mercado/index>. Acesso em: 01 jun. 2010.

ASTUDILLO, V. M.; DORA, F. J.; SILVA, J. A da. Ecosistemas y estratégias regionales de control de la fiebre aftosa. Aplication al caso do Rio Grande do Sul, Brasil. Boletim do Cintro Panamericano Fiebre Aftosa, v. 52, p. 47-61, 1986

ASTUDILLO, V. M.; ROSENBERG, F. J.; ZOTELLE, A.; OLASCOAGA, R. C. Considerações sobre a saúde animal na América Latina. A Hora Veterinária, Rio grande do Sul, v. 9, n. 54, 8. p, 1990.

AZEVEDO, P. F.; BÁNKUTI, F. I. Na clandestinidade: o mercado informal de carne bovina. In: INTERNACIONAL CONFERENCE ON AGRI-FOOD CHAIN/NETWORKS ECONOMICS AND MANAGEMENT, 2001, Ribeirão Preto, São Paulo. Anais..., 2001. v. 1, p. 1-12.

AZEVEDO, S.S. Caracterização epidemiológica da brucelose bovina no Estado do Espírito Santo. 2006. 103 f. Tese (Doutorado em Medicina Veterinária) Faculdade de Medicina Veterinária e Zootecnia, Universidade de São Paulo, São Paulo, 2006.

AZEVEDO, S. S.; FERREIRA NETO, J. S.; DIAS, R. A.; FERREIRA, F.; AMAKU, M.; FIGUEIREDO, V. C. F.; LÔBO, J. R.; GONÇALVES, V. S. P.; SOUZA, A. C.; VASCONCELLOS, S. A. Situação epidemiológica da brucelose bovina no Estado do Espírito Santo. Arquivo Brasileiro de Medicina Veterinária e Zootécnica, v. 61, p.14-18, 2009. Suplemento 1.

BAKER, J. F.; LONG, C. R.; POSADA, G. A. Comparison of a five-brees dialed: size, growth, condition and pubertal characters of second-generation heifers. Journal of Animal Science, v. 67, n. 5, p. 1218-1229, 1989.

BANKUTI, F. I. Abates clandestinos de bovinos: uma análise das características do ambiente institucional. In: CONGRESSO BRASILEIRO DE ECONOMIA E SOCIOLOGIA RURAL, 39., 2001, Recipe-PE. Anais...Sociedade Brasileira de Economia, Admnistração e Sociologia Rural. Disponível em: $<$ http://www.pensa.org.br/anexos/biblioteca/1332007143619_.pdf>. Acesso em: 5 maio2010.

BÁNKUTI, F. I. Entraves e incentivos ao abate clandestino de bovinos no Brasil. 2002. 159 f. Dissertação (Mestrado em Engenharia de Produção) - Universidade Federal de São Carlos, São Carlos, 2002.

BÁNKUTI, F. I.; SCHIAVI, S. M. A.; SOUZA FILHO, H. M. Quem são os produtores de leite que vendem em mercados informais? In: CONGRESSO DA SOCIEDADE BRASILEIRA DE ECONOMIA E SOCIOLOGIA RURAL, 43., 2005. Ribeirão Preto, SP. Anais... Ribeirão Preto, SP: Sociedade Brasileira de Economia, Administração e Sociologia Rural. Instituições, Eficiência, Gestão e Contratos no Sistema Agroindustrial, 2005. 
BARBOSA, P. F.; BUENO, R. S. Sistemas mistos de produção de leite e carne bovina.In: SIMPÓSIO SOBRE MANEJO E NUTRIÇÃO DE GADO DE LEITE, 2000, Goiânia, Anais... Goiânia: Colégio Brasileiro de Nutrição Animal, 2000 p. 53-68.

BARCELLOS, A.O; RAMOS, A. K. B.; VILELA, L.; JUNIOR, G. B. M. Sustentabilidade da produção animal baseada em pastagens consorciadas e no emprego de leguminosas exclusivas, na forma de banco de proteína, nos trópicos brasileiros. Revista Brasileira de Zootecnia, v. 37, p. 51-67, 2008. Suplemento.

BARIONI, L. G; MARTA JR, G. B.; RAMOS, A. K. B.; VELOSO, R. F.; RODRIGUES, D. C.; VILELA, L. Planejamento e gestão do uso de recursos forrageiros na produção de bovinos em pastejo. In: SIMPÓSIO SOBRE MANEJO DA PASTAGEM. 2003, Piracicaba. Anais... São Paulo: Fundação de estudos agrários Luís de Queiroz, 2003. p. 105-153.

BARUSELLI, P. S.; MARQUES, M. O.; CARVALHO, N. A. T.; MADUREIRA, E. H.; CAMPOS FILHO, P. Efeitos de diferentes protocolos de inseminação artificial em tempo fixo na eficiência reprodutiva de vacas de corte lactantes. Revista Brasileira de Reprodução Animal, Belo Horizonte, v. 26, p. 218-221, 2002.

BARNHAM, M.; THORNTON, T. J., LANGE, K. Nephritis caused by Streptococcus zooepidemicus (Lancefield group C). Lancet. v. 1, p. 945-948, 1983.

BEER, J. Doenças infecciosas em animais domésticos. São Paulo: Roca, 1999. $394 \mathrm{p}$.

BONJOUR, S. C. M.; FIGUEIREDO, A. M. R; MARTA, J. M. C. A pecuária de corte no Estado do Mato Grosso. In: CONGRESSO SOCIEDADE BRASILEIRA DE ECONOMIA, ADMNISTRAÇÃO E SOCIOLOGIA RURAL, 46., 2008, Rio Branco. Anais...Rio Branco: Sociedade Brasileira de Economia, Administração e Sociologia Rural, 2008. Disponível em: <http://www.sober.org.br/palestra/9/519.pdf>. Acesso em: 21 maio 2010

BUSO, G. A análise do perfil do consumidor de carne bovina na cidade de São Paulo. Dissertação (Mestrado em administração) - Departamento de Engenharia de Produção, Universidade Federal de São Carlos, São Carlos, 2000.

BRANDÃO, S.C.C. Leite: legislação, responsabilidade e saúde pública. Revista Balde Branco. São Paulo, v. 360, p. 68-71, 1994.

BRESSAN, M.; VILELA, D.. Restrições técnicas, econômicas e institucionais ao desenvolvimento da cadeia produtiva do leite no Brasil - Região Sul: MCT/CNPq/PADCT. Juiz de Fora: EMBRAPA - CNPGL. 1999. 56 p.

BELOTI, V.; BARROS, M. A. F.; SOUZA, J. A.; NERO, L. A.; SANTANA, E. H. W.; BALARIN, O.; CURIAKI, Y. Avaliação da qualidade do leite cru comercializado em Cornélio Procópio, Paraná. Controle do consumo e da comercialização. Semina: Ciências Agrárias, Londrina, Paraná. v. 20, n. 1, p. 12-15, 1999. 
BINELLI, M.; MACHADO, R.; BERGAMASCHI, M. A. C. M.; SILVA, J. C. B.; IBIAPINA, B. T.; BISINOTTO, R. S. Conceitos e aplicações de estratégias antiluteolíticas visando o incremento da taxa de concepção em bovinos. In: Simpósio Internacional de Reprodução Animal Aplicada, 2., 2006, Londrina, PR. Anais...2006. p.93-100.

BODDEY, R. M.; ALVES, B. J. R.; URQUIAGA, S. S. Seqüestro de carbono em solos sob sistemas agropecuários produtivos. EMBRAPA Agrobiologia, Seropédica-RJ, 2004. Folder. Disponível em: <http://www.cnpab.embrapa.br/pesquisas/folders/folder_sequestro_carbono.pdf>. Acesso em: 21 maio 2010.

BRASIL. Ministério da Agricultura e Abastecimento. Diagnóstico de saúde animal, Brasília: 1977. 735 p.

BRASIL. Ministério da Agricultura e Abastecimento. Instrução normativa $\mathrm{n}^{\circ} 2,10$ de janeiro de 2001. Institui o Programa Nacional de Controle e Erradicação da Brucelose e Tuberculose Animal. Diário Oficial da União, Brasília, 11 jan 2001, Sec. I, p. 5. Disponível em: <www.agricultura.gov.br>. Acesso em: 31 maio2010.

BRASIL, Ministério da Agricultura, Pecuária e Abastecimento. Instrução Normativa $n^{\circ}$ 51, 18 de setembro de 2002 Aprovar os Regulamentos Técnicos de Produção, Identidade e Qualidade do Leite tipo A, do Leite tipo B, do Leite tipo C, do Leite Pasteurizado e do Leite Cru Refrigerado e o Regulamento Técnico da Coleta de Leite Cru Refrigerado e seu Transporte a Granel, em conformidade com os Anexos a esta Instrução Normativa. Diário Oficial da União, Brasília, 20 set. 2002. Seção I, p.13-22. 20.

BRASIL. Ministério da Agricultura, Pecuária e Abastecimento. Manual técnico do programa nacional de controle e erradicação da brucelose e tuberculose. Brasília, 2006. Disponível em: <http://www.agricultura.gov.br/ >. Acesso em: 15 maio 2010.

BRASIL. Ministério da Agricultura, Pecuária e Abastecimento. Portaria No 162, DE 18 DE OUTUBRO DE 1994. Aprova as Normas complementares anexas à presente Portaria, baixadas pelo Departamento de Defesa Animal, que versam sobre a Fiscalização e o Controle Zoossanitário das Exposições, Feiras, Leilões e outras aglomerações de animais, em todo território Nacional. Diário Oficial da União, Brasília, 21 out. 1994. Sec. I, p. 15934.

BRITO, L. G.; SALMAN, A. K. D.; GONÇALES, M. A. R.; FIGUEIRÓ, M. R. Cartilha para o produtor de leite de Rondônia. Parte II: aspectos técnicos. Porto Velho: Embrapa Rondônia, 2007. 40 p. (Embrapa Rondônia. Documentos, 116).

CANADÁ. Health and Welfare Canada. Yersinia enterocolitica gastroenteritis outbreak: Montreal. Canada diseases weekly report, v. 2, p.73-74, 1976.

CEZAR, I. M.; QUEIROZ, H. P.; THIAGO, L. R. L. S.; CASSALES, F. L. G.; COSTA, F. P. Sistemas de produção de gado de corte no Brasil: uma descrição com 
ênfase no regime alimentar e no abate. Campo Grande: Embrapa, 2005. (Documentos Embrapa Gado de Corte, n. 151).

CARDOSO, E. G. Confinamento de bovinos. EMBRAPA. Texto base distribuído no Curso "Suplementação em Pasto e Confinamento de Bovinos", Campo Grande, MS. 2000.

em:

$<$ http://www.cnpgc.embrapa.br/publicacoes/naoseriadas/cursosuplementacao/confin amento/>. Acesso em: 31 maio 2010.

CARVALHO, P. C. F.;FISHER, V.; DOS SANTOS, D. T.; RIBEIRO, A. M. L.; QUADROS, F. L. F.; ,CASTILHOS, Z. M. S.; POLI, C. H. E. C.; MONTEIRO, A. L. G.; NABINGER, C.;GENRO, T. C. M.; JACQUES, A. V. A. Produção animal no bioma Campos Sulinos. Brazilian Journal of Animal Science, João Pessoa, v. 35, p. 156202, 2006. Suplemento especial.

CATÃO, R. M. R; CEBALLOS, B. S. O. Listeria spp., coliformes totais e fecais e E.coli no leite cru e pasteurizado de uma indústria de laticínios, no Estado da Paraíba (Brasil). Ciência e Tecnologia de Alimentos, Campinas, SP, v. 21, n. 3, p. 281-287, 2001.

CDC. CENTERS FOR DISEASE CONTROL. Group C streptococcal infections associated with eating homemade cheese: New Mexico. CDC - Morbidity and Mortality Weekly Report, v.32, p.510-516, 1983.

CERRI, C. E. P.; EASTER, M.; PAUSTIAN, K. Simulating SOC changes in 11 land use change from Brazilian Amazon within RothC and Century models. Agriculture, Ecosystems and Environment, v. 122, p. 46-57, 2007.

CHATE, S. C.; DIAS, R. A.; AMAKU, M.; FERREIRA, F.; MORAES, G. M.; COSTA NETO, A. A.; MONTEIRO, L. A. R. C.; LÔBO, J. R.; FIGUEIREDO, V. C. F.; GOLÇALVES, V. S. P.; FERREIRA NETO, J. S. Situação epidemiológica da brucelose bovina no Estado do Mato Grosso do Sul. Arquivo Brasileiro de Medicina Veterinária e Zootecnia, v. 61, p. 46-55, 2009. Suplemento 1.

CÔRREA, E. S.; VIEIRA, A.; COSTA, F. P.; CEZAR, I. M. Sistema semi-intensivo de produção de carne de bovinos nelores no Centro-Oeste do Brasil. Campo Grande: Embrapa Gado de Corte, 2000. 49 p. (Embrapa Gado de Corte. Documentos, 95).

CORREA, M.; RONCADA, M.J. Características microscópicas de queijos prato, mussarela e mineiro comercializados em feiras livres da cidade de São Paulo, Revista de Saúde Pública, v. 31, n. 3, p. 296-301, 1997.

COTRIM, M.S. Pecuária familiar na região da Serra do Sudeste do Rio Grande do Sul: um estudo sobre a origem e a situação agroeconômica do pecuarista familiar no município de Cangaçu/RS. 2003. 142 f. Dissertação (Mestrado em Desenvolvimento Rural)- Faculdade de Ciências Econômicas, Universidade Federal do Rio Grande do Sul, Rio Grande do Sul, 2003. 
CRAWFORD, R. P.; HUBER, J. D.; ADAMS, B. S. Epidemiology and surveillance. In: NIELSEN, K.; DUNCAN, J. R. Animal brucellosis. Boca Raton: CRC Press, 1990. p. 131-151.

DEAN, A. G. Epilnfo version 6: A word-processing, database, and statistic program for public health on IBM-compatible microcomputers. Atlanta: Center for Diseases Control and Prevention, 1994. 601 p.

DIAS, J. A.; ALFIERI, A. A.; MÉDICI, K. C.; FREITAS, J. C.; FERREIRA-NETO, J. S.; MULLER, E. E. Fatores de risco associados à infecção pelo herpesvírus bovino $1 \mathrm{em}$ rebanhos bovinos da região Oeste do Estado do Paraná, Pesquisa Veterinária Brasileira, v. 28, n. 3, p. 161-168, 2008.

DIAS, J. A.; MULLER, E. E.; DIAS, R. A.; FREITAS, J. C.; AMAKU, M.; FERREIRA, F.; SILVA, M. C. P.; LÔBO, J.R.; FIGUEIREDO, V. C. F. GONÇALVES, V. S. P.; FERREIRA NETO, J. S. Situação epidemiológica da brucelose bovina no Estado do Paraná. Arquivo Brasileiro de Medicina Veterinária e Zootécnica. v. 61, p. 66-76, 2009b. Suplemento 1.

DIAS, R. A. Caracterização espacial da brucelose bovina no estado de São Paulo. 2004. 111p. Tese (Doutorado em epidemiologia experimental aplicada às zoonoses) - Faculdade de Medicina Veterinária e Zootecnia, Universidade de São Paulo. São Paulo, 2004.

DIAS, R. A.; GONÇALVES, V. S. P.; FIGUEIREDO, V. C. F.; LÔBO, J. R.; LIMA, Z. M. B.; PAULIN, L. M. S.; GUNNEWIEK, M. F. K.; AMAKU, M.; FERREIRA NETO, J. S.; FERREIRA, F. Situação epidemiológica da brucelose bovina no Estado de São Paulo. Arquivo Brasileiro de Medicina Veterinária e Zootécnica. v. 61, p. 118125, 2009a. Suplemento 1.

DOMINGUES, O. Gado leiteiro para o Brasil: gado europeu, gado indiano, gado bubalino. São Paulo: Nobel, 1977. 112 p.

DUARTE, V.N. Caracterização dos principais segmentos da cadeia produtiva do leite em Santa Catarina. 2002. Dissertação (Mestrado em Engenharia da produção) Universidade Federal de Santa Catarina, Florianópolis, 2002.

EGITO, A. A. Diversidade genética, ancestralidade individual e miscigenação nas raças bovinas no Brasil com base em microssatélites e haplótipos de DNA mitrocondrial subsídios para a conservação. 2007. 232f. Tese (Doutorado em Ciências Biológicas) - Instituto de Ciências Biológicas, Universidade de Brasília, Distrito Federal, 2007.

EPIINFO 6.04d. Atlanta: Center for Diseases Control and Prevention, 2001. Disponível em: <http://www.cdc.gov>. Acesso em: 23 out. 2007. 
FACÓ, O.; LÔBO, R. N. B.; FILHO, R. M. Idade ao primeiro parto e intervalo de partos de cinco grupos genéticos Holandês $\times$ Gir no Brasil, Revista Brasileira de Zootecnia, v. 34, n. 6, p. 1920-1926, 2005.

FAO. FOOD AND AGRICULTURE ORGANIZATION. FAOSTAT-Top production of cow milk, whole, fresh. 2007. Disponível em: <http://faostat.fao.org/site/339/default.aspx>. Acesso em: 5 maio 2010.

FARIA, J. F. Situação da brucelose no Brasil. Comunicação Científica da Faculdade de Medicina Veterinária e Zootecnia da Universidade de São Paulo, São Paulo, v. 8, n. 2, p. 161-175, 1984.

FARINA, E. M. M. Q.; JANK, M. S.; NASSAR, A. M.; RIBEIRO, F. A. F. Leite clandestino: um problema real. Boletim do leite, ano 7, n. 81, p.1-3, 2000.

FAUSTINO, M. A. G.; LIMA, M. M.; ALVES, L. C.; SANTOS, A. L. G.; SANTANAM V. L. A. Causas de condenação à inspeção sanitária em abatedouro de bovinos da cidade de Valença, Rio de Janeiro. Revista Higiene Alimentar, São Paulo. v. 17, n. 108, p. 32-35, 2003.

FERNANDES, E. N.; BRESSAN, M.;VERNEQUE, R. S. Zoneamento da pecuária leiteira da região sul do Brasil. Ciência Rural, Santa Maria-RS, v. 34, n. 2, p. 485491, 2004.

FERNANDES JR., J. A. Inseminação artificial em gado de corte: impacto da equipe de inseminadores nos resultados obtidos. 2001. 87 f. Dissertação (Mestrado em Medicina Veterinária) - Faculdade de Ciências Agrárias e Veterinárias Campus Jaboticabal, Universidade Estadual Paulista, Jaboticabal, 2001.

FERRÃO, L.S. A produção de leite e o profissional veterinário na percepção de produtores de leite de São Leopoldo-MG, 1999. 2000. 47 p. Dissertação (Mestrado em Medicina Veterinária Preventiva) - Escola de Veterinária, Universidade Federal de Minas Gerais, Belo Horizonte, 2000.

FERRAZ, J. B. S. Impacto econômico na pecuária de leite e de corte do Brasil, como aumento da utilização da inseminação artificial. Revista Brasileira de Reprodução Animal, v. 20, p. 95-98, 1996.

FERREIRA, M.D.B.; LOPES, B.C. A experiência de Minas Gerais na produção de F1. In: SIMPÓSIO MINAS LEITE: ASPECTOS TÉCNICOS ECONÔMICOS E SOCIAIS DA ATIVIDADE LEITEIRA, 4., 2002, Juiz de Fora, MG. Juiz de Fora: Embrapa Gado de Leite, p.137-161, 2002.

FLETCHER, R. H.; FLETCHER, S. W.; WAGNER, E. H. Clinical epidemiology: the essentials. 2. ed. Baltimore: Williams \& Wilkins, 1998. 246 p.

FONTOURA, L. F. M. Macanudo Taurino: uma espécie em extinção? um estudo sobre o processo de modernização na pecuária da Campanha gaúcha. 2000. 300 p. Tese (Doutorado em Geografia Humana) - Instituto de Geografia, Universidade de São Paulo (USP), São Paulo, 2000. 
FOX, M. D.; KAUFMANN, A. F. Brucellosis in the United States, 1965-1974. Journal of Infectious Diseases, v. 136, p. 312-316, 1977.

FORNARA, D. A. TILMAN, D. Plant functional composition influences rates of soil carbon and nitrogen accumulation. Journal of Ecology, v. 9, p. 314-322, 2008.

FROIS, M. C. M. Caracterização das formas de organização da produção pecuária e das modalidades de ocorrência de febre aftosa nas mesorregiões homogêneas central mineira e oeste de Minas Gerais, 1980-1994. 1995. 101 p. Dissertação (Mestrado em Medicina Veterinária) - Escola de Veterinária, Universidade Federal de Minas Gerais, Belo Horizonte, 1995.

GARCIA, J. L.; NAVARRO, I. T.; OGAWA, L.; OLIVEIRA, R. C.; KOBILKA, E. Soroprevalência, epidemiologia e avaliação ocular da toxoplasmose humana na zona rural de Jaguapitã (Paraná), Brasil. Revista Panamericana de Salud Pública, v. 6, n. 3, 1999.

GARCIA-CARRILO, C. La brucellosis de los animales em América y su relación com La infección humana. Paris: Office Internacional dês Epizooties, 1987. 303 p.

GASQUES, J. G.; REZENDE, G. C.; VERDE, C. M. V.; CONCEIÇÃO, J. C. P. R.; CARVALHO, J. C. S.; SALERNO, M. S. Desempenho e crescimento do agronegócio no Brasil. Brasília: IPEA, 2004. Disponível em: <http://desafios2.ipea.gov.br/pub/td/2004/td_1009.pdf> Acesso em: 1 jun. 2010.

GOMES, S. T. Diagnóstico da pecuária leiteira no Estado de Minas Gerais em 2005: relatório de pesquisa. Belo Horizonte: FAEMG, 2006. 156 p.

GOMES, S. T. Diagnóstico e perspectivas da produção de leite no Brasil. In: Restrições técnicas, econômicas e institucionais ao desenvolvimento da cadeia produtiva do leite no Brasil. Brasília: MCT/CNPq/PADCT, Juiz de Fora: Embrapa Gado de Leite, 1999.

GOMES, S. T. Leite sem inspeção: novos números e a voz do consumidor. Balde Branco, São Paulo, v. 36, n. 429, p. 47-53, jul. 2000.

GOMES, S. T.; VILELA, D.; CALEGAR, G. M. Transformações da cadeia produtiva do leite no Brasil. Viçosa, MG: UFV/Departamento de Economia Rural, 1997. $20 \mathrm{p}$.

GONÇALVES, V. S. P.; DELFINO, M. K. V. C.; DIAS, R. A; FERREIRA, F.; AMAKU, M.; FERREIRA NETO, J. S.; FIGUEIREDO, V. C. F.; LÔBO, J. R. Situação epidemiológica da brucelose bovina no Estado de Minas Gerais. Arquivo Brasileiro de Medicina Veterinária e Zootécnica, v. 61, p. 35-45, 2009b. Suplemento 1.

GONÇALVES, V. S. P.; RIBEIRO, L. A.; CALDAS, R. A.; FRANCISCO, P. F. C; DIAS, R. A; FERREIRA, F.; AMAKU, M.; FERREIRA NETO, J. S.; FIGUEIREDO, V. C. F.; LÔBO, J.R. Situação epidemiológica da brucelose bovina no Distrito Federal. 
Arquivo Brasileiro de Medicina Veterinária e Zootécnica, v. 61, p.14-18, 2009a. Suplemento 1.

GOTTSCHALL, C. S.; MARQUES, P. R.; CANELLAS, L. C.; ALMEIDA, M. R. Aspectos relacionados à sincronização do estro e ovulação em bovinos de corte. A hora Veterinária, n. 164, 2008.

GOULART, I. L.; ALVES, P. A. P. M.; MORAES, A. F.; ARAÚJO, L. G. C.; JESUS, V. L. T. Comparação entre dois procedimentos para determinação do melhor momento de inseminação artificial em bovinos. Revista Brasileira Reprodução Animal, v. 26, p. 216-218, 2002.

GRECCO, F. B.; SCHILD, A. L.; QUEVEDO, P.; ASSIS-BRASIL, N. D.; KOMMERS, G. D.; PEREIRA, C. M.; SOARES, M. P. Pitiose cutânea em bovinos na região Sul do Rio Grande do Sul. Pesquisa Veterinária Brasileira, v. 29, n. 11, p. 938-942, 2009.

GUIMARÃES, J. D.; ALVES, G. A.; COSTA, E. P. Eficiências reprodutivas e produtivas em vacas das Raças Gir, Holandês e cruzados Holandês × Zebu. Revista Brasileira de Zootecnia, v. 31, n. 2, p. 641-647, 2002.

HELFAND, S. M.; REZENDE, G. C. Região e espaço no desenvolvimento agrícola brasileiro. Rio de Janeiro: IPEA. 2003. cap. 4 p. 173-212.

HOLANDA JR., E. V.; GOMES, K. P. L. Grau de especialização e margem líquida da renda da atividade leiteira em Minas Gerais.In: ENCONTRO DE PESQUISA DA ESCOLA DE VETERINÁRIA DA UFMG, 16, 1998. Anais... Belo Horizonte, p. 195, 1998.

HOLMAN, F. Evaluación económica de sistemas de producción de leche en el trópico. Archivos Latinoamericanos de Producción Animal, v. 6, n. 1, p. 1931.Suplemento 1, 1998.

HUMPHREYS, L. R. Tropical forages: their hole in sustentainable agriculture. Esses, UK: Longman Scientific \& Technical, 1994, 414p.

IBGE. INSTITUTO BRASILEIRO DE GEOGRAFIA E ESTATÍSTICA. Censo agropecuário 2006: Brasil, grandes regiões e unidades da federação, Rio de Janeiro, 2006, p. 1-777. Disponível em: <www.agricultura.gov.br>. Acesso em 6 maio 2010.

IBGE. INSTITUTO BRASILEIRO DE GEOGRAFIA E ESTATÍSTICA. Divisão regional do Brasil em mesorregiões. 2010. Disponível em: <http://www.ibge.gov.br/home/geociencias/cartogramas/mesorregiao.html>. Acesso em: 6 maio 2010.

IBGE. INSTITUTO BRASILEIRO DE GEOGRAFIA E ESTATístiCA. Produção Pecuária Municipal. 2004 Rio de Janeiro, v. 32, p.1-35. Disponível em: <www.ibge.gov.br>. Acesso em: 31 maio 2010 
IBGE. INSTITUTO BRASILEIRO DE GEOGRAFIA E ESTATÍSTICA. Produção Pecuária Municipal. 2008 Rio de Janeiro, v. 36, p.1-55. Disponível em: <www.ibge.gov.br>. Acesso em: 31 maio 2010

IBGE. INSTITUTO BRASILEIRO DE GEOGRAFIA E ESTATÍSTICA. Sistema IBGE de recuperação automática. Peso total das carcaças de bovinos abatidos em $2005 . \quad$ Disponível em: <http://www.sidra.ibge.gov.br/bda/ tabela/listabl.asp?c=606\&z=t\&o=20>. Acesso em: 5 maio 2010.

IBGE. INSTITUTO BRASILEIRO DE GEOGRAFIA E ESTATÍSTICA. Sistema IBGE de recuperação automática. Área dos estabelecimentos por grupos de área total e utilização das terras. 2006b. Disponível em: $<$ http://www.sidra.ibge.gov.br/bda/tabela/listabl3.asp?c=316\&n=0\&u=0\&z=t\&o=20\&i= P>. Acesso em: 6 maio 2010.

JANK, M. S.; GALAN, V. B. Competitividade do sistema agroindustrial do leite. São Paulo: USP-PENSA, $1999 . \quad$ Disponível em: <http://www.fundacaofia.com.br/pensa/pdf/relatorios/ipea/Vol_II_Leite.PDF> Acesso: 27 maio 2010.

JOSAHKIAN, L. A.; MACHADO, C. H. C. Manual do programa de melhoramento genético das raças zebuínas. Uberaba: $A B C Z, 1998.96$ p.

JUNIOR, A. B.; REIS, R. P.; REIS, A. J. Estrutura de mercado de produtos lácteos no município de Lavras, MG. Organizações Rurais e Agroindustriais. v. 03, n. 2, 2001.

JUNQUEIRA, J. R. C.; ALFIERI, A. A. Falhas da reprodução na pecuária de corte com ênfase para as causas infecciosas. Semina: Ciências Agrárias, Londrina, v. 27, n. 2, p. 289-298, 2006.

KLEEBURG, H.H. Tuberculosis and other mycobacteriosis. In: HUBBERT, W. T.; MCCULLOCK, W. F.; SCHNURRENBERGER, P. R., (Ed.) Diseases transmitted from animals to man. 6. ed. Springfield, Ill: Charles C Thomas Publisher; 1975. p. 315.

KLEIN-GUNNEWIEK, M. F. C.; AMAKU, M.; DIAS, R. A.; FERREIRA, F.; GITTI, C. B.; PEREIRA, L. A.; FIGUEIREDO, V. C. F.; LÔBO, J. R.; GONÇALVES, V. S. P.; FERREIRA NETO, J. S. Situação epidemiológica da brucelose bovina no Estado do Rio de Janeiro. Arquivo Brasileiro de Medicina Veterinária e Zootécnica. v. 61, p. 77-84, 2009. Suplemento 1.

KOMATSU, R.S. Origem dos queijos minas artesanais produzidos em Uberlândia-MG e ocorrência de Staphylococcus coagulase positiva. 2008. 39 p. Dissertação (mestrado) - Faculdade de Medicina Veterinária, Universidade Federal de Uberlândia, Uberlândia, 2008.

LEAL, A. B. M.; LEAL, A. T.; SANTURIO, J. M.; KOMMERS, G. D.; CATTO, J. B. Pitiose eqüina no Pantanal brasileiro: aspectos clínico-patológicos de casos típicos e atípicos. Pesquisa Veterinária Brasileira, v. 21, n. 4, p. 151-156, 2001. 
LEITE, R. C. Controle da diarréia bovina a vírus (DBV) e rinotraqueíte infecciosa bovina (IBR). Revista Brasileira de Reprodução Animal, Belo Horizonte, v. 23, n. 4, p. 531- 535, 1999.

LEME, P.R. Desempenho em confinamento e características de carcaça de bovinos machos de diferentes cruzamentos abatidos em três faixas de peso. Revista Brasileira de Zootecnia, v. 29, n. 6, p. 2347-2353, 2000. Suplemento.

LILENBAUM, W. Atualização em leptospiroses bovinas. Revista Brasileira de Medicina Veterinária, Rio de Janeiro, v.18, n. 1, p. 9-13, 1996.

LIMA, M. A. Agropecuária brasileira e as mudanças climáticas globais: caracterização do problema, oportunidades e desafios. Cadernos de Ciência \& Tecnologia, Brasília, v. 19, n. 3, p. 451-472, 2002.

LOPES, M. A.; MAGALHÃES, G. P. Análise da rentabilidade da terminação de bovinos de corte em confinamentos: um estudo de caso. Arquivo Brasileiro de Medicina Veterinária e Zootecnia, Belo Horizonte, v. 57, n. 3, p. 374-379, 2005.

LOPES, M. A.; SANTOS, G. dos; ROSA, L. V.; LOPES, N. M. Rentabilidade da terminação em confinamento de bovinos de corte castrados e não castrados. Boletim da Indústria Animal, Nova Odessa, v. 62, n. 4, p. 289-294, 2005.

MACIEL, J. F.; CARVALHO, E. A.; SANTOS, L. S.; ARAÚJO, J. B. de; NUNES, V. S. Qualidade microbiológica de leite cru comercializado em Itapetininga-BA. Revista Brasileira de Saúde e Produção Animal, v. 9, n. 3, p. 443-448, 2008.

MACHADO, S. G. Marcadores moleculares associados a características de importância econômica em bovinos da raça Girolando. 2001. 103 f. Tese (Doutorado em Genética) - Faculdade de Medicina de Ribeirão Preto, Universidade de São Paulo, Ribeirão Preto, 2001.

MADALENA, F. E. A cadeia do leite no Brasil. In: Produção de Leite e Sociedade MADALENA, F. E; MATOS, L. L; HOLANDA JR., E. V. (Ed.). Belo Horizonte: FEPMVZ, 2001a. p. 1-26.

MADALENA, F. E. Economic evaluation of breeding objectives for milk and beef production in tropical enviroments. In: WORLD CONGRESS ON GENETICS APPLIED TO LIVESTOCK PRODUCTION, 3., 1986, Lincoln, NA: Proceedings... Lincoln, WCGALP, v.9, p.33-43, 1986.

MADALENA, F. E. Produção de carne com mestiços de raças leiteiras. In: SIMPÓSIO DE PRODUÇÃO DE GADO DE CORTE, 2001 Viçosa, MG, Anais... Viçosa: Simpósio de Produção de Gado de Corte, 2., 2001b. Disponível em: <http://www.simcorte.com/index/Palestras/s_simcorte/08_madalena.PDF>. Acesso em: 21 maio 2010.

MARTHA JÚNIOR, G. B.; VILELA, L.; BARIONI, L. G.; SOUSA, D. M. G. de; BARCELLOS, A. O. Manejo da adubação nitrogenada em pastagem. In: SIMPÓSIO 
SOBRE MANEJO DA PASTAGEM, 21., 2004, Piracicaba. Anais...Piracicaba: Fundação de Estudos Agrários Luiz de Queiroz, 2004. p.155-215.

MARQUES, A. P.; CORREA, F. R.; SOARES, M. P.; ORTOLANI, E. L.;GIULIODORI, M. J. Mortes súbitas em bovinos associadas à carência de cobre. Pesquisa Veterinária Brasileira. v. 23 n.1, p. 21-32, 2003.

MELO, A. D. S.; REIS, R. P. Tanques de expansão e resfriamento de leite como alternativa de desenvolvimento regional para produtores familiares. Organizações Rurais \& Agroindustriais. Lavras-MG, v. 9, n. 1, p. 111-122, 2007.

MARTIN, M. L.; SHIPMAN, L. D.; WELLS, J. G. Isolation of Escherichia coli 0157:H7 from dairy cattle associated with two cases of haemolytic uraemic syndrome [letter]. Lancet. 1986; v. 2, p. 1043.

MARTINEZ, M. L.; YAMAGUCHI, L. C. T.; VERNEQUE, R. S. Aplicativo para cálculo do custo da monta natural e da inseminação artificial em bovinos, Embrapa/CNPGL/ASBIA, 2004. Disponível em: http://www.asbia.org.br/download/gado_leite/manual_usuario.pdf >. Acesso em: 13 de maio de 2010.

MARVULO, M. F. V.; FERREIRA, F.; DIAS, R. A.; AMAKU, M.; GROFF, V. S. P.; GONÇALVES, V. S. P.; FIGUEIREDO, V. C. F.; LÔBO, J. R.; FERREIRA NETO, J. S. Situação epidemiológica da brucelose bovina no Estado do Rio Grande do Sul. Arquivo Brasileiro de Medicina Veterinária e Zootécnica, v. 61, p. 93-102, 2009 Suplemento 1.

MÉDICI, K. C.; ALFIERI, A. A.; ALFIERI, A. F. Prevalência de anticorpos neutralizantes contra o herpesvírus bovino tipo 1, decorrente de infecção natural, em rebanhos com distúrbios reprodutivos. Ciência Rural, Santa Maria, v. 30, n. 2, p. 347-350, 2000.

MICHELS, I. L.; SPROESSER, R. L.; MENDONÇA, C. G. Cadeia produtiva da carne bovina de Mato Grosso do Sul. Campo Grande: Oeste, 2001.

MONTENEGRO, J.; ABARCA, S. Fijación de carbono, emisión de metano y oxido nitroso en sistemas de produción bovina en Costa Rica. In: Intensificación de la ganaderia em Centroamérica - benefícios economicos y ambientales. CATIEFAO-SIDE. Editado por Nuetra Terra, 2000, 334 p.

NASCIMENTO, M. G. F.; D'ANGELIS, F. H. F.; NASCIMENTO, E. R.; RESENDE, O. A. Envolvimento de micoplasmas em vacas com distúrbios reprodutivos, Acta Scientiae Veterinariae, v. 33, n. 2, p. 195-199, 2005.

NEGREIROS, R. L.; DIAS, R. A; FERREIRA NETO, J. S.; GONÇALVES, V. S. P.; SILVA, M. C. P.; FIGUEIREDO, V. C. F.; LÔBO, J. R.; FREITAS, J.; AMAKU, M. Situação epidemiológica da brucelose bovina no Estado de Mato Grosso. Arquivo Brasileiro de Medicina Veterinária e Zootécnica. v. 61, p. 56-65, 2009. Suplemento 1. 
NICOLETTI, P. The epidemiology of bovine brucellosis. Advances in Veterinary Science and Comparative Methods, v. 24, p. 69-98, 1980.

NICOLOSO, R. S.; LOVATO, T.; AMADO, T. J. C.; BAYER, C.; LANZANOVA, M. E. Balanço do carbono orgânico no solo sob integração lavoura-pecuária no sul do Brasil. Revista Brasileira de Ciência do Solo, v. 32, p. 2425-2433, 2008.

NOORDHUIZEN, J. P. T. M.; FRANKENA, K.; VAN DER HOOFD, C. M.; GRAAT, E. A. M. Application of quantitative methods in veterinary epidemiology. Wageningen: Wageningen Press, 1997. 445 p.

OBIAGA, J. A.; ROSENBERG, F. J.; ASTUDILlO, V. M., GOIÉ, R. Las caracteristicas de la producción pecuaria como determinantes de los ecossistemas de fiebre aftosa. Boletim del Centro Panamericano de Fiebre Aftosa, v. 33-34, p. 33-42, 1979.

O'DONOVAN, P. B.; SILVA, J. M.; EUCLIDES, V. P. B. Nutritions value of Brachiaria decumbens and native pasture harvested in several maturing stages. Embrapa Gado de Corte, Campo Grande, 1979. (Embrapa Gado de Corte - Comunicado Técnico 22). Disponível em: <http://www.cnpgc.embrapa.br/publicacoes/cot/COT03.html.>. Acesso em: 6 maio 2010.

OGATA, R. A.; GONÇALVES, V. S. P.; FIGUEIREDO, V. C. F.; LÔBO, J. R.; RODRIGUES, A. L.; AMAKU, M.; FERREIRA, F.; FERREIRA NETO, J. S.; DIAS, R. A. Situação epidemiológica da brucelose bovina no Estado do Tocantins. Arquivo Brasileiro de Medicina Veterinária e Zootécnica, v. 61, p. 126-134, 2009. Suplemento 1.

OLIVEIRA NETO, O. J.; LIMA, J.J.; CÉSAR, V. A. M.; REZENDE, S. O.; DREES, C. Diagnóstico organizacional de uma propriedade rural especializada em cria de bovinos de corte no estado do Tocantins - Brasil. In: XLVI CONGRESSO SOCIEDADE BRASILEIRA DE ECONOMIA, ADMNISTRAÇÃO E SOCIOLOGIA RURAL, 2008, Rio Branco, Anais...: Sociedade Brasileira de Economia, Administração e Sociologia Rural. Disponível em: <http://www.sober.org.br>. Acesso em: 31 maio 2010.

OLIVEIRA, S. M.; FILHA, E. S. Fasciolose hepática. Revista do Instituto Biológico, São Paulo, v. 71, n. 1, p. 5-7, 2009.

OLIVEIRA, N.M.S.; NASCIMENTO, L.C.; FIORINI, J.E. Isolamento e identificação de bactérias facultativas mesofílicas em carnes frescas bovinas e suínas. Revista Higiene Alimentar, São Paulo, v. 16, n. 91, p. 68-74, 2002.

OLIVEIRA, M. N.; ALMEIDA, S. C. R.; SILVA, F. A. M. Tanques coletivos de resfriamento de leite: impactos na inserção no mercado e no aumento da renda da agricultura familiar em Unaí-MG. In: SIMPÓSIO NACIONAL DO CERRADO. DESAFIOS E ESTRATÉGIAS PARA O EQUILÍBRIO ENTRE SOCIEDADE, AGRONEGÓCIO E RECURSOS NATURAIS, 9., Brasília, DF. 2008. Disponível em: <www.cpac.embrapa.br/download/610/t>. Acesso em 11 maio 2010. 
OLASCOAGA, R. C.; ROSENBERG, F. J.; ASTUDILLO, V. M. La producción y la salud animal y sus iterrrelaciones con la salud pública veterinária en América Latina $y$ el Caribe. Scientific and Technical Review of the Office International des Epizooties, v. 10, n. 4, p. 1087-1100, 1991.

PAIVA, A. O.; FARIA, G. E. Estoque de carbono no solo sob cerrado sensu strictu no Distrito Federal, Brasil, Revista Trópica - Ciências Agrárias e Biológicas, v. 1, n. 1, p. 59, 2007.

PARRY, W. H. Milk-borne diseases. Lancet. v. 2, p. 216-219, 1966.

PICININ, L. C. A. Qualidade do leite e da água de algumas propriedades leiteiras de Minas Gerais. 2003. 89 p. Dissertação (Mestrado em Medicina Veterinária Preventiva) - Escola de Veterinária, Universidade Federal de Minas Gerais, Belo Horizonte, 2003.

PINTO, C. L. O.; MARTINS, M. L.; VANETTI, M. C. D. Qualidade microbiológica de leite cru refrigerado e isolamento de bactérias psicrotróficas proteolíticas. Ciência e Tecnologia de Alimentos, Campinas, v. 26, n. 3, p. 645-651, 2006.

PELLEGRIN, A. O.; GUIMARÃES, P. H. D. A. S.; SERENO, J. R. B.; FIGUEIREDO, J. P.; LAGE, A. P.; MOREIRA, E. C.; LEITE, R. C. Prevalência da leptospirose em bovinos do Pantanal mato-grossense. Embrapa Pantanal, 2009. (Embrapa PantanalComunicado Técnico 22). Disponível em: <http://www.cpap.embrapa.br/publicacoes/online/COT22.pdf >. Acesso em 22 maio 2010.

PEREZ G. C.; VASCONCELOS, J. L. M.; SANTOS, R. M.; LIMA, F. S.; PEREIRA, E. T. N. Avaliação de protocolos de inseminação artificial em tempo fixo utilizando MGA em vacas Nelores paridas. Revista Brasileira de Reprodução Animal, v. 27, p. 428-430, 2003.

POESTER, F. P.; GONÇALVES, V. S. P.; LAGE, A. P. Brucellosis in Brazil. Veterinary Microbiology, v. 90, n. 1-4. p. 55-62, 2002.

PRADO, E. Características sócio-econômicas e sanitárias da pecuária bovina leiteira do município de Divinópolis/MG. 1989. 145p. Dissertação (Mestrado em Medicina Veterinária) - Escola de Veterinária, Universidade Federal de Minas Gerais, Belo Horizonte, 1989.

RAMíREZ C. E., MATTIOLI G. A., TITTARELLI C. M., GIULIODORI M. J.; YANO H. Cattle hypocuprosis in Argentina associated with periodically flooded soils. Livestock Production Science, v. 55, p. 47-52, 1998

REIS, R. P.; MEDEIROS, A. L.; MONTEIRO, L. A. Custos da produção da atividade leiteira na região sul de Minas Gerais. Disponível em: <http://ageconsearch.umn.edu/bitstream/43379/2/revista_v3_n2_juldez_2001_5.pdf>. Acesso em: 11 maio 2010. 
RESTLE, J. Substituição do grão de sorgo por casca de soja na dieta de novilhos terminados em confinamento. Revista Brasileira de Zootecnia, Viçosa, v. 33, n. 4, p. 1009-1015, 2004.

RICHTZENHAIN, L. J.; ALFIERI, A. A.; LEITE, R. C.; WEIBLEN, R.; MORO, E.; UMEHARA, O. Pesquisa de anticorpos séricos contra o herpesvírus bovino tipo $1 \mathrm{em}$ fêmeas de propriedades com histórico de problemas reprodutivos, localizadas em 21 estados brasileiros. Arquivo do Instituto Biológico, São Paulo, v. 66, p. 127, 1999. Suplemento 1.

ROCHA, M. A.; GOUVEIA, A. M. G.; LEITE, R. C. O vírus da IBR e a inseminação artificial em bovinos. Revista Brasileira de Reprodução Animal, Belo Horizonte, v. 22, n. 2, p. 70-73, 1998.

ROCHA, W. V.; GONÇALVES, V. S. P.; COELHO, C. G. N. F. L.; BRITO, W. M. E. D.; DIAS, R. A; DELFINO, M. K. V. C.; FERREIRA, F.; AMAKU, M.; FERREIRA NETO, J. S.; FIGUEIREDO, V. C. F.; LÔBO, J. R.; BRITO, L. A. B. Situação epidemiológica da brucelose bovina no Estado de Goiás. Arquivo Brasileiro de Medicina Veterinária e Zootécnica, v.61, p.27-34, 2009. Suplemento 1.

RODRIGUES, A. L.; BEZZI, M. L. As transformações socioeconômicas e a permanência do latifúndio na microrregião geográfica da Campanha Central. IN: SIMPÓSIO NACIONAL DE GEOGRAFIA AGRÁRIA, 3., 2005, Presidente Prudente, SP, Disponível em: $<$ http://www4.fct.unesp.br/nera/publicacoes/singa2005/Trabalhos/Artigos/Aline\%20de \%20Lima\%20Rodrigues.pdf>. Acesso em: 21 maio 2010.

ROSENBERG, F. J. GÓIC, R. M. Programas de controle e prevención de la fiebre aftosa em las Américas. Boletim del Centro Panamericano de Fiebre Afotsa. Rio de Janeiro, n. 12, p. 1-22, 1973.

SALTON, J.; MIELNICZUK, J.; BAYER, C. Agregação e estabilidade de agregados do solo em sistemas agropecuários em Mato Grosso do Sul. Revista Brasileira de Ciência do Solo, v. 32, p.11-21, 2008.

SCHUCHAT, A.; SWAMINATHAN, B.; BROOME, C. V. Epidemiology of human listeriosis. Clinical Microbiology Reviews, v.4, p. 169-183, 1991.

SEVERO, C. M.; MIGUEL, L. A. A Sustentabilidade dos Sistemas de Produção de Bovinocultura de Corte do Estado do Rio Grande do Sul. IN: REDES, Universidade de Santa Cruz do Sul (UNISC), v. 11, n.3, Santa Cruz do Sul: Editora da UNISC, p. $213-234,2006$.

SIKUZAWA, S.; AMAKU, M.; DIAS, R. A.; FERREIRA NETO, J. S.; MARTINS, C.; GONÇALVES, V. S. P.; FIGUEIREDO, V. C. F.; LÔBO, J. R.; FERREIRA, F. Situação epidemiológica da brucelose bovina no Estado de Santa Catarina. Arquivo Brasileiro de Medicina Veterinária e Zootécnica, v.61, p.103-108, 2009. Suplemento 1. 
SILVA, A. S.; COSTA E SILVA, E. V.; NOGUEIRA, E.; ZÚCCARI, C. E. S. N. Avaliação do custo/benefício da inseminação artificial convencional e em tempo fixo de fêmeas bovinas pluríparas de corte. Revista Brasileira de Reprodução Animal, Belo Horizonte, v.31, n.4, p.443-455, 2007.

SILVA, V. G. S. O.; DIAS, R. A.; FERREIRA, F.; AMAKU, M.; COSTA, E. L. S.; LÔBO, J. R.; FIGUEIREDO, V. C. F.; GONÇALVES, V. S. P.; FERREIRA NETO, J. S. Situação epidemiológica da brucelose bovina no Estado de Sergipe. Arquivo Brasileiro de Medicina Veterinária e Zootécnica, v.61, p.109-117, 2009 Suplemento 1.

SILVA, V. G. S. O. Situação epidemiológica da brucelose bovina no Estado de Sergipe. 2008. 56p. Dissertação (Mestrado em Epidemiologia Experimental Aplicada às Zoonoses) - Faculdade de Medicina Veterinária e Zootecnia, Universidade de São Paulo, 2008.

SPSS INC. SPSS base 9.0. Chicago, 1999b. 1 CD-Rom.

SPSS INC. Spss base 9.0 user's guide. Chicago: SPSS Inc., 1999a. 740 p.

SOUZA, D. M. G. de; VILELA, L.; REIN, T. A.; LOBATO, E. Eficiência da adubação fosfatada em dois sistemas de cultivo em latossolo de Cerrado. In: CONGRESSO BRASILEIRO DE CIÊNCIA DO SOLO, 26, 1997, Rio de Janeiro, Anais... Rio de Janeiro: Sociedade Brasileira de Ciência do Solo, 1997, p.57-60.

TAKIUCHI, E.; ALFIERI, A.F.; ALFIERI, A. A. Herpesvírus bovino tipo 1: Tópicos sobre a infecção e métodos de diagnóstico. Semina: Ciências Agrárias, Londrina, v. 22, n. 2, p. 203-209, 2001.

TAYLOR, P. R.; WEINSTEIN, W. M. BRYNER, J. H. Campylobacter fetus infection in human subjects: association with raw milk. The American Journal of Medicine. $v$. 66 , p. $779-783,1979$.

TAYLOR, D. N.; BIED, J. M.; MUNRO, J. S.; FELDMAN, R. A. Salmonella dublin infections in the United States, 1979-1980. The Journal of Infectious Diseases.v. 146, p. 322-327, 1982.

TEIXEIRA, R. I. Caracterização das formas de produção pecuária bovina leiteira de Santos Dumont/MG. 1989. 61f. Dissertação (Mestrado em Medicina Veterinária) - Escola de Veterinária, Universidade Federal de Minas Gerais, Belo Horizonte, 1989.

THRUSFIELD, M. Veterinary epidemiology. 2. ed. Cambridge: Blackwell Science, 1995. $479 \mathrm{p}$.

TOWNSEND, M. R.; RESTLE, J.; SANCHEZ, L. M. B. Desempenho de animais com diferentes idades em regime de confinamento. In: REUNIÃO ANUAL DA SOCIEDADE BRASILEIRA DE ZOOTECNIA, 24.; 1988, Viçosa, MG. Anais... Viçosa, MG: Sociedade Brasileira de Zootecnia, 1988. p. 283. 
UNIVERSITY OF GUELPH. Herdacc version 3, 1995. Disponível em: <http://www.vetschools.co.uk/EpiVetNet/files/herdacc.exe>. Acesso em: 15 maio2010.

VALLE, E.R.do; ANDREOTTI, R.; THIAGO, L. R. L. S. Estratégias para aumento da eficiência reprodutiva e produtiva em bovinos de corte. Campo Grande: EMBRAPACNPGC, 1998. 80p. (EMBRAPA-CNPGC. Documentos, 71).

VASCONCELLOS, S. A.; ITO, F. H.; CÔRTES, J. A. Bases para a prevenção da brucelose animal. Comunicação Científica da Faculdade de Medicina Veterinária e Zootecnia da Universidade de São Paulo, São Paulo, v. 11, n. 1, p. 25-36, 1987.

VIANA, F. C.; CRUZ, F. E. R.; LAENDER, F. C. Diagnóstico de situação da produção bovina do leite do município de Sete Lagoas, Minas Gerais. Arquivo Brasileiro de Medicina Veterinária e Zootecnia, v. 39, p. 699-717, 1987.

VILELA, D.; BRESSAN, M. Restrições técnicas, econômicas e institucionais ao desenvolvimento da cadeia produtiva do leite no Brasil. Brasília: MCT/CNPq/PADCT, 1999. $211 \mathrm{p}$.

VILLAR, K. S.; AMAKU, M.; DIAS, R. A.; FERREIRA NETO, J. S.; BENITEZ, F.; GONÇALVES, V. S. P.; FIGUEIREDO, V. C. F.; LÔBO, J. R.; FERREIRA, F. Situação epidemiológica da brucelose bovina no Estado de Rondônia. Arquivo Brasileiro de Medicina Veterinária e Zootécnica, v.61, p.85-92, 2009. Suplemento 1.

ZAR, J.H. Biostatistical analysis. 3ed. New Jersey: Prentice Hall, 1999, 613p.

ZIMMER, A. H.; BARBOSA, R. A. Manejo de pastagens para produção sustentável. Anais do ZOOTEC 2005, Campo Grande, MS. Disponível em: <http://www.ufrrj.br/posgrad/cpz/forragem/9.pdf>. Acesso em: 21 maio 2010.

ZOCCAL, R.; ASSIS, A. G.; EVANGELISTA, S. R. M. Distribuição geográfica da pecuária leiteira na Brasil. Circular Técnica, Juiz de Fora: Embrapa Gado de Leite, MG, n. 88, p. 01-08, 2006.

ZOTTELE, A.; TAMAYO, H.; BRIEVA, S.; IRIARTE, L. Family production animalhealth strategies. Boletim del Centro Panamericano de Fiebre Aftosa, v.59, p.5564, 1993. 


\section{ANEXO A - QUESTIONÁRIO EPIDEMIOLÓGICO APLICADO NAS PROPRIEDADES AMOSTRADAS.}

(Continua)

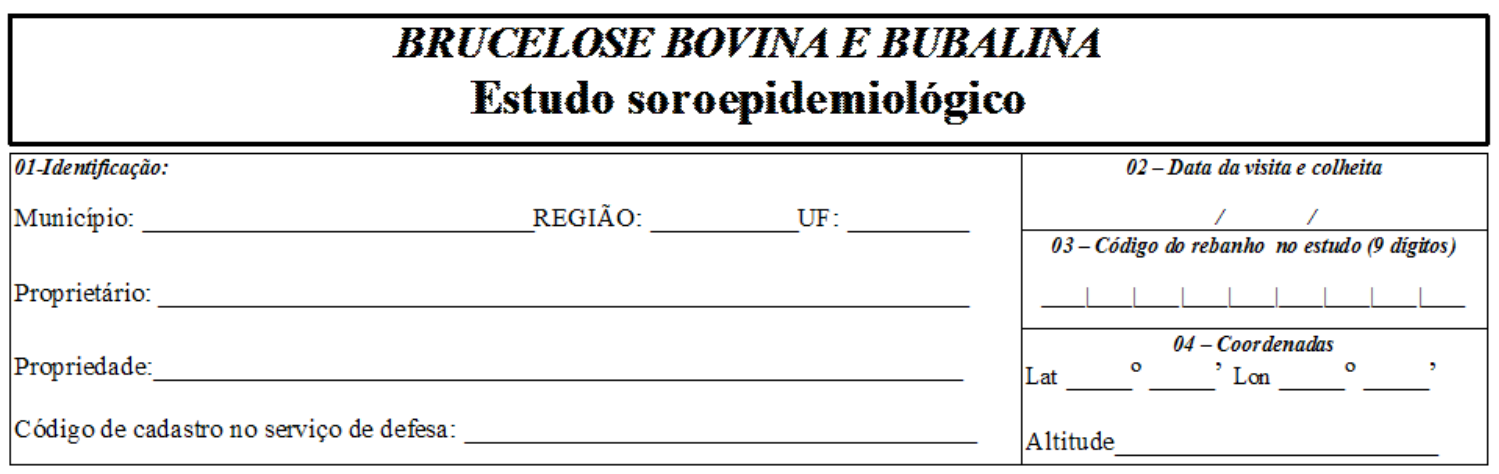

05- Tipo da Exploração: $\square$ corte $\square$ leite $\square$ mista

06- Tipo de Criação: $\square$ confinado $\square$ semi-confinado $\square$ extensivo

07- $\mathbf{N}^{0}$ de Ordenhas por dia: $\square 1$ ordenha $\square 2$ ou 3 ordenhas $\square$ Não ordenha

08- Tipo de Ordenha: $\square$ manual $\square$ mecânica ao pé $\square$ mecânica em sala de ordenha $\square$ Não ordenha

09- Produção de leite: a) $\mathrm{N}^{0}$ de vacas em lactação:

b) Produção diária de leite na fazenda: __ litros

10- Usa inseminação artificial? $\square$ não $\square$ usa inseminação artificial e touro $\square$ usa só inseminação artificial

11- Raça predominante - Bovinos: $\square$ zebu $\square$ europeu de leite $\quad \square$ europeu de corte $\square$ mestiço $\square$ outras raças - Bubalinos: $\square$ murrah $\square$ mediterrâneo $\square$ carabao $\square$ jaffarabadi $\square$ outras raças

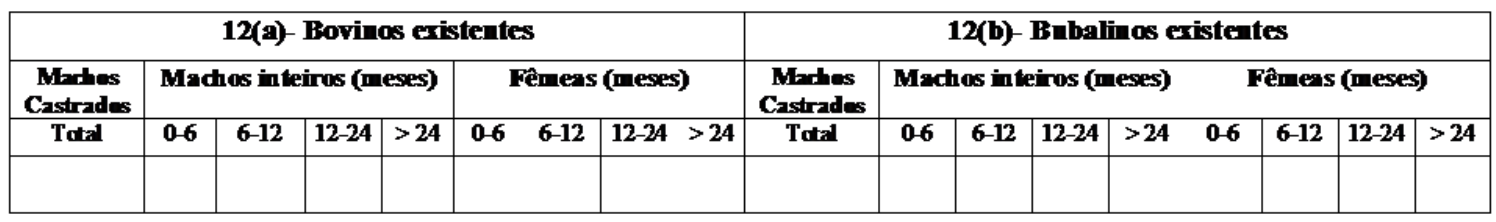

13- Outras espécies na propriedade: $\square$ ovinos/caprinos $\square$ equídeos $\square$ suínos $\square$ aves $\square$ cão $\square$ gato

14- Espécies silvestres em vida livre na propriedade: $\square$ não tem $\square$ cervídeos $\square$ capivaras $\square$ outras:.

15- Alguma vaca/búfala abortou nos últimos 12 meses? $\square$ não $\square$ sim $\square$ não sabe

16- O que faz com o feto abortado e a placenta? $\square$ enterra/joga em fossa/queima $\square$ alimenta porco/cão $\square$ não faz nada

17- Faz testes para diagnóstico de brucelose? $\square$ não $\square$ sim

Regularidade dos testes: $\quad \square$ uma vez ao ano $\quad \square$ duas vezes ao ano $\square$ quando compra animais

$\square$ quando há casos de aborto na fazenda $\square$ quando exigido para trânsito/eventos/crédito

18- Compra fêmeas ou machos com finalidade de reprodução? $\square$ não $\square$ sim

Onde/de quem: $\square$ em exposição $\square$ em leilão/feira $\square$ de comerciante de gado $\square$ diretamente de outras fazendas

19- Vende fêmeas ou machos para reprodução? $\square$ não $\square$ sim

A quem/onde: $\square$ em exposição $\square$ em leilão/feira $\square$ a comerciante de gado $\square$ diretamente a outras fazendas

20- Vacina contra brucelose? $\square$ não $\square$ sim, apenas fêmeas até 8 meses de idade $\square$ sim, fêmeas de qualquer idade

21- Local de abate das fêmeas e machos adultos no fim da vida reprodutiva:

$\square$ na própria fazenda $\square$ em estabelecimento sem inspeção veterinária

$\square$ em estabelecimento de abate com inspeção veterinária $\square$ não abate

22- Aluga pastos em alguma época do ano? $\square$ não $\square \operatorname{sim}$

23- Tem pastos em comum com outras propriedades? $\square$ não $\square$ sim

24- Existem na propriedade áreas alagadiças às quais o gado tem acesso? $\square$ não $\quad \square$ sim

25- Tem piquete separado para fêmeas na fase de parto e/ou pós-parto? $\square$ não $\quad \square \operatorname{sim}$

26- A quem entrega leite? $\square$ cooperativa $\square$ laticínio $\square$ direto ao consumidor $\square$ não entrega

27- Resfriamento do leite: $\square$ não faz $\square$ faz Como: $\square$ em resfriador ou tanque de expansão próprio

$\square$ em resfriador ou tanque de expansão coletivo

28- A entrega do leite é feita a granel? $\square$ não $\square \operatorname{sim}$

29- Produz queijo e/ou manteiga na propriedade? $\square$ não $\square$ sim Finalidade: $\square$ p/ consumo próprio $\square$ p/ venda

30- Consome leite cru? $\square$ não $\square$ sim

31-Tem assistência veterinária? $\square$ não $\square \operatorname{sim}$ De que tipo? $\square$ veterinário da cooperativa $\square$ veterinário particular 
(Conclusão)

\begin{tabular}{|c|c|c|c|c|c|c|c|c|c|c|c|c|}
\hline \multicolumn{9}{|c|}{32 -INFORMAÇÕES SOBRE AS AMOSTRAS COLHIDAS } & \multicolumn{4}{|c|}{33 - RESULTADOS LABORATORLAIS (3) } \\
\hline $\mathrm{s}^{\circ}$ & $\begin{array}{l}\text { NÚMF RO DO FRASCO } \\
\text { Cód. do estudo + } \mathrm{N}^{\circ} \text { sequêncial } \\
\text { (11 d digitos) }\end{array}$ & $\begin{array}{c}\text { Espécie } \\
\text { (1) }\end{array}$ & $\begin{array}{l}\text { Idade } \\
\text { (anos) }\end{array}$ & $\begin{array}{c}N^{\circ} \text { de } \\
\text { pariçōes }\end{array}$ & 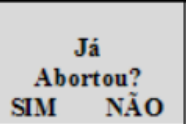 & BRU. & $\begin{array}{l}\text { VACINAS (2) } \\
\text { LEP. IBR }\end{array}$ & BVD & $\mid \begin{array}{c}\text { AAT } \\
(-) \text { ou }(+)\end{array}$ & $\begin{array}{c}\text { SAL } \\
\text { (Título) }\end{array}$ & $\begin{array}{l}\text { 2-MF } \\
\text { (Titulo) }\end{array}$ & $\begin{array}{c}\text { Resultado Final } \\
\text { (NEG) (INC) (POS) }\end{array}$ \\
\hline 1 & & & & & & & & & & & & \\
\hline 2 & & & & & & & & & & & & \\
\hline 3 & & & & & & & & & & & & \\
\hline 4 & & & & & & & & & & & & \\
\hline 5 & & & & & & & & & & & & \\
\hline 6 & & & & & & & & & & & & \\
\hline 7 & & & & & & & & & & & & \\
\hline 8 & & & & & & & & & & & & \\
\hline 9 & & & & & & & & & & & & \\
\hline 10 & & & & & & & & & & & & \\
\hline 11 & & & & & & & & & & & & \\
\hline .2 & & & & & & & & & & & & \\
\hline 13 & & & & & & & & & & & & \\
\hline 14 & & & & & & & & & & & & \\
\hline 15 & & & & & & & & & & & & \\
\hline
\end{tabular}

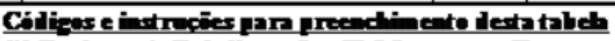

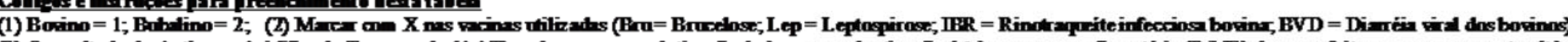

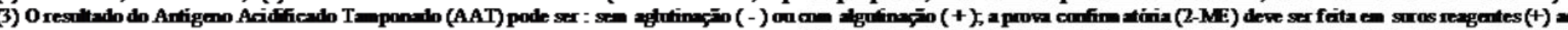

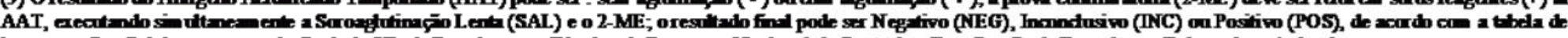

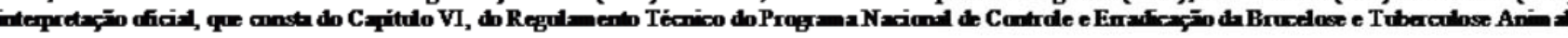

34 - RESULTADO FINAL - CLASSIFICAÇĀO DA PROPRIEDADE: $\quad \square$ NEGATIVA $\square$ INCONCLUSIVA $\square$ POSITIVA 
ANEXO B - MANUAL DE PROCEDIMENTOS DO INQUÉRITO SOROEPIDEMIOLÓGICO DA BRUCELOSE

Serviço Público Federal

Ministério da Agricultura, Pecuária e Abastecimento

Secretaria de Defesa Agropecuária

DEPARTAMENTO DE DEFESA ANIMAL

MANUAL DE PROCEDIMENTOS

BRASÍLIA - DF

NOVEMBRO - 2001 


\section{1- APRESENTAÇÃO E OBJETIVOS}

O inquérito soroepidemiológico da brucelose tem como objetivo geral auxiliar as Unidades Federativas na planificação de estratégias e ações de controle e erradicação da brucelose. Com esse trabalho, serão fornecidos subsídios para melhor coordenação e execução do Regulamento Técnico do Programa Nacional de Controle e Erradicação da Brucelose e Tuberculose Animal (PNCEBT), o qual foi aprovado através da Instrução Normativa $n^{\circ} 2$, de 10 de janeiro de 2001, da Secretaria de Defesa Agropecuária do Ministério da Agricultura, Pecuária e Abastecimento.

O presente Manual pretende esclarecer e facilitar o trabalho a ser executado pelos profissionais dos serviços oficiais, além de padronizar as ações de levantamento soroepidemiológico, contribuindo para uma análise homogênea da ocorrência da brucelose bovina e bubalina no país e tomada de decisões consistentes.

Os objetivos específicos deste trabalho são: (1) estimar a prevalência e distribuição geográfica de propriedades com rebanhos bovinos e bubalinos infectados com brucelose, (2) estimar a prevalência de animais sororeagentes à brucelose e (3) identificar tipos de criação, práticas de manejo e fatores de risco que possam estar associados à presença da brucelose nas diferentes Unidades Federativas do país.

\section{2- METODOLOGIA DE TRABALHO}

A ocorrência da brucelose será estimada através de um processo amostral que detectará com um intervalo de confiança pré-estabelecido e com técnicas de boa sensibilidade e especificidade, a prevalência de propriedades e animais com brucelose, permitindo que os resultados sejam extrapolados para a população alvo.

Os parâmetros epidemiológicos variam de acordo com os distintos sistemas de produção, manejo dos animais, finalidade da exploração, tamanho médio de rebanhos e sistema de comercialização. Portanto, para o presente estudo, deverão ser feitas estratificações das Unidades Federativas, de acordo com os critérios mencionados. Para cada estrato, deve-se conhecer o número de propriedades com bovinos e/ou bubalinos, o número total de bovinos e bubalinos e o número de fêmeas com idade igual ou superior a 2 anos.

Cada um dos estratos representará uma realidade epidemiológica distinta e, praticamente, independente.

O estudo amostral será realizado em duas etapas: (1) primeiramente, sortea-se, de forma aleatória, um número pré-estabelecido de unidades primárias de amostragem (propriedades/rebanhos)e (2) será investigado o estado sanitário do rebanho, através da escolha, de forma aleatória, de um número pré-estabelecido de unidades secundárias (fêmeas com idade igual ou superior a 2 anos).

Os parâmetros epidemiológicos, conforme mencionado, apresentam variações de acordo com os sistemas de produção considerados e, além disso, variam também em função da região considerada. Portanto, antes da apresentação de valores estatísticos, é necessário que seja feito um detalhamento das regiões sob estudo e de suas subdivisões.

Assim sendo, cada Unidade Federativa deverá ser dividida em estratos distintos. 


\section{3- COORDENAÇÃO DO INQUÉRITO}

Será feita por uma equipe ou um responsável do serviço oficial de defesa sanitária animal da Unidade Federativa.

Os contatos (telefone, e-mail, fax) para esclarecimento de dúvidas e orientações referentes ao trabalho a ser executado no campo, deverão ser divulgados para todos os profissionais que estarão envolvidos no inquérito.

O inquérito está sendo apoiado em nível central pela gerência do PNCEBT, no DDA/SDA/MAPA, em colaboração com a FMVZ - USP.

\section{4- ESCOLHA DAS PROPRIEDADES A SEREM AMOSTRADAS}

As propriedades são as unidades primárias ou unidades epidemiológicas de amostragem e serão escolhidas de forma aleatória. Nas propriedades, será alvo do inquérito o principal rebanho (aquele de valor econômico ou que seja o principal objetivo de produção), no qual os animais estejam submetidos às mesmas condições de manejo (condições de risco).

A unidade amostral primária, neste trabalho representada por cada uma das propriedades amostradas, é definida como um grupo de animais em contato suficiente para que todos tenham o mesmo risco de serem infectados por um agente infeccioso que entre no grupo, ou seja, o agrupamento dos animais em um rebanho sob os mesmos tipos de controle e manejo (mesma condição de risco).

Para cada estrato definido na Unidade Federativa, a escolha das unidades primárias ou epidemiológicas de amostragem deverá obedecer a um processo aleatório.

No caso de ser necessário substituir alguma propriedade sorteada inicialmente, deve-se escolher a propriedade mais próxima, com mesmas características de produção. Evitar substituir por propriedade com atividade muito diferente da inicial (por exemplo, não substituir uma propriedade de gado de leite por outra especializada em gado de corte). Havendo dúvida, deve-se sempre consultar a coordenação do inquérito e notificar todas e quaisquer alterações à lista inicial.

Dentro das propriedades encontram-se as unidades amostrais secundárias, que são as fêmeas bovinas e bubalinas maiores de dois anos de idade, ou seja, os animais sob estudo.

\section{5- ESCOLHA DOS ANIMAIS A SEREM AMOSTRADOS}

Em cada propriedade sorteada, onde existam até 99 fêmeas na faixa etária igual ou superior a 2 anos, deverão ser amostradas 10 fêmeas com idade igual ou superior a 2 anos de idade, ou todas as fêmeas desta faixa etária se elas forem menos do que 10.

Caso existam mais que 99 fêmeas de idade igual ou superior a 2 anos de idade, na propriedade sorteada, deverão ser amostradas 15 fêmeas dentro desta faixa etária estipulada.

Deverão ser excluídas das amostras as fêmeas que estejam no período de peri-parto, ou seja, aproximadamente 15 dias antes do parto e nos 15 dias após o parto.

A escolha das fêmeas deverá ser feita aleatoriamente.

\section{6- PARÂMETROS ESTATÍSTICOS E EPIDEMIOLÓGICOS, POPULAÇÃO ALVO E TAMANHO DA AMOSTRA}




\section{1- Cálculo do número de propriedades/rebanhos (unidades primárias de amostragem)}

O método de cálculo do número de unidades amostrais depende do objetivo do estudo. Como já foi descrito, o presente projeto tem como primeiro objetivo estimar a prevalência de rebanhos infectados por Brucella abortus. Assim, em cada estrato regional de amostragem será realizada uma seleção aleatória de rebanhos. O resultado será uma prevalência estimada com um intervalo de confiança de $95 \%$, o qual define a precisão da amostra (i.e. a confiança com que se pode inferir os resultados da amostra para a população alvo). O tamanho da amostra para estimar uma proporção é determinado pelo grau de confiança do resultado, pelo nível de precisão desejado e pelo valor de prevalência esperado, ou mais provável (Noorduizen et al., 1997). É também necessário considerar a capacidade operacional e financeira disponível para realizar o trabalho de campo com qualidade.

A tabela seguinte apresenta alguns níveis de precisão de amostragem que resultam de vários tamanhos de amostra, para diversos valores de prevalência. Os valores de precisão apresentados foram calculados utilizando a fórmula (Noordhuizen et al., 1997):

- $\quad \mathbf{L}=(\mathbf{Z} \alpha * \mathbf{S D}) / \sqrt{ } \mathbf{n}$, sendo:

$\mathrm{L}=$ erro absoluto; $\mathrm{Z} \alpha=$ valor da distribuição normal para o grau de confiança especificado; SD = desvio padrão $=\sqrt{ }($ prevalência* $(1$-prevalência $)) ; n=n^{\circ}$ de amostras.

\begin{tabular}{|c|c|c|}
\hline & \multicolumn{2}{|c|}{$\begin{array}{c}\text { ERRO ABSOLUTO DA AMOSTRA (EM } \\
\%)\end{array}$} \\
\hline $\begin{array}{l}\text { PREVALEN } \\
\text { CIA } \\
\text { ESPERADA } \\
(\%)\end{array}$ & $\begin{array}{c}150 \text { REBANHOS } \\
\text { (grau de confiança }= \\
95 \%)\end{array}$ & $\begin{array}{c}300 \text { REBANHOS } \\
\text { (grau de confiança }= \\
95 \%)\end{array}$ \\
\hline 5 & 3,46 & 2,43 \\
\hline 10 & 4,76 & 3,34 \\
\hline 20 & 6,35 & 4,46 \\
\hline 30 & 7,28 & 5,11 \\
\hline 40 & 7,78 & 5,46 \\
\hline 50 & 7,94 & 5,57 \\
\hline
\end{tabular}

Como exemplo, se forem amostrados 300 propriedades/rebanhos num determinado estrato de amostragem onde se encontraria 10\% de rebanhos com animais soropositivos, o resultado seria: a prevalência de rebanhos infectados no estrato é de $10 \%$, com um intervalo de confiança de $95 \%$ que varia entre $6,66 \%$ e $13,34 \%$.

Neste estudo, optou-se por uma amostra de $\mathbf{3 0 0}$ propriedades/rebanhos em cada estrato regional de amostragem, visando não apenas obter boa precisão da estimativa, mas também garantir que a análise de fatores de risco não será inviabilizada por o número de observações ser insuficiente. Em estratos onde a capacidade operacional não permitir amostrar esse número de rebanhos, estabeleceu-se que a amostra deverá incluir pelo menos 150 propriedades/rebanhos. 


\section{2- Cálculo do número de animais (unidades secundárias de amostragem)}

Uma vez calculado o número de unidades de amostragem primárias (propriedades/rebanhos), é necessário determinar o número de unidades de amostragem secundárias (animais) em cada rebanho sorteado, i.e. em quantos animais será realizado o diagnóstico de brucelose. Nesta etapa da amostragem pretende-se classificar o rebanho quanto à existência de animais sororeagentes.

Quando animais são testados individualmente para determinar o estado do rebanho, a validade do teste de diagnóstico, determinada por sua sensibilidade e especificidade, deve ser avaliada de forma agregada (Martin et al., 1992; Donald et al., 1994; Jordan, 1996). A sensibilidade de rebanho (SenR) é a probabilidade de um rebanho infectado ser classificado como positivo pelo teste. A especificidade de rebanho (EspR) é a probabilidade de um rebanho livre de infecção ser classificado como negativo. Se a SenR for baixa, o $\mathrm{n}^{\mathrm{o}}$ de rebanhos falsos negativos será alto. Se a EspR for baixa, o $\mathrm{n}^{\circ}$ de rebanhos falsos positivos será alto. Só conhecendo a SenR, a EspR e o $\mathrm{n}^{\circ}$ de rebanhos positivos no teste de diagnóstico (prevalência aparente - $\mathrm{Pa}$ ), se pode calcular a prevalência real $(\mathrm{Pr})$ de rebanhos infectados, conforme a seguinte formula (Martin et al., 1992): $\mathrm{Pr}=(\mathrm{Pa}+\mathrm{EspR}-1) /($ SenR + EspR - 1). Também é necessário conhecer estes parâmetros para calcular os Valores Preditivo Positivo e Preditivo Negativo do diagnóstico em nível de rebanho, os quais são a melhor expressão da confiança que podemos ter no resultado de um teste. O calculo da amostra de animais será feito de forma a obter EspR e SenR de pelo menos 90\%. Assumiu-se que em rebanhos infectados, com até 99 fêmeas adultas, em média 20\% desses animais estaria infectado. Esse valor baixaria para $15 \%$ em rebanhos infectados, constituídos por 100 ou mais fêmeas adultas.

A SenR e EspR dependem de (Jordan, 1996): (1) sensibilidade e especificidade do teste, em nível individual; (2) do número de animais testados e tamanho do rebanho; e (3) do número mínimo de animais positivos para classificar o rebanho como infectado - ponto de corte. A SenR está diretamente relacionada com o $\mathrm{n}^{0}$ de animais testados e com a prevalência de infecção. A EspR está inversamente relacionada com o ${ }^{\circ}$ de animais testados. Utilizando um software específico (Herdacc, copyright David Jordan, 1995) foram simulados vários tamanhos de amostra, tendo-se optado por:

- 10 fêmeas (da faixa etária definida), se o rebanho for constituído por até 99 fêmeas (da faixa etária definida), ou todas as fêmeas existentes nessa faixa etária se não totalizarem 10 animais;

- 15 fêmeas (da faixa etária definida), se o rebanho for constituído por mais de 99 fêmeas (da faixa etária definida).

Deve ser ressaltado que esses cálculos são baseados no princípio de que a amostragem é feita sem substituição, assumindo uma distribuição hipergeométrica.

\section{7- MÉTODOS DE DIAGNÓSTICO}

Serão empregados dois testes, em série, nos soros das fêmeas amostradas. Como teste de triagem será empregada a prova do Antígeno Acidificado Tamponado (AAT). Os soros que reagirem positivamente ao teste de triagem serão então submetidos ao segundo teste, chamado de confirmatório, o 2-Mercaptoetanol (2-ME), o qual confere maior especificidade ao diagnóstico.

Os testes de AAT e 2-ME deverão ser feitos pelo(s) laboratório(s) indicado(s) pelo serviço de defesa oficial de cada Unidade Federativa. 
O laboratório efetuará a classificação final da propriedade/rebanho, identificando-a como positiva, inconclusiva ou negativa, respectivamente, caso sejam encontrados resultados sorológicos de fêmeas positivas, inconclusivas ou negativas.

\section{8- ESTRUTURA OPERACIONAL}

Níveis operacionais propostos e fluxo para remessa das informações e materiais colhidos

O sucesso deste inquérito dependerá diretamente da qualidade das ações realizadas em todos os níveis de operacionalização, desde o levantamento das informações e colheita das amostras, passando pelo envio destas aos laboratórios/órgãos centrais e chegando até a emissão e interpretação dos resultados laboratoriais. A seguir, seguem propostas dos níveis de comprometimento e atribuições relativos a este trabalho.

\section{a) Nível local}

Deverá efetuar a visita à propriedade sorteada, procedendo o preenchimento do formulário do estudo soroepidemiológico, a escolha aleatória das fêmeas a serem amostradas, a colheita de sangue com sua respectiva identificação nos frascos e o preenchimento das informações solicitadas quanto às fêmeas amostradas.

A equipe de campo responsável por este trabalho deverá ser composta por um médico veterinário e pelo menos um auxiliar agropecuário.

Caberá ao Médico Veterinário a identificação das propriedades sorteadas, junto ao cadastro daquela unidade veterinária, o preenchimento do formulário do estudo soroepidemiológico, a escolha aleatória das fêmeas a serem amostrados, o preenchimento do formulário de colheita e identificação dos frascos com amostras de sangue. Ao auxiliar caberá a colheita de sangue propriamente dita.

O material deverá ser devidamente embalado e enviado para o laboratório indicado, procedendo-se conforme especificado no item sobre procedimentos para colheita, conservação e remessa de amostra de soro sangüíneo.

b) Nível central

Constituído por uma equipe responsável ou coordenador do inquérito da prevalência da brucelose na Unidade Federativa e pelo responsável pelo laboratório de diagnóstico.

À equipe responsável ou ao coordenador caberá a coordenação dos serviços, o suprimento e distribuição de materiais para colheita de amostras e a conferência da qualidade do material colhido e das informações do formulário durante o recebimento no laboratório. 
As equipes dos níveis locais dos diferentes estratos deverão receber uma listagem com o número de ordem das propriedades que foram sorteadas para serem amostradas, por município, que estão na base de cadastro da unidade veterinária local.

Exemplo:

Num determinado estrato do Paraná, para o município de Adrianópolis, foram escolhidas 2 propriedades, as de números 15 e 96 . Assim, o responsável pela identificação destas 2 propriedades (no nível local) deverá escolher junto ao cadastro de propriedades com bovinos e/ou bubalinos do município de Adrianópolis, aquelas que representam a $15^{\mathrm{a}}$ e a $96^{\mathrm{a}}$ fichas da relação de fichas dispostas seqüencialmente no cadastro da Unidade Veterinária.

Portanto, a escolha aleatória das propriedades será realizada pela equipe da coordenação do inquérito na Unidade Federativa, ficando a responsabilidade de identificação das mesmas junto ao cadastro de cada estrato a cargo da unidade veterinária local. Para que esta identificação seja possível, é necessário que o cadastro das propriedades de cada município esteja numerado seqüencialmente.

Cada propriedade amostrada deverá ter uma identificação única que passará a ser o CÓDIGO DO REBANHO NO ESTUDO, sendo constituído pelo número do município no cadastro do IBGE (7 dígitos), onde está situada a propriedade, e mais o número de ordem da propriedade selecionada (2 dígitos), em cada município. Exemplo:

Em Unaí, Minas Gerais, se forem amostradas 5 propriedades, existirão 5 códigos, um para cada uma das propriedades:

$$
\begin{aligned}
& 317040401 \\
& 317040402 \\
& 317040403 \\
& 317040404 \\
& 317040405
\end{aligned}
$$

Sendo que:

3170404 é o código do IBGE de Unaí - MG, enquanto os 2 dígitos finais, de 01 a 05, correspondem ao número de ordem das propriedades que vão ser amostradas no município.

\section{c) Nível laboratorial}

O laboratório responsável pelo diagnóstico deverá conferir e processar o material recebido e emitir os resultados finais, realizando, previamente, a conferência do material recebido junto com a coordenadoria do inquérito.

O laboratório deverá, também, fazer a classificação sanitária da propriedade, conforme especificado no CAMPO 34 do formulário, considerando o conjunto dos resultados sorológicos.

Os resultados deverão ser encaminhados ao coordenador do inquérito no Estado e posteriormente à gerência do PNCEBT no DDA/SDA/MAPA.

\section{9- SELEÇÃO DOS ANIMAIS A SEREM SANGRADOS}

Uma vez separadas as fêmeas na faixa etária específica para colheita de sangue, é necessário fazer uma seleção aleatória das mesmas. Para isto, deverá ser empregado um dos dois métodos exemplificados no quadro seguinte, através de amostragem aleatória simples ou amostragem aleatória sistemática. 
Para saber qual dos dois métodos deve ser empregado, basta dividir o total de fêmeas com idade igual ou superior a 2 anos existentes na propriedade/rebanho a ser trabalhado, pelo total de animais a sangrar (amostra). Se o resultado for inferior a 2 deverá ser empregado o método aleatório simples; caso o resultado seja igual superior a 2, empregar o método aleatório sistemático. Os exemplos que se seguem demonstram os dois métodos de amostragem:

\section{a) Amostragem aleatória simples:}

Para sortear uma amostra de X animais, começar em qualquer ponto da Tabela de Números Aleatórios e sortear números ao longo das colunas ou linhas (adotar uma seqüência e continuar nela até seleção de todos os números). Se for sorteado um número repetido, ou que não esteja incluído no intervalo de números pretendidos, continue e escolha o próximo número na tabela.

Exemplo (consultar a tabela de números aleatórios) para sortear uma amostra aleatória de 10 fêmeas em uma propriedade com 26 fêmeas:

(1) Comece em qualquer ponto da tabela

(2) Selecione, na coluna abaixo do ponto escolhido, um número por vez, escrevendo-o em folha à parte. Incluir apenas números entre 01 e 26. Rejeitar números repetidos.

Por exemplo, na seqüência de números apresentada abaixo (começando no número 07, na primeira linha da tabela), seriam sorteados os 10 números sublinhados:

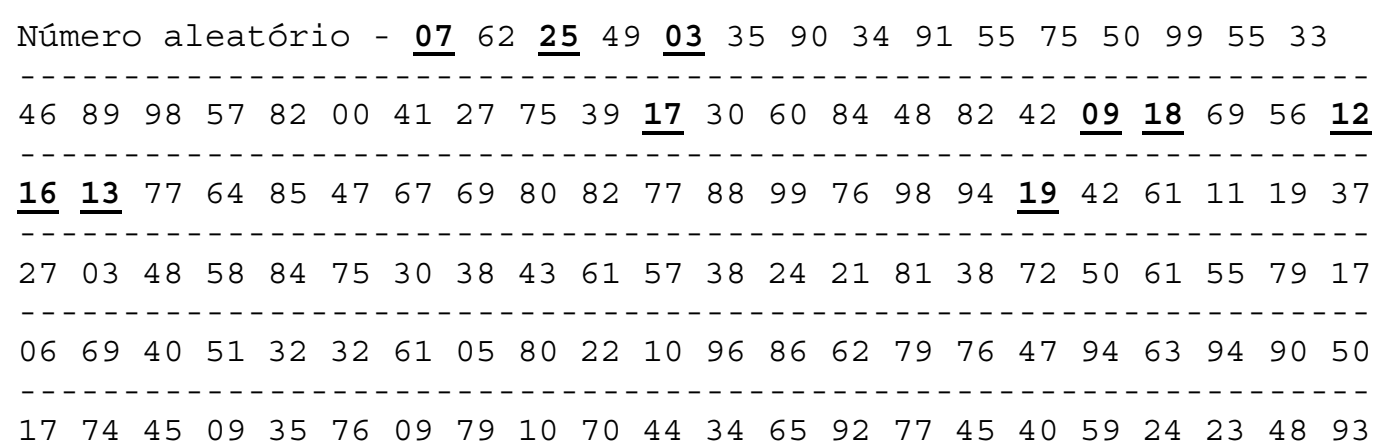

A nossa amostra seria constituída pelos animais número: 03, 07, 09, 12, 13, 16, 17, 18, 19 e 25

A ordem numérica será simplesmente a seqüência em que os animais se encontram distribuídos no brete.

\section{b) Amostragem aleatória sistemática:}

Em uma amostragem aleatória sistemática, são sorteados $\mathbf{n}$ animais, pertencentes a uma população composta por um total de $\mathbf{N}$ animais. Em primeiro lugar sorteia-se um número aleatório menor do que $\mathbf{N} / \mathbf{n}$ (consultar Tabela de Números Aleatórios). Depois são sorteados animais em intervalos regulares iguais a $\mathbf{N} / \mathbf{n}$.

Exemplo: para obter uma amostra de 15 (n) fêmeas > 2 anos, em um rebanho composto por 180 (N) matrizes (todas acima de 2 anos de idade).

Sortear um número aleatório entre 1 e 12 (N/n = 180/15 = 12), consultando a Tabela de Números Aleatórios - por exemplo 03;

( 1) Sangrar o animal n ${ }^{0} \mathbf{0 3}$; depois sangrar em intervalos de 12 animais: 03, 15, 27, 39, 51, 63, 75, 87, 99, 111, 123, 135, 147, 159 e 171. 
ANEXO I

\begin{tabular}{|c|c|c|c|c|c|c|c|c|c|c|c|c|c|c|c|c|c|c|c|}
\hline \multirow[b]{2}{*}{71} & \multirow[b]{2}{*}{94} & \multirow[b]{2}{*}{53} & \multirow[b]{2}{*}{11} & \multirow[b]{2}{*}{80} & \multicolumn{6}{|c|}{ TABELA DE NÚMEROS } & \multicolumn{4}{|c|}{ ALEATÓRIOS } & \multirow[b]{2}{*}{08} & \multirow[b]{2}{*}{43} & \multirow[b]{2}{*}{14} & \multirow[b]{2}{*}{34} & \multirow[b]{2}{*}{84} \\
\hline & & & & & 76 & 45 & 41 & 46 & 53 & 07 & 16 & 72 & 44 & 76 & & & & & \\
\hline 65 & 73 & 18 & 64 & 40 & 29 & 13 & 54 & 14 & 29 & 62 & 13 & 50 & 34 & 79 & 96 & 38 & 21 & 57 & 87 \\
\hline 11 & 02 & 88 & 25 & 48 & 97 & 67 & 68 & 85 & 24 & 25 & 77 & 61 & 65 & 99 & 85 & 61 & 31 & 83 & 87 \\
\hline 41 & 50 & 70 & 98 & 60 & 31 & 95 & 26 & 27 & 81 & 49 & 64 & 55 & 92 & 14 & 31 & 83 & 09 & 38 & 73 \\
\hline 91 & 49 & 56 & 22 & 45 & 50 & 22 & 83 & 16 & 42 & 03 & 85 & 79 & 77 & 68 & 20 & 05 & 88 & 51 & 50 \\
\hline 42 & 22 & 85 & 70 & 13 & 86 & 28 & 42 & 49 & 20 & 35 & 47 & 17 & 45 & 51 & 17 & 51 & 85 & 06 & 43 \\
\hline 64 & 52 & 60 & 76 & 14 & 20 & 34 & 60 & 38 & 67 & 90 & 67 & 06 & 40 & 90 & 26 & 21 & 52 & 13 & 59 \\
\hline 93 & 55 & 20 & 82 & 64 & 27 & 21 & 07 & 38 & 60 & 34 & 69 & 69 & 59 & 82 & 84 & 03 & 67 & 60 & 72 \\
\hline 68 & 86 & 44 & 19 & 66 & 67 & 56 & 69 & 17 & 68 & 91 & 80 & 40 & 24 & 68 & 44 & 93 & 68 & 65 & 81 \\
\hline 93 & 95 & 53 & 87 & 94 & 69 & 36 & 32 & 85 & 94 & 55 & 82 & 51 & 23 & 32 & 91 & 99 & 66 & 37 & 64 \\
\hline 41 & 18 & 25 & 98 & 90 & 15 & 69 & 65 & 11 & 97 & 75 & 77 & 32 & 48 & 77 & 43 & 05 & 96 & 27 & 32 \\
\hline 74 & 57 & 40 & 82 & 96 & 09 & 61 & 20 & 06 & 33 & 50 & 88 & 32 & 93 & 13 & 00 & 20 & 01 & 26 & 51 \\
\hline 77 & 06 & 29 & 73 & 92 & 03 & 79 & 02 & 66 & 62 & 99 & 96 & 61 & 96 & 50 & 38 & 65 & 39 & 33 & 80 \\
\hline 15 & 96 & 80 & 44 & 35 & 95 & 93 & 68 & 83 & 39 & 55 & 76 & 05 & 36 & 92 & 95 & 42 & 81 & 02 & 50 \\
\hline 49 & 94 & 37 & 31 & 13 & 34 & 36 & 85 & 70 & 62 & 33 & 98 & 80 & 20 & 73 & 52 & 92 & 34 & 47 & 83 \\
\hline 11 & 68 & 89 & 86 & 57 & 93 & 25 & 16 & 72 & 38 & 46 & 94 & 22 & 32 & 63 & 36 & 71 & 75 & 59 & 28 \\
\hline 75 & 85 & 37 & 41 & 85 & 96 & 39 & 54 & 52 & 22 & 89 & 19 & 10 & 09 & 75 & 96 & 48 & 40 & 70 & 50 \\
\hline 06 & 58 & 81 & 61 & 56 & 18 & 39 & 08 & 58 & 08 & 98 & 42 & 96 & 76 & 11 & 23 & 36 & 55 & 54 & 13 \\
\hline 58 & 84 & 76 & 42 & 62 & 66 & 70 & 92 & 44 & 95 & 65 & 61 & 86 & 60 & 39 & 97 & 25 & 06 & 65 & 40 \\
\hline 70 & 03 & 46 & 74 & 01 & 56 & 09 & 05 & 68 & 54 & 57 & 11 & 62 & 54 & 06 & 20 & 29 & 28 & 49 & 31 \\
\hline 63 & 36 & 31 & 54 & 88 & 95 & 15 & 71 & 04 & 57 & 82 & 19 & 79 & 14 & 08 & 40 & 07 & 07 & 75 & 88 \\
\hline 43 & 88 & 50 & 49 & 13 & 68 & 09 & 11 & 47 & 63 & 00 & 37 & 76 & 97 & 83 & 82 & 11 & 50 & 69 & 70 \\
\hline 68 & 38 & 69 & 26 & 37 & 77 & 02 & 27 & 84 & 67 & 41 & 27 & 47 & 82 & 01 & 51 & 62 & 76 & 61 & 69 \\
\hline 28 & 26 & 24 & 08 & 03 & 72 & 23 & 45 & 78 & 40 & 27 & 03 & 94 & 26 & 44 & 40 & 67 & 13 & 62 & 89 \\
\hline 55 & 35 & 30 & 14 & 95 & 96 & 40 & 60 & 65 & 32 & 75 & 48 & 63 & 50 & 38 & 11 & 16 & 12 & 40 & 82 \\
\hline 45 & 16 & 75 & 95 & 65 & 05 & 63 & 34 & 75 & 22 & 39 & 58 & 94 & 64 & 50 & 90 & 29 & 21 & 63 & 40 \\
\hline 75 & 97 & 03 & 90 & 17 & 56 & 70 & 83 & 39 & 25 & 17 & 84 & 90 & 60 & 66 & 99 & 58 & 66 & 24 & 76 \\
\hline 40 & 89 & 92 & 28 & 25 & 67 & 03 & 42 & 15 & 80 & 30 & 75 & 50 & 45 & 34 & 39 & 34 & 44 & 66 & 33 \\
\hline 50 & 76 & 21 & 84 & 19 & 89 & 18 & 81 & 57 & 10 & 60 & 30 & 17 & 84 & 98 & 67 & 25 & 14 & 76 & 01 \\
\hline 46 & 32 & 62 & 68 & 47 & 52 & 98 & 29 & 32 & 97 & 84 & 38 & 74 & 90 & 11 & 62 & 62 & 52 & 08 & 33 \\
\hline 45 & 43 & 48 & 55 & 39 & 56 & 49 & 15 & 22 & 33 & 48 & 43 & 45 & 66 & 50 & 44 & 27 & 05 & 65 & 92 \\
\hline 09 & 85 & 95 & 46 & 91 & 51 & 35 & 40 & 80 & 30 & 82 & 61 & 09 & 80 & 99 & 06 & 16 & 38 & 46 & 78 \\
\hline 95 & 10 & 85 & 90 & 57 & 06 & 42 & 48 & 49 & 97 & 42 & 57 & 35 & 56 & 86 & 76 & 32 & 96 & 29 & 89 \\
\hline 58 & 35 & 50 & 97 & 35 & 45 & 67 & 31 & 32 & 46 & 09 & 38 & 76 & 88 & 45 & 11 & 57 & 06 & 55 & 45 \\
\hline 79 & 33 & 76 & 45 & 59 & 42 & 57 & 17 & 77 & 25 & 18 & 24 & 09 & 17 & 82 & 92 & 13 & 68 & 42 & 76 \\
\hline 50 & 79 & 70 & 40 & 48 & 70 & 70 & 16 & 45 & 54 & 69 & 21 & 79 & 20 & 54 & 73 & 10 & 59 & 23 & 28 \\
\hline 61 & 90 & 17 & 05 & 68 & 54 & 17 & 16 & 31 & 88 & 56 & 81 & 10 & 20 & 75 & 07 & 45 & 15 & 97 & 64 \\
\hline 46 & 73 & 27 & 80 & 18 & 75 & 00 & 55 & 85 & 06 & 12 & 38 & 70 & 09 & 29 & 37 & 04 & 59 & 53 & 58 \\
\hline
\end{tabular}

\section{0- INSTRUÇÕES DE PREENCHIMENTO DO FORMULÁRIO DE ESTUDO SOROEPIDEMIOLÓGICO DA BRUCELOSE BOVINA E BUBALINA E COLHEITA DE AMOSTRAS}

É importante que o formulário esteja devidamente e integralmente preenchido, para que as análises e interpretações sejam corretas. O formulário deverá ser preenchido em uma única via e copiado em xerox. A via original deve acompanhar os soros até o laboratório e a cópia xerográfica ser enviada à Coordenação Estadual do Inquérito. 
Salienta-se que o formulário não deverá ser passado a limpo. A via original, mesmo que contenha algumas sujidades do campo, é que deverá ser enviada juntamente com as amostras. Assim sendo, deve-se cuidar e estar atento para evitar excesso de sujidades.

Apesar do formulário ser de fácil preenchimento, convém ter atenção em alguns pontos específicos.

As questões e campos a serem respondidos estão relacionados a seguir, com suas respectivas instruções para preenchimento.

\section{CAMPO 1- IDENTIFICAÇÃO}

Deverá ser utilizada letra de forma legível e maiúscula, DEVENDO SER PREENCHIDO NA UNIDADE LOCAL do serviço de defesa animal, antes de ir à propriedade.

Deverá ser identificado o município onde a propriedade está localizada e sua respectiva Unidade Federativa, o nome completo do(s) proprietário(s) dos animais e o nome da Propriedade. O código de cadastro a ser identificado é o número (ou código) de identificação da propriedade no serviço de defesa oficial local.

A REGIÃO é o $n^{0}$ do estrato de amostragem ao qual pertence o município em questão, conforme definido no plano amostral do estado. Este campo deverá ser preenchido pelo coordenador do levantamento.

\section{CAMPO 2- DATA DA VISITA E COLHEITA}

Deverá ser preenchido utilizando-se dois dígitos no dia e no mês da visita, quando será respondido o formulário e efetuada a colheita de amostras. O ano deverá ser indicado com os quatro dígitos.

\section{CAMPO 3- CÓDIGO DO REBANHO NO ESTUDO (9 DÍGITOS)}

Este código será a base do controle das amostras e informações das propriedades, sendo de fundamental importância.

Os primeiros 7 (sete) dígitos são de identificação do município onde a propriedade está localizada, correspondente ao número de identificação no IBGE, que é único para cada município do país. Os últimos 2 (dois) dígitos são relativos à ordem de seqüência das propriedades daquele município a serem trabalhadas no inquérito.

Exemplo:

Em Unaí, Minas Gerais, se forem amostradas 5 propriedades, existirão 5 códigos:

317040401

317040402

317040403

317040404

317040405

Sendo que: 3170404 é o código do IBGE de Unaí - MG, enquanto os 2 dígitos finais, de 01 a 05, correspondem ao número de ordem das propriedades que vão ser amostradas no município.

\section{CAMPO 4- COORDENADAS}

O objetivo é ter a localização geográfica exata ou a mais exata possível da propriedade (sede) onde estão os animais amostrados. Preferencialmente, deverá ser preenchido 
utilizando-se aparelho GPS. A latitude e a longitude deverão ser identificadas com graus e minutos e a altitude, em metros em relação ao nível do mar.

\section{QUESTÃO 5- TIPO DE EXPLORAÇÃO}

Marcar uma única opção, aquela que mais caracterize o rebanho amostrado na propriedade.

Entende-se por "corte" aqueles rebanhos destinados a cria, recria e engorda ou qualquer uma destas fases separadamente, desde que os animais tenham como objetivo final a engorda para posterior abate (pecuária de corte) e produção de carne. A existência de alguns animais para produção de leite na propriedade (geralmente para consumo próprio), não descaracteriza esse rebanho como sendo de corte, desde que esta produção leiteira não seja uma atividade de importância econômica.

Entende-se por "leite" os rebanhos que podem ser caracterizados como pertencentes à pecuária de leite. Têm por finalidade e atividade principal a produção leiteira, independente do destino dado ao leite produzido (consumo próprio ou venda).

Na opção "mista”, encontram-se aquelas explorações onde o rebanho possui animais criados com objetivo de produzir leite e também animais para cria, recria e engorda ou parte deste ciclo, com objetivo final de abate e produção de carne. Os animais da produção leiteira e os da produção de carne convivem em ambientes comuns e/ou fazem uso de instalações em comum.

OBS: Em propriedades que possuam rebanhos separados de corte e de leite (explorações distintas geograficamente e de manejos independentes e diferentes), este levantamento soroepidemiológico deverá ser realizado naquele rebanho de maior importância econômica para a propriedade.

\section{QUESTÃO 6- TIPO DE CRIAÇÃO}

Marcar uma única opção, aquela que melhor caracterize o rebanho amostrado na propriedade.

Considera-se "confinado" aquele tipo de exploração intensiva onde os animais são mantidos em espaço limitado e reduzido, sendo a alimentação (volumoso, concentrado, sal mineral) e água fornecidas de forma sistemática e controlada, dentro do próprio local onde eles estão alojados.

Em "semi-confinado" encontram-se os tipos de criação semi-intensiva onde os animais permanecem na pastagem e recebem suplementação alimentar (volumoso e/ou concentrado) durante todo o ano ou parte deste (por exemplo, na época da seca).

Como "extensivo" entende-se os tipos de criação nos quais os animais são mantidos exclusivamente em regime de pasto, podendo receber concentrado protéico e/ou sal mineral.

\section{QUESTÃO 7- NÚMERO DE ORDENHAS POR DIA}

Marcar uma única opção, aquela que caracterize o rebanho amostrado na propriedade.

\section{QUESTÃO 8- TIPO DE ORDENHA}

Escolher uma única opção, aquela que caracterize o rebanho amostrado.

Marcar "manual” se a ordenha for feita por serviço de pessoal que não utiliza nenhum equipamento específico, utilizando somente as mãos e recipiente para o leite ordenhado.

A opção "mecânica ao pé” deverá ser marcada quando a ordenha for feita utilizando-se ordenhadeira mecânica, pelo sistema de balde ou latão ao pé, onde não há circuito fechado.

Entende-se por "mecânica em sala de ordenha" a ordenha realizada em circuito fechado, instalado em sala de ordenha apropriada. 
Se não é feita ordenha do rebanho amostrado (exemplo: gado de corte), deverá ser marcada a opção "não ordenha”.

\section{QUESTÃO 9- PRODUÇÃO DE LEITE}

Indicar o número de vacas que estão em lactação (sendo ordenhadas) no rebanho da propriedade, na ocasião do inquérito soroepidemiológico e a média de produção total de leite por dia, em litros. Caso o rebanho amostrado seja constituído somente por animais de corte, onde não é feita ordenha, este item deverá ser deixado sem resposta.

\section{QUESTÃO 10- USA INSEMINAÇÃO ARTIFICIAL?}

Marcar uma única opção, aquela que caracterize o rebanho amostrado na propriedade.

\section{QUESTÃO 11- RAÇA PREDOMINANTE}

Marcar uma única opção, aquela que caracterize a propriedade amostrada.

Quando o rebanho amostrado for de bovinos, escolher as opções indicadas, considerando:

- zebu: qualquer raça de bovinos da espécie Bos indicus. Exemplo: considera-se raça zebu predominante quando o rebanho for composto por: (1) bovinos de uma única raça (ex: nelore); (2) bovinos de duas ou mais raças diferentes (ex: nelore e guzerá); (3) bovinos resultantes de cruzamentos entre raças zebuínas, independente do grau de sangue (ex: nelore X guzerá).

- europeu de leite: raças de origem européia, ou seja, bovinos da espécie Bos taurus, especializadas em produção leiteira, podendo o rebanho ser constituído por animais de uma única raça ou de cruzamentos entre raças desta mesma espécie. Exemplo: holandês e jersey.

- europeu de corte: raças de origem européia, ou seja, bovinos da espécie Bos taurus, especializadas em produção de carne, podendo o rebanho ser constituído por animais de uma única raça ou de cruzamentos entre raças desta mesma espécie. Exemplo: angus, charolês e simental.

- mestiço: é o bovino resultante de cruzamentos entre raças, não permitindo que ele seja caracterizado dentro de uma ou mais raças específicas, sendo, portanto, considerado como sem raça definida.

- outras raças: todas as categorias que não se enquadrarem nas opções acima. São incluídos aqui os bovinos resultantes de cruzamentos entre as espécies Bos taurus e Bos indicus, que dão origem ao gado cruzado (europeus $\mathrm{X}$ zebus), independente do grau de sangue. Exemplo: girolanda.

Quando o rebanho amostrado for de bubalinos, escolher uma das opções indicadas, considerando as características fenotípicas mais específicas da raça predominante. Caso as características fenotípicas não sejam suficientes para identificar uma das raças indicadas, marcar a opção “outras raças”.

\section{CAMPO 12- (a) BOVINOS EXISTENTES E (b) BUBALINOS EXISTENTES}

Escrever no espaço próprio o número de animais existentes, de acordo com a indicação de sexo e faixa etária (em meses).

O preenchimento deverá ser feito conforme a resposta obtida na propriedade e não de acordo com a ficha de controle do serviço oficial. O objetivo não é fiscalizar o criador, mas saber a realidade daquele rebanho, sem fins punitivos para aqueles que indicarem quantidades diferentes das conhecidas pelo serviço oficial. 


\section{QUESTÃO 13- OUTRAS ESPÉCIES NA PROPRIEDADE}

Marcar uma ou mais das opções que indicam as espécies que estão presentes na propriedade.

\section{QUESTÃO 14- ESPÉCIES SIVESTRES EM VIDA LIVRE NA PROPRIEDADE}

Marcar uma ou mais das opções que correspondam às espécies de animais já avistadas na propriedade, fazendo parte da fauna do ambiente e não criadas em cativeiro. Caso não tenha sido vista nenhuma espécie silvestre de vida livre, marcar "não tem”.

Na opção "outras”, escrever no espaço próprio qual(is) outra(s) espécie(s) avistada(s).

OBS: excluem-se deste item todas as aves.

\section{QUESTÃo 15- ALGUMA VACA/BÚFALA ABORTOU NOS ÚLTIMOS 12 MESES?}

Marcar uma única opção, procurando fazer com que esta não seja uma resposta imediata, pois poderá ter havido casos no rebanho amostrado que podem não ser lembrados com facilidade. O entrevistador pode fazer perguntas indiretas que permitam chegar à resposta correta; evitando usar termos muito técnicos com os entrevistados.

Deve-se evitar a opção "não sabe”, procurando sugerir a quem está respondendo a busca de ajuda com uma outra pessoa da propriedade que poderia esclarecer a resposta.

\section{QUESTÃO 16- O QUE FAZ COM O FETO ABORTADO E A PLACENTA?}

Marcar uma ou mais opções, de forma a obter correspondência com as ações executadas no rebanho amostrado. Em casos de jogar em leitos de água, optar pela resposta "não faz nada”, pois entende-se que, não fazendo nada ou não dando um destino adequado, está havendo contaminação do ambiente.

\section{QUESTÃO 17- FAZ TESTES PARA DIAGNÓSTICO DE BRUCELOSE?}

Marcar uma única das opções e, sendo a resposta "sim", marcar uma ou mais das opções que indicam a regularidade dos testes e as possíveis outras ocasiões em que eles são feitos na propriedade.

\section{QUESTÃO 18- COMPRA FÊMEAS OU MACHOS COM FINALIDADE DE REPRODUÇÃO?}

Marcar uma única das opções, aquela que indique esta atividade no rebanho amostrado e, em caso da resposta ser "sim", completar a questão marcando uma ou mais das opções que correspondam às respostas de "de onde" ou "de quem".

OBS: Lembrar que o objetivo não é fiscalizar a propriedade.

\section{QUESTÃO 19- VENDE FÊMEAS OU MACHOS PARA REPRODUÇÃO?}

Marcar uma única das opções, aquela que indique esta atividade no rebanho amostrado e, em caso da resposta ser "sim", completar a questão marcando uma ou mais das opções que correspondam às respostas de "a quem" ou "onde".

OBS: Lembrar que o objetivo não é fiscalizar a propriedade.

\section{QUESTÃO 20- VACINA CONTRA BRUCELOSE?}

Marcar uma única opção, aquela que indique a atividade no rebanho amostrado, independente das informações constantes na ficha de controle da propriedade no serviço oficial.

\section{QUESTÃO 21- LOCAL DE ABATE DAS FÊMEAS E MACHOS ADULTOS NO FIM DA VIDA REPRODUTIVA}


Marcar uma ou mais das opções que caracterizem a atividade no rebanho amostrado. Pode haver mais de uma resposta.

Caracteriza-se como “estabelecimento sem inspeção veterinária” os açougues ou açougueiros que compram animais para abate e venda da carne, sem inspeção oficial.

\section{QUESTÃo 22- ALUGA PASTO EM ALGUMA ÉPOCA DO ANO?}

Marcar uma única opção, aquela que indique esta atividade na propriedade. Marcar "sim" se a propriedade aluga pastos próprios para terceiros ou se aluga pastos de terceiros para colocar seu rebanho. Marcar "não” se não aluga pastos.

\section{QUESTÃO 23- TEM PASTOS EM COMUM COM OUTRAS PROPRIEDADES?}

Marcar uma opção adequada, considerando que pastos em comum são aqueles onde os animais de duas ou mais propriedades permanecem, por qualquer período de tempo, sob pastejo em comum.

\section{QUESTÃO 24- EXISTEM NA PROPRIEDADE ÁREAS ALAGADIÇAS ÀS QUAIS O GADO TEM ACESSO?}

Marcar uma opção, aquela que caracterize a situação do rebanho amostrado.

\section{QUESTÃO 25- TEM PIQUETE SEPARADO PARA FÊMEAS NA FASE DE PARTO E/OU PÓS-PARTO?}

Marcar uma opção, aquela que indique a situação para o rebanho amostrado.

\section{QUESTÃO 26- A QUEM ENTREGA LEITE?}

Marcar uma ou mais das opções, aquela(s) que indique(m) a atividade na propriedade.

\section{QUESTÃO 27- RESFRIAMENTO DO LEITE}

Marcar a opção correspondente à atividade na propriedade e, sendo a resposta "faz", complementar marcando a opção de como é feito o resfriamento.

\section{QUESTÃO 28- A ENTREGA DO LEITE É FEITA A GRANEL?}

Marcar a opção que indique a atividade na propriedade.

Entende-se por "entrega de leite a granel” quando o leite é armazenado em tanque de expansão e coletado em caminhões próprios (tanque).

O leite entregue em latão corresponde à resposta "não”.

\section{QUESTÃO 29- PRODUZ QUEIJO E/OU MANTEIGA NA PROPRIEDADE?}

Marcar uma das opções, aquela que indique a atividade na propriedade.

Sendo a resposta "sim", marcar uma ou mais das opções que sejam adequadas à finalidade dada ao produto.

\section{QUESTÃO 30- CONSOME LEITE CRU?}

Marcar a opção que indique este hábito na propriedade.

\section{QUESTÃO 31- TEM ASSISTÊNCIA VETERINÁRIA?}

Considera-se "assistência veterinária" a atividade de médicos veterinários que tenham uma regularidade de visitas, com orientações específicas no manejo produtivo e/ou sanitário do rebanho. Nesta questão, não se considera como "assistência veterinária” visitas de 
profissionais para atendimento a casos isolados de urgência (exemplo: atendimento a um animal intoxicado ou com problemas de parto).

Marcar a opção "sim” se houver assistência veterinária à propriedade e "não", caso não haja assistência veterinária. Havendo assistência, complementar com as opções seguintes.

O médico veterinário responsável pelo preenchimento do formulário deverá identificar-se no espaço próprio, colocando nome completo por extenso e com letra de forma, e assinando no local indicado.

\section{CAMPO 32- INFORMAÇÕES SOBRE AS AMOSTRAS COLHIDAS}

Deve ser salientado que não se deve proceder colheita de amostras de sangue de fêmeas que estejam no peri-parto (no período que precede o parto - em torno de 15 dias antesou 15 dias após o parto).

O campo "número do frasco" deverá ser preenchido utilizando a mesma numeração que constará nos frascos com sangue e, posteriormente com soro, das fêmeas amostradas. Esse número corresponde ao código do rebanho no estudo (9 dígitos - vide CAMPO 3) e mais 2 dígitos relativos à ordem sequencial das fêmeas amostradas na propriedade, totalizando 11 dígitos.

Exemplo:

Se na primeira propriedade amostrada em Unaí - MG, forem colhidas amostras de sangue de 10 vacas, os números de identificação no formulário e no tubo de sangue/soro serão:

$\begin{array}{ll}31704040101 & 31704040106 \\ 31704040102 & 31704040107 \\ 31704040103 & 31704040108 \\ 31704040104 & 31704040109 \\ 31704040105 & 31704040110\end{array}$

$\underline{\text { Sendo: }}$

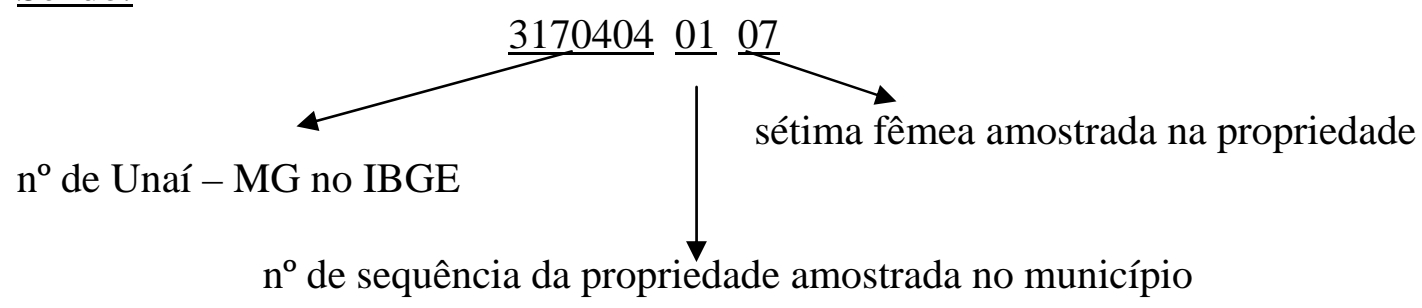

Desta forma, não haverá repetição de números de identificação de soros.

A espécie deverá ser identificada como (1), no caso de serem fêmeas bovinas, ou (2), se forem fêmeas bubalinas.

A idade das fêmeas amostradas deverá ser escrita em anos.

O número de parições deve ser aquele correspondente à quantidade de partos das fêmeas amostradas, durante toda sua vida reprodutiva. Considera-se também como parição as natimortalidades e os abortos ocorridos na vida reprodutiva da fêmea. 
Na questão “já abortou ?”, deve-se fazer um “X” na opção “sim” ou “não”, conforme o histórico reprodutivo da fêmea amostrada. Em algumas ocasiões, a pessoa que responde terá lembrança do ocorrido. Quando não houver lembrança de aborto, mas houver dados arquivados em documentação das fêmeas do rebanho, deverá ser procedido levantamento para saber se há registro de aborto na fêmea amostrada.

No campo correspondente às vacinas, marcar com um " $X$ ” as vacinas utilizadas na fêmea amostrada.

\section{CAMPO 33- RESULTADOS LABORATORIAIS}

Este campo deverá ser preenchido somente no laboratório responsável pelas execução das provas de diagnóstico indicadas, conforme orientação do item (3), abaixo do quadro.

\section{CAMPO 34- CLASSIFICAÇÃO SANITÁRIA DA PROPRIEDADE}

Este campo deverá ser preenchido pelo laboratório, considerando o conjunto dos resultados sorológicos.

A propriedade será classificada como negativa quando os resultados sorológicos de todas as fêmeas forem negativos.

A propriedade será classificada como inconclusiva quando existirem apenas resultados sorológicos negativos e inconclusivo(s) de uma ou mais fêmeas.

A propriedade será classificada como positiva, quando existir pelo menos um resultado sorológico positivo de alguma das fêmeas.

\section{1- PROCEDIMENTOS PARA COLHEITA, CONSERVAÇÃO E REMESSA DE AMOSTRA DE SORO SANGÜÍNEO}

A adoção de boas práticas no processo de colheita, conservação e remessa de amostras constitui um dos principais fatores na obtenção de material adequado para o diagnóstico laboratorial. O responsável pela equipe de colheita deverá conferir os materiais recebidos e executar todas as atividades dentro de normas e critérios técnicos.

A preparação e entrega do material de colheita às equipes de campo ficará sob responsabilidade do coordenação estadual do inquérito. O material de colheita será preparado levando-se em conta o número de propriedades a serem visitadas e o número de fêmeas a serem sangradas (sugere-se que seja preparado um "kit" para cada propriedade).

A amostra de sangue deverá ser colhida através de punção da veia jugular após contenção do animal e limpeza e desinfecção do local de punção, empregando-se uma agulha descartável ou estéril por animal. O sangue colhido deverá estar em frasco previamente identificado com o $\mathrm{N}^{\circ}$ DO FRASCO. Esses frascos deverão ser mantidos com leve inclinação, em local fresco até que ocorra a retração do coágulo.

Todo o material empregado na sangria deverá ser descartados em sacos plásticos e levado para a unidade local para que seja enterrado ou incinerado em local apropriado.

Nas amostras de sangue que não tiveram a separação total do soro e do coágulo, devese proceder da seguinte forma: descolar o coágulo da parede do frasco (com cuidado, usando material individual e descartável) e deixá-lo em refrigeração por 60 minutos, para que o coágulo retraia e solte maior quantidade de soro. Este soro, provavelmente ainda ficará sujo com algumas hemácias, devendo portanto ser centrifugado na Unidade Veterinária, por 2 
minutos em 2000 rpm. Ao final da centrifugação, o soro límpido deverá ser transferido para outro frasco com a identificação da amostra.

Todos os soros deverão ser transferidos para frascos identificados com o número da amostra e deverão estar límpidos, sem hemólise ou contaminação e com volume mínimo de dois mililitros. O material deverá ser congelado em embalagens firmes, de forma que fiquem seguros e de forma a evitar o vazamento dos soros. As embalagens devem ser feitas por rebanho/propriedade amostrada e identificadas exteriormente com o Código do Rebanho no Estudo. Todo o material será encaminhado ao laboratório em caixas isotérmicas, podendo ser colocadas embalagens de várias propriedades numa mesma caixa. Dentro das caixas isotérmicas, deverá haver também gelo embalado em sacos plásticos (para evitar vazamento de água) ou sachês de gelo reciclável em quantidades adequadas à manutenção das condições de congelamento das amostras. No laboratório, as amostras deverão ser conferidas com os respectivos FORMULÁRIOS.

\section{2- PARTICIPAÇÃO DOS CRIADORES}

A brucelose bovina e bubalina é uma doença de notificação obrigatória no Brasil e a legislação vigente determina que os animais com reações positivas no diagnóstico sorológico sejam sacrificados ou destruídos. Como o objetivo do trabalho é diagnosticar a prevalência da doença nos rebanhos e animais das Unidades Federativas, como forma de conhecer a realidade e auxiliar nas estratégias de controle que serão empregadas em cada região, as fêmeas amostradas não deverão ser marcadas ou identificadas.

Os resultados finais de classificação das propriedades (positiva, negativa ou inconclusiva) não serão divulgados, com o objetivo de resguardar os proprietários que terão cedido amostra de sangue dos animais para o levantamento da situação epidemiológica da doença nos Estados. Esses resultados são confidenciais e permanecerão com a coordenação do inquérito, a qual deverá, juntamente com a coordenação estadual do Programa Nacional de Controle e Erradicação da Brucelose e Tuberculose Animal (PNCEBT), tomar as providências cabíveis, utilizando os resultados como "ferramentas de trabalho" para o controle da doença e melhor desenvolvimento desse Programa no Estado.

Caso o proprietário das fêmeas queira saber os resultados, deverá estar ciente de que terá que, obrigatoriamente, sacrificar as fêmeas positivas e realizar mais exames, por sua conta, para diagnosticar as fêmeas classificadas como inconclusivas nos exames prévios. Sendo novamente inconclusivas ou positivas aos novos testes, também serão sacrificadas. Nessa hipótese apresentada, do produtor querer saber os resultados, o serviço oficial de defesa deverá estar preparado para acompanhar e fiscalizar o sacrifício das fêmeas positivas. Salienta-se que, neste caso, deve-se orientar para que todos os bovinos e/ou bubalinos sejam, então, submetidas a diagnóstico e posterior sacrifício das reagentes, iniciando-se um processo de saneamento da propriedade, conforme especificado no Regulamento Técnico do PNCEBT. É necessário, também, que esse produtor tenha assistência veterinária para efetuar o trabalho. 